Zweiter Beratungsgegenstand:

\title{
Verwaltungsrecht als Vorgabe für Zivil- und Strafrecht
}

1. Bericht von Prof. Dr. Meinhard Scbröder, Trier

Inhalt

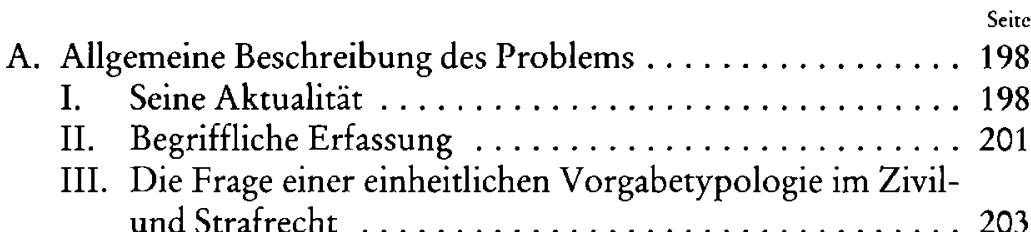

B. Gründe und Gegengründe für eine Vorgabewirkung des

Verwaltungsrechts ........................ 204

I. Ausgangslage ........................ 204

II. Gründe . . . . . . . . . . . . . . . . . . . . . . . . . . 204

1. Gründe, die im Zivil- und Strafrecht selbst liegen . . . 204

2. Übergeordnete, insbesondere verfassungsrechtliche Gründe ........................ 205

a) Der Topos der Einheit und Widerspruchsfreiheit der Rechtsordnung . . . . . . . . . . . 205

b) Systemgerechtigkeit .............. 206

c) Vertrauensschutz und administrativer Kompetenzschutz ................. 207

d) Grundrechtlicher Sanktions- und Verfahrensschutz ....................... 208

III. Gegengründe . . . . . . . . . . . . . . . . . 209

C. Verwaltungsrechtliche Vorgaben im Strafrecht ....... 210

I. Bestandsaufnahme der Verknüpfungen zwischen Verwaltungsrecht und Strafrecht in der Strafgesetzgebung . . 210

1. Tatbestandliche Anknüpfung . .......... 210

2. Berücksichtigung des Verwaltungsrechts als Rechtfertigungsgrund .................. 212

3. Berücksichtigung des Verwaltungsrechts als Strafbarkeitseinschränkung $\ldots \ldots \ldots \ldots \ldots \ldots \ldots 212$ 
II. Ausgewählte Einzelfragen . . . . . . . . . . . . 213

1. Eingrenzung ...................... 213

2. Die Vorgabewirkung des Verwaltungsrechts für den Strafgesetzgeber ................... 213

3. Die strafrechtliche Relevanz von Verwaltungsvorschriften .................... 215

a) "Gesetzesvertretende" Verwaltungsvorschriften . . 215

b) Normkonkretisierende Verwaltungsvorschriften . 217

4. Die Vorgabewirkung einzelfallbezogenen Verwaltungshandelns .................... 220

a) Zur prinzipiellen Abhängigkeit des Strafrechts von administrativen Einzelanordnungen . . . . . . 220

b) Die Tatbestandswirkung von Verwaltungsakten . . 221

c) Die strafrechtliche Ersetzung behördlicher Gestattungen ................... 225

5. Die Strafbarkeit von Amtsträgern . . . . . . . . 227

6. Die Aussetzung des Strafverfahrens . . . . . . . . . 228

III. Schlußbemerkung $\ldots \ldots \ldots \ldots \ldots \ldots \ldots \ldots 230$ 


\section{A. Allgemeine Beschreibung des Problems}

\section{Seine Aktualität}

Verwaltungsrechtliche Vorprägungen eines Sachverhaltes sind im Zivil- und Strafrecht prinzipiell geläufig. Man denke nur an genehmigungsbedürftige Privatrechtsgeschäfte, an die schon vom Reichsgericht im Grundsatz anerkannte rechtfertigende Wirkung öffentlichrechtlicher Genehmigungen im Recht der unerlaubten Handlungen', an die Jahre zurückreichende Diskussion über die Auswirkungen des baurechtlichen auf den zivilrechtlichen Nachbarschutz ${ }^{2}$. Verfahrensrechtlich ist auf $\$ 148 \mathrm{ZPO}$ hinzuweisen, der ausdrücklich die Aussetzung des Rechtsstreits im Hinblick auf vorgreifliche verwaltungsrechtliche Klärungen ermöglicht. Im Strafrecht ist die Anknüpfung an das Verwaltungsrecht seit jeher in $\$ 113$ StGB oder im Amtsträgerbegriff ( $\$ 11 \mathrm{StGB}$ ) offenkundig. Über die Strafbewehrung der Nichtbefolgung von Verwaltungsakten ist schon Anfang der 70er Jahre diskutiert worden ${ }^{3}$. Die strafrechtliche Legalisierungswirkung öffentlichrechtlicher Erlaubnisse hat gleichfalls Tradition ${ }^{4}$. Worin liegt demnach die besondere Aktualität und Problematik des Themas? Man wird diese Frage nicht einheitlich für das Zivil- und Strafrecht beantworten können.

Zivilrechtliche Relevanz hat vor allem die ständige Ausweitung und Ausdifferenzierung des Verwaltungsrechts. Sie beeinflußt, um nur einige Stichworte zu nennen, in wachsendem Maße das private Immissionsschutzrecht ${ }^{5}$, sie fördert den Ausbau umweltspezifischer Ver-

\footnotetext{
$1 R G Z 161,203 \mathrm{ff}$.

2 Siehe nur Marburger, Ausbau des Individualschutzes gegen Umweltbelastungen als Aufgabe des bürgerlichen und des öffentlichen Rechts, Gutachten für den 56. DJT 1986, Vhdlg. Bd. I C 38 ff.; K. Kleinlein, Das System des Nachbarrechts, 1986.

${ }^{3}$ Schenke, Strafbarkeit der Zuwiderhandlung gegen einen sofort vollziehbaren, nachträglich aufgehobenen strafbewehrten Verwaltungsakt, JR 1970, 449; P. Krause, Strafbarkeit des Verstoßes gegen rechtswidrige Verwaltungsakte? BGH, NJW 1969, 2023, JuS 1970, 221; D. Lorenz, Die Folgepflicht gegenüber rechtswidrigen Verwaltungsakten und die Strafbarkeit des Ungehorsams, DVBl. 1971, 165; Stern, Die Bindungswirkung von Verkehrszeichen im Ordnungswidrigkeitsverfahren, in: Festschrift f. R. Lange, 1976, 859; Arnbold, Die Strafbewehrung von Verwaltungsakten, 1978; Gerhards, Die Strafbarkeit des Ungehorsams gegen Verwaltungsakte, NJW 1978, 86; Haaf, Die Fernwirkung behördlicher Entscheidungen, 1984.

${ }^{4}$ RGSt. 37, $151 \mathrm{ff}$. zu $\$ 167$ StGB.

5 Marburger, wie vor, C $102 \mathrm{ff}$., $106 \mathrm{ff} ., 111 \mathrm{ff}$.
} 
kehrspflichten im Rahmen des $₫ 823$ Abs. $1 \mathrm{BGB}^{6}$ und verändert den Begriff der Schutzgesetze des Abs.2, unter den nun auch umweltrechtliche Vorschriften bis hin zu Emissions- und Immissionsgrenzwerten fallen können? ${ }^{7}$ Die Legalisierungswirkung öffentlich-rechtlicher Genehmigungen erreicht durch deren ständige Ausweitung eine neue haftungsrechtliche Dimension ${ }^{8}$. Die Beweislastregeln verändern sich ${ }^{9}$. Einen gesicherten Konsens gibt es noch nicht. Die Meinungsfronten verlaufen vielfach zwischen einer öffentlich-rechtlichen und einer zivilrechtlichen Betrachtungsweise. Alles in allem drängt die Frage mehr denn je, inwieweit dem Umwelt- und öffentlichen Nachbarrecht eine Führungsrolle über zivilrechtliche Ansprüche zukommt $^{10}$, ob mit einer "Interpretationsherrschaft “ über die verwaltungsrechtlich nicht ohnehin präkludierten Ansprüche zu rechnen ist ${ }^{11}$.

Was die Beziebungen des Verwaltungsrechts zum Strafrecht anlangt, so ist die Entwicklung eher umgekehrt. Veränderungen haben sich durch das Strafrecht ergeben. Bemerkenswert ist zunächst dessen Ausweitung auf Materien, die in enger Verbindung zum Verwaltungsrecht stehen. Das gilt etwa für das Subventions-, vor allem aber das Umweltstrafrecht. Seine Herauslösung aus dem sogenannten Nebenstrafrecht und der Einbau in das StGB hat begriffliche und inhaltliche Abhängigkeiten der Strafgesetzgebung und -anwendung vom Verwaltungsrecht augenfällig gemacht ${ }^{12}$. Suspekt erscheint vor allem die Bindung an Entscheidungen der Verwaltung, die mit strafrechtlichen Kategorien unvereinbar sein soll, weil sie dazu führen kann, daß verwaltungsrechtswidriges Verhalten strafrechtlich perpetuiert wird

6 Marburger, wie vor, C $120 \mathrm{ff}$; U. Hübner, Haftungsprobleme der technischen Kontrolle, U'TR 4 (1988), 121 (146f.).

7 BGHZ 86, 356 (362); Marburger, wie vor, C $122 \mathrm{f}$.

${ }^{8}$ Dazu jüngst $G$. Wagner, Öffentlich-rechtliche Genehmigung und zivilrechtliche Rechtswidrigkeit, 1989 und Peine, Privatrechtsgestaltung durch Anlagengenehmigung, NJW 1990, $2442 \mathrm{ff}$.

9 Vgl. Kloepfer, Umweltrecht, 1989, \$4 Rdn. 320 ff. m. Nachw.; ferner Marburger, a. a. O., C 123 ff.; Hübner (Fn. 6), S. 148 ff.; Hoppe/Beckmann, Umweltrecht, 1989, §11 Rdn. $27 \mathrm{f}$.

10 Brener, Ausbau des Individualschutzes gegen Umweltbelastungen als Aufgabe des öffentlichen Rechts, DVBl. 1986, 846 (854).

11 Kloepfer, wie vor, $\$ 4 \mathrm{Rdn} .302$.

12 Vgl. Ossenbïhl, Empfehlen sich Änderungen im strafrechtlichen Umweltschutz, insbesondere in Verbindung mit dem Verwaltungsrecht?, Referat in: Vhdlg. des 57. DJT, Bd. II, L 42 mit Fn. 17. 
oder an sich strafbares Tun rechtfertigt ${ }^{13}$. Dementsprechend gibt es Tendenzen einer Befreiung des Strafrechts vom „publizistischen Denken $^{14}$, das Bestreben, einer "Kastration des Strafrechts“, seiner Abhängigkeit von Einzelentscheidungen der Verwaltung mit Ermessens- und Beurteilungsspielraum ${ }^{15}$ durch verwaltungsrechtsunabhängige strafrechtliche Bewertungen vorzubeugen. Das zum Teil ungenügende Verständnis verwaltungsrechtlicher Gegebenheiten ${ }^{16}$, vor allem des verwaltungsrechtlich maßgeblichen Opportunitätsprinzips ${ }^{17}$ verstärkt solche Tendenzen noch. - Eine zweite Beobachtung hängt damit zusammen, besitzt aber auch eigenes Gewicht: Es gibt den Versuch, oder soll man sagen die Versuchung, vermeintliche oder wirkliche Vollzugsdefizite der Verwaltung ohne hinreichende Würdigung der Verwaltungsrechtslage mit Mitteln des Strafrechts auszugleichen. Beispiele liefert neben dem Umweltstrafrecht ${ }^{18}$ das Steuerstrafrecht. Vielleicht unter dem Eindruck der öffentlichen Mißbilligung haben Strafgerichte die mittelbare Parteienfinanzierung über staatsbürgerliche Vereinigungen, die jahrelang unbeanstandet geblieben war, als Steuerhinterziehung im Sinne des $\$ 370$ AO gewertet, noch ehe die steuerrechtliche Abzugsfähigkeit derartiger Spenden geklärt war ${ }^{19}$. Das Unbehagen an strafrechtlichen Sanktionen bei verwaltungsrechtlich ungeklärten Sachlagen, das angesichts dieser Steuer-

13 Siehe nur Kühl, Probleme der Verwaltungsakzessorietät des Strafrechts, insbesondere im Umweltstrafrecht, Festschrift Lackner, 1987, 815 (834 ff.) und Schall, Umweltschutz durch Strafrecht: Anspruch und Wirklichkeit, NJW 1990, 1263 (1266 ff.).

${ }_{14}$ Formulierung von Loos, Gemeinschädliche Sachbeschädigung ( $\$ 304 \mathrm{StGB}$ ) durch Überkleben von Wahlplakaten? - LG Wiesbaden, NJW 1978, 2107, JuS 1979, 699 (701).

15 Prononciert etwa R. Keller, Empfehlen sich Änderungen im strafrechtlichen Umweltschutz, Referat in: Vhdlg. des 57. DJT, Bd. II L 19; Kübl, wie Fn. 13.

${ }_{16}$ Dazu Heine, Verwaltungsakzessorietät des Umweltstrafrechts, NJW 1990, 2425 (2427).

17 Samson, Konflikte zwischen öffentlich-rechtlichem und strafrechtlichem Umweltschutz, JZ 1988, 800 (802f.); Heine/Meinberg, Empfehlen sich Änderungen im strafrechtlichen Umweltschutz, insbesondere in Verbindung mit dem Verwaltungsrecht?, Gutachten für den 57. DJT, in: Vhdlg. Bd. I D 56.

${ }_{18}$ Vgl. Hansmann, Verwaltungshandeln und Strafverfolgung - Konkurrierende Instrumente des Umweltrechts?, in: Dokumentation zum 9. Verwaltungsrichtertag 1989, 217 (225f.).

19 Näher P. Kirchbof, Der bestandskräftige Steuerbescheid im Steuerverfahren und Steuerstrafverfahren, NJW 1985, 2977 (2978ff.) und Koblmann, Steuerstrafrecht, $\$ 370 \mathrm{AO}$ Rdn. $62 \mathrm{ff}$. und die Klärung durch $B F H$, NJW 1986, 1897, NJW 1988, 1110. 
strafverfahren artikuliert wurde ${ }^{20}$, beleuchtet einen weiteren Aspekt der zunehmend problematischen Beziehungen zwischen Verwaltungsrecht und Strafrecht.

Verständlich, daß auf dem skizzierten Hintergrund der Topos der Einheit oder Widerspruchsfreiheit der Rechtsordnung bemüht wird ${ }^{2 !}$ : Sind doch die Beziehungen zwischen dem Verwaltungsrecht und dem Zivil- und Strafrecht dichter denn je, produzieren aber gerade dadurch vielfache, noch nicht bewältigte Kollisionen. So kommt es zu divergierenden Rechtsfolgen. Für den Bürger sind sie mißlich, weil er nicht versteht, weshalb sein verwaltungsrechtlich erlaubtes oder nicht beanstandetes Verhalten gleichwohl zivil- oder strafrechtliche Sanktionen nach sich zieht. Als an öffentlich-rechtlichen Vorgängen unbeteiligter Dritter kann er enttäuscht sein, wenn seine zivilrechtlichen Ansprüche durch verwaltungsrechtliche Vorgaben eingeschränkt oder ausgeschlossen werden ${ }^{22}$. Aus der Sicht der Verwaltung geht es um ihre Beurteilungs- und Entscheidungskompetenz, die durch eine verwaltungsrechtsferne Zivil- und Strafrechtspraxis womöglich konterkariert wird, und um das Risiko einer strafrechtlichen Verantwortlichkeit des Amtswalters.

\section{Begriffliche Erfassung}

Die Aufgabe, Kriterien und Maßstäbe zu finden, die sicherstellen, daß verwaltungsrechtliche Vorprägungen eines Sachverhalts auch im Zivil- und Strafrecht angemessen beachtet werden, bringt der Begriff der verwaltungsrechtlichen Vorgabe weitaus besser zum Ausdruck als der zum Teil übliche der Akzessorietät. Bekanntlich werden Kollisionen zwischen Verwaltungsrecht und Strafrecht, insbesondere dem Umweltstrafrecht nach verbreiteter Konvention unter dem Stichwort der Akzessorietät behandelt. Durchweg wird dabei zwischen einer Verwaltungsrechtsakzessorietät und einer Verwaltungsaktsakzessorietät unterschieden. Erstere soll die Abhängigkeit des Strafrechts von Verwaltungsrechtsvorschriften, letztere von Einzelfallentscheidungen der Verwaltung bezeichnen ${ }^{23}$. Hin und wieder wird die Akzessorietät

${ }^{20}$ Dazu etwa Volk, Spenden - Steuern - Strafrecht, JZ 1983, $223 \mathrm{ff}$.; H. Coing, Die Parteispendenaffäre und der Rechtsstaat, FAZ Nr. 118 v. 23. 5. 1985, S. 11.

21 Siehe etwa Hansmann (Fn. 18), S. 220.

22 Siehe dazu Wagner (Fn. 8), S. 111 ff.; Ossenbühl, Verwaltungsrecht als Vorgabe für Zivil- und Strafrecht, DVBI. 1990, 963 (968).

${ }^{23}$ Statt vieler: Breuer, Konflikte zwischen Verwaltung und Strafverfolgung, DÖV 1987, 169 (179). 
auch auf die Begrifflichkeit bezogen, um hervorzuheben, daß das Strafrecht Begriffe des Verwaltungsrechts übernommen habe ${ }^{24}$. Drei Gründe lassen es angezeigt erscheinen, den Begriff der Akzessorietät zu vermeiden, erst recht nicht in bezug auf das Zivilrecht anzuwenden, wo er bisher auch nicht üblich ist.

Erstens liegt im Begriff der Akzessorietät die Behauptung einer prinzipiell feststehenden, lediglich erläuterungsbedürftigen Abhängigkeit des Straf- und womöglich Zivilrechts vom Verwaltungsrecht. Eine derart feststehende Beziehung gibt es indessen schon im Verhältnis Verwaltungsrecht-Strafrecht nicht. Nach wie vor wird die Akzessorietät als unangemessene Abhängigkeit des Strafrechts vom Verwaltungsrecht bekämpft ${ }^{25}$, gibt es keinen Konsens über ihren Inhalt, sondern eher unklare Vorstellungen ${ }^{26}$. Eine Übernahme dieses Streits in das Zivilrecht durch Verwendung von Akzessorietätsvorstellungen bringt nichts ein.

Zweitens bestehen grundsätzliche Bedenken, ob Akzessorietätsvorstellungen einer Auflösung von Wertungsdifferenzen zwischen verschiedenen Teilrechtsordnungen überhaupt gerecht werden. Auf diese Weise würde nämlich die „akzessorische“ Rechtsordnung zur bloßen Neben- bzw. Annexordnung, der im Blick auf das Verwaltungsrecht von vornherein eigenständige Bewertungen eines Sachverhaltes versagt sind. Ein solches Ergebnis mag sich nach eingehender rechtlicher Beweisführung ergeben, sollte jedoch nicht begrifflich präjudiziert werden.

Drittens ist der materiell-rechtliche Begriff der Akzessorietät wenig geeignet, die verfahrensrechtlichen Aspekte des Themas zu erfassen. Durch die in ihm angelegte Behauptung einer feststehenden Beziehung des Verwaltungsrechts zum Straf- bzw. Zivilrecht suggeriert er, daß verwaltungsrechtliche Fragen ausnahmslos bloße "Vorfragen“ sind, über die der Zivil- oder Strafrichter selbst entscheidet. In Wahrheit stellt sich gerade angesichts besonders enger Beziehungen zwischen dem Verwaltungsrecht und dem Zivil- und Strafrecht die

24 Vgl. Schall (Fn. 13), S. 1265; Prümm, Umweltschutzrecht, 1989, S. 358.

${ }^{25}$ Siehe Trifterer, Umweltstrafrecht, in: Lexikon des Rechts (1989), 919 (Reduktion der Akzessorietät); zuletzt Schall, wie vor, S. $1265 \mathrm{ff}$. - Zu optimistisch: Tröndle, Verwaltungshandeln und Strafverfolgung - Konkurrierende Instrumente des Umweltrechts, in: Dokumentation zum 9. Verwaltungsrichtertag 1989, $233 \mathrm{ff}$. (233) und Gerbardt, Verwaltungsrecht als Vorgabe des Zivil- und Strafrechts, BayVBl. 1990, 549 (551).

${ }_{26}$ Tiedemann, Tatbestandsfunktionen im Nebenstrafrecht, 1969, S.45; Kübl (Fn. 13), S. 826; Papier, Diskussionsbeitrag, in: Vhdlg. des 57. DJ'T, Bd. II L 102. 
Frage, ob die in der Verfahrensaussetzung liegende Chance, Wertungswidersprüche zwischen Teilrechtsordnungen zu vermeiden ${ }^{27}$, mehr als bisher genutzt werden muß. Auch unter dem verfahrensrechtlichen Blickwinkel erscheint damit der Begriff der verwaltungsrechtlichen Vorgabe umfassender und neutraler als der der Akzessorietät.

\section{Die Frage einer einheitlichen Vorgabetypologie im Zivil- und Strafrecht}

Das Thema zielt auf typologische Aufbereitung: $\mathrm{Zu}$ bestimmen ist, wie das Zivil- und Strafrecht die einzelnen verwaltungsrechtlichen Vorgaben nach Art, Dichte und Bindungswirkung einschließlich eventueller verfahrensrechtlicher Konsequenzen zu berücksichtigen hat. Denkbar ist, daß die Typologie für das Zivil- und Strafrecht die gleiche ist und folglich die ihr zugrunde liegenden Kriterien und Maßstäbe hier wie dort gelten. Indessen bestehen Zweifel, ob eine einheitliche Vorgabentypologie gelingen kann ${ }^{28}$. Gewiß können sich Gemeinsamkeiten herausstellen, die für das Zivil- und Strafrecht gleichermaßen Bedeutung haben ${ }^{29}$. Das mag etwa unter dem Gesichtspunkt der Sicherung der Beurteilungs- und Entscheidungsfreiheit der Verwaltung oder verfahrensrechtlicher Konsequenzen aus verwaltungsrechtlichen Vorgaben der Fall sein. Auf der anderen Seite ist mit mehr oder weniger markanten Unterschieden zu rechnen, die eine getrennte Behandlung des Zivil- und Strafrechts methodisch wie sachlich rechtfertigen. Ohne Anspruch auf Vollständigkeit gehören dazu etwaige zivil- und strafrechtssystematische Besonderheiten, die auch in einer Typologie verwaltungsrechtlicher Vorgaben nicht ohne weiteres untergehen dürfen. Des weiteren sind die verwaltungsrechtlichen Vorgaben im Strafrecht - typischerweise anders als im Zivilrecht - nicht nur ein Thema der Rechtsanwendung, sondern auch auf der Ebene der Gesetzgebung zu bedenken.

27 Hierzu Baumbach/Lauterbach/Albers/Hartmann, ZPO, 48. Aufl. 1990, vor $\$ 148$ ZPO Anm. 2; K. Schmidt, Verfahrenskoordination bei Anfechtungssachen im Falle der Bestätigung angefochtener Beschlüsse, NJW 1979, 409 (411); speziell zum Steuerstrafverfahren: Isensee, Aussetzung des Steuerstrafverfahrens - Rechtsstaatliche Ermessensdirektiven, NJW 1985, 1007 (1008).

28 Zustimmend Ossenbübl (Fn. 22), S. $967 \mathrm{f}$.

29 Insofern sind vergleichende Untersuchungen, etwa zur Legalisierungswirkung öffentlich-rechtlicher Genehmigungen, die das Zivil- und Strafrecht einbeziehen, im Ansatz berechtigt: siehe nur Wagner (Fn. 8). 


\section{B. Gründe und Gegengründe für eine Vorgabewirkung des Verwaltungsrechts}

\section{Ausgangslage}

Rekurriert man auf den Topos der Einheit oder Widerspruchsfreiheit der Rechtsordnung, liegt es nahe, die Forderung zu erheben, daß sich das Zivil- und Strafrecht zu verwaltungsrechtlichen Vorprägungen eines Sachverhalts nicht in Widerspruch setzen dürfe: Was verwaltungsrechtlich gestattet ist, kann auch zivil- und strafrechtlich nicht beanstandet werden ${ }^{30}$. Fragwürdig wird diese Forderung, sobald man sich vor Augen führt, daß die Teilbereiche der Rechtsordnung unterschiedliche Aufgaben haben, ihre Verhaltensanweisungen deshalb nicht von vornherein übereinstimmen und auch nicht übereinstimmen müssen ${ }^{31}$. Aus dieser Vorüberlegung ergibt sich die Ambivalenz des Vorgabeproblems. Es gibt Gründe für, aber auch gegen eine Vorgabewirkung des Verwaltungsrechts im Zivil- und Strafrecht. Sie sollen zunächst in einem Überblick festgehalten und ihre rechtlichen Fundamente, die nicht immer offen zutage liegen, bestimmt werden.

\section{Gründe}

1. Gründe, die im Zivil- und Strafrecht selbst liegen

Mitunter ergeben sich bereits aus einschlägigen Normen des Zivilund Strafrechts Gründe, die eine Verpflichtung begründen, die Anknüpfung an verwaltungsrechtliche Vorgaben zu suchen. Durch ihre vorrangige Beachtung vollziehen die rechtsanwendenden Instanzen eine gesetzgeberische Entscheidung nach, die womöglich Kollisionen mit dem Verwaltungsrecht ausschließen soll. Zugleich wird der schwierige Rekurs auf allgemeinere Prinzipien und Grundsätze über die Berücksichtigung verwaltungsrechtlicher Vorgaben ganz oder teilweise entbehrlich.

Beispiele in diesem Sinne bieten die Duldungspflicht bei Eigentumsstörungen ( $\$ 1004 \mathrm{Abs} .2 \mathrm{BGB}$ ), die auch verwaltungsrechtliche Gründe haben kann, und der Begriff der Ortsüblichkeit im Sinne des $\$ 906 \mathrm{BGB}$, in dem sich im Einzelfall gleichfalls Verwaltungsrecht und

\footnotetext{
${ }^{30} \mathrm{Vgl}$. zuletzt Ossenbübl, wie vor, S. 968, mit Einschränkung für das Strafrecht.

${ }^{31} \mathrm{Vgl}$. P. Kirchbof, Unterschiedliche Rechtswidrigkeiten in einer einheitlichen Rechtsordnung, 1978, S. 10; H. Vogel, Wertungsdivergenzen zwischen Steuerrecht, Zivilrecht und Strafrecht, NJW 1986, 2986.
} 
Zivilrecht verzahnen können ${ }^{32}$. Im Strafrecht finden sich Normen, die verwaltungsrechtliche Begriffe rezipieren und damit ein starkes Indiz für ihre verwaltungsrechtskonforme Auslegung begründen ${ }^{33}$, oder die im Tatbestand an vollziehbare, nicht notwendigerweise rechtmäßige Verwaltungsakte anknüpfen, was den Verzicht auf eine Rechtmäßigkeitsprüfung durch die Strafjustiz nahelegt ${ }^{34}$. Ferner schafft die wirksame verwaltungsrechtliche Erlaubnis oder Genehmigung einen prinzipiellen Grund für ihre rechtfertigende Wirkung auch im Zivil- und Strafrecht, weil deren Rechtfertigungsgründe nicht abschließend festliegen ${ }^{35}$.

\section{2. Übergeordnete, insbesondere verfassungsrechtliche Gründe}

Häufiger wird das einfache Recht keine „speziellen Lösungshilfen“ bereithalten, die eine „Brücke“ zum Verwaltungsrecht schlagen sol$\operatorname{len}^{36}$. Dann können sich Gründe für eine Vorgabewirkung aus übergeordneten, insbesondere verfassungsrechtlichen Postulaten ergeben.

\section{a) Der Topos der Einheit und Widerspruchsfreiheit der Rechtsordnung}

Ein höchst problematischer Grund für die Vorgabewirkung des Verwaltungsrechts ist die immer wieder berufene ${ }^{37}$ Einheit der Rechtsordnung. Angesichts unterschiedlicher Aufgaben der Teilrechtsordnungen, deren Auffächerung und Differenzierung in Einzelaussagen „Errungenschaft eines um Einzelfallgerechtigkeit und Situationsnähe bemühten Rechtsstaates" ist ${ }^{38}$, erweist sich der Einheitstopos als viel

32 Vgl. statt aller: Schlichter, in: ders./Stich, Berl. Komm. z. Baugesetzbuch (1988), Vorbem. zu den $\$ \$ 29-38$ Rdn. 4; siehe auch Ossenbübl (Fn. 22), II 1.

${ }_{33}$ Siehe dazu BT-Drucks. 8/2382, S. 10; Winkelbauer, Die Verwaltungsakzessorietät, 1985, S. 12 und Prümm, wie Fn. 24; andererseits $B G H$, NJW 1987, 1280 betr. $\$ 326$ Abs. 1 Nr. 3 StGB; s. auch $B G H$, NJW 1990, 2477 f.

${ }^{34} B \operatorname{VerfGE~75,} 329$ (346); 80, 244 (256) und Chr. Bickel, Anwendungsprobleme des Umweltstrafrechts aus öffentlich-rechtlicher Sicht, in: Meinberg/Möhrenschlager/Link (Hrsg.), Umweltstrafrecht, 1989, 261 (261 f.); Näheres unten C. II. 4.b).

35 Vgl, bereits Kirchhof (Fn. 31), S. 27.

${ }^{36}$ Formulierung von Kirchbof, wie vor.

37 Siehe Beschlüsse der strafrechtlichen Abteilung des 57.DJT 1988, Vhdlg. Bd. II sub. A 7 a L 1980; Heine/Meinberg (Fn. 17), D 48; Rogall, Diskussionsbeitrag, in: Vhdlg. d. 57. DJT, Bd. II L 120.

${ }^{38}$ Kircbbof, wie vor, S. 8; im gleichen Sinne Wagner (Fn. 8), S. 94; siehe auch Hallwaß, Rechtmäßigkeit behördlich geduldeter Umweltbeeinträchtigungen, NuR 1987, 297 (300), der von einer weiten Auslegung des Einheitsgedankens mit entgegengesetzten Ergebnissen spricht. 
zu pauschaler Maßstab für die Verknüpfung von Teilrechtsordnungen. Er ist deshalb auch nicht rechtsstaatlich begründbar, vielmehr dazu angetan, legitime, nach Art. 3 sogar verfassungsrechtlich notwendige Wertungsdifferenzen zwischen Rechtsgebieten hinter einem bloßen Ideal der Einheit ${ }^{39}$ verschwinden zu lassen. Man denke nur an die vom Standpunkt des Steuerrechts aus einleuchtende, in $\$ \$ 40 \mathrm{ff}$. AO angeordnete Besteuerung zivilrechtlich mißbilligter Rechtsgeschäfte ${ }^{40}$.

Solchen Wertungsdifferenzen trägt der Versuch, die Anknüpfung an verwaltungsrechtliche Vorgaben im Zivil- und Strafrecht mit Hilfe des Grundsatzes der Widerspruchsfreibeit der Rechtsordnung zu erreichen $^{41}$, besser Rechnung. Weit führt er indessen nicht. Er läßt offen, wann - gemessen an den unterschiedlichen Aufgaben und Konstellationen des Zivil- und Strafrechts im Verhältnis zum Verwaltungsrecht - eine rechtsstaatlich mißbilligenswerte Desorientierung des Bürgers infolge widersprüchlicher Verhaltensanweisungen ${ }^{42}$ eintritt. Die Widerspruchsfreiheit der Rechtsordnung umschreibt somit zwar ein rechtsstaatlich gebotenes Ergebnis. Sie bestimmt indessen nicht, wann und wie an das Verwaltungsrecht anzuknüpfen ist.

\section{b) Systemgerechtigkeit}

$\mathrm{Zu}$ den im Verwaltungsrecht wurzelnden Gründen für eine Vorgabewirkung des Verwaltungsrechts gehört das vor allem mit Art. 3 GG in Verbindung stehende Gebot der Systemgerechtigkeit. Es beinhaltet nicht nur für den Gesetzgeber selbst, sondern auch für die rechtsanwendenden Instanzen die Verpflichtung zur folgerichtigen Weiterführung einer einmal statuierten gesetzlichen Ordnung. Seiner Anwendung auf die Beziehungen des Verwaltungsrechts zum Zivil- und Strafrecht steht auf den ersten Blick entgegen, daß hier verschiedene Regelungssysteme in einen folgerichtigen Zusammenhang gebracht werden sollen. Ein prinzipieller Einwand ist dies aber nicht. Willkür in der Rechtsetzung und -(s)anwendung kann es auch dann geben, wenn Sachverhalte in den einzelnen Teilrechtsordnungen ohne ein-

${ }^{39}$ Dazu eingehend und überzeugend $P$. Fischer, in: Hübschmann/Hepp/Spitaler, AO, $\$ 40$ Rdn. 19; ferner E.J. Lampe, Diskussionsbeitrag, wie Fn. 37, L 158; Samson (Fn. 17), S. 801 f; richtig jetzt auch die Bedenken bei Gerhardt (Fn. 25), S. 550.

${ }^{40}$ Dazu Kirchhof, wie vor, S. 10, und in neuerer Zeit H. Vogel (Fn. 31).

41 So etwa Ossenbühl (Fn. 22), durchgängig; Wagner, wie vor, S. 95, 99.

${ }^{42}$ Diese Konkretisierung des Rechtsstaatsprinzips beispielsweise Brener (Fn. 23), S. 177; Wagner, wie vor, S.151. 
leuchtenden Grund unterschiedlich bewertet werden ${ }^{43} . \mathrm{Zu}$ beachten ist allerdings, daß die dirigierende Kraft der Systemgerechtigkeit, bedingt durch die Eigengesetzlichkeiten der Teilrechtsordnungen, schwächer ist als im Kontext einer einzelnen Rechtsmaterie ${ }^{44}$. Am ehesten wird sie mit Bezug auf das Strafrecht wirken, soweit dieses mit dem Ziel der Sanktionsverstärkung eingesetzt wird.

\section{c) Vertrauensschutz und administrativer Kompetenzschutz}

Das Verwaltungsrecht ist auf administrativen Vollzug angewiesen und ausgerichtet. Auch der Bürger erfährt es regelmäßig in der von der Verwaltung „konkretisierten und mediatisierten Gestalt“45. Daraus ergeben sich zusätzliche Gründe gerade für die Vorgabewirkung administrativer Entscheidungen im Zivil- und Strafrecht. Sie liegen nicht allein im Schutz desjenigen, der auf die Legalisierungszoirkung bebördlicher Gestattungen vertrauen können soll ${ }^{46}$ - im Zivilrecht freilich nur mit Einschränkungen, wenn es um Ansprüche Dritter geht, über die verwaltungsrechtlich nicht entschieden wurde. Die zivil- und strafrechtliche Anknüpfung an administrative Entscheidungen kann auch aus Gründen des Kompetenzscbutzes der Verwaltung geboten sein, wenn die Zusammenschau zivil- oder strafrechtlicher Normen mit dem Verwaltungsrecht einen Beurteilungs- und Entscheidungsvorrang der Verwaltung im Verhältnis zu abweichenden Einschätzungen der ordentlichen Gerichtsbarkeit ergibt. Je nach Rechtslage kann ein solcher Vorrang über die Bindung an wirksame behördliche Festlegungen dadurch hinausgehen, daß zivil- oder strafrechtliche Bewertungen eines Sachverhalts nicht ohne vorgängige Entscheidung der Verwaltung vorgenommen werden dürfen, wie dies im Steuerrecht diskutiert wird ${ }^{47}$. Immer ist der Vorrang Ausdruck einer spezifischen Verantwortung und Qualifikation der Exekutive in der Bestimmung dessen, was für die Gesetzeskonkretisierung not-

${ }^{43}$ Vgl. bereits Kirchhof, wie vor, S. 31 und H.Schneider, Gesetzgebung, 1982, Rdn. 57 f.; zweifelnd Breuer, wie vor, S. $176 \mathrm{f}$.

44 Vgl. dazu v. Mangoldt/Klein/Starck, Grundgesetz, 3. Aufl., Art. 3 Rdn. 37 und Jarass/Pieroth, Grundgesetz, 1989, Art. 3 Rdn. 19.

${ }_{45}$ Breuer (Fn. 23), S. 177.

46 So die strafrechtliche Literatur, siehe etwa Horn, Umweltstrafrecht - eine After-Disziplin, UPR 1983, 362 (367); Seier, Probleme des Umweltstrafrechts, JA 1985, 23 (25).

$47 \mathrm{Vgl}$. die entsprechende Einschätzung in bezug auf das Steuerstrafrecht bei Isensee (Fn. 27), S. 1009 f. und Kirchbof (Fn. 19), S. 2984. 
wendig und für den Bürger im Einzelfall rechtens sein soll ${ }^{48}$. Er steht deshalb in direkter Beziehung zum Gewaltenteilungsgrundsatz und zum rechtsstaatlichen Gebot klarer Kompetenzabgrenzung ${ }^{49}$.

\section{d) Grundrechtlicher Sanktions- und Verfabrensschutz}

Als Sanktions- und Verfahrensschranke zum Schutz der Grundrechte kann sich das Verwaltungsrecht auswirken, wenn aus VerstöBen strafrecbtliche Konsequenzen gezogen werden sollen. Hintergrund dieses Ansatzes ist, daß Strafen im freiheitlichen Rechtsstaat immer letztes Mittel bleiben müssen ${ }^{50}$, weil sie typischerweise den stärksten Eingriff mit sich bringen. Unausweichlich wird deshalb bei Anknüpfung an die Verletzung verwaltungsrechtlicher Pflichten eine „vergleichende Gesamtwürdigung verwaltungsrechtlicher, ordnungswidrigkeitenrechtlicher und strafrechtlicher Reaktionsmöglichkeiten ${ }^{\text {"51. }}$. Dabei kann sich herausstellen, daß der Einsatz der Strafsanktion prinzipiell nicht erforderlich oder im Einzelfall unangemessen ist ${ }^{52}$.

Bei strittiger Verwaltungsrechtskonformität eines Verhaltens, von der die Strafbarkeit abhängt, können sich aus dem Postulat „Strafe als ultima ratio" und aus der verfahrensprägenden Dimension der Grundrechte $^{53}$ Auswirkungen auf den zeitlichen Ablauf des Strafverfahrens ergeben. Der Strafrichter wird in einem solchen Falle zu prüfen haben, ob nicht trotz bestehender Vorfragenkompetenz dem grundrechtsschonenderen Verwaltungs- bzw. Verwaltungsgerichtsverfahren ${ }^{54} \mathrm{der}$ Vortritt zu lassen ist, sofern eine Aussetzung hierzu verfahrensrechtlich die Möglichkeit bietet. Die bislang nicht konsensfähige Erweiterung der Garantie des Art. 19 Abs. 4 GG auf den Schutz vor dem

48 Mit Recht betont von Isensee, wie vor, S. 1009; Kirchbof, wie vor, S. 2987. Vgl. auch Ossenbübl (Fn. 12), L 42 ff. und jüngst Gerbardt (Fn. 25), S. $551 \mathrm{ff}$.

49 Im ersteren Sinne Isensee, wie vor, S. 1009, und Kirchbof, wie vor; im letzteren Sinne: Breuer (Fn. 23), S. 179, 180.

50 Siehe etwa $B \operatorname{VerfGE} 6,389$ (433); 39, 1 (47); - im strafrechtlichen Schrifttum ist z. T. von "Subsidiarität" des Strafrechts die Rede, so etwa H.L. Günther, Die Genese eines Straftatbestandes, JuS 1978, 8 (13).

51 Zum ganzen bereits Breuer, wie vor, S. 177.

${ }^{52} \mathrm{Vgl}$. Ossenbübl (Fn. 12), L $40 \mathrm{ff}$. und Schendel, Sanktionen im Umweltrecht, dargestellt am Beispiel des Wasserrechts, UTA 9 (1989), 189 (201 ff).

${ }_{53}$ In diese Richtung bereits Isensee (Fn. 27), S. 1010. - Allgemein zur verfahrensprägenden Dimension der Grundrechte zuletzt Stern, Staatsrecht, Bd. III/1 (1988), $\$ 69$ V6, 7.

${ }^{54}$ Argument von Kirchhof (Fn. 19), S. 2984. 
Richter ${ }^{55}$ wird damit entbehrlich. Keinesfalls hilft Art. 101 Abs. 1 Satz 1 GG weiter: Da das Verwaltungsrecht nach $\$ \$ 262 \mathrm{StPO}^{56}$ und 396 AO prinzipiell in die strafgerichtliche Vorfragenkompetenz fällt, verletzt die Mitentscheidung darüber nicht den gesetzlichen Richter ${ }^{57}$.

\section{Gegengründe}

Gegengründe gegen eine Vorgabewirkung des Verwaltungsrechts werden - veranlaßt durch die in der Gesetzgebung besonders augenfällige Abhängigkeit des Strafrechts vom Verwaltungsrecht - vor allem im strafrechtlichen Schrifttum thematisiert. Dabei spielt der Gesichtspunkt eine erstrangige Rolle, dem Strafrecht die Eigenständigkeit zu sichern. Als deren Ausdruck erscheint die Möglichkeit autonomer Ausformung des Rechtsgüterschutzes ${ }^{58}$, der Anspruch, den Grad der Berücksichtigung des Verwaltungsrechts von den maßgeblichen Wertungen des Strafrechts abhängig zu machen ${ }^{59}$ und sich von verwaltungsrechtlichen Vorgaben zu befreien, sofern Eigengesetzlichkeiten und Regelungsziele des Strafrechts es notwendig machen $^{60}$. Über die Tragfähigkeit dieses Autonomieanspruchs ist an dieser Stelle nichts zu sagen. Daß er aber in bestimmten Problemzusammenhängen einen Grund gegen die Vorgabewirkung des Verwaltungsrechts oder für deren Einschränkung darstellen kann, läßt sich nicht von vornherein in Abrede stellen. Das gilt sinngemäß auch für das Zivilrecht. Es unterscheidet sich vom Verwaltungsrecht durch "grundsätzlich unterschiedliche Ausgangspunkte und Funktionen "61, auch dann noch, wenn es u.a. in bezug auf die Eigentumsordnung einer wachsenden „Entprivatisierung" ausgesetzt sein sollte ${ }^{62}$.

${ }^{55} \mathrm{Vgl}$. Kirchbof, wie vor, m. Nachw. in Fn. 94. - Nach der nicht überzeugenden Auffassung von $K \ddot{z} b l$ (Fn. 13), S. 846, zwingt Art. 19 Abs. 4 zur eigenständigen Prüfung des Strafrichters.

56 Der insoweit entsprechend gilt: Gollwitzer, in: Loewe/Rosenberg, StPO, 24. Aufl., $\$ 262$ Rdn. 1 (1986).

57 Zutreffend Gollwitzer, wie vor, Rdn. 5 m. Nachw.

58 Rudolphi, Primat des Strafrechts im Umweltschutz? (I), NStZ 1984, 193 (194); siehe auch Brener (Fn. 23), S. 178.

59 Scbünemann, Die Strafbarkeit von Amtsträgern im Gewässerstrafrecht, wistra 1986, 235 (239); Heine/Meinberg (Fn. 17), D 121.

60 Winkelbauer, Die Verwaltungsabhängigkeit des Umweltstrafrechts, DÖV 1988, 723 (725).

${ }_{61} \mathrm{Vgl}$. nur Maurer, Allgemeines Verwaltungsrecht, 7. Aufl. 1990, $\$ 3 \mathrm{Rdn} .13$.

$62 \mathrm{Vgl}$. Isensee, Die Ambivalenz des Eigentumsgrundrechts, in: Ossenbühl (Hrsg.), Eigentumsgarantie und Umweltschutz, 1990, $3 \mathrm{ff} ., 11 \mathrm{ff}$. 


\section{Verwaltungsrechtliche Vorgaben im Strafrecht}

I. Bestandsaufnahme der Verknüpfungen zwischen Verwaltungsrecht und Strafrecht in der Strafgesetzgebung

Geht man den Gründen und Gegengründen einer Vorgabewirkung des Verwaltungsrechts im Strafrecht genauer nach, erweist sich, im Grundsätzlichen wie bei der notwendigen Auffächerung in Einzelprobleme, eine Bestandsaufnahme der Strafgesetzgebung als hilfreich. Aus ihr ergeben sich Fragen an den Gesetzgeber. Sie bestimmt zu einem wesentlichen Teil den Rahmen, in dem die Rechtsanwendung verwaltungsrechtliche Vorgaben folgerichtig weiterzuführen und dadurch zur Widerspruchsfreiheit der Rechtsordnung beizutragen hat ${ }^{63}$.

\section{Tatbestandliche Anknüpfung}

Am verbreitetsten ist in der Strafgesetzgebung die tatbestandliche Anknüpfung an das Verwaltungsrecht. Im Detail bietet sich ein höchst unterschiedliches Bild, das nur stichwortartig beschrieben werden kann.

(1) Begriffe, die aus dem Verwaltungsrecht stammen oder ibm geläufig sind, werden z.T. explizit modifiziert ${ }^{64}$. In der Regel ist es jedoch der Rechtsanwendung überlassen, zu bestimmen, ob ein Begriff im verwaltungsrechtlichen oder in einem spezifisch strafrechtlichen Sinne zu verstehen ist ${ }^{65}$.

${ }^{63}$ Hierzu allgemein: P. Kirchbof (Fn. 31), S. $31 \mathrm{f}$.

${ }_{64}$ Zum Gewässerbegriff: $₫ 324$ StGB und Schönke/Schröder/Cramer, $\$ 324$ Rdn. 3; Steindorf, Leipziger Kommentar zum StGB (LK), $\$ 324$ Rdn. 8; zum Anlagenbegriff: $\$ 325 \mathrm{StGB}$ und Schönke/Schröder/Stree, Rdn. 4; Steindorf, LK $\$ 325$ Rdn. 17; zum Abfallbegriff: $\$ 326$ Abs. 1 StGB und Scbönke/Schröder/Lenckner, Rdn. 2 a.

${ }^{65}$ Beispiele sind neben der altbekannten rechtmäßigen Diensthandlung im Sinne des $₫ 113$ StGB die Begriffe der öffentlichen Sicherheit in $\$ 125$ Abs. 1 StGB, des Giftes bzw. der gesundheitsgefährdenden Stoffe, der Freisetzung von Giften in Umweltmedien ( $\$ \$ 319,330$ a StGB) und der schädlichen Umwelteinwirkungen im Umweltstrafrecht. Auch der Subventionsbegriff des $\$ 264$ Abs. 6 StGB gehört hierher, soweit er darauf abstellt, daß die Subvention wenigstens teilweise einen Wirtschaftsförderungszweck haben muß: Schönke/Schröder/Lenckner, $\$ 264$ Rdn. 19; Tiedemann, in: LK $\$ 264$ Rdn. 41. 
(2) Vermehrt ist die als Ordnungswidrigkeit geläufige $M i ß a c h-$ tung $^{66}$ eines vollziehbaren Verwaltungsaktes durch das Umweltstrafrecht zum Tatbestand von Strafnormen geworden ${ }^{67}$.

(3) Nur selten knüpft die Strafbarkeit ausdrücklich an die Rechtmäßigkeit einer Amtshandlung an: Im Strafgesetzbuch vor allem beim Widerstand gegen die Staatsgewalt $(\$ 113 \mathrm{StGB})$ sowie beim Vollstreckungs- und Siegelbruch ( $\$ 136 \mathrm{StGB})$.

(4) Mehrfach stellt das Strafgesetzbuch das Handeln obne vorberige verwaltungsbebördliche Gestattung unter Strafe - so beim unerlaubten Glücksspiel $(\$ 284 \mathrm{StGB})$ und neuerdings im Umweltstrafrecht.

(5) Die im Nebenstrafrecht verbreitete Anknüpfung der Strafbarkeit an näher bezeichnete Verwaltungsrechtsnormen findet sich auch im Strafgesetzbuch, so in $\$ 315$ a Abs. $1 \mathrm{Nr}$.2, der grob pflichtwidrige Verstöße gegen Rechtsvorschriften zur Sicherheit des Verkehrs erfaßt, die zur Gefährdung von Personen und Sachgütern führen, und im Umweltstrafrecht.

(6) Neuerdings greift der Gesetzgeber im Strafgesetzbuch verstärkt zu einer im Schrifttum als „Zauberformel“ apostrophierten Tatbestandsumschreibung ${ }^{68}$ : Für strafbar erklärt werden bestimmte Verhaltensweisen, die "unter Verletzung verwaltungsrechtlicher Pflichten" erfolgen ${ }^{69}$. Nach der geltenden, künftig generalisierten Legaldefinition umfaßt die Formel Verstöße gegen Rechtsvorschriften, vollziehbare Untersagungen, Anordnungen und Auflagen, die dem Strahlen- bzw. Umweltschutz dienen ${ }^{70}$. Bemerkenswert ist zudem, daß die Strafbarkeit derzeit durchweg erst bei groben Verstößen der genannten Art

${ }_{66}$ Vgl. nur $\$ 144$ Abs. 1 Nr. 3 GewO; $\$ 46$ Abs. 1 Nr. 3 AtomG; $\$ 39$ Gentechnikgesetz.

$67 \$ \$ 311 \mathrm{~d}, 327,328$ Abs. 1, 329 Abs. 1 Satz 2, 330 Abs. 1 Nr. 2-4 StGB. Außerhalb des Umweltstrafrechts ist auf die nach $\$ 20$ Vereinsgesetz strafbare Zuwiderhandlung gegen ein vollziehbares Vereinigungsverbot hinzuweisen. Darüber hinaus stellt $\$ 85$ Abs. 1 Nr. 2 StGB mit höherem Strafmaß die Mißachtung eines unanfechtbaren Vereinigungsverbotes unter Strafe.

${ }_{68}$ So Steindorf, in: LK vor $\$ 324 \mathrm{Rdn} .10$.

${ }^{69}$ Derzeit: $\$ \$ 311$ d, 325 StGB. Künftig maßgebend auch für die Bodenverunreinigung, sonstige Immissionen, die Nichtablieferung radioaktiver Abfälle, die Lagerung von Gefahrstoffen oder radioaktiven Stoffen und die Beförderung gefährlicher Güter: Entwurf eines Strafrechtsänderungsgesetzes - Zweites Gesetz zur Bekämpfung der Umweltkriminalität, BT-Drucks. $11 / 6453$ v. 14.2. $1990, \$ \$ 324$ a, 325 a, 326 Abs. 3,328 Abs. 3, Abs. 4 .

$70 \$ \$ 311 \mathrm{~d}$ Abs. 4, 325 Abs. 4 StGB; BT-Drucks. a. a. O., $\$ 330 \mathrm{~d}$ Nr. 4. 
einsetzt, während das künftige Recht stärker differenzieren will ${ }^{11}$. Im Einzelfall wird damit eine Gewichtung der verletzten verwaltungsrechtlichen Pflicht notwendig ${ }^{72}$.

(7) Einen besonderen Fall der Verletzung verwaltungsrechtlicher Pflichten stellt die Anknüpfung der Strafbarkeit an die Verletzung von Informationspflichten zum eigenen Vorteil dar. So ist für den Tatbestand des Subventionsbetruges nach $\$ 264 \mathrm{StGB}$ u. a. wesentlich, daß der Täter unvollständige oder unrichtige Angaben über subventionserhebliche Tatsachen macht oder solche Angaben unterläßt. Darauf, ob dieses Verhalten Einfluß auf die Subventionsentscheidung gehabt hat, kommt es nicht an. Demgegenüber muß bei der Steuerhinterziehung nach $\$ 370 \mathrm{AO}$ die ähnlich formulierte Verletzung der steuerrechtlichen Informationspflichten zu einer Steuerverkürzung geführt haben.

\section{Berücksichtigung des Verwaltungsrechts als Rechtfertigungsgrund}

Verschiedentlich knüpfen Strafnormen trotz Nähe des geschützten Rechtsgutes zum Verwaltungsrecht an dieses nicht im Tatbestand an. Verwaltungsrechtskonformes Handeln kann dann im Rahmen des Rechtswidrigkeitsurteils Berücksichtigung finden. Das trifft etwa auf die Vergiftungstatbestände $(\mathbb{S} 319,330$ a StGB), die Gewässerverunreinigung ( $\$ 324 \mathrm{StGB}), \mathrm{z}$. T. die Abfallbeseitigung ( $\$ 326 \mathrm{Abs.} 1 \mathrm{StGB}$ ) sowie die schwere Umweltgefährdung ( $\$ 330$ a StGB) zu ${ }^{73}$.

\section{Berücksichtigung des Verwaltungsrechts als Strafbarkeits- einschränkung}

Strafbarkeitseinschränkend berücksichtigt die Strafgesetzgebung z.T. die Auswirkungen einer Straftat auf Rechtsgüter, die (auch) verwaltungsrechtlich geschützt sind, und das Bemühen um Rückgängigmachung.

$71 \int \mathbb{S} 311 \mathrm{~d}$ Abs. 4, 325 Abs. 4 StGB. Im gleichen, an die grobe Pflichtwidrigkeit anknüpfenden Sinne BT-Drucks. a. a. O., $\$ 311$ d Abs. 3, $\$ \$ 325$ Abs. 2, 328 Abs. 3, 4; demgegenüber einfacher Verstoß nach $\$ \subseteq 311 \mathrm{~d}$ Abs. 1, 324 a, 325 Abs. 1, 325 a, 326 Abs. 3 des Entwurfes.

72 Siehe nur Schönke/Schröder/Stree, $\$ 325 \mathrm{Rdn} .8$. - Entsprechendes gilt für den Tatbestand der Abfallbeseitigung, soweit dieser auf wesentliche Abweichungen von einem vorgeschriebenen oder zugelassenen Verfahren abstellt. Damit wird im Sinne einer Minimaklausel ausgeschlossen, daß jede an sich verwaltungsrechtswidrige Abweichung den Tatbestand erfüllt.

${ }^{73}$ Streitig wie hier Steindorf, LK $₫ 326$ Rdn. 60; Sack, Umweltstrafrecht, $₫ 326$ Rdn. 145. Teilweise abweichend Schönke/Schröder/Lenckner, $\$ 326$ Rdn. 16. 
(1) Im Umweltstrafrecht hat das Bestreben, geringfügige Verstöße gegen das Verwaltungsrecht von der Strafbarkeit auszunehmen ${ }^{74}$, seinen Niederschlag auch in einem Strafausschließungsgrund sui generis, der sog. Minima-Klausel gefunden ${ }^{75}$. Danach bleibt die Beseitigung geringer Abfallmengen straflos, wenn sie „offensichtlich" nicht zu schädlichen Umwelteinwirkungen führt ( $\$ 326$ Abs. $5 \mathrm{StGB}$ ).

(2) Vorschriften, die einen Anreiz zur Beseitigung der Folgen eines Verwaltungsrechtsverstoßes schaffen sollen, begegnen in unterschiedlichen Varianten: Nach $\$ 330$ b StGB kann die Strafe gemildert oder von ihr abgesehen werden, wenn der Täter im Falle einer schweren Umweltgefährdung oder der Freisetzung von Giften freiwillig die Gefahr abwendet oder sich bei Abwendung durch Dritte darum ernsthaft bemüht. Beim Subventionsbetrug bleibt straflos, wer die Subventionsgewährung verhindert oder sich darum ernsthaft bemüht (\$264 Abs. 4 StGB). Ähnliches gilt für die Steuerhinterziehung bei Selbstanzeige $(\$ 373 \mathrm{AO})$.

\section{Ausgewäblte Einzelfragen}

\section{Eingrenzung}

Um das gesetzliche Erscheinungsbild der Verknüpfungen des Verwaltungsrechts mit dem Strafrecht ranken sich zahlreiche Kontroversen. Aus diesen können nur wenige aufgegriffen werden. Dabei handelt es sich um solche, die einerseits von prinzipiellem, zukunftsbezogenem Interesse sind, an denen sich andererseits die Tragfähigkeit der Gründe für und gegen eine Vorgabewirkung des Verwaltungsrechts genauer demonstrieren läßt.

\section{Die Vorgabewirkung des Verwaltungsrechts für den Strafgesetzgeber}

Die Bestandsaufnahme des materiellen Strafrechts ergibt eine unterschiedliche Verknüpfungsdichte mit dem Verwaltungsrecht, je nachdem, ob die Anknüpfung auf der Ebene der Tatbestandsumschreibung erfolgt, ob sich die „verwaltungsrechtliche Vorwürdigung des Sach-

\footnotetext{
74 Vgl. oben 1. (6.), am Ende, aber auch $\$ 329$ Abs. 3 StGB und das dort genannte Merkmal schwerwiegender Eingriffe (hierzu BT-Drucks. 8/2382, S. 22 und allgemein Ostendorf, Das Geringfügigkeitsprinzip als strafrechtliche Auslegungsregel, GA 1982, $333 \mathrm{f}$.).

75 Siehe dazu Steindorf, LK, $\$ 326$ Rdn. 67.
} 
verhaltes“ im "generellen Negativbegriff“ „unbefugt“ „,versteckt" oder im Bereich der Schuld bzw. Rechtsfolgen zu berücksichtigen ist. Die Ansicht, daß die Entscheidung des Gesetzgebers für die eine oder andere Variante letztlich ohne Bedeutung sei, wenn nur die Konkordanz mit dem Verwaltungsrecht im Ergebnis angemessen gewährleistet werde ${ }^{77}$, überzeugt nicht. Erfolgt die Berücksichtigung nicht schon im Tatbestand, ist die Vorgabewirkung des Verwaltungsrechts schwächer: Der Gesetzgeber hat sich für eine verwaltungsrechtsunabhängige Fixierung des strafwürdigen Verhaltens entschieden; der strafrechtsspezifische Freiraum zur Berücksichtigung verwaltungsrechtlicher Vorgaben ist zugunsten der Strafjustiz zumindest tendenziell und kollisionsfördernd erweitert. An diese Beobachtung schließt die Frage an, inwieweit sich der Strafgesetzgeber bei der Gestaltung der Straftatbestände von verwaltungsrechtlichen Vorprägungen eines Lebensbereichs lösen darf. Ein auffälliges und vieldiskutiertes Beispiel ist die weitgehend verwaltungsrechtsunabhängige Gestaltung des Straftatbestandes der Gewässerverunreinigung.

In diesem Zusammenhang ist die Ansicht geäußert worden, dem Strafrecht bleibe in bezug auf Lebensbereiche, die durch das Verwaltungsrecht und dessen administrative Konkretisierung "besetzt" sind, grundsätzlich keine Domäne zu eigenständiger Normierung. Verwaltungsrechtsunabhängig dürfe nur „superqualifiziertes“ Handlungsund Erfolgsunrecht strafrechtlich sanktioniert werden ${ }^{78}$. Die Gesetzgebung entspricht ihr aufs Ganze gesehen durchaus, indem sie mit steigender Tendenz verwaltungsrechtliche Vorgaben bereits in die tatbestandliche Umschreibung strafwürdigen Unrechts aufnimmt. Andererseits dürfte es gerade im Einzelfall schwerfallen, den Strafgesetzgeber auf eine sanktionsverstärkende, unmittelbar an das Verwaltungsrecht anschließende Ausgestaltung des Straftatbestandes festzulegen. Die Einheit der Rechtsordnung ist dazu als Pauschalformel nicht geeignet. Das Gebot der Widerspruchsfreiheit verbietet zwar die Desorientierung des Bürgers durch widersprüchliche Verhaltens-

76 So Tiedemann, Die Neuordnung des Umweltstrafrechts, 1980, S. 25 in bezug auf das Umweltstrafrecht.

77 Generell bejahend: Tiedemann/Kindhäuser, Umweltstrafrecht - Bewährung oder Reform, NStZ 1988, 337 (342). Verneinend: Breuer (Fn. 23), S. 180; Samson (Fn. 17), S. 801. Vorsichtiger Papier, Zur Disharmonie zwischen Verwaltungs- und strafrechtlichen Bewertungsmaßstäben im Gewässerstrafrecht, NuR 1986, 1 (2).

${ }_{78}$ So insbesondere Breuer (Fn. 23), S. 178, und ders., Empfehlen sich Änderungen des Umweltstrafrechts, insbesondere in Verbindung mit dem Verwaltungsrecht, NJW 1988, 2072 (2077). 
anweisungen. Als ergebnisorientierter Maßstab zwingt es jedoch nicht zu einer bereits am Straftatbestand ansetzenden Anknüpfung an verwaltungsrechtliche Vorgaben. Bleibt der Topos der Systemgerechtigkeit. Ihm mag man entnehmen, daß eine das Verwaltungsrecht „konsequent" weiterführende Strafgesetzgebung in besonderem Maße gefordert ist, wenn es um die strafrechtliche Bewertung eines Lebensbereiches geht, dessen Gestaltung Aufgabe der Verwaltung und der von ihr in Form gebracht ist. Doch verfügt der Gesetzgeber über eine weitgehende Freiheit, sozialschädliches Verhalten strafrechtlich zu fixieren. Deshalb läßt sich kaum der Vorwurf der Systemwidrigkeit erheben, wenn sich der Strafgesetzgeber aus Gründen, die nicht evident sachwidrig sind und hinreichendes Gewicht besitzen, für einen strafrechtlichen Rechtsgüterschutz entscheidet, bei dem die Verwaltungsrechtswidrigkeit nur eine unter mehreren sozialschädlichen Verhaltensweisen darstellt und deshalb Einfluß erst auf das Rechtswidrigkeitsurteil oder die Schuldfeststellung gewinnt. Solche Gründe liegen nicht nur im Schutz höchstpersönlicher Rechtsgüter. Sie können auch, wie bei $\$ 324$ StGB, umweltspezifischer Natur sein oder allgemeiner darauf beruhen, daß der Gesetzgeber in der administrativen Konkretisierung eines Lebensbereiches keinen sicheren oder flächendeckenden Schutz erblickt ${ }^{79}$. Aus verwaltungsrechtlicher Sicht mag dieses Ergebnis „befremdlich“" erscheinen ${ }^{80}$. Aus strafrechtspolitischer Sicht kann es unvermeidbar sein. Wegen der bereits hervorgehobenen kollisionsfördernden Wirkung einer vom Verwaltungsrecht abweichenden tatbestandlichen Umschreibung strafbewehrten Verhaltens ist der Gesetzgeber allerdings gut beraten, wenn er von seiner Gestaltungsfreiheit in bezug auf verwaltungsrechtliche Vorprägungen bei der Strafrechtsnormierung nur sparsam Gebraucht macht.

\section{Die strafrechtliche Relevanz von Verwaltungsvorschriften}

Die strafrechtliche Relevanz von Verwaltungsvorschriften läßt sich am Beispiel des Subventionsbetruges und des Umweltstrafrechts demonstrieren.

\section{a) "Gesetzesvertretende" Verwaltungsvorschriften}

Bei gesetzesfrei gewährten Subventionen ergeben sich die subventionserheblichen Tatsachen, über die getäuscht wird oder deren

79 Siehe hierzu Steindorf, LK, $₫ 324$ Rdn. 6 betr. $\$ 324$ StGB.

${ }^{80}$ So Breuer, Änderungen des Umweltstrafrechts (Fn. 78), S. 2079 betr. $\$ 324$ StGB. 
Angabe „entgegen den Rechtsvorschriften über die Subventionsgewährung" unterbleibt, typischerweise aus Verwaltungsvorschriften, die die "Funktion von gesetzesvertretenden Verordnungen " baben ${ }^{81}$. Die Vorgabewirkung dieser Vorschriften für das Strafrecht wird im Hinblick auf den Gesetzesvorbehalt des Art. 103 Abs. 2 GG diskutiert ${ }^{82}$.

Unproblematisch ist die Vorgabewirkung bei positiven Täuschungshandlungen. $\$ 264$ Abs. 1 Nr. 1 StGB umschreibt, insoweit dem allgemeinen Betrugstatbestand vergleichbar, die Täuschungshandlung selbst und hinreichend präzise. In der Bezugnahme der Verwaltung auf Verwaltungsvorschriften liegt deshalb keine den Gesetzesvorbehalt involvierende konstitutive Bestimmung des Straftatbestandes ${ }^{83}$. Anders liegt es bei der rechtsvorschriftswidrig unterlassenen Angabe subventionserheblicher Tatsachen im Sinne des $\$ 264$ Abs. 1 Nr. 2 StGB. Fallen darunter auch Verwaltungsvorschriften, bestimmen diese Inhalt und Umfang der Aufklärungspflicht konstitutiv. Aus der Sicht des Strafrechts ist dies mit Art. 103 Abs. 2 GG unvereinbar, weil danach die Strafbarkeit nur durch außenverbindliche Rechtsnormen festgelegt werden darf. Man behilft sich deshalb mit der in $\$ 3$ Subventionsgesetz statuierten allgemeinen Offenbarungspflicht über subventionserhebliche Tatsachen ${ }^{84}$. Verwaltungsrechtlich könnte entgegengehalten werden, $d a ß$ "gesetzesvertretende“ Verwaltungsvorschriften in der Leistungsverwaltung zunehmend als "originäres Administrativrecht mit Außenwirkung" aufgefaßt werden und diese Entwicklung folgerichtig auch zu einer Neuinterpretation des strafrechtlichen Gesetzesvorbehaltes führen müsse ${ }^{85}$. Indessen ist diese Entwicklung nicht abgeschlossen. Daß das Strafrecht ihr vorgreift, wird man nicht verlangen können. Eine konstitutiv die Strafbarkeit bestimmende Vorgabewirkung gesetzesvertretender Verwaltungsvorschriften scheidet deshalb solange und insoweit aus, wie die Außenwirkung im Verwaltungsrecht nicht definitiv geklärt ist.

${ }^{81} \mathrm{Vgl}$. Ossenbühl, in: Erichsen/Martens, Allgemeines Verwaltungsrecht, 8. Aufl. 1988, § 7 IV 2 b) bb) m. w. Nachw.

${ }^{82}$ W. Löwer, Rechtspolitische und verfassungsrechtliche Bedenken gegen das 1. Wirtschaftskriminalitätsgesetz, JZ 1979, 621 (629f.); Ranft, Die Rechtsprechung zum sogenannten Subventionsbetrug ( $\$ 264$ StGB), NJW 1986, 3163 (3170f.); Schönke/Schröder/Lenckner, \$264 Rdn. 34, 52 f.; BayObLG, NJW 1982, $2202 \mathrm{f}$.

${ }_{33}$ Abweichend nur Löwer, a. a. $\mathrm{O}$.

${ }^{84}$ Schönke/Schröder/Lenckner, a. a. O., Rdn. 53 m.w. Nachw.; vgl. aber auch Bay $O b L G$, wie vor.

${ }^{85}$ So Löwer, wie vor. - Zum Grundsätzlichen auch Ossenbühl, Verwaltungsvorschriften und Grundgesetz, 1968, S. $493 \mathrm{ff}$. 


\section{b) Normkonkretisierende Verwaltungsvorschriften}

aa) Erhebliche Konflikte mit dem Strafrecht zeichnen sich bei den sogenannten normkonkretisierenden Verwaltungsvorschriften ab, wie sie namentlich im Umweltrecht zur näheren Festlegung naturwissenschaftlich-technischer Standards (gesetzlich) vorgesehen sind ${ }^{86}$. Wegen ihrer angeblich fehlenden Außenwirkung wird ihnen als solchen die bindende Wirkung abgesprochen ${ }^{87}$. Erst durch die Bezugnahme in einem Verwaltungsbescheid sollen sie auch strafrechtliche Relevanz bekommen ${ }^{88}$, nach anderer Ansicht für die strafrechtliche Würdigung nur Anhaltspunkte bieten ${ }^{89}$, zumal wenn sie mit strafrechtlichen Verhaltensmaßstäben nicht übereinstimmen ${ }^{90}$. Dem entspricht, daß die Strafgesetzgebung von ihnen keine Notiz nimmt ${ }^{91}$, obschon sich im Verwaltungsrecht inzwischen eine Bindung der Verwaltungsgerichte an normkonkretisierende Verwaltungsvorschriften abzeichnet. Diese Bindung beruht wesentlich darauf, daß die Vorschriften naturwissenschaftlich-technische Aussagen enthalten und ihr Zustandekommen in einem besonderen Verfahren eine Sachgerechtigkeit verbürgt, die Abweichungen nur bei Veralten oder atypischen Fallgestaltungen erlaubt ${ }^{92}$.

Für den Bereich des Strafrechts sollte aus den nachfolgend genannten Gründen gleichfalls eine prinzipielle Bindung der Strafjustiz an

86 Vgl. nur $\$ 7$ a WHG; $₫ 48$ BImSchG; $₫ 4$ Abs. 5 AbfallG; $\$ 45$ Abs. 2 Strahlenschutzverordnung und Ossenbübl, Autonome Rechtsetzung der Verwaltung, in: Isensee/Kirchhof, Handbuch des Staatsrechts, Bd. III (1988), $₫ 65 \mathrm{Rdn} .7 \mathrm{ff}$.

${ }^{87}$ Siehe Rudolphi (Fn. 58), S. 250; Scbönke/Schröder/Stree, $\$ 325$ Rdn. 19; Steindorf, LK, $\$ 325$ Rdn. 6; Tiedemann/Kindhäuser (Fn. 76), S. 243 f.

${ }_{88}$ Möbrenschlager, Neuere Entwicklungen im Umweltstrafrecht des Strafgesetzbuches, NuR 1983, 209, 213.

${ }^{89}$ Schönke/Schröder/Stree, wie vor; verwaltungsrechtsnäher (generelle Aussagekraft als Sachverständigengutachten): Heinz, Probleme des Umweltstrafrechts im Spiegel der Literatur, NStZ 1981, 253 (257); Scbönke/Schröder/Stree, \$325 Rdn. 19.

90 So etwa Rudolphi (Fn. 58), S. 251; Schönke/Schröder/Stree, wie vor; Lackner, StGB, 18. Aufl. 1989, $\$ 325$ Anm. 5; Sack, Umweltstrafrecht, $₫ 325$ StGB Rdn. 40 (trotz prinzipieller Bejahung der Bindungswirkung in Rdn. 18).

91 Dazu BT-Drucks. 11/6453, S. 11 sub. 4 und S. 30, linke Spalte. - Dies in gewissem Gegensatz zur Bezugnahme auf allgemeine Regeln der Technik in den $\$ \$ 323$ und 330 Abs. 1 Nr. 3 StGB. Bedenken hinsichtlich dieser Bezugnahme aber bei Schünemann, Die Regeln der Technik im Strafrecht, Festschrift Lackner, 1987, 367 ff.; dazu Lackner, $\$ 323$ Anm. 2 b.

${ }_{92}$ BVerwGE 72, 300 (320f.) - Whyl; OVG Münster, DVBl. 1988, 152 (153) TA Luft. 
normkonkretisierende Verwaltungsvorschriften angenommen werden $^{93}$. Einerseits ist der strafrechtliche Pflichtverstoß ohne Zuhilfenahme der darin niedergelegten Standards, insbesondere Grenzwerte, häufig nicht zu ermitteln und können strafrechtliche Freiräume entstehen, wenn nur der Erlaubnisbescheid Verbindlichkeit erzeugt ${ }^{94}$. Das gilt namentlich dann, wenn die Strafbarkeit an die Verletzung verwaltungsrechtlicher Pflichten anknüpft. Andererseits sind die Strafverfolgungsorgane weder befugt noch in der Lage, die im strafrechtlichen Schrifttum erhobene Forderung nach eigenständigen strafrechtlichen Grenzwerten zu erfüllen: rechtlich nicht, weil es sich dabei um eine verhaltensbestimmende Standardisierung handelt, die einer spezifischen Sachverantwortung für die Gestaltung der Verwaltungsrechtslage entspringt. Sie ist dem Verwaltungsgesetzgeber, hinsichtlich der näheren Spezifizierung der Verwaltung, vorbehalten ${ }^{95}$. Hinzu kommt, daß die Standardisierung nicht in der strafrechtstypischen Einzelfallbeurteilung, sondern nur generalisierend erfolgen kann, wenn man nicht in Dilettantismus verfallen will. Ein Sachverständigengutachten im Einzelfall ersetzt sie jedenfalls nicht ${ }^{96}$.

Ein besonderer, die Bindung der Strafjustiz an normkonkretisierende Verwaltungsvorschriften tragender Gesichtspunkt ergibt sich aus der Sicht des Bürgers. Er darf prinzipiell darauf vertrauen, daß sein durch normkonkretisierende Verwaltungsvorschriften mitgeprägter Pflichtenumfang auch strafrechtlich respektiert wird.

Bleibt das Bedenken, daß eine Bindung der Strafjustiz an normkonkretisierende Verwaltungsvorschriften mit dem strafrechtlichen Gesetzesvorbehalt des Art. 103 Abs. 2 GG kollidiert. Es läßt sich nicht dadurch überwinden, daß ein Verwaltungsakt den Vorschriften Außenverbindlichkeit gibt. Auch in diesem Fall müßte zusätzlich

${ }_{93}$ So Ossenbuhl (Fn. 22), S. 969 und 972 und wie Fn. 12, L 44 f.; vgl. auch Hansmann (Fn. 18), S. 227 und Breuer (Fn.23), S.178, wonach das verwaltungsrechtsbezogene Strafrecht am Konkretisierungspotential des Verwaltungsrechts teilhaben muß.

${ }_{94}$ Vgl. Ossenbübl, Diskussionsbeitrag, in: Vhdlg. d. 57. DJT (1988), Bd. II, L 134; Laufhütte, Überlegungen zur Änderung des Umweltstrafrechts, DRiZ 1989, 337 (338). - Ob sie originäres Administrativrecht darstellen (dazu zuletzt eingehend M.Gerhardt, Normkonkretisierende Verwaltungsvorschriften, in: Dokumentation zum 9. Verwaltungsrichtertag, 1989, $40 \mathrm{ff}$.), kann aus den im Text genannten Gründen offenbleiben.

95 BVerwGE 72, 300 (316f.) im Anschluß an VG Schleswig, NJW 1980, 1296; OVG Lüneburg, NVwZ 1985, 35 f.

${ }_{96} \mathrm{Vgl}$. auch Seelmann, Atypische Zurechnungsstrukturen im Umweltstrafrecht, NJW 1990, 1257 (1261 sub. IV 1); positiver Hansmann (Fn. 18), S. $226 \mathrm{f}$. 
darauf abgestellt werden, daß normkonkretisierende Verwaltungsvorschriften keine "verwaltungsautonomen" Standards setzen, sondern generalklauselartig umschriebene Vorgaben der Verwaltungsgesetzgebung näher auszeichnen und deshalb die Strafbarkeit nicht konstitutiv bestimmen. Vieles spricht dafür, daß sie, ähnlich wie in $\$ 264$ Abs. 1 Nr. 1 StGB, dann auch unabhängig von Verwaltungsakten Bezugspunkt des Strafrechts sein können.

bb) Von der Bindungswirkung für die Strafjustiz zu unterscheiden ist die Frage, ob administrative Standards in normkonkretisierenden Verwaltungsvorschriften in jedem Falle und womöglich als alleiniger Maßstab für den strafrechtlichen Pflichtverstoß taugen. Zur Veranschaulichung kann die Kontroverse über die strafrechtliche Relevanz der wasserrechtlichen Überwachungswerte dienen ${ }^{97}$, die in den Verwaltungsvorschriften zu $\$ 7$ a WHG vorgesehen und im Einzelfall durch den Erlaubnisbescheid festgesetzt werden. Nach den einschlägigen Vorschriften gilt ein Überwachungswert als eingehalten, wenn das arithmetische Mittel der letzten fünf gewässeraufsichtlichen Untersuchungsergebnisse diesen Wert nicht überschreitet, alternativ auch dann, wenn hiervon fünf Untersuchungsergebnisse unter dem Überwachungswert bleiben und keine Einzelprobe um mehr als 100\% darüber liegt ${ }^{98}$. Strafrechtlich geht es darum, ob die Überschreitung eines Überwachungswertes ohne weiteres als „unbefugte" Gewässerverunreinigung qualifiziert werden darf.

Letztlich beruhen alle hier nicht weiter behandelten Schwierigkeiten bei der strafrechtlichen Verarbeitung der wasserrechtlichen Überwachungswerte darauf, daß ein aus Gründen der Verwaltungsvereinfachung geschaffenes und daraufhin konzipiertes Kontrollinstrument der Verwaltung zur Konkretisierung des strafrechtlichen Pflichtverstoßes herangezogen wird ${ }^{99}$. Dahinter steht die stillschweigende Annahme, das Strafrecht lasse sich mit allen verwaltungsrechtlichen Entwicklungen in ein stimmiges Verhältnis bringen. Sie ist durchaus problematisch, weil die Bedürfnisse der Verwaltung nicht ohne weiteres mit den spezifischen Anforderungen konvergieren, die Art. 103

97 Jüngste kritische Darstellung bei Kloepfer/Brandner, Rechtsprobleme der Grenzwerte für Abwassereinleitungen, ZfW 28 (1989), 1 (17ff.).

98 Beispiel für die erste Variante: 2. AbwasserVV vom 10.1.1980 Pkt. 2.3, für die zweite Variante: RahmenabwasserVV vom 1.9.1989, beide abgedruckt bei Kloepfer, Umweltschutz, Nr. 200/2 und 200/0.

${ }_{99}$ Berechtigte Bedenken bei Salzwedel, Diskussionsbeitrag, in: Vhdlg. d. 57. DJT (1988), Bd. II L 139; Ossenbühl (Fn. 12), L 50, 52; Gieseke/Wiedemann/ Czychowski, WHG, 5. Aufl. 1989, \$324 Rdn. 33 m. w. Nachw. 
Abs. 2 GG und die Verhältnismäßigkeit an den strafrechtlichen Eingriff stellen. Auch bei prinzipieller Bindung der Strafjustiz an normkonkretisierende Verwaltungsvorschriften wird deshalb die Prüfung notwendig, ob einschlägige Standards nach Zweck und Ausgestaltung auch strafrechtsspezifischen Maßstäben, etwa der Sorgfaltspflicht, genügen. Womöglich müssen i.E. schärfere Anforderungen an den strafrechtlichen Pflichtverstoß gestellt werden. Einiges spricht dafür, daß dies jedenfalls bei den wasserrechtlichen Überwachungswerten der Fall ist ${ }^{100}$.

\section{Die Vorgabewirkung einzelfallbezogenen Verwaltungshandelns}

Die schärfsten Frontstellungen des Strafrechts, insbesondere auch in der Praxis, haben sich in der Vergangenheit gegen die Vorgabewirkung des einzelfallbezogenen Verwaltungshandelns herausgebildet.

\section{a) Zur prinzipiellen Abbängigkeit des Strafrechts von administrativen Einzelanordnungen}

Soweit die prinzipielle Abhängigkeit des Strafrechts von administrativen Einzelanordnungen moniert wird, ist die Annahme bestimmend, daß letztlich nicht der Gesetzgeber, sondern die Verwaltung in Widerspruch zu Art. 103 Abs. 2, 104 Abs. 1 Satz 1 und 92 GG über die inhaltliche Ausgestaltung der Straftatbestände und die Strafbarkeit befinde. Besonders anstößig wirken dabei Konkretisierungsspielräume der Verwaltung, offensichtlich weil sie strafrechtlichen Legalitätsvorstellungen zuwiderlaufen ${ }^{101}$. In der Sache überzeugen die Bedenken nicht.

Das $B V \operatorname{erf} G$ beanstandet die Anknüpfung einer Strafandrohung an gesetzeskonkretisierende Verwaltungsakte unter dem Blickwinkel der Art. 103 Abs. 2, 104 Abs. 1 Satz 1 GG nur, wenn die Verwaltungsakte mangels einer ausreichenden Ermächtigungsgrundlage inhaltlich nicht hinreichend bestimmt sind ${ }^{102}$. Es akzeptiert damit die rechtsstaatliche Funktion verhaltensbestimmender Einzelakte der Verwaltung auch als Bezugspunkt des Strafrechts. Das entspricht der Überlegung, daß in der Regel erst der das Verwaltungsgesetz konkretisierende Verwal-

100 In diesem Sinne auch Salzwedel, Ossenbübl, wie vor, und Papier, Strafrechtliche Probleme des Gewässerschutzes, in: Krebs/Oldiges/Papier, Aktuelle Probleme des Gewässerschutzes, 1989, 61 (72, $73 \mathrm{f}$.).

101 Prononciert Kübl (Fn. 13), S. 834 ff.; Schall (Fn. 25), S. 1266; AG Nördlingen, NStZ 1986, $315 \mathrm{ff}$.; zum folgenden auch Heine (Fn. 16), S. $2430 \mathrm{ff}$.

102 BVerfGE 75, 329 (346); 78, 344 (382f.); 80, 244 (256f.). 
tungsakt festlegt, was für den Bürger rechtens ist. Ohne diese Konkretisierung ergäben sich erhebliche Probleme hinsichtlich der Bestimmtheit der Strafandrohung und könnten nur die allergröbsten verwaltungsrechtlichen Verstöße strafrechtlich geahndet werden, was dem Strafrecht einen guten Teil seiner Effizienz nähme ${ }^{103}$. Jedenfalls nimmt die Verwaltung mit Erlaß eines gesetzeskonkretisierenden Verwaltungsaktes keine Aufgabe der Strafgesetzgebung bzw. Strafrechtspflege wahr. Der Verwaltungsakt bleibt Vollzugsakt des Verwaltungsgesetzes auch dann, wenn er strafrechtliche Relevanz haben soll ${ }^{104}$.

\section{b) Die Tatbestandswirkung von Verwaltungsakten}

Die zum Teil als „sklavische“ Abhängigkeit des Strafrechts vom Verwaltungsrecht kritisierte Bindung der Strafjustiz an wirksame, wenngleich im Einzelfall feblerbafte Verwaltungsakte ist die Konsequenz der sogenannten Tatbestandswirkung von Verwaltungsakten.

aa) Existenz und Inhalt eines Verwaltungsaktes sind von allen Behörden und Gerichten, die nicht zur Aufhebung befugt sind, als maßgeblich hinzunehmen ${ }^{105}$. Als normale Folge der äußeren und inneren Wirksamkeit bedarf die Tatbestandswirkung des Verwaltungsaktes grundsätzlich keiner besonderen Anordnung ${ }^{106}$. Der Gesetzgeber kann sie aber in der Gestaltung der Rechtsnorm besonders zum Ausdruck bringen, wie er sie andererseits auch ausschließen kann. Das Strafrecht bietet für alle genannten Modalitäten Beispiele. Die besondere Anordnung kann in Vorschriften gesehen werden, die bei der Umschreibung des tatbestandlichen Unrechts an (vollziehbare) Verwaltungsakte ohne Rücksicht auf ihre inhaltliche Richtigkeit anknüpfen ${ }^{107}$. Ein Ausschlußfall ist $\$ 113$ Abs. $3 \mathrm{StGB}$, wonach nur die rechtmäßige Diensthandlung strafbarkeitsbegründend wirkt ${ }^{108}$. Die

103 Siehe Ossenbübl (Fn.12), L 47; ders., Diskussionsbeitrag, in: Vhdlg. d. 57. DJT (1988), L 134; Hansmann (Fn.18), S.227. Aus strafrechtlicher Sicht im wesentlichen zutreffend: Tiedemann/Kindbäuser (Fn.76), S.344; Winkelbauer (Fn. 60), S. 725. - Siehe auch Heine/Meinberg, Das Umweltstrafrecht - Grundlagen und Perspektiven einer erneuerten Reform, GA 1990, 3 (15f.).

${ }_{104}$ Zutreffend Breuer (Fn. 78), S. 2078; im strafrechtlichen Schriftum: Rudolphi (Fn. 58), S. 249; Meurer, Umweltschutz durch Umweltstrafrecht, NJW 1988, 2065 (2067f.); Heine/Meinberg (Fn.17), D. $55 \mathrm{f}$.

105 Statt aller: Kopp, Verwaltungsverfahrensgesetz, 4. Aufl. 1986, Vorbem. 26 zu $\$ 35$.

${ }_{106}$ Kopp, wie vor, Rdn. 29; Kircbbof (Fn. 19), S. 2983.

$107 \mathrm{Vgl}$. oben B. II. 1.

108 Kirchbof, wie vor, mit Fn. 85. 
besondere Anordnung fehlt schließlich durchweg, wo der Verwaltungsakt erst auf das strafrechtliche Rechtswidrigkeitsurteil einwirkt. Weitere Klärungen sind vom Strafgesetzgeber derzeit nicht zu erwarten ${ }^{109}$.

Die Tatbestandswirkung beruht letztlich auf den Prinzipien der Funktionenteilung und der Rechtsstaatlichkeit. Sie schützt primär die Zuständigkeit und Verantwortung der Erlaßbehörde für die Konkretisierung und Gestaltung der Verwaltungsrechtslage ${ }^{110}$, zugleich aber auch die prinzipiell berechtigte Erwartung des einzelnen, daß seine durch einen Verwaltungsakt bestimmten Rechte und Pflichten nicht von dritter Seite anders bestimmt oder annulliert werden ${ }^{111}$. Dementsprechend problematisch sind Bestrebungen im Strafrecht, die auf eine Befreiung von der Tatbestandswirkung zielen: sei es, daß sie die Bindungswirkung nur bei rechtmäßigen Verwaltungsakten anerkennen $^{112}$ oder sie von einer nach spezifisch strafrechtlichen Gesichtspunkten vorzunehmenden Rechtmäßigkeitsprüfung abhängig machen wollen ${ }^{113}$. Beides bedingt einen strafgerichtlichen Kontrollanspruch in bezug auf die Rechtmäßigkeit strafrechtsrelevanter Verwaltungsakte. Das Strafrecht wird als Korrektiv verwaltungsbehördlicher Entscheidungen eingesetzt ${ }^{114}$. Soweit hierin nicht bereits ein Verstoß gegen die strafgesetzliche Anordnung der Tatbestandswirkung liegt, wird der administrative Interpretations ${ }^{115}$ und Konkretisierungsvorrang mißachtet, der sich aus der gesetzlich begründeten Vollzugsverantwortung der Verwaltung ergibt. Darüber hinaus steht der Adressat eines strafgerichtlich nicht für bindend erachteten Verwaltungsaktes im Ergebnis womöglich einer Verhaltensanforderung gegenüber, mit der er nach der Verwaltungsrechtslage nicht rechnen mußte. Derartige Auswirkungen einer Befreiung von der Tatbestandswirkung sind verfassungs- und verwaltungsrechtlich nicht annehmbar. Gleichwohl bedarf die Vorgabewirkung der Verwaltungsakte für die Strafjustiz in verschiedener Hinsicht weiterer Absicherung und Erläuterung.

109 Vgl. BT-Drucks. 11/6413, S. 11.

110 Isensee (Fn. 27), S. 1009 und Kirchbof, wie vor, S. 2983 f. (beide für das Steuerrecht). Allgemein insbesondere Ossenbübl (Fn.22), III. 3.c); siehe jetzt auch Gerbardt (Fn.25), S. $551 \mathrm{f}$.

${ }_{111}$ Isensee, wie vor, S. 1010. - Gegen diesen Gesichtspunkt aber Gerhardt, wie vor.

112 So etwa LG Hanau, NJW 1988, 571; OLG Frankfurt, UPR 1988, 28 (31).

113 So Schünemann (Fn. 59), S. 239. Zum Ganzen auch Schönke/Schröder/Cramer, vor $\$ 324 \mathrm{Rdn} .16 \mathrm{~b} / \mathrm{c}$ m. w. Nachw.

114 Hansmann (Fn. 18), S. 228.

115 Ausdruck von Isensee (Fn. 27), S. 1009. 
bb) Ein erster Punkt betrifft die Annahme, daß sich die Tatbestandswirkung nicht auf sogenannte deklaratorische Verwaltungsakte beziehe. Die Verurteilung wegen Steuerhinterziehung durch verdeckte Parteispenden beruhte u. a. darauf, daß die Strafgerichte einschlägige Steuerbescheide unbeachtet ließen. Sie gingen davon aus, die Bescheide seien bloß "deklaratorisch“, die maßgebliche von den Betroffenen verkürzte Steuerschuld könne daher in unmittelbarem Durchgriff auf das Steuergesetz bestimmt werden ${ }^{116}$. Dem ist nachdrücklich zu widersprechen: Auch in Verwaltungsbereichen mit sehr dichten gesetzlichen Vorgaben wie im Steuerrecht haben Verwaltungsakte i.d.R. konstitutive Wirkung, zumindest in dem Sinne, daß sie die Individualrechtslage „durch und im Umfang der Reduzierung tatsächlicher und/oder rechtlicher Unschärfen “117 klären und stabilisieren $^{118}$. Deshalb bedarf es in den Fällen, in denen steuererhebliche, den Behörden bekannte, rechtlich strittige Vorgänge im Steuerbescheid steuermindernd berücksichtigt wurden, auch nicht der Konstruktion einer behördlichen Duldung, um die Strafbarkeit wegen Steuerverkürzungen auszuschließen ${ }^{119}$.

cc) Bekämpft wird die Bindung der Strafgerichte an Verwaltungsakte auch in den Fällen, in denen sie zur Strafbarkeit des Verstoßes gegen einen rechtswidrigen Verwaltungsakt oder des Handelns ohne behördliche Gestattung führen kann ${ }^{120}$. Bemängelt wird das Fehlen eines hinreichenden Strafbedürfnisses; es werde letztlich nur der

116 Vgl. AG Köln, NJW 1985, 1037 (1040); AG Bochum, ebd., S. 1968 (1970): Nur das Gesetz bestimmt die Steuerschuld. Noch schärfer: LG Hamburg, NJW 1986, 1885 (1886): Kein Interpretations- und Konkretisierungsvorrang in der Finanzverwaltung. In der Sache ebenso $B G H$, NJW 1987, 1274 (1275), der, wie schon OLG Hamm, NJW 1978, 283 (284), jede Bindung an Entscheidungen der Finanzbehörden ablehnt.

117 Formulierung von P.Fischer, in: Hübschmann/Hepp/Spitaler, AO, $\$ 38$ Rdn. 11 .

118 Überzeugend: Kirchbof (Fn. 19), S.2978; ders., Strafwürdigkeit einer den Steuerbescheid erfüllenden Steuerzahlung? NJW 1986, 1315. - Ablehnend Rößler, Nochmals: Der bestandskräftige Steuerbescheid im Steuerverfahren und im Steuerstrafverfahren, ebd., S. 972 f.; Reiß, Widersprechende Entscheidungen von Strafund Finanzgerichten in derselben Rechtssache, StuW 1986, 68 (70); Hermes/ Wieland, Die staatliche Duldung rechtswidrigen Verhaltens, 1988, S. $97 \mathrm{ff}$.; Tipkel Lang, Steuerrecht, 12. Aufl. 1989, S. 136.

119 Hierzu Hermes/Wieland, wie vor, S.62 ff. und Rüping, Die Mitverantwortung des Staates als Strafverfolgungsverbot, 1983.

${ }_{120}$ Im strafrechtlichen Schrifttum etwa: Ostendorf, Die strafrechtliche Rechtmäßigkeit rechtswidrigen hoheitlichen Handelns, JZ 1981, 165 (170); Kübl (Fn. 13), S. 849 ff; Schall (Fn. 25), S. 1267. 
Verwaltungsungehorsam pönalisiert. Andererseits hält man es für unangemessen, wenn die spätere Aufhebung des Verwaltungsaktes bzw. die Erteilung der Erlaubnis die Strafbarkeit unberührt läßt ${ }^{121}$. Der zuerst genannte Einwand trägt nur, wenn der Verstoß gegen den Verwaltungsakt oder die Genehmigungspflicht als alleiniger Grund für die Strafbarkeit zu werten ist. Im Kernstrafrecht geht es jedoch durchweg auch um den Schutz dahinterstehender materieller Rechtsgüter, so daß von einem bloßen Verwaltungsungehorsam nicht die Rede sein kann ${ }^{122}$. Im übrigen bestehen erhebliche Bedenken, ob die aus strafrechtlicher Sicht unverhältnismäßige Pönalisierung des Verwaltungsungehorsams durch die Befreiung von der Tatbestandswirkung erzielt werden darf und nicht vielmehr der Weg über Art. 100 GG zu beschreiten wäre. - Schwerer wiegt die Befürchtung, daß nach Begebung der Tat eintretende Korrekturen der Verwaltungsrechtslage strafrechtlich nicht berïcksichtigt werden. Aber auch insoweit bedarf es keiner Einschränkung der Tatbestandswirkung. Die bekannte Entscheidung des Bundesgerichtshofs zum Verkehrsstrafrecht, wonach die spätere Aufhebung die Strafbarkeit wegen Verstoßes gegen ein Verkehrszeichen nicht berührt ${ }^{123}$, kann kaum Allgemeingültigkeit beanspruchen ${ }^{124}$. Sie mag auf staatliche Ordnungsinteressen zutreffen, überzeugt aber nicht, wenn die Strafbarkeit an die Verletzung anderer materieller, hinter dem Verwaltungsakt stehender Schutzinteressen verwaltungsrechtlicher Art anknüpft ${ }^{125}$. Bleiben Korrekturen des Verwaltungsaktes hier unberücksichtigt, ist der Strafzweck verfehlt, die Bestrafung unverhältnismäßig. Treten solche Korrekturen noch während des Strafverfahrens ein, muß ihnen durch einen besonderen Strafaufhebungsgrund Rechnung getragen wer-

121 Siehe Lackner, $\$ 325$ Anm. 3 c; Schönke/Scbröder/Cramer, Vor $\$ 324 \mathrm{ff}$. Rdn. 21; Dabs/Redeker, Empfehlen sich Änderungen im strafrechtlichen Umweltschutz, insbesondere in Verbindung mit dem Verwaltungsrecht, DVBl. 1988, 803 (810).

${ }_{122}$ Zutreffend hervorgehoben bereits von Breuer (Fn. 23), S. 181. Im strafrechtlichen Schrifttum: Tiedemann/Kindhäuser (Fn. 76), S. 243 f.; Rengier, Die öffentlich-rechtliche Genehmigung im Strafrecht, ZStW 1989, 874 (881). Siehe in diesem Zusammenhang neuerdings $B G H$, NJW 1990, 918 zu $\$ 132$ a StGB, der auch insoweit auf materielle Interessen abstellt.

${ }^{123}$ BGHSt. 23, 86 (93).

124 So aber zuletzt OLG Karlsrube, NJW 1988, 1604 (1605) betr. das Volkszählungsgesetz.

${ }^{125}$ In diesem Sinne bereits Lorenz (Fn. 3), S.170f. Zum folgenden auch Hill, Die befugte Gewässerbenutzung nach dem Wasserhaushaltsgesetz, GewArch 1981, $183(186)$. 
den ${ }^{126}$. Stehen sie noch aus, bedarf es zusätzlich verfahrensrechtlicher Lösungen, insbesondere im Wege der Aussetzung des Verfahrens ${ }^{127}$. Darauf ist zurückzukommen.

dd) Im Blick speziell auf die Tatbestandswirkung behördlicher Gestattungsakte sind zwei zusätzliche Aspekte hervorzuheben. Die Bindung rechtfertigt nicht die Verletzung strafrechtlich geschützter Individualrechtsgüter wie Leben und Gesundheit ${ }^{128}$. Andererseits darf sie nicht für Erlaubnisse „zurückgedrängt“ werden, die „veraltet“ sind, unredlich erworben oder deren Rechtswidrigkeit der Erlaubnisnehmer kennt, wie dies im Strafrecht unter Berufung auf das Rechtsmißbrauchsverbot geschieht ${ }^{129}$. Auch hier liegt ein Übergriff in die Entscheidungs- und Beurteilungskompetenz der Verwaltung vor, der sich zudem in Widerspruch zu den verwaltungsrechtlichen Regeln über die Rücknahme rechtswidriger Verwaltungsakte setzt. Zumindest bei tatbestandsbestimmenden Erlaubnissen, die hinsichtlich ihrer Wirksamkeit und Bestandskraft schon von Gesetzes wegen auf das Verwaltungsrecht verweisen, ist auch Art. 103 Abs. 2 GG verletzt, weil die gesetzliche Verweisung zu Lasten des Angeklagten mißachtet wird ${ }^{130}$.

\section{c) Die strafrechtliche Ersetzung behördlicher Gestattungen}

Der administrative Interpretations- und Konkretisierungsvorrang ist auch ausschlaggebend für die Bewertung der strafrechtlichen Ersetzung behördlicher Gestattungsakte.

${ }^{126}$ Siehe Schönke/Schröder/Cramer, Vor $\$ 324 \mathrm{Rdn} .21$; Wüterich, Die Bedeutung von Verwaltungsakten für die Strafbarkeit wegen Umweltvergehen, NStZ 1987, 106 (108) und Möbrenschlager, Reformansätze und Perspektiven, in: Meinberg/Möhrenschlager/Link (Fn. 5), 291 (293).

127 Siehe bereits Gerhards (Fn. 3), S. 89; zuletzt Ossenbühl (Fn. 22), S. 973, unter Bezugnahme auf Isensee (Fn.27) und Kirchbof (Fn.19) - beide zum Steuerrecht.

${ }_{128} \mathrm{Vgl}$. Heine/Meinberg (Fn.17), D 50 f, und Schall (Fn. 25), S. 1267, jeweils m. w. Nachw.; zum Umfang der Legalisierungswirkung behördlicher Gestattungen jüngst auch Heine (Fn. 101), S. $2431 \mathrm{ff}$.

129 Besonders bemerkenswert: StA Mannbeim, NJW 1976, 585 (586) für veraltete Genehmigungen; LG Hanau, NJW 1988, 571 (576) für Kenntnis der Rechtswidrigkeit. - Nachweise zum Schrifttum, das vielfach auf Unredlichkeit abstellt, bei Schall, wie vor. - Zum folgenden Gerbardt (Fn. 25), S. 552.

130 Weitgehend überzeugend Rengier (Fn. 122), S. 885 ff. und Ossenbübl (Fn. 22), S. 973. Vgl. auch schon die Stellungnahmen von Dolde und Horn zum Urteil des LG Hanau in NJW 1988,2339(2331)bzw. 2335(2336 f.); Möhrenschlager(Fn. 126), S. 293, der deshalb eine Korrektur der $\int \$ 43 \mathrm{f}$. VwVfG erwägt. - Abweichend für rechtfertigende Erkenntnisse etwa Lenckner, Behördliche Genehmigungen und der Gedanke des Rechtsmißbrauchs im Strafrecht, Festschrift für G. Pfeiffer, 1988, 27 (35ff.). 
aa) Zur Diskussion steht zunächst, inwieweit ungenehmigtes, verwaltungsrechtlich jedoch genehmigungsfähiges Verhalten strafrechtlich als genehmigt behandelt werden kann. Mit Recht wird dies verneint, soweit dadurch eine Verkürzung der in Verwaltungsgesetzen häufig anzutreffenden administrativen Beurteilungs- und Ermessensspielräume in bezug auf die Erteilung von Genehmigungen eintritt ${ }^{131}$. Anderes soll gelten, wenn ein Rechtsanspruch auf die Erteilung der Genehmigung, insbesondere infolge einer Ermessensreduzierung auf Null besteht ${ }^{132}$. Diese Ausnahme verdient jedoch keine Zustimmung ${ }^{133}$. Mit dem gesetzlichen Erfordernis einer behördlichen Gestattung wird immer eine spezifische Verantwortung der Verwaltung für die Erteilung bzw. Ablehnung begründet, die ihr die Strafjustiz nicht abnehmen kann. Das gilt auch für die Klärung, ob in concreto eine Ermessensschrumpfung eingetreten ist. Die nachträglich erteilte Genehmigung muß freilich strafrechtlich in gleicher Weise wie bei der Tatbestandswirkung eines Verwaltungsaktes berücksichtigt werden.

bb) Nur mit Einschränkungen zuzustimmen ist der Auffassung, die bewußtem und aktivem Dulden seitens der Bebörde strafrechtlich die Wirkung einer Gestattung beilegen möchte, um (sachgerechten) Opportunitätserwägungen der Verwaltung auch strafrechtlich Geltung zu verschaffen ${ }^{134}$. Von der tatsächlichen Schwierigkeit der Feststellung einer solchen Duldung im Einzelfall einmal abgesehen, mag man argumentieren: „Was die zuständige Behörde nicht, nicht mehr oder nur nach einer angemessenen Übergangsfrist verbieten darf", sollte prinzipiell auch strafrechtlich nicht unerlaubt sein ${ }^{135}$. Akzeptabel ist dies jedoch nur, wenn die "aktive" behördliche Hinnahme eines Verhaltens nach den einschlägigen Normen des Verwaltungsrechts überhaupt als Erteilung einer Erlaubnis bzw. Genehmigung qualifiziert werden darf, insbesondere kein förmlicher Gestattungsakt vor-

131 Vgl. statt vieler Heine/Meinberg (Fn.17), D $51 \mathrm{~m}$. Nachw. in Fn. 114.

132 So etwa Rudolphi (Fn. 85), S. 197 f.; Papier (Fn. 77), S. 6; ders., Strafrechtliche Probleme des Gewässerschutzes (Fn. 100), S. 66 f.; J.Brauer, Die strafrechtliche Behandlung genehmigungsfähigen, aber nicht genehmigten Verhaltens, 1988, S. $56 \mathrm{ff} ., 114 \mathrm{ff}$.

133 Weitgehend übereinstimmend Breuer (Fn. 23), S. 181 und neuerdings Rengier (Fn. 122), S. $902 \mathrm{ff}$.

134 Nachweise bei Heine/Meinberg (Fn.17), D 51; neuerdings auch Rengier, wie vor, S. 906 f.; Fluck, Die Duldung des unerlaubten Betreibens genehmigungsbedürftiger Anlagen, NuR 1990, S. 197 ff. und Wasmuth/Koch, Rechtfertigende Wirkung der behördlichen Duldung im Umweltstrafrecht, NJW 1990, $2434 \mathrm{ff}$.

135 Papier, wie Fn. 145. 
liegen muß ${ }^{136}$. Entsprechendes gilt, wenn die Behörde in Kenntnis bestimmter Verhaltensweisen nicht einschreitet. Die mit der Verwaltungsrechtslage nicht abgestimmte Annahme einer tatbestands- oder rechtswidrigkeitsausschließenden Wirkung verletzt den Entscheidungsvorrang der Verwaltung. Davon unberührt bleibt die Berücksichtigung bei der Schuldfeststellung ${ }^{137}$.

\section{Die Strafbarkeit von Amtsträgern}

Der Umstand, daß die strafgerichtliche Verurteilung des Bürgers in der Praxis an fehlerhaften, wenngleich bindenden administrativen Vorgaben scheitern kann, legt den strafrechtlichen Durchgriff auf den verantwortlichen Amtswalter nahe. Er wird vor allem im Umweltstrafrecht diskutiert und in der einschlägigen strafgerichtlichen Praxis unternommen ${ }^{138}$.

Im Kern geht es bei der Strafbarkeit vom Amtsträgern darum, ob jeder Verstoß eines Amtswalters gegen Verwaltungsrecht ein strafrechtliches Risiko nach sich ziehen und dies sogar dann gelten sollte, wenn, wie im Falle der verdeckten Parteispenden, der Verstoß verwaltungsrechtlich noch gar nicht (abschließend) geklärt ist. Wer diese Fragen grundsätzlich bejaht, macht die Strafjustiz funktionswidrig zur Kontrollinstanz über den Verwaltungsvollzug und zerstört auf dem Weg über die Amtsträgerhaftung den verfassungsrechtlich und gesetzlich begründeten Interpretations- und Konkretisierungsvorrang der Verwaltung ${ }^{139}$. Zudem wird die Handlungsbereitschaft des Amtswalters geschwächt ${ }^{140}$, und zwar selbst dann, wenn ein Ermittlungsverfahren später nicht zur Verurteilung führt ${ }^{141}$. Das gilt insbesondere für Bereiche der Verwaltung, die rechtlich und tatsächlich schwierige Fragen aufwerfen und von daher besonders fehleranfällig sind ${ }^{142}$. Aus

136 Zutreffend Breuer, Probleme der Zusammenarbeit zwischen Verwaltung und Strafverfolgung auf dem Gebiete des Umweltschutzes, AöR 115 (1990), 448 (465); Hansmann (Fn. 18), S. 227; vgl. auch Hermes/Wieland (Fn. 118), S. 14 ff., 105.

${ }^{137}$ Dazu im Zusammenhang mit der Parteispendenaffäre $L G$ München $I$, DSt. 1982, 482 (483); BFH, FR 1987, $71 \mathrm{f}$.

138 Jüngste eingehende Darstellung mit Nachweisen aus strafrechtlicher Sicht bei Tröndle (Fn. 25); verwaltungsrechtlich: Papier, Strafbarkeit von Amtsträgern im Umweltstrafrecht, NJW 1988, 1113 ff.; Breuer (Fn. 78), S. 2083 f.

$139 \mathrm{Vgl}$. bereits Breuer, wie vor, S. 2083; im strafrechtlichen Schrifttum erkannt von Steindorf, LK, $\$ 324$ Rdn. 57, 66 ff.; siehe auch Bickel (Fn. 25), S. $277 \mathrm{ff}$.

140 Zuletzt hervorgehoben von Hansmann (Fn. 18), S. 228.

${ }_{141}$ Dazu Tröndle (Fn. 25), S. 237.

$142 \mathrm{Vgl}$. Brener, wie vor. 
diesen Gründen kommt eine strafrechtliche Verantwortlichkeit des Amtswalters nur in Betracht, wenn sein Verhalten durch ein über die bloße Verwaltungsrechtswidrigkeit hinausweisendes Unrecht qualifiziert ist ${ }^{143}$ - etwa bei kollusivem Zusammenwirken mit Privatpersonen, sonstigem unredlichen Verhalten und bei der Verletzung höchstpersönlicher Individualrechtsgüter. Dieserhalb erwogene Spezialregelungen müssen vor Art. 3 GG Bestand haben. Ihre Beschränkung auf einzelne Bereiche des Verwaltungsvollzuges wie des Umweltrechts muß sachlich einleuchten ${ }^{144}$. Der Nachweis dürfte nicht leicht gelingen.

\section{Die Aussetzung des Strafverfabrens}

Bei der Bewältigung potentieller Konflikte zwischen Verwaltungsrecht und Strafrecht spielen verfahrensrechtliche Möglichkeiten, die zur Vermeidung von Wertungswidersprüchen und daraus erwachsenden Entscheidungsdivergenzen beitragen können, bis heute nur eine bescheidende Rolle ${ }^{145}$.

Angesichts der häufigen Vorgreiflichkeit verwaltungsrecbtlicher Fragen im Strafverfahren richtet sich die Aufmerksamkeit zwangsläufig auf dessen Aussetzung - dies um so mehr, als solche Fragen in der Strafrechtspraxis zum Teil höchst anfechtbar behandelt werden ${ }^{146}$. Auf den ersten Blick scheint die Aussetzung das immer gegebene Mittel zu sein, um einem bestehenden Entscheidungsvorrang der Verwaltung bzw. der Verwaltungsgerichtsbarkeit und dem grundrechtlich bedingten Sanktions- und Verfahrensschutz Rechnung zu tragen. Bei genauerer Betrachtung ergeben sich jedoch Zweifel.

Nach den einschlägigen Vorschriften $(\$ \$ 262$ Abs. 2 StPO, 396 $\mathrm{AO})^{147}$ steht die Aussetzung im Ermessen der Organe der Strafjustiz. Eine generelle Aussetzungspflicht scheidet damit von vornherein aus. Diskutabel ist die Verdichtung des Aussetzungsermessens bis hin zur

143 Zutreffend Papier (Fn. 100), S. 78 f.

144 Richtig erkannt in BT-Drucks. 8/3633, S. 20 betr. den Umweltschutz.

145 Ein früher Hinweis auf ihre Bedeutung bei Tiedemann (Fn. 26), S. $52 \mathrm{f}$.

146 Bickel, NStZ 1988, 181 (182) - Urteilsanm.; Winkelbauer, Atomrechtliches Genehmigungsverfahren und Strafrecht - LG Hanau, NJW 1988, 571, JuS 1988, 691 (691f.). Für das Steuerrecht: Klaus Ulsenbeimer, Das Madaus-Urteil des Amtsgerichts Köln - Leitfaden oder Irrweg im Dickicht der Parteispendenaffäre, NJW 1985, 1929.

$147 \$ 154 \mathrm{~d}$ StPO kann hier außer Betracht bleiben, weil er sachfremde Erwägungen eines Anzeigeerstatters, die aufwendige Ermittlungen nach sich ziehen können, abwehren soll: siehe Kleinknecht/Meyer, StPO, $\$ 154 \mathrm{~d}$ Anm. 1 . 
Aussetzungspflicht im Einzelfall. Im Schrifttum wird eine Aussetzungspflicht seit langem mit guten Gründen befürwortet, wenn sich die Aufhebung eines sanktionsbewehrten Verwaltungsaktes abzeichnet ${ }^{148}$. Das Umweltstrafrecht hat ihr weitere Zustimmung verschafft ${ }^{149}$. Die strafrechtliche Praxis hat sich dieser Forderung jedoch bislang verschlossen. Neue Gesichtspunkte für eine Verdichtung des Aussetzungsermessens haben sich in der Parteispendenaffäre herauskristallisiert. Sie sind umfassender und verdienen eine genauere Betrachtung.

Nach Auffassung des $B$ VerfG muß der Strafrichter die Aussetzung im Steuerstrafverfahren bei "schwierigen steuerrechtlicben" Fragen von Amts wegen nach pflichtgemäßem Ermessen prüfen ${ }^{150}$. Deutlicher und weitergehend erscheinen im steuerrechtlichen Schrifttum als ermessensreduzierende Kriterien etwa die Gefahr widersprüchlicher Auslegung, die Klärungsbedürftigkeit grundsätzlicher steuerrechtlicher Fragen, die strafgerichtliche Abweichung von einer bestimmten Besteuerungspraxis bzw. einschlägigen Steuerbescheiden oder von einer informalen behördlichen Duldung ${ }^{151}$. Zweifellos wäre die damit erzielte Einengung der Vorfragenkompetenz aus der Sicht des gesamten Verwaltungsrechts wünschenswert. Sie reduziert das Risiko divergierender Entscheidungen gerade bei der häufig strittigen oder nicht geklärten Verwaltungsrechtskonformität durch die Beschneidung strafrechtsautonomer Wertung. Die für die Aussetzung im Steuerstrafverfahren entwickelten Grundsätze können jedoch auf andere Strafverfahren nur begrenzt übertragen werden. Sie beruhen nämlich entscheidend auf der Unselbständigkeit des Steuerstrafrechts, auf dessen Charakter als bloßem „Folgerecht" des Steuerrechts ${ }^{152}$. Die

\footnotetext{
148 Stern (Fn. 3), S. 869, 875; Gerhards (Fn. 3), S. 89.

149 Siehe etwa Wüterich (Fn.126), S.109; Dabs/Redeker (Fn.121), S.810 m. w. Nachw.; Winkelbauer, wie vor; Möbrenschlager (Fn. 126), S. 293.

150 NJW 1985, 1915. - Eingehend zu $\$ 396$ AO: Koblmann, Aussetzung des Steuerstrafverfahrens gemäß $\$ 396$ AO und prozessuale Fürsorgepflicht, Festschrift Klug, Bd. II (1983), 507 ff.; siehe auch Gast-de Haan, Ermessensschranken bei der Aussetzung des Besteuerungsverfahrens gemäß $\$ 396$ AO, DStZ 1983, 254 f., die ungeklärte steuerrechtliche Fragen treffend als Musterfall der Aussetzung bezeichnet.

151 Vgl. Isensee (Fn.27), S.1010; Kirchbof (Fn. 19), S. 2984 f.; Koblmann (Fn. 19), $\$ 396$ AO Rdn. 45; Tipke/Lang (Fn. 118), S.763. - Weitgehend ablehnend: Reiß (Fn. 118), S. 70, 72 und Heuer, Die Rechtspflicht zur Aussetzung des Steuerstrafverfahrens bei divergenzgeneigten Vorfragen $-\$ 396$ AO im System der Rechtsordnung, DStZ 1985, 291 (292ff.).

${ }^{152}$ Vgl. Isensee, wie vor, S. 1008 f.; Kirchbof, wie vor. S. 2982.
} 
lediglich sanktionsverstärkende Qualität des Steuerstrafrechts zwingt den Strafrichter in besonderer Weise dazu, seine Entscheidungen mit dem vorgreiflichen Steuerschuldrecht sorgfältig abzustimmen. Eine vergleichbare Rechtslage gibt es außerhalb des Steuerstrafrechts im sonstigen „Nebenstrafrecht" sowie bei den Strafnormen des „Kernstrafrechts", die ausdrücklich und unmittelbar im Tatbestand an das Verwaltungsrecht anknüpfen, nach geläufigem Sprachgebrauch also „akzessorisch“ gestaltet sind. Allzu große Erwartungen sollten allerdings in die sich danach für durchaus erhebliche Bereiche des Verwaltungsrechts abzeichnende Einengung der strafgerichtlichen Vorfragenkompetenz nicht gesetzt werden. So ist damit zu rechnen, daß Gesichtspunkte, die das Aussetzungsermessen reduzieren könnten, durch Erwägungen des Beschleunigungsgebotes zurückgedrängt werden $^{153}$, zumal die Aussetzung im Geltungsbereich der StPO keinen Einfluß auf die Verjährung hat ${ }^{154}$. Schon im Steuerrecht zeigt sich außerdem, daß die Strafgerichte den Schwierigkeitsgrad einer Rechtsfrage bzw. den Klärungsbedarf herunterspielen ${ }^{155}$ oder auf die Kenntnis des Angeklagten von der Verwaltungsrechtslage abstellen ${ }^{156}$, um der Aussetzung auszuweichen. Damit ist auch im Geltungsbereich des $\$ 262$ Abs. 2 StPO zu rechnen. Man mag dies als Ermessensmißbrauch tadeln $^{157}$ : Das Risiko revisionsgerichtlicher Aufhebung - die Revision müßte wohl auf einen Verfahrensfehler gestützt werden - ist vorerst gering, wie einschlägige Aussagen des $B G H$ ergeben $^{158}$. Das könnte sich ändern, wenn das $B V \operatorname{Verf} G$ auf der Grundlage einer Verfassungsbeschwerde gegen ein letztinstanzliches Urteil Gelegenheit bekommt, genauer festzulegen, wann die Ablehnung der Aussetzung den grundrechtlich gebotenen Sanktions- und Verfahrensschutz verletzt.

\section{Schlußbemerkung}

Prototypische Bedeutung für die vielfältigen Aspekte der Vorgabewirkung auf das Strafrecht haben derzeit das Umwelt- und Steuerrecht. Abgeschlossen ist die Entwicklung damit sicher nicht: Der

153 Dazu LG Bonn, NJW 1985, 3033 (3034) betr. das Steuerrecht, und allgemein Dabs/Redeker (Fn. 121), S.810f.

154 Statt vieler: Lackner, $\$ 78$ Anm. 1 b) cc).

155 So $L G$ Bonn, wie vor.

156 So LG Hamburg, NJW 1986, 1885 (1887).

157 Kirchbof, wie vor, S.2985.

${ }_{158}$ NJW 1987, 1274; vgl. auch $B G H$, NStZ 1985, 126. 
Gesetzgeber wird sie fördern; die wissenschaftliche Diskussion und rechtspraktische Behandlung bedarf weiterer Vertiefung. In einer Zwischenbilanz wird man immerhin festhalten können, daß das Kardinalproblem in der funktionsgerechten Abgrenzung der Verantwortungsbereiche der Verwaltung einerseits und der Organe der Strafjustiz andererseits liegt ${ }^{159}$. Die Abgrenzung muß gleichermaßen gewährleisten, daß der Bürger nicht durch die Inanspruchnahme „verwaltungsrechtlichen Nebenwissens " 160 seitens des Strafrichters zwischen die Fronten gerät. In dem Maße, in dem dies gelingt, ist die rechtsstaatliche Aufgabe einer widerspruchsfreien Rechtsordnung erfüllt.

159 Siehe jetzt auch Gerbardt (Fn. 25), S. 552.

160 Ausdruck von Lüderssen, Diskussionsbeitrag, in: Vhdlg. des 57. DJT (1988), Bd. II L 114. 
Leitsätze des Berichterstatters über:

\section{Verwaltungsrecht als Vorgabe für Zivil- und Strafrecht}

\section{A. Allgemeine Beschreibung des Problems}

1. Der Begriff der verwaltungsrechtlichen Vorgabe ist der Fragestellung angemessener als der im Strafrecht übliche der Akzessorietät.

2. Denkbar ist, daß die einzelnen verwaltungsrechtlichen Vorgaben nach Art, Dichte und Bindungswirkung einschließlich verfabrensrechtlicher Konsequenzen im Zivil- und Strafrecht gleichermaßen Geltung beanspruchen. Mebr oder weniger markante Unterschiede rechtfertigen jedoch methodisch wie sachlich eine getrennte Behandlung. $Z u$ diesen Unterschieden rechnen zivil- und strafrechtssystematische Besonderheiten sowie der Umstand, daß verwaltungsrechtliche Vorgaben im Strafrecht nicht nur ein Thema der Rechtsanwendung, sondern auch der Gesetzgebung sind.

B. Gründe und Gegengründe für eine Vorgabewirkung des Verwaltungsrechts

3. Die Teilbereiche der Rechtsordnung haben unterschiedliche Aufgaben; ibre Verhaltensanweisungen stimmen deshalb nicht von vornherein überein und müssen dies auch nicht. Daraus resultiert die Ambivalenz des Vorgabeproblems: Es gibt Gründe für, aber auch gegen eine Vorgabewirkung des Verwaltungsrechts für das Zivil-und Strafrecht.

4. Mitunter ergeben sich bereits aus einschlägigen Normen des Zivil- und Strafrechts Gründe, die Anknüpfung an verwaltungsrechtliche Vorgaben zu suchen. Durch ibre vorrangige Beachtung vollziehen die rechtsanwendenden Instanzen eine gesetzgeberische Entscheidung nach, die womöglich Kollisionen mit dem Verwaltungsrecht ausschließen soll.

5. a) Ein böchst problematischer Grund für die Vorgabewirkung des Verwaltungsrechts ist die Einheit der Rechtsordnung. Er ist rechtsstaatlich nicht begründbar, vielmebr dazu angetan, legitime, nach Art. 3 GG verfassungsrechtlich notwendige Wertungsdifferenzen zwi- 
schen Rechtsgebieten hinter einem bloßen Ideal der Einheit verschreinden $z$ lassen.

5. b) Der Grundsatz der Widerspruchsfreiheit der Rechtsordnung umschreibt zwar ein rechtsstaatlich gebotenes Ergebnis. Er bestimmt indessen nicht, wann und wie an das Verwaltungsrecht anzuknüpfen ist.

6. Es besteben keine grundsätzlichen Bedenken, das Gebot der Systemgerechtigkeit auf die Beziebungen des Verwaltungsrechts zum Zivil- und Strafrecht anzuwenden. Allerdings ist seine dirigierende Kraft, bedingt durch die Eigengesetzlichkeiten der Teilrechtsordnungen, schwächer als im Kontext einer einzelnen Rechtsmaterie. Am ebesten wird es mit Bezug auf das Strafrecht wirken, soweit dieses mit dem Ziel der Sanktionsverstärkung eingesetzt wird.

7. Zusätzliche Gründe kommen für die Vorgabewirkung administrativer Einzelentscheidungen in Betracht.

a) Prinzipiellen Respektverdient das Vertrauen in die Legalisierungswirkung bebördlicher Gestattungen.

b) Die Anknüpfung an administrative Entscheidungen kann auch aus Gründen des Kompetenzschutzes der Verwaltung geboten sein, wenn die Zusammenschau zivil-oder strafrechtlichter Normen mit dem Verwaltungsrecht einen Beurteilungs- und Entscheidungsvorrang der Verwaltung im Verhältnis zuabweichenden Einschätzungen in der ordentlichen Gerichtsbarkeit ergibt. Der Vorrang ist Ausdruck einer spezifischen Verantwortung und Qualifikation der Exekutive in der Bestimmung dessen, was für die Gesetzeskonkretisierung notwendig und für den Bürger im Einzelfall rechtens sein soll. Er steht in direkter Beziebung zum Gewaltenteilungsgrundsatz und zum rechtsstaatlichen Gebot klarer Kompetenzabgrenzung.

8. a) Strafen müssen im freiheitlichen Rechtsstaat letztes Mittel bleiben. Unausweichlich wird deshalb bei Anknüpfung an die Verletzung verwaltungsrechtlicher Pflichten eine vergleichende Gesamtwürdigung verwaltungsrechtlicher, ordnungswidrigkeitenrechtlicher und strafrechtlicher Reaktionsmöglichkeiten. Dabeikann sich herausstellen, daß der Einsatz der Strafsanktion prinzipiell nicht erforderlich oder im Einzelfall unangemessen ist.

8. b) Bei strittiger Verwaltungsrechtskonformität eines Verbaltens, von der die Strafbarkeit abbängig ist, können sich aus dem Postulat Strafe als ultima ratio und aus der verfabrensprägenden Dimension der Grundrechte Auswirkungen auf den zeitlichen Ablauf des Strafverfahrens ergeben. Sie kann Anlaß zur Prüfung geben, ob nicht trotz bestehender Vorfragenkompetenz dem grundrechtsschonenderen Verwaltungs-bzw. Verwaltungsgerichtsverfahren der Vortritt zu lassen ist, sofern hierzu verfabrensrechtlich die Möglichkeit besteht. 
9. Gründe gegen eine Vorgabewirkung des Verwaltungsrechts liegen in dem berechtigten Anliegen, dem Zivil- und Strafrecht die Eigenständigkeit zu sichern. Ausdruck dieser Eigenständigkeit sind insbesondere vom Verwaltungsrecht abweichende Ausformungen des Rechtsgüterschutzes sowie Eigengesetzlichkeiten und besondere Regelungsziele.

\section{Verwaltungsrechtliche Vorgaben im Strafrecht}

10. a) Stärker als im Zivilrecht ist in der Strafgesetzgebung die Anknüpfung an das Verwaltungsrecht, die auf verschiedenen Ebenen erfolgt, charakteristisch.

10. b) Geschiebt die Anknüpfung nicht schon im Tatbestand, ist die Vorgabewirkung des Verwaltungsrechts schwächer: Der Gesetzgeber hat sich für eine verwaltungsrechtsunabhängige Fixierung des strafwürdigen Verbaltens entschieden; der strafrechtsspezifische Freiraum zur Berïcksichtigung verwaltungsrechtlicher Vorgaben ist zugunsten der Strafjustiz zumindest tendenziell und kollisionsfördernd erweitert.

10. c) Der Gesetzgeber verfügt über eine weitgebende Freibeit, sozialschädliches Verbalten strafrechtlich zu fixieren. Deshalb läßt sich kaum der Vorwurf der Systemwidrigkeit erbeben, wenn er sich aus Gründen, die nicht evident sachwidrig sind und binreichendes Gewicht besitzen, für einen strafrechtlichen Rechtsgüterschutz entscheidet, bei dem die Verwaltungsrechtswidrigkeit nur eine unter mebreren sozialschädlichen Verhaltensweisen darstellt und deshalb Einfluß erst auf das Rechtswidrigkeitsurteil oder die Scbuldfeststellung gewinnt. Solche Gründe liegen nicht nur im Schutz böchstpersönlicher Rechtsgüter, sie können auch darauf beruhen, daß der Gesetzgeber in der administrativen Konkretisierung eines Lebensbereiches keinen sicheren oder flächendeckenden Schutz erblickt. Von seiner Gestaltungsfreibeit sollte er nur sparsam Gebrauch machen.

11. Eine konstitutiv die Strafbarkeit bestimmende Vorgabewirkung "gesetzesvertretender" Verwaltungsvorschriften scheidet derzeit aus.

12. Sogenannte "normkonkretisierende" Verwaltungsvorschriften sollten grundsätzlich auch die Strafjustiz binden.

a) Darin niedergelegte Standards, insbesondere Grenzwerte, sind zur Konkretisierung des strafrechtlichen Pflichtverstoßes häufig unentbehrlich. Sie entspringen einer spezifischen Sachverantwortung für die Verwaltungsrechtslage, die den Organen der Strafjustiz nicht zukommt. Der Bürger darf prinzipiell darauf vertrauen, daß sein durch normkonkretisierende Verwaltungsvorschriften mitgeprägter Pflichtenumfang auch strafrechtlich respektiert wird. 
b) Etwaige Bedenken gegen eine Bindung unter dem Gesichtspunkt des Art. 103 Abs. 2 GG lassen sich nicht allein durch die Außenverbindlichkeit des Verwaltungsaktes überwinden. Auch in diesem Fall muß zusätzlich darauf abgestellt werden, daß normkonkretisierende Verwaltungsvorschriften keine "verzealtungsautonomen" Standards setzen, sondern generalklauselartig umschriebene Vorgaben der Verwaltungsgesetzgebung näher auszeichnen und deshalb die Strafbarkeit nicht konstitutiv bestimmen. Vieles spricht dafür, daß sie dann auch unabbängig von Verwaltungsakten Bezugspunkt des Strafrechts sein können.

c) Die Bindung entbebt nicht der Prüfung, ob einschlägige Standards nach Zweck und Ausgestaltung auch strafrechtsspezifischen Maßstäben, etwa der Sorgfaltspflicht, genügen.

13. Die Anknüpfung einer Strafandrohung an gesetzeskonkretisierende Verwaltungsakte ist unter dem Blickwinkel der Art. 103 Abs. 2, 104 Abs. 1 Satz 1 GG unbedenklich. Obne den konkretisierenden Verwaltungsakt ergeben sich erbebliche Probleme binsichtlich der Bestimmtheit der Strafandrobung und können nur die allergröbsten verwaltungsrechtlichen Verstöße strafrechtlich geabndet werden.

14. a) Die Bindung der Strafjustiz an wirksame, wenngleich im Einzelfall feblerhafte Verwaltungsakte ist die Konsequenz der sogenannten Tatbestandswirkung.

14. b) Die Tatbestandswirkung berubt letztlich auf den Prinzipien der Funktionenteilung und Rechtsstaatlichkeit. Sie schützt primär die Zuständigkeit und Verantwortung der Erlaßbebörde für die Konkretisierung und Gestaltung der Verwaltungsrechtslage, zugleich aber auch die prinzipiell berechtigte Erwartung des einzelnen, daß seine durch einen Verwaltungsakt bestimmten Rechte und Pflichten nicht von dritter Seite anders bestimmt oder annulliert werden.

15. Deklaratorische Verwaltungsakte sind von der Tatbestandswirkung nicht ausgenommen. Auch in Verwaltungsbereichen mit sehr dichten gesetzlichen Vorgaben, wie im Steuerrecht, haben Verwaltungsakte in der Regel konstitutive Wirkung in dem Sinne, daß sie die Individualrechtslage klären und stabilisieren. Diese Wirkung darf ibnen nicht durch einen unmittelbaren strafgerichtlichen Durchgriff auf das Verwaltungsgesetz genommen werden.

16. a) Die Strafbarkeit des Verstoßes gegen einen rechtswidrigen Verwaltungsakt oder des Handelns ohne behördliche Gestattung läßt sich nicht generell mit dem Argument bekämpfen, es werde letztlich nur der Verwaltungsungehorsam pönalisiert. Das Kernstrafrecht schützt durchweg auch materielle Rechtsgüter. Im übrigen bestehen erbebliche Bedenken, ob die aus strafrechtlicher Sicht unverbältnismä- 
Bige Pönalisierung des Verwaltungsungehorsams durch die Befreiung von der Tatbestandswirkung erzielt werden darf und nicht der Weg über Art.100 GG zu beschreiten wäre.

16. b) Die Entscheidung des Bundesgerichtshofs, wonach die spätere Aufhebung die Strafbarkeit wegen Verstoßes gegen ein Verkebrszeichen nicht berübrt, mag auf den Schutz staatlicher Ordnungsinteressen zutreffen, überzengt aber nicht, wenn die Strafbarkeit auch an die Verletzung anderer materieller Schutzinteressen anknüpft. Korrekturen des Verwaltungsaktes müssen dann entsprechend der Verfahrenslage berïcksichtigt werden.

17. a) Die Tatbestandswirkung behördlicher Gestattungsakte erfaßt nicht die Verletzung strafrecbtlich geschützter Individualrechtsgüter.

17. b) Die Bindung an Erlaubnisse, die angeblich veraltet sind, unredlich erworben oder deren Rechtswidrigkeit der Erlaubnisnehmer kennt, läßt sich strafrechtlich nicht unter Berufung auf das Rechtsmißbrauchsverbot beseitigen. Anderenfalls käme es zu einem Übergriff in die Entscheidungs- und Beurteilungskompetenz der Verwaltung und $z$ u einem Widerspruch $z$ u den Regeln über die Rücknabme rechtswidriger Verwaltungsakte. Bei tatbestandsbestimmenden Erlaubnissen, die binsichtlich ibrer Wirksamkeit und Bestandskraft schon von Gesetzes wegen auf das Verwaltungsrecht verweisen, ist auch Art. $103 \mathrm{Abs.} 2$ GG verletzt, weil die gesetzliche Verweisung zu Lasten des Angeklagten mißachtet wird.

18. a) Ungenebmigtes, verwaltungsrechtlich jedoch genehmigungsfähiges Verhalten darf strafrechtlich nicht als genebmigt behandelt werden. Mit dem gesetzlichen Erfordernis einer bebördlichen Gestattung wird immer eine spezifische Verantwortung der Verwealtung für die Erteilung bzw. Ablebnung begründet, die ibr die Strafjustiz nicht abnebmen kann. Dies gilt auch für die Klärung, $o b$ in concreto eine Ermessensschrumpfung eingetreten ist. Die nachträglich erteilte Genehmigung muß strafrechtlich in gleicher Weise wie bei der Tatbestandswirkung eines Verwaltungsaktes berücksichtigt werden.

18. b) Die sogenannte aktive bebördliche Duldung eines Verhaltens vermag strafrechtlich nur zu rechtfertigen, wenn sie nach den einschlägigen Normen des Verwaltungsrechts als Erteilung einer Erlaubnis bzw. Genebmigung qualifiziert werden kann. Entsprechendes gilt, wenn die Bebörde in Kenntnis bestimmter Verbaltensweisen nicht einschreitet. Anderenfalls ist der Entscheidungsvorrang der Verwaltung verletzt. Davon unberübrt bleibt die Berücksichtigung bei der Schuldfeststellung.

19. Eine Strafbarkeit von Amtsträgern kommt nur bei über die bloße Verwaltungsrechtswidrigkeit hinausweisendem Unrecht in 
Betracht. Anwendungsfälle sind kollusives Zusammenwirken mit Privatpersonen, sonstiges unredliches Verhalten und die Verletzung böchstpersönlicher Individualrechtsgüter. Dieserhalb erwogene Spezialregelungen müssen vor Art.3 GG Bestand haben.

20. Das Ermessen zur Aussetzung des Strafverfabrens kann sich insbesondere zur Vermeidung widersprüchlicher Entscheidungen bei scbwierigen und klärungsbedürftigen Verwaltungsrechtsfragen oder bei strafgerichtlicher Abweichung von einer etablierten Verwaltungspraxis zur Aussetzungspflicht verdichten. Dies kann jedoch nur dort gelten, wo das Strafrecht unmittelbar und sanktionsverstärkend im Tatbestand an das Verwaltungsrecht anknüpft. Ein Gegengesichtspunkt kann das Beschleunigungsgebot sein. Das Risiko einer revisionsgerichtlichen Aufbebung wegen feblerhafter Ausübung des Aussetzungsermessens ist bisher gering. 


\title{
Verwaltungsrecht als Vorgabe für Zivil- und Strafrecht
}

2. Bericht von Prof. Dr. Hans D. Jarass, Bochum

\author{
Inhalt
}

Seite

I. Einleitung ....................... 239

1. Die Vorgaben des Verwaltungsrechts für das Privatrecht als Untersuchungsfeld . . . . . . . . . . . . . . . . . 239

2. Die „Publifizierung " und Verdrängung des Privatrechts . . 239

II. Problembeschreibung anhand ausgewählter Problemfelder .. 241

1. Einfluß auf die Auslegung und Anwendung des $\$ 906$ BGB 241

2. Einfluß auf Kausalitätsfeststellungen ............ 243

3. Ausschluß von Ansprüchen durch Genehmigungen und Zulassungen . . . . . . . . . . . . . . . . . . . 244

4. Deliktische Schadensersatzansprüche ........... 246

5. Rechtswidrige Rechtsgeschäfte . . . . . . . . . . 248

6. Unlauterer Wettbewerb . . . . . . . . . . . . . 249

III. Systematisierung der privatrechtsbeeinflussenden Wirkung verwaltungsrechtlicher Regelungen . . . . . . . . . . . . 250

1. Einflußintensität ..................... 250

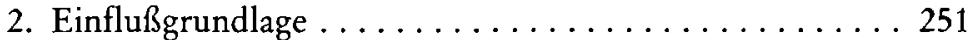

3. Einflußnehmende Größe . . . . . . . . . . . . . . 252

IV. Theoretischer Hintergrund . . . . . . . . . . . . . . . . . 254

1. Dritt- bzw. Ausstrahlungswirkung . .......... 254

2. Durchsetzung verwaltungsrechtlicher Standards ..... 255

3. Überschreitung von Organisations- bzw. Systemgrenzen . 257

V. Nichtbeachtung der verwaltungsrechtlichen Legalität und die Einheit der Rechtsordnung . . . . . . . . . . . . . . 259

1. Die Fälle der Nichtbeachtung der verwaltungsrechtlichen Legalität .......................... 259

2. Normwidersprüche und Wertungswidersprüche ..... 261

3. Der Einfluß der Genehmigungskonformität . . . . . . 263

4. Der Einfluß der Verwaltungsnormkonformität ...... 265

5. Verwaltungsnormkonformität vs. Verwaltungsaktskonformität ....................... 267

VI. Schluß ........................ 269 


\section{Einleitung}

\section{Die Vorgaben des Verwaltungsrechts für das Privatrecht als Untersuchungsfeld}

Nach den Ausführungen von Herrn Schröder, die vor allem dem Strafrecht gewidmet waren, ist es nunmehr meine Aufgabe, die Vorgaben des Verwaltungsrechts für das Privatrecht zu behandeln. Dieses Teilthema mag weniger spektakulär sein als der von Herrn Schröder behandelte Bereich, der in den vergangenen Jahren zu engagierten, gelegentlich sogar empörten Stellungnahmen führte. Interessant ist das privatrechtliche Teilthema allemal, auch deshalb, weil es in seiner Gesamtheit bislang wenig Aufmerksamkeit gefunden hat. Eine umfassende dogmatische Aufbereitung fehlt. Nur für einzelne Anwendungsfelder, vor allem im Bereich des Nachbarrechts, gibt es nähere Untersuchungen. Die Perspektive der Rechtswissenschaft ist - nicht ohne Grund - ganz darauf gerichtet, das öffentliche vom privaten Recht zu trennen ${ }^{1}$. Dabei gerät das Zusammenspiel und die Zuordnung der beiden Rechtsbereiche nur zu leicht aus dem Blickfeld.

Bei unserem Thema geht es um die Einflüsse des Verwaltungsrechts auf die Beziehungen zwischen Privatpersonen. Ähnliche Fragen stellen sich, wenn es um den Einfluß des Verwaltungsrechts auf Beziehungen zwischen einer Privatperson und dem privatrechtlich handelnden Staat geht ${ }^{2}$. In diesem Falle schrumpft jedoch die für unser Thema kennzeichnende Dreiecksbeziehung häufig zu einem Zwei-PersonenVerhältnis. Nicht zuletzt aus diesem Grunde werde ich den Einfluß des Verwaltungsrechts auf das Verwaltungsprivatrecht lediglich am Rande berühren.

\section{Die „Publifizierung“ und Verdrängung des Privatrechts}

Die Feststellung, daß unser Thema bisher übergreifend noch kaum untersucht wurde, gilt nur für rechtsdogmatische Untersuchungen. Auf der rechtspolitischen Ebene wird der Einfluß des Verwaltungsrechts auf das Privatrecht seit langem diskutiert. Bereits 1919 wies

\footnotetext{
1 Dazu etwa D.Schmidt, Die Unterscheidung von privatem und öffentlichem Recht, 1985.

2 In unserem Zusammenhang Ossenbübl, DVBl. 1990, 966; Gerhardt, BayVBl. 1990, 553. Allgemein dazu Ehlers, Verwaltung in Privatrechtsform, 1984.
} 
Hedemann auf die „Publifizierung des bürgerlichen Rechts“ hin ${ }^{3}$. In Frankreich stellte Georges Ripert im Jahre 1949 lakonisch fest: "Tout devient droit public «4. Ludwig Raiser sprach 1972 von einem „Rückzug“ des Privatrechts und fragte, ob es sich dabei „um einen irreversiblen Vorgang handelt “5. Das darin zum Ausdruck kommende Unbehagen des Privatrechtlers hat Medicus in einem Vortrag im letzten Jahr (im Hinblick auf die negatorische Unterlassungsklage) gar zu der Feststellung veranlaßt, daß das "zivilrechtliche Urgestein“ von dem öffentlich-rechtlichen „Schutt“" durch den es überlagert werde, befreit werden müsse ${ }^{6}$.

Die wachsende Bedeutung des öffentlichen Rechts zu Lasten des Privatrechts ${ }^{7}$, die natürlich auch von den Fachvertretern des öffentlichen Rechts konstatiert wurde, wie etwa von Peter Badura, um nur einen Namen zu nennen ${ }^{8}$, betrifft nicht nur das Verwaltungsrecht. Die außerordentliche Gestaltungskraft, die das Verfassungsrecht unter dem Grundgesetz entwickelt hat, gehört mit dazu. Doch der Anteil des Verwaltungsrechts ist nicht unerheblich.

Nun sollte man die Publifizierung und Verdrängung des Privatrechts durch das öffentliche Recht nicht überschätzen: Die Gefahr, daß das Privatrecht zu einer Randerscheinung wird, wie das bei Privatrechtlern gelegentlich anklingt ${ }^{9}$, besteht nicht. Aber als Trendaussage ist sie zutreffend. Das ist um so bemerkenswerter, als noch um die Jahrhundertwende die Emanzipation des Verwaltungsrechts vom Privatrecht das Thema war. Den Selbststand des Verwaltungsrechts gegenüber dem sehr viel älteren Privatrecht herzustellen und zu sichern, war für Otto Mayer eine zentrale Aufgabe der Verwaltungsrechtswissenschaft ${ }^{10}$.

\footnotetext{
${ }^{3}$ Hedemann, Einführung in die Rechtswissenschaft, 1. Aufl. 1919, 134; 2. Aufl. 1927, 228.

${ }^{4}$ Ripert, Le Déclin du droit, 1949, 37 unter Übernahme einer Formulierung von Jean Portalis.

5 Raiser, Die Zukunft des Privatrechts, 1971, 14.

6 Medicus, NuR 1990, 150.

7 Die Gewichtsverschiebung zwischen dem öffentlichen Recht und dem Privatrecht beruht nicht darauf, daß privates Recht aufgehoben und durch öffentliches Recht ersetzt wird. Vielmehr wird das formell unveränderte Privatrecht durch öffentliches Recht unterlaufen, überholt und überlagert; Schmidt (Fn. 1), 17.

${ }^{8}$ Badura, Staatsrecht, 1986, A 6; Berg, Verw. 1988, $319 \mathrm{ff}$.

9 Vgl. die Nachweise bei Schmidt (Fn. 1), 16.

10 O. Mayer, Deutsches Verwaltungsrecht, Bd. 1, 3. Aufl. 1924, 14, $113 \mathrm{ff}$; dazu Forsthoff, Verwaltungsrecht, 10. Aufl. 1973, 52, $168 \mathrm{f}$.
} 
Schließlich möchte ich schon eingangs darauf hinweisen, daß unser Thema mit plakativen Charakterisierungen nicht zu bewältigen ist. Die These, das Privatrecht fördere die Freiheit des Bürgers, während das öffentliche Recht sie beschränke ${ }^{11}$, ist sowenig hilfreich wie die umgekehrte Aussage, daß das öffentliche Recht dem Allgemeininteresse zum Durchbruch verhelfe, das Privatrecht dagegen nur Individualinteressen fördere ${ }^{12}$.

\section{Problembeschreibung anhand ausgewählter Problemfelder}

\section{Einfluß auf die Auslegung und Anwendung des $₫ 906 B G B$}

Der Stellenwert des Verwaltungsrechts für das Privatrecht ist bislang vor allem im Bereich des Nachbar- und Umweltrechts diskutiert worden. Das legt es nahe, unser Thema von dieser Seite her anzugehen. Im Zentrum des privaten Nachbarrechts steht die Vorschrift des $\$ 906$ BGB. Sie bestimmt, welche Einwirkungen ein Nachbar dulden muß und welche Schutz- und Ausgleichsansprüche er gegebenenfalls geltend machen kann. Die Bedeutung dieser Regelung ist erheblich größer als man das auf den ersten Blick vermutet. Insbesondere gilt sie nicht nur für Abwehransprüche, sondern wird auch auf Schadensersatzansprüche angewandt ${ }^{13}$. Der Einfluß des Verwaltungsrechts auf diese Vorschrift ist daher nicht ohne Interesse.

a) $\$ 906$ BGB gilt für unwägbare Einwirkungen und damit für nichts anderes als für Immissionen. Das legt einen Einfluß des öffentlichen Immissionsschutzrechts nahe. Er kann zunächst bei den Kriterien der Wesentlichkeit und der Ortsüblichkeit ansetzen, die die Grenze der hinzunehmenden Einwirkungen beschreiben. In einer Entscheidung aus diesem Jahre hat denn auch der Bundesgerichtshof festgestellt, daß wesentliche Beeinträchtigungen i.S.d. $\$ 906$ Abs. 1 BGB identisch sind mit den schädlichen Umwelteinwirkungen des Bundes-Immissionsschutzgesetzes ${ }^{14}$. Praktische Folgen für das Privat-

1 So Zöllner, JuS 1988, 329 ff; dagegen zu Recht Schmidt (Fn. 1), $166 \mathrm{ff}, 196 \mathrm{ff}$; Ossenbühl, DÖV 1990, $966 \mathrm{f}$.

${ }_{12} \mathrm{Vgl}$. Kloepfer, in: Breuer u. a. (Hrsg.), Umweltschutz und Privatrecht, 1990, 44.

13 Etwa Baur, in: Soergel, Bürgerliches Gesetzbuch, 11. Aufl. 1978, $\$ 906$ Rdn.6. Darüber hinaus gelten die Vorgaben des $\$ 906$ BGB auch für Pächter und Mieter der Nachbargrundstücke. Endlich werden die Abgrenzungen des $\$ 906$ Abs. 1, Abs. 2 S. 1 BGB auch auf die Eigentümer beweglicher Sachen angewandt; $B G H Z$ 92, 143/149.

${ }_{14} B G H$, DVBI. 1990, 772; ebenso BVerw $G E$ 79, 254/258. 
recht hat das Immissionsschutzrecht weniger auf der Ebene der Gesetze und Rechtsverordnungen als auf der Ebene der Verwaltungsvorschriften. So werden die TA Luft und die TA Lärm zur Bestimmung der Wesentlichkeit von Einwirkungen herangezogen ${ }^{15}$. Eine echte Bindung wird allerdings durchweg abgelehnt; die Einhaltung von Verwaltungsvorschriften oder deren Überschreitung sind bei der Beweiswürdigung zu berücksichtigen ${ }^{16}$. Zur Illustration sei auf die Baumschulentscheidung oder die Kupolofenentscheidung des Bundesgerichtshofs verwiesen ${ }^{17}$.

Neben dem Immissionsschutzrecht kann auch das öffentliche Baurecht das private Nachbarrecht beeinflussen. Für die Diskussion um die zureichende Beachtung des Verwaltungsrechts steht dieser Bereich sogar ganz im Vordergrund. In der vieldiskutierten Tennisplatzentscheidung ${ }^{18}$ ging es um die Frage, ob der Umstand, daß ein Tennisplatz in einem bauplanungsrechtlich dafür vorgesehenen Gebiet liegt, privatrechtliche Abwehr- und Schadensersatzansprüche ausschließt. Die Rechtsprechung und die überwiegende Auffassung in der Literatur lehnen das $a b^{19}$. Die bauplanungsrechtliche Ausweisung spiele weder für die Frage der Erheblichkeit noch für die Frage der Ortsüblichkeit eine entscheidende Rolle ${ }^{20}$. Sie bilde allenfalls einen gewissen Anhaltspunkt, ein Indiz. In der verwaltungsrechtlichen Literatur wird das, etwa von Hans-Jürgen Papier, kritisiert, weil auf diese Weise die baurechtlichen Planungen durchkreuzt werden können ${ }^{21}$.

15 Baur (Fn. 13), \$906 Rdn. 24; Roth in: Staudinger, Das Bürgerliche Gesetzbuch, 12. Aufl. 1989, $\$ 906 \mathrm{Rdn} .178$.

16 Baur (Fn. 13), \$906 Rdn. 25 mit Nachw.; Gerlach, JZ 1988, 161. Zudem ist die Überschreitung der Grenzwerte aussagekräftiger als deren Einhaltung; $B G H Z$ 70, 102/110; Marburger, Gutachten zum 56. Deutschen Juristentag, 1986, C $107 \mathrm{ff}$.

$17 B G H Z 70,102 / 105 \mathrm{ff} ; 92,143 / 148,151 \mathrm{ff}$.

$18 B G H$, NJW 1983, 751; dazu Peine, JuS 1987, 169 ff.

19 BGH, NJW 1983, 751; 1976, 1205; DVBl. 1971, 745; Medicus, JZ 1986, 784; Hohloch, in: Kimminich/v. Lersner/Storm (Hrsg.), Handwörterbuch des Umweltrechts, Bd. 2, 703 f; Säcker, in: Münchener Kommentar zum Bürgerlichen Gesetzbuch, 2. Aufl. 1986, $\$ 906 \mathrm{Rdn} .16 \mathrm{ff}$.

${ }^{20}$ Rotb (Fn. 15), \$906 Rdn. $188 \mathrm{ff}$. Insbesondere komme es für die Ortsüblichkeit entscheidend auf die tatsächlichen Verhältnisse, nicht auf die baurechtliche Ausweisung an; $B G H$, DVB1. 1971, 749; NJW 1976, 1205; 1983, 752; Baur (Fn. 13), \$906 Rdn. 12.

${ }_{21}$ Papier, in: Pickart/Gelzer/Papier (Hrsg.), Umwelteinwirkungen durch Sportanlagen, 1984, 97; Trzaskalik, DVBI. 1981, 71; Kleinlein, NVwZ 1982, 668; Peine, JuS 1987, 175 f; Gaentzsch, NVwZ 1986, $601 \mathrm{ff}$. 
b) Vor allem die Aussagen der TA Luft werden von der Rechtsprechung noch bei anderen Voraussetzungen des $\$ 906$ BGB genutzt. Das Überschreiten von Grenzwerten der TA Luft wird etwa als Anhaltspunkt herangezogen, ob Schutzvorkehrungen (i.S.d. Abs. 2 S.1) zumutbar sind oder ob die hinzunehmende Beeinträchtigung die Nutzung des Nachbargrundstücks (i.S.d. Abs. 2 S.2) über das zumutbare Maß hinaus behindert ${ }^{22}$. Ein Grenzwert der TA Luft kann damit für ganz unterschiedliche Tatbestandsmerkmale Bedeutung erlangen, obwohl ein bestimmter Grenzwert eigentlich nur Aussagen zu einer Frage enthalten kann ${ }^{23}$. Für die Praxis wird dieser Befund dadurch entschärft, daß Verwaltungsvorschriften die Zivilgerichte nicht wirklich binden, sondern allein einen Anhaltspunkt liefern, der dann im Einzelfall ein sehr unterschiedliches Gewicht haben kann ${ }^{24}$.

\section{Einfluß auf Kausalitätsfeststellungen}

Ein auf den ersten Blick überraschender, zugleich aber zunehmend wichtig werdender Einfluß des Verwaltungsrechts zeigt sich im Bereich der Kausalitätsfeststellungen. Ein privatrechtlicher Abwehroder Schadensersatzanspruch setzt voraus, daß die von einer Anlage ausgehenden Emissionen zu Immissionen im Einwirkungsbereich geführt haben und diese Immissionen ursächlich für die Beeinträchtigung des Betroffenen waren. Dieser doppelte Ursachennachweis ist dem Betroffenen etwa bei Luftverunreinigungen häufig nicht möglich. Um so wichtiger ist für ihn, daß die Rechtsprechung in der Überschreitung der Immissionsgrenzwerte, aber auch der Emissionswerte der TA Luft ein Indiz für die Ursächlichkeit der Anlage sieht ${ }^{25}$.

Dieser Ansatz wird im Entwurf des neuen Umwelthaftungsgesetzes aufgegriffen und ausgebaut ${ }^{26}$. Die dort vorgesehene Vermutung der Ursächlichkeit von Anlagen, die "nach den Gegebenheiten des Einzel-

22 Zu Abs. 2 S. 1 BGHZ 90, 102/111; Marburger (Fn. 16), C 110f; Hagen, UPR 1985 , 193. Insoweit wirkt auch der Einfluß des neuen $\$ 17$ Abs. 2 BImSchG; Roth (Fn. 15), 9906 Rdn. 208. Außerdem BGHZ 64, 220/223. Zu Abs. 2 S. 2 Baur (Fn. 13), \$906 Rdn. 13; Roth (Fn. 15), \$906 Rdn. 234; Hager, NJW 1986, 1964.

23 Vgl. dazu Hansmann, in: Landmann/Rohmer, Gewerbeordnung, Bd.3, $\$ 48$ BImSchG Rdn. $28 \mathrm{ff}$.

${ }^{24}$ S. oben a. Zur praktischen Bedeutung beweisrechtlicher Differenzierungen s. unten Fn. 77.

${ }^{25}$ BGHZ 70, 102/107; 92, 143/149 ff; Roth (Fn. 15), \$906 Rdn. 176; Hager, NJW 1986, 1966.

26 Vom 23. 2. 1990, BR-Drs. 127/90. 
falles geeignet (sind), den entstandenen Schaden zu verursachen ${ }^{427}$, ist ausgeschlossen, wenn der Anlagenbetreiber alle auf Schäden der fraglichen Art bezogenen verwaltungsrechtlichen Pflichten eingehalten hat ${ }^{28}$.

\section{Ausschluß von Ansprüchen durch Genehmigungen und Zulassungen}

a) Kommen wir zu einer anderen Form des verwaltungsrechtlichen Einflusses auf das Privatrecht: Bei einer Reihe von Genehmigungen und Zulassungen sehen die einschlägigen Gesetze ausdrücklich vor, daß nach Unanfechtbarkeit der betreffenden Genehmigung bzw. Zulassung privatrechtliche Ansprüche nicht mehr geltend gemacht werden können. Diese Präklusionswirkung geht dabei unterschiedlich weit: $\$ 14$ BImSchG schließt ebenso wie $\$ 23$ GentG Ansprüche auf Einstellung des Anlagenbetriebs aus ${ }^{29}$, nicht jedoch Ansprüche auf Schutzvorkehrungen oder Schadensersatz ${ }^{30}$. $\$ 75$ Abs. 2 VwVfG schließt für Planfeststellungen auch Schutzvorkehrungsansprüche aus $^{31}$. Und $\$ 11$ WHG präkludiert sogar Schadensersatzansprüche ${ }^{32}$. In der zivilrechtlichen Literatur werden die Präklusionsnormen zudem als allgemeine Rechtfertigungsklauseln betrachtet, mit der Folge, daß auch Schadensersatzansprüche gemäß $\$ 823$ BGB entfallen ${ }^{33}$. Die verwaltungsrechtliche Literatur lehnt das überwiegend $a b^{34}$.

27 Sofern keine Ursache außerhalb der vom Umwelthaftungsgesetz erfaßten Anlagen in Betracht kommt; $\$ 7$ des Entwurfs.

${ }^{28}$ Die Pflichten ergeben sich aus Auflagen sowie aus vollziehbaren Anordnungen und Rechtsvorschriften; vgl. \$6 des Entwurfs. Soweit verwaltungsrechtlich gebotene Kontrollen zur Einhaltung dieser Pflichten durchgeführt wurden und sich dabei keine Anhaltspunkte für die Verletzung von Betriebspflichten ergaben, wird die Einhaltung der Pflichten vermutet.

${ }^{29}$ Soweit sie nicht auf besonderen Titeln beruhen; Baur (Fn. 13), $\$ 903 \mathrm{Rdn} .94$.

30 Die Vorschrift gilt auch für atomrechtliche und gentechnische Genehmigungen sowie für luftverkehrsrechtliche Genehmigungen; $\$ 7$ Abs. 6 AtG; $\$ 11$ LuftVG. Darüber hinaus ist $₫ 14 \mathrm{BImSchG}$ bei verschiedenen landesrechtlichen Zulassungen anwendbar; Roth (Fn. 15), $\$ 906 \mathrm{Rdn} .26$.

31 Ob Ansprüche aufgrund besonderer privatrechtlicher Titel präkludiert werden, ist umstritten; dafür Kopp, $\mathrm{V}_{w} V f G, 4$. Aufl. 1986, $\$ 75 \mathrm{Rdn} .3$; dagegen zu Recht Bonk, in: Stelkens/Bonk/Leonhardt, VwVfG, 3. Aufl. 1990, \$75 Rdn. 23.

32 Dazu Giesecke/Wiedemann/Czychozeski, Wasserhaushaltsgesetz, 5. Aufl. 1990, $\$ 11$ Rdn. 3.

33 Wagner, Öffentlich-rechtliche Genehmigung und zivilrechtliche Rechtswidrigkeit, 1989, 20, 108 f; Fikentscher, Schuldrecht, 7. Aufl. 1985, 793 f; Gerlach, Privatrecht und Umweltschutz im System des Umweltrechts, 1989, 222.

${ }^{34}$ Feldhaus, $\$ 14$ Anm. 11; Stich/Porger, $\$ 14$ Anm. 23; widersprüchlich Peine JZ 1990, 201. 
Die Rechtsprechung hat zu dieser Frage keine Stellung bezogen ${ }^{35}$. Im Ergebnis hat sie allgemeine Schadensersatzansprüche - soweit ersichtlich - niemals an einer der genannten Präklusionsvorschriften scheitern lassen. Möglicherweise liegt das aber auch daran, daß sie auf die Präklusionsvorschriften höchst selten eingeht, obwohl es in vielen Entscheidungen um Anlagen ging, bei denen diese Vorschriften durchaus eine Rolle hätten spielen können ${ }^{36}$.

b) Nach einer im Vordringen befindlichen Meinung in der verwaltungsrechtlichen Literatur sollen nicht nur Genehmigungen, für die eine ausdrückliche Regelung der dargestellten Art vorhanden ist, privatrechtliche Ansprüche ausschließen und einschränken ${ }^{37}$. Rüdiger Breuer nimmt etwa für die Bangenehmigung an, daß ihr eine formellrechtliche Gestaltungswirkung zukomme, die privatrechtliche Abwehransprüche ausschließe, solange die Genehmigung besteht ${ }^{38}$. Die Rechtsprechung hat das nicht akzeptiert, weder für die Baugenehmigung $^{39}$, noch für andere Genehmigungen, bei denen eine Präklusion gesetzlich nicht angeordnet ist ${ }^{40}$. Die in $\$ 1004$ Abs. 2 BGB vorgesehene Duldungspflicht ändert daran nichts. Die Vorschrift hat nach ganz h. A. keine bindungsbegründenden Wirkungen, sondern weist nur auf andernorts begründete Bindungen hin ${ }^{41}$.

${ }^{35} R G Z 84,298 / 303 ; 122,134 / 138 ; 159,129 / 135$ sprechen eher für die verwaltungsrechtliche Literatur.

${ }^{36} \mathrm{Vgl}$. Wagner (Fn. 33), $14 \mathrm{f}$.

${ }^{37}$ Allerdings ist dabei nicht immer klar, ob die Präklusion durch die der Genehmigung zugrunde liegenden Vorschriften oder durch die Genehmigung selbst bewirkt wird.

${ }^{38}$ Breuer, in: v. Münch (Hrsg.), Besonderes Verwaltungsrecht, 8. Aufl. 1988, 649 f; ebenso Schapp, Das Verhältnis von privatem und öffentlichem Nachbarrecht, 1978, $164 \mathrm{ff}$; Schrödter, in: ders., Baugesetzbuch, 4.Aufl. 1980, $\$ 31$ Rdn. 23; Gaentzsch, NVwZ 1986, 605.

39 BGH, NJW 1959, 2014; BayObLGZ 1979, 1625; ebenso Steinberg, NJW 1984, 462; Kleinlein, NVwZ 1982, 669; Gerlach, JZ 1988, 172; Baur, in: Gedächtnisschrift für Martens, 1987, 550 f; vorsichtig Rotb (Fn. 15), $\$ 906 \mathrm{Rdn} .33$.

${ }^{40} B G H Z$ 69, 118/124; speziell zur gaststättenrechtlichen Genehmigung $B G H$, NJW 1959, 2014; zur wasserrechtlichen Erlaubnis BGHZ 88, 34/40 f. Anders $R G Z$ 161, 208 für bergbauliche Berechtigungen; durch die Einführung eines bergrechtlichen Planfeststellungsverfahrens ist dieses Problem überholt. Gegen eine Bindungswirkung bei einfachen Genehmigungen Hagen, UPR 1985, 197; Wagner (Fn. 33), 203 ff; Roth (Fn. 15), $\$ 906$ Rdn. 34.

${ }^{41}$ Vgl. Wagner (Fn. 33), 131; Medicus, in: Münchener Kommentar zum Bürgerlichen Gesetzbuch, 2. Aufl. 1986, $\$ 1004$ Rdn. 56; Gurski, in: Staudinger, Bürgerliches Gesetzbuch, 12. Aufl. 1989, $\$ 1004$ Rdn. $129 \mathrm{ff}$. 


\section{Deliktische Schadensersatzansprüche}

Verwaltungsrechtliche Vorgaben spielen des weiteren bei deliktischen Schadensersatzansprüchen eine Rolle. Praktische Relevanz hat das weniger im Bereich des behandelten privaten Nachbarrechts: Nach Auffassung der Rechtsprechung wird die Unerlaubtheit der betreffenden Handlung entscheidend durch die Vorgaben des $\$ 906$ BGB bestimmt ${ }^{42}$. In anderen Fällen kommt demgegenüber der Einfluß des Verwaltungsrechts auf die Auslegung und Anwendung des $\$ 823$ BGB zum Tragen, etwa bei einem Streit um eine Wassernutzung ${ }^{43}$.

a) Gemäß $\int 823 A b s .2 B G B$ muß Schadensersatz leisten, wer gegen ein Gesetz verstößt, das den Schutz eines anderen bezweckt. Schutzgesetze können anerkanntermaßen auch Normen des Verwaltungsrechts $\operatorname{sein}^{44}$, nicht jedoch Verwaltungsvorschriften ${ }^{45}$. Darüber hinaus stuft die Rechtsprechung selbst Verwaltungsakte als Schutzgesetze ein, etwa die Anordnungen einer Jagdbehörde ${ }^{46}$ oder die Nebenbestimmung zu einer Genehmigung ${ }^{47}$. Kennzeichnend für Schutzgesetze ist, daß sie zumindest auch einen Individualschutz gewähren sollen ${ }^{48}$; ein wichtiges Indiz bildet die hinreichend klare Abgrenzung des Kreises der geschützten Personen ${ }^{49}$. Schließlich sei darauf hingewie-

${ }^{42} B G H Z$ 90, 255/258; Roth (Fn. 15), $\$ 906$ Rdn. 56; Baur (Fn. 13), $\$ 906$ Rdn. 6. Damit erspart sich die Zivilrechtsprechung ein genaueres Eingehen auf verwaltungsrechtliche Normen. S. oben.

${ }^{43}$ S. dazu $B G H Z 69,1 \mathrm{ff}$.

${ }^{44}$ Schäfer, in: Staudinger, Bürgerliches Gesetzbuch, 12. Aufl. 1986, $\$ 823$ Rdn. 576, auch untergesetzlicher Art, etwa gemeindliche Satzungen (OLG Düsseldorf, VersR 1980, 142). Für berufsrechtliche Satzungen soll das dagegen nicht gelten; Schäfer, a. a.O., $\$ 823 \mathrm{Rdn} .577$.

45 Medicus, JZ 1986, 783; Mertens, in: Münchener Kommentar zum Bürgerlichen Gesetzbuch, 2. Aufl. 1986, \$823 Rdn. 158; einschränkend Hoppe/Beckmann, Umweltrecht, 1989, $\$ 15$ Rdn. 12.

46 BGHZ 62, 265/267; OLG Hamm, JZ 1981, 277; Steffen, in: Kommentar der Reichsgerichtsräte zum Bürgerlichen Gesetzbuch, 12. Aufl. 1989, $\$ 823$ Rdn. 538.

${ }^{47}$ OLG Hamm, JZ 1981, 277. In der Literatur wird dies kritisiert, das Ergebnis aber gleichwohl akzeptiert, indem man die Ermächtigungsnorm als Schutznorm einstuft; Mertens (Fn. 45), $\$ 823 \mathrm{Rdn} .153$.

$48 B G H Z 66,388 / 390$.

${ }^{49} B G H Z$ 40, 306/307; Schäfer (Fn. 44), $\$ 823$ Rdn. 579. Diese Definition stimmt weitgehend mit der Bestimmung des drittschützenden Charakters öffentlich-rechtlicher Normen überein, ohne daß deshalb im Ergebnis immer Einigkeit besteht (vgl. $B G H Z$ 40,306/312). Die Einstufung einer Norm als Schutznorm hängt nicht nur davon $a b$, ob dies im Lichte der Schutznorm sinnvoll, sondern auch davon, ob 
sen, daß die Verletzung eines Schutzgesetzes nicht nur eine Tatbestandsvoraussetzung ist, sondern unter gewissen Voraussetzungen zudem ein Indiz für die Ursächlichkeit und das Verschulden bildet ${ }^{50}$.

b) Auch im Bereich des $\int 823$ Abs. $1 B G B$ können verwaltungsrechtliche Regelungen Einfluß nehmen. So werden die durch Genehmigungen verliehenen Rechtspositionen gelegentlich als durch Abs. 1 geschützte, subjektive Rechte eingestuft, etwa eine wasserrechtliche Bewilligung ${ }^{51}$. In Betracht kämen auch Genehmigungen für berufliche und wirtschaftliche Tätigkeiten; in der Praxis wird darauf jedoch kaum zurückgegriffen.

Einen weiteren Ansatzpunkt liefern die für $\$ 823$ Abs. 1 BGB bedeutsamen Verkehrssicherungspflichten. Der Bundesgerichtshof hat dazu in einer jüngeren Entscheidung festgehalten, daß Gesetze und Rechtsverordnungen, wenn sie Regelungen für gefährliche Produkte enthalten, die Sorgfaltspflichten des Herstellers konkretisieren, weshalb ihre Verletzung auf eine Pflichtverletzung hinweist. Andererseits enthalten die Normen in aller Regel kein „abschließendes Verhaltensprogramm“", mit der Folge, daß ihre Beachtung eine Verkehrspflichtverletzung nicht ausschließt ${ }^{52}$.

Endlich wird in Einzelfällen angenommen, daß die Einhaltung von verwaltungsrechtlichen Vorgaben einen Rechtfertigungsgrund bildet oder das Verschulden ausschließ $\mathrm{t}^{53}$. Insgesamt können verwaltungsrechtliche Regelungen bei vielen Tatbestandsvoraussetzungen der deliktischen Ansprüche bedeutsam werden. Bedenkt man das, muß es

das im Sinne der Deliktshaftung tragbar ist $(B G H Z$ 66, 390; Steffen [Fn. 46], $\$ 823$ Rdn. 52). Ein fehlender drittschützender Charakter im öffentlichen Recht schließt aber negativ einen Schutzgesetzcharakter aus (BGHZ 86, $362 \mathrm{~m}$. Nachw.).

${ }^{50}$ Zur Ursächlichkeit $B G H$, VersR 1961,828 ; LM $\$ 823 \mathrm{Nr} .11$ b E f; Schäfer (Fn. 44), $\$ 823$ Rdn. 609. Zum Verschulden Steffen (Fn. 46), \$823 Rdn. 566; Mertens (Fn. 45), $\$ 823$ Rdn. 164.

${ }^{51} B G H$, NJW 1976, 46; $B G H Z$ 69, 1/6f. Dabei ist allerdings die Reichweite der subjektiv-rechtlichen Position zu beachten.

$52 B G H$, NJW 1987, 372; 1987, 1011. Dementsprechend kann eine Treppe auch dann verkehrsunsicher sein, wenn sie baupolizeilich genehmigt wurde $(B G H$, VersR 1962, 332; ebenso $B G H$, VersR 1969, 665; NJW 1987, 373). Anders dagegen $B G H Z$ 62, 265/270 für die Pflichten des Jagdausübungsberechtigten. Verwaltungsvorschriften werden als Anhaltspunkt für die Bestimmung der Verkehrssicherungspflichten genutzt; Schäfer (Fn. 44), \$823 Rdn. 577.

53 Zur Rechtfertigung s. Steffen (Fn. 46), \$823 Rdn. 390; Diederichsen, Gutachten zum 56. Deutschen Juristentag 1986, Bd. II, L 65 sowie die Regelung des $\$ 1$ Abs. 2 Nr. 4 ProdHG. Zum Verschulden $B G H Z$ 90, 143/152; Schäfer (Fn. 44), $\$ 823$ Rdn. 504 . 
überraschen, daß die Zivilgerichte auf verwaltungsrechtliche Regelungen doch in recht wenigen Fällen eingehen.

\section{Rechtswidrige Rechtsgeschäfte}

Ein anderes Problemfeld ist der Einfluß des Verwaltungsrechts auf die Gültigkeit von Rechtsgeschäften. Gemäß $\$ 134$ BGB sind Rechtsgeschäfte nichtig, die gegen ein gesetzliches Verbot verstoßen. Solche Verbotsgesetze sind insbesondere in verwaltungsrechtlichen Normen enthalten; sie bilden sogar das Hauptanwendungsfeld des $\$ 134$ $\mathrm{BGB}^{54}$.

Ob eine bestimmte Vorschrift ein Verbotsgesetz ist, muß an Hand des Gesetzeszwecks beurteilt werden. Dabei spielt die Unterscheidung von Verbotsgesetzen und bloßen Ordnungsvorschriften eine wichtige Rolle ${ }^{55}$. Verbotsgesetze kennzeichnet eine Mißbilligung von Inhalt und Erfolg des Rechtsgeschäfts, während Ordnungsvorschriften sich gegen äußere Umstände richten ${ }^{56}$. Die Anwendung dieser Unterscheidung ist im Einzelfall mit großen Unsicherheiten behaftet. So ist ein Verkauf nach Ladenschluß wirksam ${ }^{57}$, nicht dagegen ein Vertrag, der gegen das Schwarzarbeitsgesetz ${ }^{58}$ oder gegen das Verbot von Darlehensverträgen im Reisegewerbe verstößt $\mathrm{t}^{59}$. Eine Beratung unter Verstoß gegen das Rechtsberatungsgesetz wird als nichtig angesehen $^{60}$, nicht jedoch ein Bankgeschäft oder eine Beratung durch einen Steuerberater unter Verletzung der jeweiligen Vorschriften ${ }^{61}$.

${ }^{54}$ Hefermebl in: Soergel, Das Bürgerliche Gesetzbuch, 12. Aufl. 1986, $\$ 134$ Rdn. 6; Canaris, Gesetzliches Verbot und Rechtsgeschäft, 1983, 16. Umstritten ist, ob das Schutzgesetz notwendig ein förmliches Gesetz sein muß (so Mayer-Maly, in: Münchener Kommentar zum Bürgerlichen Gesetzbuch, 2. Aufl. 1984, $\$ 134$ Rdn.28), oder ob auch eine Rechtsverordnung genügt ( $B G H Z$ 37, 363/365). Verwaltungsakte können dagegen keine Verbotsgesetze sein; Brox in: Erman, Bürgerliches Gesetzbuch, 7. Aufl. 1981, $\$ 134$ Rdn. 8.

$55 \mathrm{Vgl}$. Hefermebl (Fn. 54), $\$ 134$ Rdn. 20; Mayer-Maly (Fn. 54), $\$ 134$ Rdn. $47 \mathrm{ff}$. Als bloße Ordnungsvorschrift wird etwa die Preisangabenverordnung eingestuft; $B G H$, WM 1979, 52; 1980, 1113; ZIP 1982, 1046.

56 Hefermebl (Fn. 54), \$134 Rdn. 14, 20; Brox (Fn. 54), \$134 Rdn. 11.

57 Canaris (Fn. 54), $34 \mathrm{f}$.

58 BGHZ 85, 39/44; 89, 369.

59 Zum Verbot des $\$ 56$ Abs. 1 Nr. 6 GewO $B G H Z 71,358 / 360 \mathrm{ff}$.

$60 B G H Z$ 37, 258/262. Ebenso ist der Spielvertrag, der die SpielbankenVO verletzt, nichtig; $B G H Z$ 37, 363/365 f.

${ }^{61} \mathrm{Zu}$ Bankgeschäften $B G H$, WM 1972, 853; 1978, 1269; 1980, 377. Zum Steuerberater $B G H Z 78,269 / 271 ; 78,263 / 265 \mathrm{f}$. 


\section{Unlauterer Wettbewerb}

Damit komme ich zu einem letzten Problemfeld. Gemäß $\$ 1$ UWG ist ein sittenwidriger Wettbewerb verboten. Bei einem Verstoß gegen diese Norm können Konkurrenten, aber auch bestimmte Verbände auf Unterlassung klagen ${ }^{62}$. Das ist in unserem Zusammenhang deshalb von Interesse, weil sich die Frage stellt, ob ein Wettbewerbsverhalten, das gegen verwaltungsrechtliche Regelungen verstößt, sittenwidrig ist oder nicht ${ }^{63}$.

Bei einer Reihe von Vorschriften des Verwaltungsrechts wird das uneingeschränkt bejaht, etwa bei verschiedenen Vorschriften des Heilmittelrechts ${ }^{64}$ oder der Rechtsberatung ${ }^{65}$, deren Verletzung automatisch zum Verdikt der Sittenwidrigkeit führt. Solche Vorschriften werden als wertbezogene Normen bezeichnet ${ }^{66}$. In anderen Fällen müssen zu dem Verstoß gegen eine verwaltungsrechtliche Norm noch weitere, individuelle Umstände hinzutreten, die für die Sittenwidrigkeit sprechen. Hierher gehören Verstöße gegen das Personenförderungs- und das Güterkraftverkehrsgeset $z^{67}$, gegen das Ladenschlußge$\operatorname{set}^{68}$ oder gegen das Textilkennzeichnungsgeset $z^{69}$. Der Verwaltungsrechtsverstoß hat in diesen Fällen allein indiziellen Charakter. Normen dieser Art werden als wertneutrale Vorschriften charakterisiert $^{70}$. Schließlich gibt es Fälle, in denen der Verstoß gegen verwaltungsrechtliche Normen für $\$ 1$ UWG ohne jede Relevanz ist $^{71}$.

62 S. $\$ 13$ Abs. 2 UWG.

${ }^{63}$ Eine privatrechtsbeeinflussende Wirkung kommt außer Gesetzen auch Satzungen und Verwaltungsakten zu; Mees, WPR 1985, 374.

${ }_{64} B G H Z 22,167 ; 23,184 ;$ BGH, GRUR 1970, 558.

$65 B G H$, GRUR 1961, 418; $B G H Z$ 48, 12; $B G H$, GRUR 1972, 607; kritisch dazu Tilmann, WPR 1987, $293 \mathrm{ff}$.

66 Näher Baumbach/Hefermehl, Wettbewerbsrecht, 16. Aufl. 1990, $\$ 1$ Rdn. $613 \mathrm{ff}$; Sack, WRP 1985, 9. Neben der Verletzung solcher wettbewerbsbezogenen Normen ist die Verletzung von Normen, die eine unmittelbar wettbewerbsregelnde Zielsetzung verfolgen, ohne weiteres sittenwidrig ( $B G H$, GRUR 1963, 538; Schricker, JurA WR I 1970, 72).

67 $B G H$, GRUR 1960, 193; 1973, 212.

$68 B G H$, GRUR 1976, 438; 1981, 424.

69 BGH, GRUR 1980, 302.

70 Baumbach/Hefermebl (Fn. 66), \$1 Rdn.630ff; Mees, WRP 1985, 375; Sack, WRP 1985, 9; Schricker, Gesetzesverletzung und Sittenverstoß, 1970, 260.

71 Dabei handelt es sich um Vorschriften, deren Verletzung sich auf den Wettbewerb nicht auswirkt, es sei denn, der Schutzzweck der verletzten Norm 


\section{Systematisierung der privatrechtsbeeinflussenden Wirkung verwaltungsrechtlicher Regelungen}

\section{Einflußintensität}

Die skizzierten Problemfelder ergeben ein außerordentlich vielfältiges, geradezu verwirrendes Bild verwaltungsrechtlichen Einflusses auf das Privatrecht. Sucht man diese Landschaft etwas übersichtlicher zu gestalten, dann kann man zunächst an Hand der Einflußintensität differenzieren. Bislang hat man insoweit praktisch nur zwei Gruppen unterschieden: Bindung des Privatrechts und keine Bindung ${ }^{72}$. Das wird dem erhobenen Befund nicht gerecht. Neben der vollen Bindung gibt es die Fälle der indiziellen Wirkung des Verwaltungsrechts. Das wird sich noch als bedeutsam erweisen ${ }^{73}$. Sehen wir uns die drei Stufen näher an:

a) Der Einfluß des Verwaltungsrechts ist am größten, wenn die verwaltungsrechtlichen Regelungen zwingend beachtet werden müssen. Ich bezeichne das als privatrechtsbindende Wirkung. Eine solche Bindung vermitteln etwa die behandelten Präklusionsnormen, die verwaltungsrechtlichen Schutzgesetze des $₫ 823$ Abs. 2 BGB, die verwaltungsrechtlichen Verbotsgesetze des $\$ 134$ BGB und die wertbezogenen Vorschriften des $\$ 1 \mathrm{UWG}^{74}$.

b) Geringer ist der Einfluß des Verwaltungsrechts, wenn verwaltungsrechtliche Regelungen im privatrechtlichen Bereich als Indiz, als Anhaltspunkt für eine Anspruchsvoraussetzung genutzt werden. Hierher gehören die Fälle, in denen verwaltungsrechtliche Vorgaben in der Beweiswürdigung Berücksichtigung finden. Die Verletzung verwaltungsrechtlicher Normen wirkt dann beweiserleichternd oder umgekehrt beweiserschwerend ${ }^{75}$. Beispiele liefern die Bedeutung verwaltungsrechtlicher Regelungen für die Wesentlichkeit von Einwirkungen im Bereich des $\$ 906 \mathrm{BGB}$, für den Nachweis der Ursächlich-

verlangt eine Berücksichtigung; Baumbach/Hefermehl (Fn. 66), \$1 Rdn. 665. Hierher wird der Verstoß gegen das Verbot des $\$ 49$ Abs. 4 PBefG gerechnet, Mietwagen derart bereit zu stellen, daß damit ein taxiähnlicher Verkehr erreicht wird.

72 Differenzierter allerdings Ossenbübl, der die influenzierende Einwirkung unter dem Topos der Wertungsvorgaben erfaßt (Ossenbühl, DVBI. 1990, 963), ohne jedoch die Kategorie bei den Rechtsfolgen fruchtbar zu machen (Ossenbühl, DVBI. 1990, 963).

73 S. unten V 3; V 4.

74 S. oben II 3-6.

75 S. oben II 2. 
keit, für die Verletzung von Verkehrssicherungspflichten oder für das Verschulden. Des weiteren gehören hierher die wertneutralen Normen im Bereich des $\$ 1$ UWG, deren Verletzung nur einen Anhaltspunkt für die Sittenwidrigkeit liefert ${ }^{76}$. Ich bezeichne das als indizielle Wirkung des Verwaltungsrechts für das Privatrecht.

Die tatsächliche Bedeutung der indiziellen Wirkung kann sehr unterschiedlich ausfallen ${ }^{77}$. Sie mag einer privatrechtsbindenden Wirkung nahekommen, andererseits aber auch weit davon entfernt bleiben. Wenn die Verletzung einer Norm ein Indiz für das Vorliegen einer bestimmten Voraussetzung ist, dann hängt die tatsächliche Bedeutung dieser Vermutung davon ab, wie schwierig es rein tatsächlich ist, einen Gegenbeweis zu führen. Die Vermutung der Wesentlichkeit etwa kann im Einzelfall durchaus widerlegt werden, während dies bei der Vermutung der Kausalität von Luftverunreinigungen meist ausgeschlossen ist ${ }^{78}$.

c) Schließlich sind in vielen Fällen konkurrierende Normen des öffentlichen Rechts privatrechtlich irrelevant. Man kann sie als privatrechtsneutrale Normen bezeichnen.

\section{Einflußgrundlage}

a) Die Einflüsse des Verwaltungsrechts auf das Privatrecht lassen sich des weiteren nach der Art ihrer Grundlage unterscheiden. Diese kann zunächst im Privatrecht angesiedelt sein, das sich für die verwaltungsrechtlichen Vorgaben öffnet, das verwaltungsrechtliche Regelungen rezipiert.

Dazu kann das Privatrecht ausdrücklich auf bestimmte öffentlichrechtliche Regelungen verweisen. Das mag ganz konkret geschehen, etwa wenn die Wirksamkeit einer Kündigung ausdrücklich von einer behördlichen Genehmigung abhängig gemacht wird ${ }^{79}$. Die Rezep-

\footnotetext{
76 S. oben II 6.

77 Nur ein begrenztes praktisches Gewicht kommt dagegen dem Umstand zu, daß die Rspr. den beweisrechtlichen Stellenwert zu differenzieren sucht. Die genaue Abgrenzung zwischen einer Beweiserleichterung, einer Vermutung oder einem bloßen Anhaltspunkt ist in der Anwendung meist nur schwer auszumachen. Entsprechendes gilt für den Umstand, daß die Rechtsprechung der Überschreitung von Grenzwerten meist ein höheres Gewicht für die zivilrechtliche Beurteilung zuerkennt als der Einhaltung der Grenzwerte; etwa $B G H Z 70,102 / 110$.

$78 \mathrm{~S}$. oben II 1.

79 Etwa in $\$ 9$ MutterSchG.
} 
tionsnorm kann aber auch sehr viel allgemeiner formuliert sein. Prototypen sind $\$ 823$ Abs. 2 BGB bzw. $\ 134$ BGB $^{80}$.

Eine Rezeption verwaltungsrechtlicher Vorgaben kann des weiteren über die Auslegung von Tatbestandsvoraussetzungen privatrechtlicher Normen erfolgen, ohne daß das Privatrecht ausdrücklich auf Normen des Verwaltungsrechts verweist. Das ist der Fall, wenn verwaltungsrechtliche Vorgaben als Anhaltspunkt für die Wesentlichkeit einer Beeinträchtigung oder die Verletzung von Verkehrssicherungspflichten genutzt werden ${ }^{81}$. Ein anderes Beispiel ist die Einstufung einer Genehmigung als subjektives Recht im Sinne des $\$ 823$ Abs. 1 BGB. Auch das Merkmal der Sittenwidrigkeit in $\$ 1$ UWG ist hier einzuordnen ${ }^{82}$.

b) Der Einfluß des Verwaltungsrechts auf das Privatrecht kann andererseits durch verwaltungsrechtliche Regelungen bewirkt wer$\mathrm{den}^{83}$. In diesem Falle erzwingt das Verwaltungsrecht selbst die Beachtung verwaltungsrechtlicher Vorgaben. Besonders klar ist das bei den Präklusionsvorschriften ${ }^{84}$. Hierher gehören aber auch Regelungen, die umgekehrt vorsehen, daß ein Verwaltungsakt privatrechtliche Ansprüche erzeugt, wie etwa die Ausübung des gemeindlichen Vorkaufsrechts ${ }^{85}$.

\section{Einflußnebmende Größe}

Wenn bislang von einem Einfluß des Verwaltungsrechts auf das Privatrecht gesprochen wurde, dann konnte das den Eindruck erwekken, daß es allein um den Einfluß verwaltungsrechtlicher Gesetze, Rechtsverordnungen, Satzungen geht. Diese Perspektive wäre jedoch zu eng. Der Einfluß geht auch von Verwaltungsvorschriften und zudem von Verwaltungsakten aus ${ }^{86}$. Er kann also an unterschiedlichen Größen anknüpfen.

80 Probleme ergeben sich hier regelmäßig daraus, herauszufinden, welche verwaltungsrechtlichen Normen zu diesen in Bezug genommenen Rechtsvorschriften zählen.

81 S. oben II 1.

82 S. oben II 6.

${ }^{83}$ Möglicherweise zusätzlich zur privatrechtlichen Fundierung.

84 S. oben II 3.

8s Gemäß $\$ \$ 24 \mathrm{ff}$ BauGB; dazu VGH $B W, N V w Z$ 1982, 687. Sofern man Bebauungsplänen oder Genehmigungen kraft ihrer Rechtsnatur eine Bindungswirkung für das Privatrecht zuspricht, gehört dies ebenfalls in diese Fallgruppe.

${ }_{86}$ Privatrechtspräkludierende Wirkungen können auch dem Verhalten von Privatpersonen zuerkannt sein, wie das bei $\$ 10$ Abs. 3 S. 3 BImSchG der Fall ist; BVerw G, DVBl. 1973, 645; Jarass, Bundes-Immissionschutzgesetz, 1983, $\$ 14$ 
a) Was zunächst die privatrechtsbeeinflussenden Rechtsnormen des Verwaltungsrechts betrifft, so ist bemerkenswert, daß häufig eine ausreichende Bestimmtheit verlangt wird. Konkretere Verwaltungsrechtsnormen haben eher eine privatrechtsbeeinflussende Wirkung als vage Grundsatznormen ${ }^{87}$. Wo eine privatrechtsbeeinflussende Wirkung angenommen wird, ist sie bindender oder indizieller Natur.

Verwaltungsvorschriften besitzen dagegen generell nur eine indizielle, keine privatrechtsbindende Wirkung ${ }^{88}$. Das mag man damit begründen, daß Verwaltungsvorschriften grundsätzlich ohne Außenwirkung bleiben. Andererseits können jedenfalls bestimmte Verwaltungsvorschriften Außenwirkungen entfalten ${ }^{89}$. Doch betreffen diese Außenwirkungen regelmäßig das Verhältnis zwischen Staat und Bürger. Sie auch im Verhältnis zwischen zwei Privatpersonen anzuwenden, bedeutet einen zusätzlichen Schritt.

b) Bei Verwaltungsakten verhält es sich mit der Wirkungsintensität gerade umgekehrt wie bei den Verwaltungsvorschriften. Wenn sie eine privatrechtsbeeinflussende Wirkung besitzen, ist sie regelmäßig privatrechtsbindender $\mathrm{Art}^{90}$. Man spricht dann von privatrechtsgestaltenden Verwaltungsakten ${ }^{91}$. Unser Thema stellt sich damit nicht nur auf der Normebene, wie man das vielleicht auf den ersten Blick vermutet, sondern auch und gerade auf der Vollzugsebene. Es geht um die Frage, wer letztlich darüber entscheiden kann, ob verwaltungsrechtli-

Rdn. 2; a. A. Peine, NJW 1990, 2444. Voraussetzung ist aber eine entsprechende gesetzliche Regelung. Daher ist die Rspr. abzulehnen, wonach Abwehransprüche gegen eine Anlage ausgeschlossen sind, falls sie gemeinwichtiger Natur ist $(B G H$, NJW 1970, 856; NJW 1984, 1242 f; s. aber auch $B G H Z$ 66, 40 f; kritisch Roth (Fn. 15), $\$ 906$ Rdn. 30).

87 Dies wurde vor allem im Bereich des $\$ 823$ Abs. 2 BGB herausgestellt; $B G H Z$ 40, 306/307; BayObLG, VersR 1978, 568; Steffen (Fn. 46), \$823 Rdn. 539, 545; Schäfer (Fn. 44), $₫ 823 \mathrm{Rdn} .578$. Bei Grundrechten ist man großzügiger.

88 S. oben II 1; II 4.

${ }^{89}$ S. dazu etwa Jarass, NJW 1987, $1328 \mathrm{ff}$.

90 Die Bindungswirkung ist keineswegs die bloße Folge der Bindungen, die den durch den Verwaltungsakt angewandten Normen zukommen. Einmal besitzen Verwaltungsakte in vielen Fällen Bindungswirkungen für das Privatrecht, ohne daß die angewandten Normen eine vergleichbare Wirkung entfalten. Zum zweiten läßt das Anknüpfen der Bindung an Verwaltungsakte die Bindung auch dann zum Tragen kommen, wenn der Verwaltungsakt rechtswidrig, aber wirksam ist.

${ }_{11}$ L.Schmidt, Unmittelbare Privatrechtsgestaltung durch Verwaltungsakt, 1975, $16 \mathrm{f}$; Maurer, Allgemeines Verwaltungsrecht, 6. Aufl. 1988, $160 \mathrm{ff}$; Stelkens in: Stelkens/Bonk/Leonhardt (Fn. 31), \$35 Rdn. 126; Meyer/Borgs, VwVfG, 2. Aufl. 1982, $\$ 35$ Rdn. 30; enger Forsthoff (Fn. 10), 209. Für eine Beschränkung auf Fälle der gewollten Bindung, Wertenbruch in: Festschrift für R.Schmidt, 1965, 101. 
che Normen eingehalten werden: allein die verwaltungsgerichtlich kontrollierte Exekutive oder auch der Zivilrichter ${ }^{92}$.

\section{Theoretischer Hintergrund}

Sucht man die privatrechtsbeeinflussende Wirkung des Verwaltungsrechts im Gesamtbau des Rechts und der Rechtsdogmatik zu verorten, dann bieten sich dazu verschiedene Ansätze bzw. Konzepte an, die sich gegenseitig nicht ausschließen, sondern jeweils bestimmte Aspekte unseres Problems zu erhellen vermögen.

\section{Dritt-bzw. Ausstrablungswirkung}

a) Wenn verwaltungsrechtliche Regelungen das Privatrecht beeinflussen, dann heißt das, daß eine Regelung, die eine Rechtsbeziehung zwischen Staat und Bürger steuert, über diese primäre Regelungswirkung hinaus in einer Rechtsbeziehung zwischen zwei Bürgern von Relevanz ist. Betrachtet man unser Thema aus dieser Perspektive, dann tritt es in Parallele zur Dritt- oder Ausstrahlungswirkung der Grundrechte ${ }^{93}$. Dort geht es ebenfalls um den Einfluß von - an sich das Verhältnis von Staat und Bürger steuernden - Normen auf die Beziehungen zwischen Privatpersonen ${ }^{94}$.

Eine solche Sicht kann sich darauf berufen, daß die Ausstrahlungswirkung der Grundrechte mit den in ihnen enthaltenen Wertentscheidungen bzw. objektivrechtlichen Grundsatznormen begründet wird $^{95}$. Interessanterweise spielt der Wertgehalt einer Norm auch bei der Abgrenzung der privatrechtsbindenden Normen des Verwaltungsrechts eine Rolle ${ }^{96}$, wenn auch nicht in allen Fallgruppen ${ }^{97}$.

92 Ähnlich Ossenbühl, DVBl. 1990, 964.

93 Dazu Stern, Das Staatsrecht der Bundesrepublik Deutschland, Bd. III/1 $1509 \mathrm{ff}$.

94 So gesehen sind die Ausstrahlungswirkung der Grundrechte wie die verwaltungsrechtlichen Vorgaben für das Privatrecht Teile eines größeren Themas: der Ausstrahlungswirkung des öffentlichen Rechts auf das Privatrecht.

${ }_{95} B V \operatorname{Verf} G E$ 7, 198/205 f; BVerfG, JZ 1990, 692; Jarass, AöR 110 (1985), $363 \mathrm{ff}$.

96 Im Bereich des $\$ 134$ BGB kommt es darauf an, ob eine Norm eine mißbilligende und damit wertende Entscheidung gegen das verbotene Verhalten trifft oder eine bloße Ordnungsregelung enthält; ganz ähnliche Argumente werden im Bereich des $\$ 1$ UWG verwandt (s. oben II 6). Allgemein zum systembildenden Charakter von Werten Peine, Das Recht als System, 1983, $76 \mathrm{ff}$.

97 Etwa im Bereich des $₫ 823$ Abs. 2 BGB. Immerhin wird Strafgesetzen im Zweifel ein Schutznormcharakter zuerkannt, während dies bei den Ordnungswidrigkeitentatbeständen gerade umgekehrt gesehen wird; Canaris in: Festschrift für Larenz, 1983, 50, 64, 75; zurückhaltender Schäfer (Fn. 44), $\$ 823$ Rdn. 593. 
Vergleichbar erscheint des weiteren die Differenzierung von unmittelbarer und mittelbarer Grundrechtsbindung einerseits und von privatrechtsbindender bzw. indizieller Wirkung des Verwaltungsrechts andererseits, zumal sich insoweit auch auf der Rechtsfolgenseite Parallelen zeigen werden ${ }^{98}$.

b) Ein wesentlicher Unterschied zwischen der Ausstrahlungswirkung der Grundrechte und der privatrechtsbeeinflussenden Wirkung des Verwaltungsrechts liegt darin, daß Grundrechte einen höheren Rang als das Privatrecht besitzen, während Verwaltungsrecht und Privatrecht grundsätzlich auf der gleichen Rangstufe stehen. Das erklärt, warum es, anders als im Verhältnis von Grundrechten und Privatrecht, nicht nur eine Ausstrahlungswirkung des Verwaltungsrechts auf das Privatrecht gibt, sondern auch eine Ausstrahlung des Privatrechts auf das Verwaltungsrecht ${ }^{99}$. So wird etwa die immissionsschutzrechtliche Erheblichkeit durch privatrechtliche Dienstbarkeiten beeinflußt ${ }^{100}$. Das Sozialversicherungsrecht stützt sich an vielen Stellen auf privatrechtliche Vorgaben ${ }^{101}$. Allerdings ist nicht zu übersehen, daß die Ausstrahlungswirkung des Privatrechts auf das Verwaltungsrecht erheblich seltener als die umgekehrte Ausstrahlungswirkung auftritt. Der Grund dafür dürfte vor allem darin liegen, daß das öffentliche Recht meist viel detailliertere Normierungen aufweist. Dementsprechend wird bei vagen Verwaltungsrechtsnormen eine privatrechtsbindende Wirkung nicht selten abgelehnt; andererseits werden Verwaltungsakte auch dort herangezogen, wo an sich nur auf Gesetze verwiesen wird ${ }^{102}$.

\section{Durchsetzung verwaltungsrechtlicher Standards}

Betrachtet man das Problem der verwaltungsrechtlichen Vorgaben für das Privatrecht aus der Sicht der Verwaltungswissenschaften, dann stößt man schnell auf das Thema der Implementation von Rechtsnor-

98 Ebenso wie eine unmittelbare Grundrechtsbindung kann auch eine privatrechtsbindende Wirkung des Verwaltungsrechts nur dort angenommen werden, wo sie gesetzlich vorgesehen ist; s. unten V 3.

${ }_{99}$ Ossenbübl, DVBl. 1990, 964.

100 OVG NW, UPR 1989, 390.

101 S. dazu in unserem Zusammenhang D.Schmidt (Fn. 1), 19. Des weiteren wird der öffentlich-rechtliche Abwehranspruch gegen hoheitliche Immissionen von der Regelung des $\$ 906$ BGB beeinflußt; Baur (Fn. 13), $\$ 906$ Rdn. 7 .

102 S. oben II 4; II 6. 
men, auf deren Durchsetzung und Vollzug ${ }^{103}$. Hintergrund des damit angesprochenen Forschungsfeldes ist die Einsicht, daß der Erlaß verwaltungsrechtlicher Standards allein soziale Konflikte nicht löst, auch wenn das nicht selten angenommen wird, daß es vielmehr entscheidend auf den Vollzug und die Umsetzung dieser Standards ankommt ${ }^{104}$.

Auf diesem Hintergrund lassen sich verwaltungsrechtliche Vorgaben für das Privatrecht als eine Verwendung privatrechtlicher Instrumente zur Durchsetzung verwaltungsrechtlicher Standards begreifen ${ }^{105}$. Das ist im Bereich des $\$ 823$ Abs. 2 BGB, des $\$ 134$ BGB oder des $\$ 1$ UWG besonders deutlich. Die Verletzung verwaltungsrechtlicher Festsetzungen wird durch privatrechtliche Reaktionen sanktioniert. Eine solche Sicht unserer Problemstellung läßt verständlich werden, warum (insbesondere im Bereich des $\$ 823$ BGB und des $\$ 134$ BGB) darauf abgestellt wird, ob das Verwaltungsrecht bereits einen ausreichenden Sanktionsapparat zur Verfügung stellt bzw. ob privatrechtliche Sanktionen zusätzlich sinnvoll sind ${ }^{106}$. Des weiteren kann diese Sicht den Befund erklären, daß privatrechtliche Sanktionen eher bei Verstößen zum Einsatz kommen, die den Verwaltungsbehörden in der Regel verborgen bleiben, etwa bei Verstößen gegen das Schwarzarbeits- oder das Rechtsberatungsgesetz ${ }^{107}$.

Nicht in allen Fällen der privatrechtsbeeinflussenden Wirkung paßt diese Sichtweise. Zum Teil verdrängt das Verwaltungsrecht das Privatrecht; denken Sie an die behandelten Präklusionsnormen. Hier spielt folglich die Durchsetzung verwaltungsrechtlicher Standards keine Rolle. Wo das aber der Fall ist, wirkt das Privatrecht verwaltungsrechtsunterstützend. Die zivilgerichtliche Durchsetzung tritt neben die verwaltungsgerichtliche Durchsetzung. Die vereinzelten Versuche, diese Parallelität abzuschwächen ${ }^{108}$, vermögen nicht $\mathrm{zu}$ überzeugen ${ }^{109}$. Selbst eine der letzten Bastionen der rein zivilrechtli-

${ }_{103}$ Zur Implementationsforschung etwa Mayntz (Hrsg.), Implementationpolitischer Programme, 1983; Mazmanian, Effective Policy Implementation, 1981.

$104 \mathrm{Vgl}$. Jarass, Jahrbuch des Umwelt- und Technikrechts, 1988, $97 \mathrm{ff}$.

105 Jarass (Fn. 104), 98.

106 Zu $₫ 823$ Abs. 2 BGB Steffen (Fn. 46), $\$ 823$ Rdn. 546. Zu $\$ 134$ BGB BGHZ 71, 362; Mayer-Maly (Fn. 54), \$134 Rdn. 3; Brox (Fn. 54), \$134 Rdn. 12.

107 S. oben II 5.

108 Konrad, BayVBl. 1984, 37; Schwerdtfeger, NVwZ 1983, 201.

109 Kloepfer (Fn. 12), 48 f; Peine, JuS 1987, 172; Roth (Fn. 15), \$906 Rdn. 10, 13; Baur in: Festgabe für Sontis, 1977, 191; Ossenbübl, DVBI. 1990, 968; Marburger (Fn. 16), C 42. 
chen Bewältigung von Nachbarkonflikten im Bereich der wasserrechtlichen Erlaubnis ist vor wenigen Jahren gefallen ${ }^{110}$.

\section{3. Überschreitung von Organisations- bzw. Systemgrenzen}

a) Schließlich läßt sich unser Problem als die Frage nach dem optimalen Grad der Organisationsdifferenzierung begreifen. Die Systemtheorie würde von der Abgrenzung von Teilsystemen mit jeweils eigenständiger Rationalität und der Problematik der Entdifferenzierung sprechen ${ }^{111}$. Das Verwaltungsrecht und das Privatrecht sind jeweils spezifischen Subsystemen anvertraut. Für die Auslegung und Anwendung des Verwaltungsrechts sind die Verwaltung und die Verwaltungsgerichte zuständig, für die Anwendung und Auslegung des Privatrechts die Zivilgerichte ${ }^{112}$. Beide Subsysteme besitzen eine spezifische Vollzugskultur. Die Frage nach den Vorgaben des Verwaltungsrechts für das Privatrecht wandelt sich in dieser Perspektive zur Frage nach dem Stellenwert von Entscheidungen der Verwaltung und der Verwaltungsgerichtsbarkeit für die Zivilgerichtsbarkeit ${ }^{113}$.

Die Bedeutung einer spezialisierten Gerichtsbarkeit für das entsprechende materielle Recht kann nicht hoch genug veranschlagt werden. Das allgemeine Verwaltungsrecht ist weithin ein Produkt der Verwaltungsgerichte ${ }^{114}$. Dementsprechend ist das (allgemeine) Verwaltungsrecht in den Ländern ohne eigene Verwaltungsgerichtsbarkeit weniger entwickelt. In den USA war noch bis in den dreißiger Jahren umstritten, ob es ein eigenständiges Administrative Law gibt, als eigenes Rechtsgebiet neben dem Common Law ${ }^{115}$. Die Bildung von Subsystemen erlaubt eine Spezialisierung und damit prinzipiell eine Erhöhung

110 BVerwG, DVBl. 1987, 1265; dazu Kunig, DVBl. 1988, $237 \mathrm{ff}$.

111 Vgl. dazu Lubmann, Politische Planung, 1971, $59 \mathrm{ff} ;$ Mayntz, Soziologie der öffentlichen Verwaltung, 3. Aufl. 1985, $12 \mathrm{ff}$.

112 Vergleichbare Subsystembildungen finden sich übrigens auch in der Wissenschaft sowie, wenn auch weniger ausgeprägt, in der Berufswelt; vgl. Ossenbühl, DVBl. 1990, 963.

113 In dieser Perspektive gehört auch der Stellenwert des sachlichen Verwaltungsrechts sowie von Verwaltungsakten für das Staatshaftungsrecht zu unserem Thema (vgl. Gerhardt, BayVBl. 1990, 553), etwa wenn die Zivilgerichte die Anwendung der Präklusionsregeln der $\$ \$ 214$ ff BauGB auf Entschädigungsansprüche wegen rechtswidriger Bebauungspläne ablehnen. Zur Bedeutung von Genehmigungen für das Staatshaftungsrecht Finkelnburg/Ortloff, Öffentliches Baurecht, Bd.2, 2. Aufl. 1990, 98 f; $B G H$, NJW 1985, 3027.

114 Jarass, DÖV 1981, $813 \mathrm{f}$; Jarass, DÖV 1985, $377 \mathrm{ff}$.

115 Jarass, DÖV 1985, $377 \mathrm{f}$. 
der Leistungsfähigkeit. In diesem Sinne definiert Lubmann in der ihm eigenen plakativen Form Gerechtigkeit „als adäquate Komplexität des Rechtssystems "116, wobei Komplexität in der Schaffung und Erhaltung autonomer Subsysteme besteht.

Auf diesem Hintergrund bedeutet die Beachtung verwaltungsrechtlicher Vorgaben durch die Zivilgerichte eine Überschreitung von Systemgrenzen. Das impliziert tendenziell eine Entspezialisierung und damit eine Reduzierung der Leistungsfähigkeit. Dazu kommt das Risiko widersprüchlicher Feststellungen, da die verwaltungsrechtlichen Vorgaben auch von den Verwaltungsgerichten bearbeitet wer$\operatorname{den}^{117}$. Die Beachtung von verwaltungsrechtlichen Regelungen im Privatrecht, die sicherlich zur Einheit der Rechtsordnung beiträgt, hat auf dem Systemhintergrund auch einen umgekehrten Effekt. Die Überschreitung der System- bzw. Organisationsgrenzen erzeugt Widersprüche.

Dieser Zusammenhang dürfte mit ein Grund für die Zurückhaltung der Zivilgerichte bei der Beachtung verwaltungsrechtlicher Vorgaben sein. Der Zivilrichter beschäftigt sich nur selten mit den Feinheiten des Verwaltungsrechts, weshalb das Fehlerrisiko groß ist, wenn er sich doch damit befaßt. So sucht er diese Situation möglichst zu vermeiden $^{118}$. Solange daher die Trennung von Zivil- und Verwaltungsgerichtsbarkeit fortbesteht, wird eine Beachtung von verwaltungsrechtlichen Vorgaben im Privatrecht im Prinzip besonders fehleranfällig sein. Das ist nicht nur bedauerlich, weil es damit im Einzelfall zu unzutreffenden Entscheidungen kommt. Gravierender ist, daß eine verstärkte Beschäftigung der Zivilgerichte mit dem Verwaltungsrecht zu Differenzen mit der Verwaltungsgerichtsbarkeit führen wird.

b) Die Folgeprobleme der Entdifferenzierung halten sich allerdings in Grenzen, wenn es ausreichende Mechanismen für die Abstimmung zwischen den Zivilgerichten einerseits und der Verwaltung bzw. der Verwaltungsgerichtsbarkeit andererseits gibt. Wenig Hoffnungen sollte man insoweit auf den Gemeinsamen Senat der Obersten Bundesgerichte setzen ${ }^{119}$. Das Instrument der Aussetzung des Zivilrechts-

116 Luhmann, Rechtssystem und Rechtsdogmatik, 1974, 23; ebenso Wagner (Fn. 33), 94.

117 S. oben IV 2.

118 Vgl. die Argumentation bei Diederichsen (Fn. 53), L 59.

119 Gerhardt, BayVB1. 1990, 550. Er kann nur angerufen werden, wenn sich der Rechtsstreit bereits auf der Ebene des Bundesverwaltungsgerichts bzw. des Bundesgerichtshofs befindet. 
streits kann nur wenig mehr leisten ${ }^{120}$; Herr Schröder hat dazu das Notwendige gesagt. Dagegen könnte eine gesicherte Bindung der Zivilgerichte an Verwaltungsakte und verwaltungsgerichtliche Entscheidungen die Folgeprobleme der Entdifferenzierung stark abschwächen. Eine echte Bindung an Verwaltungsakte besteht aber, wie noch zu erörtern sein wird, nur in Teilbereichen ${ }^{121}$. Eine Bindung an verwaltungsgerichtliche Entscheidungen besteht nur im Rahmen der Rechtskraft und ist damit auf die Parteien des Verwaltungsprozesses beschränkt ${ }^{122}$. Sie ist folglich in unserem Zusammenhang, in dem es um die Auswirkungen verwaltungsrechtlicher Regelungen auf die Beziehung zwischen zwei Bürgern geht, nicht nutzbar.

Zusammenfassend kann festgehalten werden, daß eine stärkere Bindung der Zivilgerichte an verwaltungsrechtliche Normen - neben den nicht zu verkennenden Vorteilen - Probleme für die sachgerechte und konsistente Fortentwicklung des Verwaltungsrechts durch die Rechtsprechung aufwirft. Eine unreflektierte, fachchauvinistische Befürwortung einer Dominanz des Verwaltungsrechts kann sich auch zu Lasten des Verwaltungsrechts auswirken.

\section{Nichtbeachtung der verwaltungsrechtlichen Legalität und die Einheit der Rechtsordnung}

\section{Die Fälle der Nichtbeachtung der verwaltungsrechtlichen Legalität}

a) Im letzten Teil soll aus dem weiten Feld unseres Themas den Fällen näher nachgegangen werden, in denen Verwaltungsrecht und Privatrecht in Konflikt geraten, weil die verwaltungsrechtliche Legalität im Privatrecht unbeachtet bleibt ${ }^{123}$. Sie haben in der bisherigen

\footnotetext{
120 Grundlage ist $\$ 148$ ZPO.

121 S. unten IV 3-5.

${ }_{122}$ Die Feststellung der Zivilgerichte, sie seien zwar nicht an Verwaltungsakte, wohl aber - aus Gründen der Rechtskraft - an Verwaltungsakte bestätigende Urteile der Verwaltungsgerichte gebunden ( $B G H Z$ 77, 338/341 f; 90, 4/12; 95, $238 \mathrm{ff} ; B G H$, DVBl. 1985, 1135; Roth [Fn. 15], $\$ 906$ Rdn. 35 f), betrifft durchweg Fälle des Verwaltungsprivatrechts oder des Staatshaftungsrecht und damit Beziehungen zwischen Staat und Bürger.

${ }^{123}$ Auf die Problemgruppe der ausreichenden Beachtung der verwaltungsrechtlichen Illegalität kann ich nicht näher eingehen; s. immerhin unten V 5. Dieses Problem stellt sich, wenn die Verletzung einer verwaltungsrechtlichen Norm im Bereich des $\$ 823$ Abs. 2 BGB, des $\$ 134$ BGB oder des $\$ 1$ UWG keine Berücksichtigung findet. Gravierende Spannungen zwischen Verwaltungsrecht und Privatrecht stellen sich hier sehr viel weniger. Vielmehr steht die sachgerechte Auslegung
} 
Diskussion besondere Aufmerksamkeit gefunden. Im Bereich des Nachbar- und Umweltrechts wird etwa kritisiert, wenn das Privatrecht einem Dritten das Recht gibt, ein bestimmtes Verhalten zu unterbinden, obgleich das Verhalten den offentlich-rechtlichen Vorgaben voll entspricht und dies vielleicht zudem durch einen behördlichen Bescheid bestätigt wurde ${ }^{124}$.

In diesem Bereich entwickelt unser Thema eine besondere Brisanz. Es stellt sich die Frage, ob nicht die Einheit der Rechtsordnung, verstanden als ihre Widerspruchsfreiheit, bedroht wird ${ }^{125}$. Das kann man nicht auf die leichte Schulter nehmen. Die Widersprucbsfreibeit ist ein unverzichtbares und zentrales Element der Rechtsordnung. Paul Kirchbof bezeichnet sie als "Geltungsgrund der Rechtsordnung“. Fritz Ossenbübl spricht von einem „obersten Prinzip der Rechtsordnung "126. Sie bildet denn auch den wesentlichen Kern des Grundsatzes der Systemgerechtigkeit ${ }^{127}$.

b) Ein Widerspruch kann in derartigen Fällen nur auftreten, wenn ein bestimmtes Verhalten durch das Verwaltungsrecht und das Privatrecht zumindest teilweise unter den gleichen Gesichtspunkten bewertet wird ${ }^{128}$. Fehlt es an einer solchen Überschneidung, ist ein Widerspruch ausgeschlossen. Wenn etwa eine Personbeförderungsgenehmigung für eine Omnibuslinie erteilt wird, steht das einer privatrechtlichen Klage gegen eine Haltestelle aus Lärmschutzgründen nicht entgegen, da der Lärm bei der Erteilung dieser Genehmigung keine Rolle spielt $^{129}$.

$\mathrm{Ob}$ es um die gleichen oder um verschiedene Gesichtspunkte geht, ist allerdings nicht immer so einfach zu beurteilen. Können zum Beispiel die Grenzwerte des Fluglärmgesetzes in privatrechtlichen Rechtsstreitigkeiten zur Beurteilung der Zumutbarkeit des Lärms herangezogen werden? Der Bundesgerichtshof hat das zu Recht abge-

und Anwendung der privatrechtlichen Rezeptionsnormen im Mittelpunkt (so auch Gerbardt, BayVB1. 1990, 553), wozu allerdings Verwaltungsrechtler mehr als bislang beitragen könnten.

124 S. etwa Gaentzsch, NVwZ 1986, 605.

125 Dazu Ossenbühl, DVBl. 1990, 967; Gerhardt, BayVBI. 1990, 550; Wagner (Fn. 33), 90 ff, 95.

126 Kirchbof, Unterschiedliche Rechtswidrigkeiten in einer einheitlichen Rechtsordnung, 1978, 8; Ossenbübl, DVBl. 1990, 967.

127 Peine (Fn. 96), $99 \mathrm{ff}$.

${ }_{128}$ Siehe auch das Beispiel bei Gerhardt, BayVBl. 1990, 550 zum Befähigungsnachweis.

$129 B G H$, DVBl. 1984, 473; ebenso BVerwG, DVBl. 1990, $774 \mathrm{ff}$. 
lehnt, weil das Fluglärmgesetz vor allem durch Baubeschränkungen künftige Kollisionsfälle gravierender Art vermeiden will, ohne ein Urteil über weniger gewichtige Fälle abzugeben ${ }^{130}$. Insgesamt muß immer genau geprüft werden, ob das Verwaltungsrecht und das Privatrecht tatsächlich auf die gleichen Gesichtspunkte abheben. Wenn das zutrifft, kann man von Konkurrenzfällen sprechen.

\section{Normwidersprüche und Wertungswidersprüche}

a) Die Beurteilung der unterschiedlichen Reaktion von Privatrecht und Verwaltungsrecht in solchen Konkurrenzfällen hängt zunächst davon ab, ob darin ein Normwiderspruch liegt oder ob man allenfalls einen Wertungswiderspruch annehmen kann. Ein Normwiderspruch besteht, wenn zwei Regelungen an den gleichen Tatbestand zwei miteinander unvereinbare Rechtsfolgen knüpfen ${ }^{131}$. $\mathrm{Er}{ }_{\text {}} m u \beta$ beseitigt werden, sei es dadurch, daß einer Norm der Vorrang zuerkannt wird, sei es dadurch, daß beide eingeschränkt werden, da es logisch undenkbar ist, daß einander ausschließende Rechtsfolgen nebeneinander eintreten “132.

In unserem Zusammenhang liegen die Voraussetzungen eines Normwiderspruchs vor, wenn das Verwaltungsrecht ein bestimmtes Verhalten einer Privatperson verbietet bzw. die Behörde ermächtigt, das Verhalten zu unterbinden, während das Privatrecht einem Dritten das Recht gibt, eben dieses Verhalten gerichtlich zu erzwingen. Solche Fälle sind selten, kommen aber vor. Man denke an eine Baumschutzsatzung, die das Fällen von Bäumen verbietet, wenn und soweit das private Nachbarrecht dem Nachbarn einen Anspruch auf Beseitigung von Bäumen in der Nähe der Grundstücksgrenze gibt ${ }^{133}$. Eine Konstellation dieser Art ist jedoch in den hier interessierenden Fällen der

$130 B G H Z 69,105 / 144 \mathrm{ff}$. Ein Wertungswiderspruch läge allenfalls vor, wenn die Grenzwerte des Fluglärmrechts überschritten sind und das Zivilrecht den Lärm gleichwohl als zumutbar einstufen würde. Das wäre aber eine unzureichende Berücksichtigung der verwaltungsrechtlichen Illegalität, nicht Legalität.

131 Larenz, Methodenlehre der Rechtswissenschaft, 1983, 256. Zum Teil wird auch von einem logischen Widerspruch gesprochen; Noll, Gesetzgebungslehre, 1973, 207; Peine (Fn. 96), 99 ff.

132 Larenz (Fn. 131), 321; Engisch, Einheit der Rechtsordnung, $46 \mathrm{ff} ;$ Bydlinski, Juristische Methodenlehre und Rechtsbegriff, 1982, 463 f; Peine, JZ 1990, 210.

133 Ein solcher Anspruch ist in den Nachbarrechtsgesetzen der Länder vorgesehen. 
verwaltungsrechtlichen Legalität regelmäßig nicht gegeben. Wenn ein bestimmtes Verhalten den verwaltungsrechtlichen Vorgaben entspricht, dann schreibt das Verwaltungsrecht dieses Verhalten nicht vor, sondern läßt es nur zu. Soweit daher das Privatrecht einem Dritten das Recht gibt, dieses Verhalten zu unterbinden oder wegen dieses Verhaltens Schadensersatz zu verlangen, liegt darin kein logischer Widerspruch und damit kein Normwiderspruch ${ }^{134}$. Auch sind aus diesem Grunde die Voraussetzungen einer echten Spezialität nicht gegeben ${ }^{135}$. Was sich dagegen aufdrängt, ist ein Wertungswiderspruch.

b) Mit der Kategorie des Wertungswiderspruchs sind Fälle gemeint, in denen die unterschiedlichen Folgen zweier Normen zwar logisch miteinander vereinbar sind, die zugrunde liegenden Wertungen einander aber widersprechen ${ }^{136}$ bzw. die Befolgung der einen Norm dem Zweck der anderen Norm widerspricht ${ }^{137}$. Die Kategorie der Wertungswidersprüche ist in ihrer Abgrenzung viel diffuser als die Kategorie des Normwiderspruchs ${ }^{138}$. Was ihre Behandlung angeht, so haben insbesondere Engisch und Larenz herausgearbeitet, daß Wertungswidersprüche nach Möglichkeit aufgelöst werden sollen, daß dies aber nicht notwendig geschehen muß ${ }^{139}$. Gegenläufige Gesichtspunkte, wie etwa Zieldifferenzierungen, können rechtfertigend wirken, wenn nicht gar den Widerspruch beseitigen ${ }^{140}$. Die Entscheidung darüber, ob die Zivilgerichte in den Konkurrenzfällen an die verwaltungsrechtlichen Vorgaben zu binden sind, läßt sich daher nicht

134 Ebenso Peine, NJW 1990, 2446. Darüber hinaus wäre ein Normwiderspruch denkbar, wenn die Entscheidung des Verwaltungsrechts über die Rechtmäßigkeit des Verhaltens für das gesamte Recht bindend wäre. Das kann aber, wie dargelegt, in der Regel nicht angenommen werden; s. unten V 3, aber auch V 5.

135 Dieser Grundsatz kommt nur dort zum Tragen, wo der Tatbestand der spezielleren Norm alle Merkmale der allgemeineren Norm enthält und darüber hinaus zumindest ein zusätzliches Merkmal; Larenz (Fn.131), $256 \mathrm{f}$. Für eine Spezialität baurechtlicher Regelungen jedoch Peine, JuS 1987, 173.

136 Larenz (Fn. 131), 321. Zum Teil wird insoweit von einem axiologischen Widerspruch gesprochen; Noll (Fn. 131), 207 f; Peine (Fn. 96), $102 \mathrm{ff}$.

137 Insoweit kann man auch von einem teleologischen Widerspruch sprechen; Noll (Fn. 131), 208; Peine (Fn. 96), 104 ff. Von einer Gleichsetzung axiologischer und teleologischer Widersprüche geht offensichtlich Canaris, Systemdenken und Systembegriff in der Jurisprudenz, 1969, 47 aus.

138 Vgl. Peine (Fn. 96), $102 \mathrm{ff}$.

139 Engisch (Fn. 132), 63; Larenz (Fn. 131), 321; Noll (Fn. 131), 208; a. A. Peine (Fn. 96), 105, der alle Widersprüche als logische einstuft.

140 Näher dazu Kirchbof (Fn. 126), 32 ff. 
pauschal und generell mit der Widerspruchsfreiheit der Rechtsordnung begründen. Vielmehr kommt es auf weitere Gesichtspunkte an. Das macht eine differenzierende Analyse erforderlich, wenn die Folgen für das Problem der verwaltungsrechtlichen Legalität gezogen werden.

\section{Der Einfluß der Genebmigungskonformität}

Kommen wir zunächst zu der durch eine Einzelfallentscheidung vermittelten Legalität, vor allem also zur Bindung der Zivilgerichte an die Genehmigungskonformität. Eine solche Bindung besteht sicherlich in den Fällen, in denen das entsprechende Gesetz sie vorsieht, insbesondere bei Genehmigungen, die mit einer Präklusionswirkung verbunden sind. Problematisch ist sie hingegen bei Genehmigungen, bei denen eine solche Regelung fehlt oder gar eine Präklusion ausdrücklich ausgeschlossen wird ${ }^{141}$, und die im folgenden als einfache Genehmigungen bezeichnet werden.

Das positive Recht spricht in solchen Fällen eher gegen eine Bindung der Zivilgerichte, auch wenn es nicht völlig ausgeschlossen ist, statt des Umkehrschlusses einen Analogieschluß zu ziehen. Wichtiger sind verfassungsrechtliche Bedenken gegen eine pauschale Bindungswirkung von einfachen Genehmigungen. Anders als die Genehmigungen mit ausdrücklicher Präklusionswirkung gewähren sie für die Verkürzung der privatrechtlichen Positionen keine Kompensation, etwa einen Anspruch gegen den Staat ${ }^{142}$. Sie sehen auch keine Anhörung des Drittbetroffenen vor ${ }^{143}$; bemerkenswerterweise beschränkt etwa $\$ 23$ GenTG die Präklusion auf Genehmigungen, die nach einer Öffentlichkeitsbeteiligung ergehen. Private Rechte ohne derartige Kompensationen abzuschneiden ist jedenfalls nicht in allen Anwendungsfällen mit den Grundrechten vereinbar ${ }^{144}$, zumal Prüfungsge-

$141 \$ 19$ Abs. 2 BImSchG für die vereinfachte immissionsschutzrechtliche Genehmigung. Die baurechtliche Genehmigung ergeht unbeschadet privater Rechte; vgl. etwa $\$ 75$ Abs. $7 \mathrm{NdsBauO}$.

142 So können im Rahmen des Planfeststellungsverfahrens Entschädigungsansprüche begründet werden.

${ }^{143}$ Genehmigungen, denen eine Präklusionswirkung zukommt, ergehen regelmäßig in einem förmlichen Verfahren. Bemerkenswerterweise schließt $\$ 23$ GenTG eine Präklusionswirkung für Genehmigungen ohne Öffentlichkeitsbeteiligung aus.

${ }_{144}$ Wagner (Fn. 33), $203 \mathrm{ff}$ (allerdings sehr weitgehend); Ossenbübl, DVBl. 1990, 967. 
genstand dieser Genehmigungen regelmäßig allein die öffentlichrechtlichen Vorgaben sind, die Genehmigungsbehörde über die Verkürzung der privaten Rechte also überhaupt nicht nachzudenken braucht. Eine echte Bindung der Zivilgerichte an verwaltungsrechtliche Genehmigungen ist daher nur akzeptabel, wenn sie ausdrücklich gesetzlich geregelt ist ${ }^{145}$ und zudem die verfassungsrechtlichen Voraussetzungen eingehalten werden.

Daran vermag auch die einem Verwaltungsakt zukommende Bindungswirkung, außer in den noch zu erörternden Fällen des derivativen Privatrechts, nichts zu ändern. Mit den damit angesprochenen Stichworten der Tatbestands- und der Feststellungswirkung, der Gestaltungswirkung oder ganz allgemein der Bestandskraft ${ }^{146}$ begibt man sich auf ungesichertes Gelände. Wieweit etwa die Feststellungen einer Genehmigung auch für Beziehungen des Adressaten zu anderen als der entscheidenden Behörde und damit innerhalb des Verwaltungsrechts verbindlich sind, ist bekanntlich umstritten ${ }^{147}$. Noch problematischer wird dies naturgemäß, wenn die Bindungswirkungen auf die Beziehungen zwischen dem Adressaten und einer dritten Privatperson erstreckt werden sollen ${ }^{148}$.

Die Ablehnung einer echten Bindung der Zivilgerichte an einfache Genehmigungen läßt allerdings das Problem eventueller Wertungswidersprüche ungelöst. Daher ist es bedeutsam, daß die dargestellten Bedenken gegen eine privatrechtsbindende Wirkung der Genehmigungskonformität für eine lediglich indizielle Wirkung nicht oder doch sehr abgeschwächt gelten. In den Konkurrenzfällen ist daher einer Genehmigung eine indizielle Wirkung zuzuerkennen ${ }^{149}$. Die Zivilgerichte müssen die Genehmigungserteilung als Anhaltspunkt

${ }^{145}$ H. A., etwa Peine, NJW 1990, $2445 \mathrm{ff}$; Wagner (Fn. 33), $203 \mathrm{ff}$. Liegt eine solche Bindung vor, kommt die Bindung auch bei rechtswidrigen Genehmigungen zum Tragen, sofern kein Rechtsmißbrauch vorliegt; dazu Wagner (Fn. 33), $243 \mathrm{ff}$, 256; Peine, NJW 1990, 2448 f. $69 \mathrm{ff}$.

${ }_{146}$ Ausführlich Seibert, Die Bindungswirkung von Verwaltungsakten, 1969,

147 Vgl. etwa $B$ VerwG, NVwZ 1990, 559; DVBl. 1990, 57 f; OVG NW, NVwZ 1985, 356; Seibert (Fn. 146), $353 \mathrm{ff}, 395 \mathrm{ff} ;$ Fluck, VerwArch 79 (1988), $406 \mathrm{ff}$; Staupe, DVBl. 1988, 609ff; Peine, JZ 1990, 201; Wagner (Fn. 33), $40 \mathrm{ff} ;$ Kollmann, DÖV 1990, 189; Gerhardt, BayVBl. 1990, 554; Jarass, Konkurrenz, Konzentration und Bindungswirkung von Genehmigungen, 1984, $68 \mathrm{ff}$.

${ }_{1+8}$ Hier eine volle Bindung allein wegen der Natur des Verwaltungsakts anzunehmen, würde bedeuten, daß der Dritte kein bloßer Dritter, sondern ebenfalls Adressat des Verwaltungsakts würde.

${ }^{149}$ Auch sie ermöglicht den Zivilgerichten eine Aussetzung gemäß $\$ 148$ ZPO. 
beachten - was gegenwärtig noch sehr unzureichend geschieht -, können aber auch zu einem abweichenden Votum gelangen.

\section{Der Einfluß der Verwaltungsnormkonformität}

Damit komme ich zu der Frage, wie es mit der Bindung der Zivilgerichte an die durch Verwaltungsnormen vermittelte Legalität bestellt ist. Können die Zivilgerichte ein Verhalten im Hinblick auf bestimmte Gesichtspunkte als rechtswidrig einstufen, obwohl das Verhalten den Verwaltungsnormen entspricht, in denen die gleichen Gesichtspunkte eine Rolle spielen?

a) Eine Bindung der Zivilgerichte an Normen des Verwaltungsrechts ist bislang vor allem für Bebauungspläne gefordert worden und sei daher für sie etwas näher analysiert. Gegen eine echte Bindung an Bebauungspläne spricht zunächst, daß ein Bebauungsplan bereits innerhalb des Verwaltungsrechts die konkreten Anforderungen anderer Normen nicht pauschal auszuschalten vermag, etwa die Anforderungen des Immissionsschutz- oder des Gaststättenrechts ${ }^{150}$. Des weiteren ist zu beachten, daß Bebauungspläne die konkreten Konflikte, um die es im Privatrecht geht, nur in sehr vager Form behandeln können. So richtig es ist, daß ein Bebauungsplan die kollidierenden privaten Interessen zum Ausgleich bringen soll ${ }^{151}$, so richtig ist es auch, daß dieser Ausgleich nicht alle Einzelheiten aller möglichen Konflikte im Anwendungsbereich des Bebauungsplans zu erfassen vermag ${ }^{152}$. Wenn ein Gewerbegebiet ausgewiesen wird, dann liegt darin keine Entscheidung, daß alle von Gewerbebetrieben erzeugten Belastungen, und seien sie auch nur durchschnittlicher Art, hingenommen werden müßten. Mit derart weitreichenden Festlegungen wäre die planaufstellende Behörde völlig überlastet. Das Bundesverwaltungsgericht hat zu Recht darauf hingewiesen, daß in einem Bebauungsplan - trotz des Grundsatzes der Konfliktbewältigung nicht alle nachbarlichen Konflikte gelöst werden können und müssen, daß ein Teil von ihnen vielmehr in den Genehmigungen abzuarbeiten ist $^{153}$. Der Bebauungsplan kann insoweit nur so etwas wie ein vorläufiges positives Gesamturteil (im untechnischen Sinne) enthalten. Das

\footnotetext{
150 Hagen, UPR 1985, 197.

151 Vgl. Peine, JuS 1987, 174.

152 So auch Hagen, UPR 1985, $198 \mathrm{f}$.

153 OVG Berlin, DVBl. 1984, $147 \mathrm{ff}$; Sendler, WiVerw. 1985, $211 \mathrm{ff}$; Battis/ Krautzberger/Löhr, BauGB, 2. Aufl. 1987, \$9 Rdn. 4, 89.
} 
gilt für die Errichtung von Gebäuden, noch mehr aber für deren Nutzung, auf die es im Privatrecht regelmäßig ankommt. All dem wird eine echte Bindung der Zivilgerichte an Bebauungspläne nicht gerecht ${ }^{154}$, vor allem auch deshalb ,- und das hat besonderes Gewicht -, weil häufig selbst der Begründung eines Bebauungsplans nicht genau zu entnehmen ist, wieweit die konkreten Einzelkonflikte thematisiert und behandelt wurden.

Wenn demgegenüber für eine Bindung der Zivilgerichte an Bebauungspläne angeführt wird, sie sei erträglich, weil und soweit die Zivilgerichte über die Rechtmäßigkeit und damit über die Wirksamkeit des Bebauungsplanes entscheiden können ${ }^{155}$, dann ist dieses Argument wegen der Ausschlußvorschriften der $\$ \$ 214 \mathrm{ff}$ BauGB Bedenken ausgesetzt. Vor allem aber steht einer echten Privatrechtsbindung das erörterte Problem der widersprüchlichen Auslegung von Verwaltungsnormen durch Zivilgerichte und Verwaltung bzw. Verwaltungsgerichtsbarkeit entgegen ${ }^{156}$.

Was bleibt, ist die Gefahr der Behinderung planerischer Gestaltung durch das Privatrecht. Nun sollte man diese Gefahr nicht überschätzen. Ossenbübl hat nicht ganz Unrecht, wenn er "den praktischen Konfliktsfall, der von den Zivilgerichten in untragbarem Widerspruch zur öffentlichen Bau- und Planungsordnung entschieden worden wäre" ${ }^{\text {"157 }}$, vermißt. Gleichwohl sollte die Gefahr einer Behinderung der Bauleitplanung nicht ganz außer Betracht bleiben. Bebauungsplänen kann und muß deshalb eine indizielle Wirkung zuerkannt werden, die etwa für die Wesentlichkeit i.S.d. $\$ 906$ BGB bedeutsam werden kann ${ }^{158}$. Dem Bebauungsplan wird dabei um so größeres Gewicht zukommen, je genauer er auf den betreffenden Konflikt belegbar eingegangen ist ${ }^{159}$.

154 Im Ergebnis ebenso Hagen, UPR 1985, $196 \mathrm{ff}$; Marburger (Fn. 16), C $102 \mathrm{ff}$; Diederichsen (Fn. 53), L 58 ff; a. A. Papier (Fn. 21), 104 ff; Gerlach, JZ 1988, 173.

155 Ossenbühl, DVBl. 1990, 966.

156 S. oben IV 3.

157 Ossenbühl, DVBl. 1990, 969; ebenso Marburger (Fn. 16), C 105 f.

158 Anerkanntermaßen beeinflußt die bauplanerische Ausweisung die Erheblichkeit von Umweltbeeinträchtigungen im Immissionschutzrecht; BVerw $G, N V w Z$ 1983, 155 f; Jarass (Fn. 86), $\$ 3$ Rdn. 30. Wenn daher der BGH die Wesentlichkeit von Beeinträchtigungen i.S.d. $\$ 906$ BGB als mit den erheblichen Umweltbeeinträchtigungen im Sinne des Bundes-Immissionsschutzgesetzes kongruent erklärt (oben Fn. 14), kann auf diesem Weg die bauplanerische Ausweisung auch im Bereich des $\$ 906$ BGB Wirkungen entfalten; vgl. Gaentzsch, NVwZ 1986, 604.

159 Im Ergebnis kann man daher die Ausführungen von Gerlach, JZ 1988, 173 weithin akzeptieren. 
b) Dieses Ergebnis dürfte sich verallgemeinern lassen, auch wenn aus Zeitgründen dem nicht nachgegangen werden kann. Der durch Verwaltungsrechtsnormen vermittelten Legalität kommt eine bindende Wirkung nur zu, wo das Gesetz sie vorsieht ${ }^{160}$. Im übrigen hat die Legalität (in Konkurrenzfällen) eine indizielle Wirkung, die vor allem dort praktische Wirkungen entfaltet, wo das Verwaltungsrecht erheblich detaillierter als das Privatrecht ist. Dann entwickelt sich die an sich gegebene wechselseitige Beeinflussung zu einer Einbahnstraße vom Verwaltungs- zum Privatrecht ${ }^{161}$. Das muß von den Zivilgerichten stärker als bisher beachtet werden. Ihnen ist, um mit Kloepfer zu sprechen, die Harmonisierung von öffentlichem und privatem Recht, namentlich im Bereich des Umweltschutzes, aufgegeben $^{162}$.

\section{Verwaltungsnormkonformität vs. Verwaltungsaktskonformität}

Eine besondere Variante des Problems verwaltungsrechtlicher Legalität ergibt sich schließlich, wenn ein Zivilgericht einen Verstoß gegen verwaltungsrechtliche Vorschriften annimmt und daraus privatrechtliche Konsequenzen zieht, obwohl die Exekutive in einer Genehmigung das fragliche Verhalten als verwaltungsrechtskonform eingestuft hat ${ }^{163}$. Das Gericht erkennt etwa einen Schadensersatzanspruch wegen der Verletzung baurechtlicher Normen zu, obwohl eine Baugenehmigung erteilt wurde. Fälle dieser Art treten nur auf, wo Privatrechtsnormen an das Verwaltungsrecht anknüpfen. In Anlehnung an die Terminologie im Nachbarrecht ${ }^{164}$ geht es um Fälle des derivativen Privatrechts. Hier stellt sich die Frage, was von den Zivilgerichten beachtet werden muß: die in ihrer Sicht aus Normen des Verwaltungsrechts folgende Illegalität oder die durch den Verwaltungsakt vermittelte Legalität. Es geht um die Frage der Konkretisierungskompetenz ${ }^{165}$.

\footnotetext{
160 Soweit ersichtlich, ist das bislang nirgends geschehen. Bei den Fällen der echten Bindung an Verwaltungsrechtsnormen geht es immer um die Beachtung der verwaltungsrechtlichen $I$ legalität.

161 Im Einzelfall mag die indizielle Wirkung fast einer Bindung gleichkommen, etwa bei den Zeitvorgaben der RasenmäherVO.

162 Kloepfer, Umweltrecht, 1990, $\$ 4$ Rdn. 302.

${ }_{163} \mathrm{Zu}$ diesem Problem in größerem Zusammenhang Engisch (Fn. 132), $13 \mathrm{ff}$.

164 Etwa Breuer, DVBl. 1983, 438; Baur (Fn. 13), \$903 Rdn. 76.

165 Vgl. dazu Mertens (Fn. 45), $\$ 823$ Rdn. 154 a.
} 
Die Zivilgerichte sind an die Konkretisierung durch den Verwaltungsakt sicherlich gebunden, wenn und soweit dem Verwaltungsakt kraft gesetzlicher Regelung eine Bindungswirkung zukommt ${ }^{166}$. Eine Bindung der Zivilgerichte ist darüber hinaus (im Bereich des derivativen Privatrechts) anerkannt, wenn der Verwaltungsakt hinsichtlich der für das Privatrecht bedeutsamen Normen des Verwaltungsrechts gestaltenden Charakter hat ${ }^{167}$. Wenn etwa von einer drittschützenden Baurechtsnorm eine Befreiung erteilt wird, dann kann nicht ein Schadensersatzanspruch wegen Verletzung dieser Norm gewährt wer$\operatorname{den}^{168}$. Entsprechendes gilt für eine ladenschlußrechtliche Ausnahmegenehmigung.

Unsicher ist dagegen, ob dies auch gilt, soweit Verwaltungsakte Feststellungen treffen ${ }^{169}$. Für eine Gleichbehandlung von gestaltenden und feststellenden Entscheidungsgehalten spricht, daß andernfalls die Bestandskraft von Verwaltungsakten unschwer unterlaufen werden kann $^{170}$. Ist etwa streitig, ob ein Bauvorhaben die baurechtlichen Abstandsvorschriften einhält und hat der Nachbar die Anfechtung der Baugenehmigung versäumt, könnte die Frage über einen quasi-negatorischen Unterlassungsanspruch doch noch gerichtlich erörtert werden. Das wäre ein Wertungswiderspruch, der einem Normwiderspruch nahekommt. Soweit daher ein Verwaltungsakt verbindlich die Vereinbarkeit eines Verhaltens mit bestimmten öffentlich-rechtlichen Normen feststellt, muß daran - wegen der dem Verwaltungsakt eigenen Bindungswirkung ${ }^{171}$ - auch der Zivilrichter (im Bereich des derivativen Privatrechts) gebunden $\operatorname{sein}^{172}$. Damit wird zudem die

166 Beispiele liefern die Präklusionsnormen.

167 Allgemeine Auffassung, etwa Breuer, DVB1. 1983, 438.

${ }_{168} B G H Z$ 66, 354/356 f. Als Begründung wird meist angeführt, daß der Verwaltungsakt das materielle Recht ändert; Ossenbübl, DVB1. 1990, 968.

${ }^{169}$ Dafür Breuer, DVBl. 1983, 438; Baur (Fn. 13), \$903 Rdn. 76; Ossenbühl, DVBl. 1990, 968; dagegen Mertens (Fn. 45), \$823 Rdn. 154 a; Marburger, Die Regeln der Technik im Recht, 1979, $482 \mathrm{f}$. Die zivilgerichtlichen Entscheidungen, in denen eine Bindung an die Baugenehmigung abgelehnt wurde, betreffen soweit ersichtlich - ausnahmslos keine verwaltungsderivativen Fälle.

170 Des weiteren spricht für die Gleichbehandlung die Unsicherheit der Abgrenzung von gestaltenden und feststellenden Entscheidungen; vgl. Seibert (Fn. 146), $117 \mathrm{f}$. Dagegen kann man anführen, daß die Bindungswirkung feststellender Verwaltungsakte bereits innerhalb des Verwaltungsrechts besonders umstritten ist.

171 Dazu oben V 3.

172 Allerdings kann er der Nachbarklage gestützt auf originäres Privatrecht stattgeben; insoweit hat er nur die indizielle Wirkung der Genehmigung zu beachten. Die Bedeutung des Streits darf daher nicht überschätzt werden. 
Beurteilungs- und Entscheidungskomptenz der Verwaltung für die Anwendung des Verwaltungsrechts sichergestellt.

Allerdings dürfen die im einzelnen häufig unsicheren Grenzen des Aussagegehalts eines feststellenden Verwaltungsakts nicht unbeachtet bleiben ${ }^{173}$. Die Feststellung der Rechtmäßigkeit einer Gaststätte in einer Baugenehmigung enthält etwa keine bindenden Feststellungen dazu, ob der Betrieb der Gaststätte den rechtlichen Vorgaben entspricht ${ }^{174}$. Für diese Frage liefert die Baugenehmigung allenfalls Anhaltspunkte.

\section{Schluß}

Summiert man die gewonnenen Befunde, dann zeigt sich, daß die Zuordnung von Verwaltungsrecht und Privatrecht bzw. von Exekutiventscheidungen und zivilgerichtlichen Entscheidungen in weiten Bereichen durch Berücksichtigung der verwaltungsrechtlichen Regelungen, nicht aber durch eine Bindung an sie gekennzeichnet ist. Das kann man, auch im Hinblick auf den Verwaltungsrechtsvollzug, hinnehmen. Die negativen Rückwirkungen der Eigenständigkeit der Zivilgerichtsbarkeit auf den Vollzug des Verwaltungsrechts können, soweit sie überhaupt auftreten, in aller Regel hingenommen werden. Die Situation stellt sich insoweit völlig anders dar als im Verhältnis von Strafrecht und Verwaltungsrecht ${ }^{175}$. Wenn das von den Strafgerichten nicht immer beachtet wird, liegt die Schuld dafür allerdings nicht notwendig bei den Strafgerichten. Denkbar ist auch, daß der Vollzug von Verwaltungsrechtsnormen derart im argen liegt, daß die Strafgerichte sich zu einer Korrektur veranlaßt sehen. Die Korrektur führt dann zu gravierenden Problemen. Der eigentliche Grund für diese Schwierigkeiten liegt in solchen Fällen aber in den Vollzugsdefiziten der Verwaltung, die ihrerseits auf noch tieferliegende Probleme, auch des materiellen Rechts, verweisen können ${ }^{176}$. Das sollte man im Auge behalten.

$173 \mathrm{Zu}$ restriktiv jedoch Kollmann, DÖV 1990, $193 \mathrm{ff}$.

174 Zur Frage, ob die Baugenehmigung überhaupt verbindliche Feststellungen neben der Freigabe enthält: Seibert (Fn. 146), 335 ff, 353. Zur Reichweite der immissionsschutzrechtlichen Genehmigung, BVerwG, UPR 1990, $154 \mathrm{f}$.

175 Zum Strafrecht etwa Ossenbübl, Gutachten zum 57. Deutschen Juristentag, 1988, L 42; Breuer, DÖV 1987, $169 \mathrm{ff}$.

176 Für die Bundesrepublik könnte man etwa fragen, ob die Spannungen zwischen Strafrecht und Steuerrecht in der Parteispendenaffäre nicht auf die unzureichenden "Checks and balances", denen die Parteien unterliegen, zurückzuführen sind. 
Im Verhältnis von Privatrecht und Verwaltungsrecht spielen derartige Probleme, wenn überhaupt, äußerst selten eine Rolle. Gleichwohl ist die skizzierte Einsicht auch hier von Nutzen: Die Ausstrahlungswirkung des Verwaltungsrechts auf das Privatrecht ist eine Folge der Leistungsfähigkeit des öffentlichen Rechts und seiner Umsetzung. Wenn es eine Aufgabe unserer Vereinigung ist, zur Leistungsfähigkeit des öffentlichen Rechts beizutragen, dann ist die Publifizierung und Verdrängung des Privatrechts ein gutes Zeichen. Allerdings darf man das Pferd nicht am Schwanze aufzäumen: Man kann nicht die weitere Publifizierung des Privatrechts unabhängig von der Leistungsfähigkeit des öffentlichen Rechts verlangen. Vielmehr gilt es die Leistungsfähigkeit des öffentlichen Rechts auszubauen; dann wird auch seine Ausstrahlungswirkung auf das Privatrecht weiter zunehmen. 
Leitsätze des 2. Berichterstatters über:

\section{Verwaltungsrecht als Vorgabe für Zivil- und Strafrecht}

Die Vorgaben des Verwaltungsrechts für das Privatrecht

\section{Einleitung}

1. Trotz der vielfach konstatierten Publifizierung und Verdrängung des Privatrechts durch das öffentliche Recht ist der Einfluß des Verwaltungsrechts auf das Privatrecht dogmatisch noch wenig aufbereitet.

\section{Problembeschreibung anhand ausgewählter Problemfelder}

2. Bei der Anwendung des $₫ 906$ BGB greift die Rechtsprechung bei verschiedenen Tatbestandsvoraussetzungen auf immissionsschutzrechtliche Vorgaben zurück, siebt in ibnen aber regelmäßig nur Anhaltspunkte. Was das öffentliche Baurecht angeht, ist die Rechtsprechung noch zurückhaltender.

3. Erhebliches praktisches Gewicht hat der Umstand, daß die Überschreitung von Grenzwerten der TA Luft als Indiz für die Ursächlichkeit einer Anlage gewertet wird. Im Entwurf des neuen Umwelthaftungsgesetzes wird dieser Ansatz aufgegriffen und erweitert.

4. Verschiedene, in einem förmlichen Verfabren zu erteilende Genebmigungen und Zulassungen schließen kraft ausdrücklicher Regelung privatrechtliche Ansprüche aus. Gleichwohl spielt die Präklusionswirkung in der Zivilrechtsprechung fast keine Rolle. Bei einfachen Genebmigungen, bei denen eine Präklusionswirkung fehlt, lehnt die herrschende Auffassung eine Bindung der Zivilgerichte $a b$.

5. Bei deliktischen Schadensersatzansprüchen spielen Regelungen des Verwaltungsrechts als Schutzgesetze i.S.d. $\int 823$ Abs. 2 BGB eine Rolle. Darüber hinaus werden im Bereich des $₫ 823$ Abs. 1 BGB zum Teil die durch Genebmigungen verliebenen Rechte als geschützte subjektive Rechte eingestuft. Des weiteren kann die Beeinträchtigung 
verwaltungsrechtlicher Pflichten einen Anbaltspunkt für die Verletzung von Verkehrssicherungspflichten liefern. Endlich spielen verwaltungsrechtliche Regelungen im Rabmen der Rechtswidrigkeit und des Verschuldens gelegentlich eine Rolle.

6. Die Gültigkeit von (privaten) Rechtsgeschäften hängt über $\int 134$ $B G B$ teilweise von der Einhaltung verwaltungsrechtlicher Vorschriften ab. Dabei wird zwischen Verbotsgesetzen und Ordnungsvorschriften unterschieden.

7. Die Frage, ob ein Wettbewerbsverhalten, das gegen verwaltungsrechtliche Regelungen verstößt, sittenwidrig i.S.d. $\mathbb{1}$ UWG ist, wird differenziert beantwortet: Die Verletzung bestimmter Regelungen ist generell sittenwidrig, die Verletzung anderer Regelungen nur dann, wenn weitere Umstände hinzutreten.

III. Systematisierung der privatrechtsbeeinflussenden Wirkung verwaltungsrechtlicher Regelungen

8. Hinsichtlich der Intensität des verwaltungsrechtlichen Einflusses auf das Privatrecht lassen sich drei Stufen unterscheiden:

- Die Vorgaben müssen zwingend beachtet werden (privatrechtsbindende Wirkung).

- Die Vorgaben bilden einen zu beachtenden Anbaltspunkt (indizielle Wirkung).

- Die Vorgaben spielen keine rechtliche Rolle.

9. Die Grundlage für den Einfluß des Privatrechts findet sich zum Teil im Privatrecht selbst, wenn es auf verwaltungsrechtliche Regelungen verweist oder wenn bei der Auslegung privatrechtlicher Normen verwaltungsrechtliche Vorgaben genutzt werden. In anderen Fällen folgt der verwaltungsrechtliche Einfluß aus entsprechenden Bestimmungen des Verwaltungsrechts.

10. Einfluß auf das Privatrecht nebmen zunächst verwaltungsrechtliche Gesetze, Rechtsverordnungen und Satzungen. Dies geschieht um so eber, je detaillierter diese Regelungen sind. Einfluß nebmen des weiteren Verwaltungsvorschriften, denen generell nur eine indizielle Wirkung zukommt. Schließlich liefern Verwaltungsakte, vor allem Genehmigungen, Vorgaben für das Privatrecht, und zwar durchweg in privatrechtsbindender Form. Damit erstreckt sich unser Thema nicht nur auf die Normebene, sondern auch auf die Vollzugsebene. 


\section{Theoretischer Hintergrund}

11. Der Einfluß des Verwaltungsrechts auf das Privatrecht stebt in einer gewissen Parallele zur Ausstrablungswirkung der Grundrecbte auf das Privatrecht. In beiden Bereichen spielt der Wertgehalt der Einfluß nebmenden Norm des öffentlichen Rechts eine Rolle. Ein wesentlicher Unterschied liegt darin, daß Grundrechte einen böheren Rang als das Privatrecht besitzen, wäbrend Verwaltungsrecht und Privatrecht grundsätzlich auf der gleichen Rangstufe steben.

12. Aus der Sicht der Verwaltungswissenschaften kann man die Beachtung verwaltungsrechtlicher Vorgaben für das Privatrecht als eine Verwendung privatrechtlicher Instrumente zur Durchsetzung verwaltungsrechtlicher Standards begreifen. Eine solche Sicht läßt verständlich werden, warum darauf abgestellt wird, ob das Verwaltungsrecht bereits einen ausreichenden Sanktionsapparat zur Verfügung stellt. Nicht in allen Fallgruppen wirkt jedoch das Privatrecht verwaltungsrechtsunterstützend; zum Teil wird es vom Verwaltungsrecht verdrängt.

13. Scbließlich läßt sich unser Problem auch als die Frage nach dem optimalen Grad der Organisationsdifferenzierung begreifen. Für die Auslegung und Anwendung des Verwaltungsrechts sind die Verwaltung und die Verwaltungsgerichte zuständig, für die Anwendung und Auslegung des Privatrechts die Zivilgerichte. Auf diesem Hintergrund bedeutet die Beachtung verwaltungsrechtlicher Vorgaben durch die Zivilgerichte eine Überschreitung der Systemgrenzen. Das impliziert tendenziell eine Entspezialisierung und damit eine Reduzierung der Leistungsfähigkeit. Dazu kommt das Risiko widersprüchlicher Feststellungen, da die verwaltungsrechtlichen Normen auch von den Verwaltungsgerichten bearbeitet werden.

V. Die Nichtbeachtung der verwaltungsrechtlichen Legalität und die Einheit der Rechtsordnung

14. Wenn Zivilgerichte den Umstand unberücksichtigt lassen, daßein bestimmtes Verhalten den verwaltungsrechtlichen Vorgaben entspricht und das vielleicht sogar durch eine Genebmigung bestätigt wurde, stellt sich die Frage, ob nicht die Einheit der Rechtsordnung, verstanden als ibre Widerspruchsfreibeit, bedrobtwird. Die Gefabrvon Widersprüchen kann allerdings nur auftreten, wenn ein bestimmtes Verhalten vom Verwaltungsrecht und vom Privatrecht zumindest teilweise binsichtlich der gleichen Gesichtspunkte bewertet wird (Konkurrenzfälle). 
15. Die Nichtbeachtung der verwaltungsrechtlichen Legalität durch die Zivilgerichte stellt keinen echten Normwiderspruch dar, der auf jeden Fall aufgelöst werden müßte, wenn und weil das Verwaltungsrecht ein Verbalten, das zivilrechtlich unterbunden werden kann, nicht vorschreibt, sondern nur zuläßt. Was sich aufdrängt, ist ein Wertungswiderspruch, der aber nicht notwendig aufgelöst werden muß. Gegenläufige Gesichtspunkte können rechtfertigend wirken, wenn nicht gar den Widerspruch beseitigen.

16. An die durch eine Genehmigung vermittelte Legalität sind die Zivilgerichte gebunden, wenn dies gesetzlich vorgeschrieben ist, insbesondere bei Genehmigungen mit Präklusionswirkung. Im übrigen vermittelt die Genebmigungskonformität (in den Konkurrenzfällen) einen Anbaltspunkt, was von den Zivilgerichten stärker berücksichtigt werden sollte.

17. Bei der durch Normen des Verwaltungsrechts vermittelten Legalität ist die Situation nicht anders. Insbesondere ist eine echte Bindung der Zivilgerichte an Bebauungspläne aus verschiedenen Gründen nicht akzeptabel. Andererseits muß einem Bebauungsplan eine indizielle Wirkung zugestanden werden, um die Gefabr einer Behinderung der bauplanerischen Gestaltung durch das Privatrecht $z u$ minimieren. Für sonstige verwaltungsrechtliche Normen dürfte, vorbehaltlich abweichender gesetzlicher Regelungen, nichts anderes gelten. Uber die indizielle Wirkung des Verwaltungsrechts können und müssen die Zivilgerichte für eine stärkere Harmonisierung von öffentlichem und privatem Recht sorgen.

18. Schließlich stellt sich in bestimmten Fällen die Frage, was von den Zivilgerichten beachtet werden muß: Die in ibrer Sicht aus Normen des Verwaltungsrechts folgende Illegalität oder die durch eine Genehmigung vermittelte Legalität. In solchen Fällen des derivativen Privatrechts besteht eine Bindung der Zivilgerichte an die Konkretisierung durch eine Genebmigung sicherlich insoweit, als die Genehmigung gestaltende Wirkungen hat. Darüber hinaus wird man auch binsichtlich bindender Feststellungen eine echte Bindung der Zivilgerichte anzunebmen haben. Allerdings sind dabei die (bäufig unsicheren) Grenzen des Aussagegehalts einer Genehmigung zu beachten.

\section{Scbluß}

19. Die Publifizierung und Verdrängung des Privatrechts spricht für die Leistungsfähigkeit des öffentlichen Rechts. Eine Fortsetzung dieser Entwicklung kann legitimerweise nur verlangt werden, wenn die Leistungsfähigkeit des öffentlichen Rechts weiter ausgebaut wird. 


\section{Aussprache und Schlußrorte}

\section{Verwaltungsrecht als Vorgabe für Zivil- und Strafrecht}

Vogel: Meine Damen und Herren! Der Vorstand hat zwei Mitglieder aus den Ländern Schweiz und Österreich gebeten, kurze Berichte darüber zu geben, wie die Problematik in ihren Ländern aussieht. Frau Weber-Dürler wird über das Thema aus schweizerischer Sicht berichten, Herr Öblinger aus österreichischer Sicht. Damit treten wir gewissermaßen schon am Vormittag in die Diskussion ein.

Weber-Dürler: Sehr geehrte Damen und Herren, die beiden Referenten haben uns aufs beste mit geistiger Nahrung versorgt. Unmerklich ist die Stunde herangerückt, in der das Bedürfnis nach leiblichen Genüssen überhandzunehmen pflegt. Ich fasse mich deshalb kurz und beschränke meine Bemerkungen auf zwei zivilrechtliche und zwei strafrechtliche Fragen, welche den Diskussionsstand in der Schweiz widerspiegeln.

Aus dem Zivilrecht möchte ich zunächst vergleichshalber das Nachbarrecht herausgreifen, weil es in der deutschen Diskussion eine wichtige Rolle spielt. Im privaten Nachbarrecht der Schweiz lassen sich keine direkten Bezüge zum öffentlichen Recht aufdecken. Rechtsprechung und herrschende Lehre betonen, der privatrechtliche Immissionsschutz (Art. 679 und 684 ZGB) sei vom öffentlichen Recht unabbängig. Öffentlich-rechtliche Bewilligungen oder Genebmigungen schließen privatrechtliche Unterlassungsansprüche grundsätzlich nicht aus. Die Zuordnung eines Gebiets zu einer bestimmten Zone gilt nach einem vielzitierten älteren Urteil nur als Indiz für die Ortsüblichkeit. Eine ähnliche Funktion wird dem Umweltschutzgesetz von 1983 oder besser seinen Ausführungsbestimmungen prophezeit, zumindest aus privatrechtlicher Warte. Allein, diese Ausführungsbestimmungen - ich denke an die Luftreinhalte-Verordnung und die Lärmschutzverordnung - stehen erst seit kurzem in Kraft, und das Bundesgericht bemüht sich zur Zeit, den kantonalen Verwaltungsgerichten die Bedeutung dieser Erlasse für das öffentliche Baurecht klarzumachen. Es ist deshalb m. E. verfrüht, jetzt schon eine Aussage darüber zu treffen, inwieweit die Grenzwerte dieser Verordnungen die privatrechtliche Rechtsprechung beeinflussen werden. 
Zweite Frage: Gibt es im schweizerischen Zivilrecht andere Bereiche, in denen eine größere Abhängigkeit vom Verwaltungsrecht besteht? Eine Abhängigkeit des Zivilrichters von Verwaltungsnormen bewirken die verschiedenen Bestimmungen, welche Widerrechtlichkeit voraussetzen, etwa eine widerrechtliche Schädigung oder einen widerrechtlichen Zweck. Auch Verstöße gegen öffentlich-rechtliche Normen können die Nichtigkeit eines Vertrags, eine Haftpflicht oder die Aufhebung einer juristischen Person nach sich ziehen. Eine Abhängigkeit von Verwaltungsakten ist im Bereich der zivilrechtlichen Nebengesetze anzutreffen, die von öffentlich-rechtlichen Elementen durchsetzt sind. Traditionelles Hauptbeispiel ist das landwirtschaftliche Bodenrecht. Die Anwendbarkeit des Sonderrechts wird großenteils durch Verfügung begründet; ferner wird etwa der Schätzwert eines Heimwesens im Hinblick auf die Belastbarkeit und das bäuerliche Erbrecht durch Verfügung festgelegt. Diese Verfügungen sind gemäß ausdrücklicher Gesetzesvorschrift für den Zivilrichter verbindlich (Art. 3 Abs. 4 und Art. 7 Abs. 2 BG über die Entschuldung landwirtschaftlicher Heimwesen, SR 211.412.12). Erwähnenswert ist noch das Bundesgesetz über den Erwerb von Grundstücken durch Personen im Ausland (SR 211.412.41). Es soll die „Überfremdung des einheimischen Bodens" verhindern, einen Mißstand, zu dem - wie mir genau bekannt ist - auch einige deutsche Staatsrechtslehrer beigetragen haben, die nicht davor zurückgeschreckt sind, in der Schweiz ein Ferienhaus oder eine Zweitwohnung zu erwerben. Das erwähnte Bundesgesetz unterstellt den Erwerb von Grundstücken einer Bewilligungspflicht und kennt als Sanktion die Nichtigkeit des Rechtsgeschäfts. Nicht genug: Wie eine findige Praxis entdeckte, kann eine zur Umgehung gegründete Aktiengesellschaft aufgelöst werden, mit der Folge, daß ihr Vermögen ans Gemeinwesen fällt und wohltuend zur Gesundung der kantonalen Finanzrechnung beiträgt (BGE 112 II $1 \mathrm{ff}$.). Der Zivilrichter ist an rechtskräftige Verwaltungsentscheidungen über die Bewilligungspflicht sowie über die Erteilung oder Verweigerung der Bewilligung gebunden (BGE 108 II $460 \mathrm{f}$.); diese Bindung ist im Gesetz nicht ausdrücklich vorgesehen und entspricht einem allgemeinen Grundsatz.

Dritter Punkt: Im Strafrecht möchte ich wiederum zunächst einen vergleichenden Blick auf ein in Deutschland brisantes Problem werfen. Das Umweltstrafrecht ist in der Schweiz bis jetzt nicht ins Kernstrafrecht vorgedrungen; es ist als Annex im Umweltschutzgesetz und im Gewässerschutzgesetz integriert. Wie in Deutschland gibt es dazu wenig publizierte Judikatur, was beim relativ jungen Umweltschutzgesetz weniger erstaunt als bei der viel weiter zurückreichenden 
Gewässerschutzgesetzgebung. Auch vom Fallmaterial her sind die Urteile eher enttäuschend, betreffen sie doch oft Bagatellen. Was die Verwaltungsakzessorietät anbetrifft, werfen die Strafbestimmungen wiewohl sie in Verwaltungsgesetzen stehen - die gleichen Probleme wie in Deutschland auf. Verschiedene Tatbestände umschreiben die strafbare Handlung als Verletzung einer bestimmten Gesetzesvorschrift oder einer Ausführungsverordnung, verweisen also auf Verwaltungsnormen. Eine zweite Gruppe von Strafbestimmungen schließt sich an Verwaltungsakte an, knüpft die Straffolge ans Nichtbefolgen einer Verfügung oder ans Fehlen einer Bewilligung. Die verschiedenen Aspekte der Verwaltungsakzessorietät haben bis jetzt weder in der Rechtsprechung noch in der Wissenschaft besondere Beachtung gefunden.

Vierter und letzter Punkt: Gibt es im schweizerischen Strafrecht andere Bereiche, in denen die heute behandelte Problematik mehr in Erscheinung getreten ist? In dieser Hinsicht enthält das schweizerische Strafgesetzbuch eine echte Perle für die Verwaltungsrechtslehrer, nämlich den Art.292 StGB, wonach der Ungehorsam gegen eine Verfügung mit Haft oder Buße bestraft wird. Dem Bestimmtheitserfordernis sucht diese Blankettstrafnorm Genüge zu tun, indem die Verfügung ausdrücklich auf die drohende Strafe und den fraglichen Artikel des StGB hinweisen muß. Von Interesse ist vor allem die Frage, $o b$ der Strafrichter die Verfügung vorfrageweise auf ibre Rechtmäßigkeit prüfen darf. Daß der Richter einen die Nichtigkeit der Verfügung bewirkenden Mangel beachten muß, ist selbstverständlich. Im übrigen scheiden sich die Geister. Aus strafrechtlicher Sicht vertritt Stratenwerth die Meinung, eine gesetzwidrige Verfügung verdiene keinen strafrechtlichen Schutz. Gygi nimmt die andere Extremposition ein; er erblickt in Art. $292 \mathrm{StGB}$ ein reines Vollstreckungsmittel und folgert, im Vollstreckungsverfahren könne eine rechtskräftige Verfügung nicht mehr in Frage gestellt werden. Das Bundesgericht hat in der neueren Rechtsprechung eine differenzierte Lösung entwickelt (BGE 98 IV $106 \mathrm{ff}$.), die ich in groben Zügen skizzieren möchte. Gebunden ist der Strafrichter an eine Verfügung, deren Rechtmäßigkeit durch ein Verwaltungsgericht festgestellt wurde. Umgekehrt hat der Strafrichter die Verfügung zu überprüfen, wenn diese nicht an ein Verwaltungsgericht gezogen werden konnte. Die in der Schweiz z. T. fehlende Verwaltungsgerichtsbarkeit wird also kompensiert durch eine strafrichterliche Prüfung. Fragwürdig ist die dritte Regel für den dazwischenliegenden Fall: Der Strafrichter darf die Verfügung auf eine offensichtliche Rechtsverletzung überprüfen, wenn der Bürger von der Möglichkeit verwaltungsgerichtlicher Kontrolle 
keinen Gebrauch gemacht hat oder der Entscheid des Verwaltungsgerichts noch aussteht. Diese differenzierte Lösung, welche das Bundesgericht zu Art. 292 StGB entwickelte, hat sich in weiteren Fällen der unrechtsbegründenden Verfügung durchgesetzt und auch schon ihren Niederschlag im Bundesgesetz über das Verwaltungsstrafrecht gefunden (Art. 77 Abs. 4; SR 313.0). Während die Bindung des Richters an Verfügungen im Zivilrecht als feste Regel gilt, bestehen im Strafrecht also Ausnahmen, welche mit dem besonderen Gewicht der Strafe begründet werden und sich einseitig zugunsten des Bürgers auswirken. Ich danke Ihnen.

Öhlinger: I. Wenn mein Bericht zur Diskussion Positives beitragen und sich nicht im Blick auf eine etwas exotische Rechtsordnung erschöpfen soll, so kann dies wohl nur darin bestehen, ein sehr stark durch die jeweilige positive Rechtsordnung geprägtes Thema durch einige zusätzliche Aspekte anzureichern. Meine Aufgabe ist es gewissermaßen, den „Möglichkeitssinn“ anzuregen, um ein Wort von Robert Musil zu gebrauchen.

Das fällt freilich bei diesem Thema nicht leicht. Im Prinzip stellen sich die Probleme in Österreich wohl nicht viel anders, als sie in den beiden Referaten dargelegt wurden. Unterschiede liegen in den Details der gewissermaßen zufälligen positiv-rechtlichen Regelungen, in die sich zu verlieren aber wohl nicht lohnt.

Deutliche Unterschiede betehen allerdings im theoretischen Bezugsrabmen. Es mag insofern eine nationale Besonderheit sein, daß sich in Österreich die Verwaltungsrechtswissenschaft mit dieser Thematik, von einer Ausnahme abgesehen (nämlich der Frage der Bindung der Zivilgerichte an verwaltungsbehördliche Bescheide) systematisch noch nicht beschäftigt hat. Soweit das Verwaltungsrecht dem Zivilrecht oder Strafrecht vorgegeben ist, wird es zu einem Thema der Zivilistik oder der Strafrechtsdogmatik, zu dem die Verwaltungsrechtler bisher nur wenig beigetragen haben. Ich bin mir nicht sicher, inwieweit uns die heutigen Referate zu einer Revision dieser öffentlich-rechtlichen Abstinenz veranlassen werden.

II. a) Um in der Reihenfolge der Referate mit dem Strafrecht zu beginnen! Hier gibt es in der Tat eine nationale Besonderheit zu vermelden, die den Fragenkomplex quantitativ und vielleicht auch qualitativ etwas reduziert. Wir kennen neben dem eigentlichen oder judiziellen Strafrecht ein eigenständiges Verwaltungsstrafrecht. Ein Vergleich etwa des Straßenverkehrsrechts oder des Steuerrechts zeigt, daß in manchen Fällen, die in Deutschland vor dem Strafrichter abzuhandeln sind, in Österreich die von der Sache her zuständige 
Verwaltungsbehörde auch die Strafe zu verhängen hat. Das trifft vor allem Delikte mit einem hohen Grad an Verwaltungsakzessorietät, die eben dann keine ist, wenn Strafbehörde und Verwaltungsbehörde identisch sind.

Vor allem von Verwaltungspraktikern wird diese Einheit von materiellem Verwaltungsrecht und Strafrecht positiv bewertet und zur Rechtfertigung des Verwaltungsstrafrechts insgesamt ins Treffen geführt, weil es die Einheit von Sachvertand und Strafrechtskompetenz dort garantiere, wo es um die Anwendung eher komplexer Regelungen, wie etwa im Steuerrecht, geht, deren genaue Kenntnis von einem Strafrichter nicht unbedingt erwartet werden kann. $\mathrm{Ob}$ dieses Argument richtig ist, wäre sicherlich eine Diskussion wert. Hätten die Anhänger dieses Arguments heute Herrn Scbröder hören können, wären sie darin wohl bestärkt worden.

Im übrigen fällt ab kommendem Jahr das Verwaltungsstrafrecht, ausgenommen das Finanzstrafrecht, in der 2. oder 3. Instanz in die Zuständigkeit gerichtsähnlicher sog. „Unabhängiger Verwaltungssenate", so daß sich unser Thema an der Nahtstelle zwischen der allgemeinen Verwaltung und dieser unabhängigen Verwaltungsbehörden wiederfinden wird.

b) Abgesehen davon kennt natürlich auch das österreichische Strafrecht viele Fälle der Verwaltungsakzessorietät, neuerdings im besonderen im Umweltstrafrecht, das erst 1989 ganz in diesem Sinne neu gestaltet wurde. Von den fünf damals geschaffenen spezifischen Umweltstraftatbeständen des StGB ist nur ein einziger nicht-verwaltungsakzessorisch. Alle anderen beziehen sich auf ein Handeln, das so wörtlich - „entgegen einer Rechtsvorschrift oder einem behördlichen Auftrag“" erfolgte - das österreichische Umweltstrafrecht ist also eindeutig nicht nur verwaltungsrechts-, sondern auch verwaltungsaktakzessorisch. Damit stellt sich auch hier das Problem der Vorgabe rechtswidriger Verwaltungsakte, das allerdings von der Strafrechtsdogmatik meines Erachtens richtig nicht als Bindungsproblem verstanden, sondern ausschließlich mit strafrechtsdogmatischen Kategorien, z. B. der Rechtfertigung, zu erfassen versucht wird.

c) Das Problem der Verwaltungsaktakzessorietät hat auch bei uns in einem Steuerverfahren mit politischem Einschlag eine Rolle gespielt. Es gibt nämlich eine Rechtsprechung des Obersten Gerichtshofs (OGH), wonach der Strafrichter an die verwaltungsbehördliche Feststellung des Bestehens einer Abgabenschuld dem Grunde und der Höhe nach gebunden ist und lediglich die subjektive Tatseite demnach Gegenstand selbständiger richterlicher Beurteilung sein kann. Der OGH schließt dies aus der Anordnung des Finanzstrafgesetzes, daß 
die Hauptverhandlung vor dem Gericht erst nach Vorliegen eines rechtskräftigen Abgabenbescheides durchgeführt werden darf. Aus einer ähnlichen, auf das verwaltungsbehördliche Strafverfahren bezogenen Regelung in Verbindung mit der verfassungsgesetzlichen Unschuldsvermutung folgert demgegenüber der VfGH genau das Gegenteil. Politisch brisant sind freilich positive Bescheide der Finanzverwaltung.

d) Eine allgemeine Verwaltungsrechtsakzessorietät des Strafrechts besteht darin, daß Verwaltungsrechtsnormen eine Richtlinie für die objektive Sorgfaltswidrigkeit bei Fabrlässigkeitsdelikten bilden. Das kann zu Lücken eines rechtspolitisch wünschenswerten Strafrechtsschutzes dort führen, wo das Verwaltungsrecht lückenhaft ist. Das wird im Augenblick am Beispiel der Gentechnologie diskutiert. Die potentiellen Gefahren für Leben und Gesundheit von Menschen durch gentechnologische Manipulationen fallen unter die Tatbestände der fahrlässigen Tötung und fahrlässigen Körperverletzung. Verwaltungsrechtsnormen, denen man objektive Verhaltensmaßstäbe beim Einsatz gentechnischer Methoden entnehmen könnte, fehlen aber noch weitgehend, so daß eine strafrechtliche Studie ${ }^{1}$ zu dem Schluß kommt, daß im Hinblick auf die Gefahren der Gentechnologie weniger das Strafrecht selbst, als vielmehr das Verwaltungsrecht einer Ergänzung bedarf, um einen zeitgemäßen Strafrechtsschutz herbeizuführen.

III. Zahlreiche Beispiele einer „Vorgabe des Verwaltungsrechts“ finden sich im Zivilrecht.

a) Um mit dem privatrechtlichen Immissionsschutzrecht $\mathrm{zu}$ beginnen! Hier wurde die österreichische Rechtslage schon 1916 der deutschen Rechtslage angepaßt, allerdings systematisch zusammengefaßt im ABGB, wo sich sowohl der dem $\$ 906$ BGB ähnliche Unterlassungsanspruch als auch der bloße Schadenersatzanspruch bei bebördlich genehmigten Anlagen findet ( $\$ 364$ Abs. 2 und 364 a ABGB). Dieser unterschiedliche systematische Zusammenhang mag zu unterschiedlichen Akzenten in der Auslegung und Anwendung geführt haben. Die österreichischen Gerichte tendieren jedenfalls, von der Verwaltungsrechtslehre unbeeinsprucht, dazu, die den Abwehranspruch ausschließenden Voraussetzungen eher eng zu interpretieren. Eine baubehördliche Genehmigung wird jedenfalls unbestritten nicht anerkannt. Der Verwaltungsrechtler kann dazu nur sagen, daß abstrakt gesehen natürlich auch eine baubehördliche Genehmigung

${ }^{1}$ Burgstaller, Gentechnologie und österreichisches Strafrecht, Wien 1990. 
eine behördliche Genehmigung ist, aber er kann nicht bestreiten, daß $\$ 364$ a $A B G B$ aus sich heraus oder im Kontext des bürgerlichen Rechts eine einschränkende Auslegung verlangt. Allerdings korrespondieren damit auch die öffentlich-rechtlichen Bauordnungen, die in den Bauverhandlungen ungelöst gebliebene privatrechtliche Ansprüche ausdrücklich auf den Zivilrechtsweg verweisen.

Was planungsrechtliche Vorgaben betrifft, so wäre an sich die Rechtslage in Österreich insofern klar, als Flächenwidmungs- und Bebauungspläne in Österreich heute unbestritten als Verordnungen gelten und ihre Verbindlichkeit von den Gerichten daher aufgrund einer eindeutigen verfassungsrechtlichen Regelung (Art. 89 B-VG) nicht in Frage gestellt werden kann. Das gilt selbst dann, wenn sich eine Widmung auf ein einzelnes Grundstück bezieht. Ein Gericht könnte allenfalls die Verfassungsmäßigkeit einer solchen Verordnung vom VfGH prüfen lassen.

Allerdings scheinen die Gerichte damit Schwierigkeiten zu haben, was nicht eine Tennisplatz-, sondern eine Fußballplatzentscheidung illustriert. In einem als Wohngebiet gewidmeten Bereich mußte ein Kläger den Lärm eines Fußballstadions (Austria-Salzburg) hinnehmen, weil er den tatsächlichen Gegebenheiten gemäß angeblich ortsüblich war und es nach dem OGH nur auf diese tatsächlichen Gegebenheiten ankommen soll, nicht auf - so der OGH wörtlich "fiktive" Zustände, die sich aus einem nicht realisierten Flächenwidmungsplan ergeben. Das ist verwaltungsrechtlich sicher höchst fragwürdig begründet. Hinzuzufügen ist allerdings, daß es das Stadion schon gab, bevor sich die Kläger dort ansiedelten und der Bebauungsplan geändert wurde. Gegen Vollzugsdefizite eines solchen Planes wäre aber wohl das verwaltungsrechtliche Instrumentarium einzusetzen. Insofern kann man dem OGH im Ergebnis beipflichten.

Wie unser OGH ihren Tennisplatzfall entschieden hätte, läßt sich im Lichte dieser Entscheidung schwer prognostizieren, auch deshalb, weil dem OGH die Judikatur des BGH vielleicht vertrauter ist als Vorgaben des österreichischen Verwaltungsrechts - dies ganz im Sinne der europäischen Dimension des Privatrechts, die gestern Herr Häberle so positiv apostrophiert hat. Bei Vorliegen einer gesetzmäßigen Widmung als "Sportstätte“ - die Gesetzmäßigkeit wäre nach Landesrecht zu beurteilen -, wäre m. E. eine Klage des Nachbarn abzuweisen, weil die Frage der Ortsüblichkeit auf der Ebene des für das Gericht verbindlichen Gesetzesrechtes (im materiellen Sinn) geregelt wäre. Um es pointiert und vielleicht für einen Privatrechtler unerträglich schmerzhaft zu formulieren: der Bebauungsplan als lex specialis zum ABGB! Planungsfehler oder sonstige Rechtsmängel der 
Flächenwidmung wären mit dem öffentlich-rechtlichen Instrumentarium zu bekämpfen. Je konkreter und flächenmäßig begrenzter eine solche Widmung ist, desto größer mag z. B. der Verdacht einer im Hinblick auf den Gleichheitssatz verfassungswidrigen Unsachlichkeit sein. Ist die Widmung weniger konkret, bleibt für die Beurteilung der Ortsüblichkeit durchaus Raum.

Immissionen aus Grundstücken, die Zwecken der Hoheitsverwaltung dienen, können auch in Österreich mit privatrechtlichen Mitteln nicht abgewehrt werden. Das haben kürzlich die Anrainer eines Flugplatzes in der Steiermark erfahren, die die Stationierung der äußerst umstrittenen - neu gekauften Abfangjäger des Bundesheeres verhindern wollten. Der OGH hat sich dabei ausdrücklich auf Rechtsprechung und Lehre in der BRD berufen. Ich hoffe, er hat diese richtig gesehen.

b) Es gibt auch im österreichischen Recht, ich möchte fast sagen: naturgemäß, eine dem $\ 823$ Abs. 2 BGB vergleichbare Regelung. Sie lautet in der etwas altertümlichen, aber so angenehmen Sprache unseres ABGB aus 1811, daß, wer ein Gesetz, das den zufälligen Beschädigungen vorzubeugen sucht, übertreten hat, für allen Nachteil haftet, welcher außer dem nicht erfolgt wäre (\$1311 ABGB). Solche Gesetze heißen auch in der österreichischen Lehre Schutzgesetze.

Ein von Herrn Jarass nur kurz angesprochenes Problem stellt sich in Österreich im Hinblick auf das Alter dieser Regelung, nämlich die Frage, ob als Schutzgesetze auch individuelle Verwaltungsakte in Betracht kommen. Das ABGB spricht zwar von "Gesetzen“, stammt aber aus einer Zeit, der unsere heutige gewaltentrennende Systematik der Rechtsatzformen noch unbekannt war. Entscheidend kann daher nur die Wertung sein, ob der Tatbestand der schadenersatzrechtlichen Rechtswidrigkeit auch an Verhaltenspflichten anknüpfen soll, die in individuell-konkreten Verwaltungsakten festgelegt $\operatorname{sind}^{2}$. So formuliert wird freilich eines deutlich: es geht bei dieser nur scheinbar spezifisch öffentlich-rechtlichen Frage ausschießlich um eine Auslegung der einschlägigen zivilrechtlichen Haftungsgrundlage. Der Beitrag des Öffentlichrechtlers muß sich auf die relativ banale, aber vielleicht dem Zivilisten nicht unbedingt geläufige Einsicht beschränken, daß auch ein Verwaltungsakt, und zwar selbst der formloseste wie etwa die Anordnung eines Verkehrspolizisten, anzuhalten oder weiterzufahren - Normqualität hat. Das ist jedenfalls in der öster-

${ }^{2}$ Karollus, Funktion und Dogmatik der Haftung aus Schutzgesetzverletzungen, Wiener Habilitationsschrift, 1990. 
reichischen öffentlich-rechtlichen Lehre seit Kelsen und Merkl diese beiden Stammväter einer eigenständigen österreichischen Verfassungs- und Verwaltungsrechtswissenschaft dürfen in einem österreichischen Landesbericht natürlich nicht fehlen - völlig unbestritten, und diese Einsicht macht es dem Zivilisten vielleicht leichter, auch individuelle Verwaltungsakte als potentielle Schutzgesetze anzuerkennen. Nach dem OGH ist ein Schutzgesetz beispielsweise eine von einer Behörde bescheidmäßig genehmigte Betriebsvorschrift einer Seilbahn, weil sie, so wörtlich, eine „obrigkeitliche Verfügung zum Schutz der beförderten Personen" beinhaltet. Es ist dies aber, wie gesagt, eine Frage, die ausschließlich aus der zivilrechtlichen Haftungsnorm heraus zu beantworten ist, wozu der Verwaltungsrechtswissenschaftler, von einigen wenigen fundamentalen Basiskenntnissen abgesehen, nichts Wesentliches beitragen kann. Auf die sich in diesem Zusammenhang stellende Frage nach der Bindung des Zivilrichters an rechtswidrige, aber rechtskräftige Verwaltungsentscheidungen komme ich noch zurück.

Auch die Frage, was materiell eine Schutznorm darstellt, wird vom Telos der zivilrechtlichen Schadenersatzregelung vorgegeben. Gewiß ist der Zivilrichter dabei genötigt, Verwaltungsrecht in seinem Bestand zu ermitteln - schon das ist ja nicht immer ganz einfach -, $\mathrm{zu}$ interpretieren und im besonderen auf seinen Zweck zu hinterfragen. Dabei mag die Hilfe der Verwaltungsrechtswissenschaft nützlich sein, denn man kann sich nicht des Eindrucks erwehren, daß die Privatrechtler dabei gelegentlich etwas unsicher dilettieren. Ob der so ermittelte Inhalt und $Z$ weck einer gegebenen verwaltungsrechtlichen Regelung einen Schutzzweck bildet, m. a. W.: ob diese Regelung den in einem konkreten Fall eingetretenen Schaden verhindern wollte, bleibt aber eine genuin zivilrechtliche Frage. Es gibt eine reiche Judikatur etwa zur Straßenverkehrsordnung, welche ihrer Bestimmungen Schutzgesetze sind - das ist die Regel - und welche allenfalls nicht. Ich sehe keinen systematischen Ansatzpunkt im Verwaltungsrecht selbst, der zu dieser Differenzierung beitragen könnte. Auch zu der in der Privatrechtslehre offenbar umstrittenen Frage, ob es auf den subjektiven oder objektiven Zweck des Gesetzes ankommt, liefert das Verwaltungsrecht selbst keinen dogmatischen Anhaltspunkt, außer vielleicht den negativen, daß der Gesetzgeber bei Festlegung verwaltungsrechtlicher Verhaltensnormen die schadenersatzrechtliche Dimension kaum einmal mitbedenkt, so daß der subjektive Schutzzweck schwer feststellbar ist.

Die Tatsache, daß die österreichische Verwaltungsgerichtsbarkeit Gesetze stark am Wortlaut haftend anzuwenden pflegt und gegenüber 
teleologischen Erwägungen sehr zurückhaltend ist, mag zwar für den Zivilrichter wenig hilfreich sein, weil dieser das Verwaltungsrecht teleologisch interpretieren $m u \beta-$ ob nun subjektiv oder objektiv, sei dahingestellt -, aber dabei nur selten auf die Zweckfeststellung des an sich für das Verwaltungsrecht primär zuständigen Verwaltungsgerichtshofs zurückgreifen kann, sondern den Zweck selbständig ermitteln muß. Beide Arten von Gerichten müssen aber die gleiche Verwaltungsrechtsnorm in jeweils völlig, und zwar strukturell, unterschiedlichen Fallkonstellationen anwenden - der VwGH in einem Verwaltungsrechtsverhältnis, im wesentlichen also im Verhältnis Staat - Privater, die Zivilgerichte in einem Zivilrechtsverhältnis -, so daß sich diese unterschiedlichen methodischen Zugänge gar nicht gegeneinander ausspielen lassen: dem Zivilgericht ist die teleologische Methode von seinem Ausgangspunkt vorgegeben; inwieweit die Teleologieskepsis der Verwaltungsgerichtsbarkeit gerechtfertigt ist, ist zwar ein Problem, es läßt sich aber gewiß nicht aus diesem Ausgangspunkt her aufrollen.

c) Ähnlich verhält es sich in der Frage der Auswirkung von Verletzungen verwaltungsrechtlicher Regelungen auf zivilrechtliche Rechtsgeschäfte. Ein Vertrag, der gegen ein gesetzliches Verbot verstößt, ist auch nach ABGB (\$879) nichtig. Ob eine Verletzung solcher Vorschriften tatsächlich die Ungültigkeit eines Rechtsgeschäftes bewirkt, hängt davon $a b$, ob es von den Zivilgerichten als Verbotsgesetz im Sinne des ABGB anerkannt wird. Hier ist die Rechtslage in Österreich offenbar nicht anders als in Deutschland.

Hinzufügen möchte ich noch dem, was Herr Jarass gesagt hat, daß das Zivilrecht ein viel differenzierteres Sanktionensystem als die Alternative gültig/ungültig kennt. Nicht Ungültigkeit, sondern eine nachträgliche Unmöglichkeit der Erfüllung auf seiten einer Gemeinde mit der Verpflichtung zum Ersatz des Nichterfüllungsschadens stellte z. B. der OGH im folgenden Fall fest: Eine Gemeinde hatte mit einem Unternehmer einen Vertrag über den Abbau einer Schottergrube auf gemeindeeigenem Grund geschlossen. Eine dafür erforderliche behördliche Bewilligung wurde später aufgrund einer negativen Stellungnahme derselben Gemeinde im Interesse einer benachbarten Wohnsiedlung verweigert.

d) An diesem Fall ließe sich zugleich sowohl die Wirkung nachträglicher verwaltungsrechtlicher Sachverhalte als auch die Wirkung der verwaltungsrechtlichen Vollzugsebene auf den Bestand zivilrechtlicher Verträge erörtern. Ein österreichisches Spezifikum mag dabei die Wirkung verwaltungsbehördlicher Entscheidungen auf zivilrechtliche Rechtsgeschäfte ein und derselben Gebietskörperschaft sein. Wir kennen $\mathrm{ja}$ in Österreich einen vergleichsweise exzessiven Umfang 
privatrechtlicher Verwaltung, die durch keinen inhaltlichen Begriff der öffentlichen Aufgaben begrenzt ist, sondern eine prinzipiell auf allen Verwaltungsgebieten bestehende Alternative zu behördlichem Handeln darstellt. (Zuletzt wurde dazu auf unserer Münchner Tagung referiert.) Öffentlich-rechtliche und privatrechtliche Aufgabenerfüllung sind daher auf allen Ebenen eng verzahnt und verwaltungsbehördliche Entscheidungen insofern nicht selten eine „Vorgabe" zivilrechtlicher Rechtsgeschäfte ein und derselben Gebietskörperschaft. Dazu, in aller Kürze ein viel diskutierter Fall. Eine Gemeinde hatte als Baubehörde die Errichtung einer Tankstelle genehmigt. Als Verwalterin der Straße und damit als Privatrechtssubjekt verweigerte später dieselbe Gemeinde - in Wahrheit natürlich eine andere Abteilung des Magistrats - die privatrechtliche Zustimmung zur Benutzung des Gehsteiges für die $\mathrm{Zu}$ - und Abfahrt. Während das Berufungsgericht der Gemeinde unter Berufung auf die Vertragsfreiheit Recht gab, entschied der OGH auf einen Kontrahierungszwang der Gemeinde und entwickelte in diesem Zusammenhang wichtige Grundsätze einer von der Verwaltungspraxis oft als rechtlich völlig ungebunden verstandenen "Privatwirtschaftsverwaltung“.

Der Fragenkomplex der öffentlich-rechtlichen Grenzen der „Privatwirtschaftsverwaltung “ der Gebietskörperschaften dürfte, wie gesagt, in Österreich besonders brisant sein, er überschreitet freilich unser engeres heutiges Thema insofern, als es dabei primär verfassungsrechtliche (wenngleich nicht nur grundrechtliche, sondern auch verwaltungsorganisatorische) Vorgaben von im übrigen doch eher atypischen Zivilrechtsverhältnissen geht.

e) Eine Fallgruppe, bei der die österreichischen Zivilgerichte die Vorgabe des Verwaltungsrechts pauschal und unkritisch zu akzeptieren pflegen und gerade deshalb zu Fehlurteilen kommen, bildet die Vertretung öffentlich-rechtlicher Körperschaften im Privatrechtsver$k e h r$. Im besonderen zu Gemeinden verweist unser altes ABGB auf die "Verfassungen derselben“ ( $\$ 867)$. Nun sehen die Gemeindeordnungen in der Regel vor, daß der Bürgermeister die Gemeinde nach außen vertritt, sie binden aber die Gültigkeit verschiedener Rechtsgeschäfte an die Mitwirkung kollegialer Organe, etwa den Gemeinderat. Für die Rechtsprechung bedeutet das Fehlen dieser Mitwirkung automatisch die Ungültigkeit des Rechtsgeschäfts. Eine gründliche zivilrechtliche Untersuchung ${ }^{3}$, der man auch von öffentlich-rechtlicher 1981.

${ }^{3}$ Wilhelm, Die Vertretung der Gebietskörperschaften im Privatrecht, Wien 
Seite nur zustimmen kann, hat gezeigt, wie sehr diese Judikatur das Erfordernis eines zivilrechtlichen Vertrauensschutzes verkennt, der ungleich differenziertere Lösungen verlangen würde.

IV. Ein Thema, das in Österreich seit rund siebzig Jahren sehr eingehend diskutiert wird, ist, wie schon gesagt, die Bindung der Zivilgerichte an verwaltungsbebördliche Entscheidungen. Am Anfang dieser Diskussion steht ein spektakulärer Fall, der vielleicht gerade deshalb die Dimension des Problems etwas verzerrt hat, die sog. SeverEhen. Sever, niederösterreichischer sozialdemokratischer Landeshauptmann nach dem Ersten Weltkrieg, dispensierte aufgrund einer Bestimmung des ABGB, die Landeshauptleute an sich zur Dispens von Ehehindernissen ermächtigte, vom Ehehindernis eines bestehenden Ehebandes, was praktisch auf eine dem damaligen österreichischen Eherecht noch unbekannte Scheidung hinauslief. Die Gerichte erklärten die Zweitehen der so Dispensierten für ungültig, der VfGH wiederum hob diese gerichtlichen Urteile auf (Art. 138 BVG). Das hatte Auseinandersetzungen zur Folge, die tief in die damalige politische Zerklüftung der österreichischen Gesellschaft hineinreichten und sogar 1929 zur Umgestaltung des Verfassungsgerichtshofes und damit zusammenhängend auch zur Emigration Hans Kelsens nach Köln führten.

Im Alltag der Gerichte und Verwaltungsbehörden stellt sich die Bindungsproblematik freilich weniger spektakulär, aber dafür dogmatisch um einiges diffiziler.

Die öffentlich-rechtliche Lehre vertritt, wie schon damals der VfGH, das Prinzip einer uneingeschränkten Bindung der Gerichte an rechtskräftige Verwaltungsakte, die keine Prüfung auf ihre Rechtmäßigkeit zuläßt. Eine gewisse Abschwächung dieser rigorosen These bildet die - erst mit einer Studie Günther Winklers erfolgte Anerkennung absolut nichtiger Verwaltungsakte bei evidenten und gravierenden Rechtsfehlern. Wahrscheinlich hätte sich schon das Problem der Sever-Ehen damit lösen lassen. Im wesentlichen ist dies auch heute die Auffassung des Obersten Gerichtshofs - dies freilich ganz im Gegensatz zur Privatrechtslehre, die die Bindung überwiegend ablehnt. Im Alltag tendieren die Gerichte heute sogar eher zu einer $z u$ weitgehenden Bindung, was durch den damit verbundenen Entlastungseffekt motiviert sein mag. Die Gerichte sehen nämlich nicht immer die Grenze dieser Bindung, die darin liegt, daß sich die Rechtskraft nur auf die an einem Verfabren beteiligten Parteien erstreckt. Gegenüber einer Partei des zivilgerichtlichen Verfahrens, die nicht auch im Verwaltungsverfahren Partei mit allen ihren Mitwirkungsrechten war, erwächst ein Bescheid nicht in Rechtskraft und bindet schon deshalb nicht die Gerichte. 
Die öffentlich-rechtliche Lehre begründet die pauschale Bindungsthese mit einer aus der Verfassung abgeleiteten Gleichwertigkeit der beiden Staatsfunktionen Gerichtsbarkeit und Verwaltung. Tatsächlich wurde gerade mit dieser Gleichwertigkeit die Juridifizierung der Verwaltung zu Beginn des Jahrhunderts erheblich vorangetrieben, gipfelnd in den Verwaltungsverfabrensgesetzen von 1925, die ein dem Zivilprozeß zumindest angenähertes Verwaltungsverfahren eingeführt haben und die auch eine dem Gerichtsurteil gleichartige Rechtskraft der Verwaltungsbescheide ohne Differenzierung zwischen deklarativen und konstitutiven Akten normieren.

Dieses Gleichwertigkeitskonzept ist allerdings durch die - einen Bestandteil der Bundesverfassung bildende - Europäische Menschenrechtskonvention in Frage gestellt worden, und zwar durch deren Garantie eines Anspruchs auf eine richterliche Entscheidung über zivilrechtliche Ansprüche und Verpflichtungen - eine Bestimmung, von der auch sonst ganz erhebliche Erschütterungen der österreichischen Rechtsordnung ausgegangen sind. Erst kürzlich hat der Straßburger Gerichtshof in einem Österreich betreffenden Fall („Obermeier") festgestellt, daß eine Bindung eines Zivilgerichts an eine von einer Verwaltungsbehörde entschiedene zivilrechtliche Vorfrage mit Art. 6 der Konvention nicht vereinbar wäre. Die Tragweite dieser Formulierung wird erst deutlich, wenn man sich vergegenwärtigt, was alles nach der extrem weiten Auslegung des Straßburger Gerichtshofs eine zivilrechtliche Frage bilden kann - nämlich das meiste, was traditionellerweise von Verwaltungsbehörden $\mathrm{zu}$ entscheiden ist, sofern davon subjektive Rechte berührt werden. Die österreichische Rechtswissenschaft wird diese Entscheidung noch aufarbeiten müssen.

Vorsitzender (Papier): Meine Damen und Herren, ich eröffne die Aussprache zum zweiten Beratungsgegenstand „Verwaltungsrecht als Vorgabe für Zivil- und Strafrecht". Die historisch gewachsene Differenzierung unserer Rechtsordnung hat immer schon zu Problemen geführt, wenn es um das Verhältnis beider Teilrechtsordnungen oder der verschiedenen Teilrechtsordnungen zueinander geht. Diese Probleme haben sich mit zunehmender Regelungsdichte des Verwaltungsrechts eher gesteigert. Sie treten heute, wenn auch nicht ausschließlich, so doch schwerpunktmäßig vor allem im Umweltrecht zutage, insbesondere seitdem der Gesetzgeber im Kernstrafrecht das Umweltstrafrecht normiert hat und sich nun auch anschickt, ein spezifisches Umwelthaftungsrecht zivilrechtlicher Art einzuführen. Die Referenten haben jeweils, so habe ich es empfunden, differenzierte Standpunkte eingenommen und sind nicht der Versuchung 
erlegen, einen unbedingten und durchgehenden Vorrang des Verwaltungsrechts „fachchauvinistisch“, um Herrn Jarass zu zitieren, zu befürworten, also dem Straf- und dem Zivilrecht stets den Rang eines bloßen Folgerechts zuzubilligen. Für die Themenstellung ist dann auch ganz bewußt der etwas apodiktisch wirkende Begriff der Akzessorietät vermieden worden und der eher „abgefederte“ Begriff der Vorgabewirkung verwendet worden. Auf der anderen Seite sind die Referenten doch deutlich den Tendenzen entgegengetreten, die dahin gehen, das Zivil-, aber vor allen Dingen das Strafrecht vom „publizistischen Denken zu befreien“, einer Tendenz, wie sie vornehmlich in der Strafrechtspflege anzutreffen ist, um wirkliche oder auch nur vermeintliche Vollzugsdefizite im Verwaltungsrecht mit den Mitteln des Straf- und Zivilrechts auszugleichen.

Meine Damen und Herren, Herr Schröder hat sich schwerpunktmäBig mit dem Verhältnis des Verwaltungsrechts zum Strafrecht, Herr Jarass mit dem Verhältnis zum Zivilrecht befaßt. Beide Referenten haben es aber nicht versäumt, die Probleme allgemein zu beschreiben und auch allgemeine Lösungsansätze zu bieten. Damit ist in gewisser Weise auch eine grobe Gliederung unserer Diskussion vorgezeichnet, die sich zunächst unter I. den allgemeinen Fragen der Vorgabewirkungen einschließlich der verfahrensrechtlichen Probleme widmen sollte; in einem zweiten Teil dann den spezifischen Fragen der Wirkungen auf das Strafrecht und schließlich drittens dem Verhältnis zwischen Verwaltungsrecht und Zivilrecht. Der allgemeine Teil wird damit nur sehr grob skizziert. Ich darf einige Stichworte nennen, die im Rahmen dieses Diskussionspunktes behandelt werden könnten und die sich auch in den Referaten widerspiegeln. Erstens: Gründe und Gegengründe für eine Vorgabewirkung des Verwaltungsrechts. Hier haben die Referenten übereinstimmend auf den Gedanken der Einheit der Rechtsordnung, der Widerspruchsfreiheit der Rechtsordnung und auf die Systemgerechtigkeit hingewiesen. Ich will die verschiedenen Topoi, die insbesondere Herr Scbröder in seinem Referat erwähnt hat, hier nicht noch einmal wiederholen. Im allgemeinen Teil der Diskussion könnten zweitens die Vorgaben des Verwaltungsrechts auf den verschiedenen Ebenen behandelt werden: einerseits auf der Ebene der Verwaltungsrechtsnorm, einschließlich der Satzung, also beispielsweise des Bebauungsplans, der Verwaltungsrichtlinien und schließlich andererseits der Verwaltungsakte. Hier könnten dann auch die speziellen Wirkungen der Verwaltungsakte behandelt werden, also etwa die Tatbestandswirkung, Feststellungswirkung, Präklusionswirkung. Dritter Aspekt im allgemeinen Teil der Diskussion ist die Bindungswirkung einerseits und die nur indizielle Wirkung des Verwaltungs- 
rechts andererseits, ein Gedanke, der vornehmlich im Referat von Herrn Jarass sehr prononciert herausgearbeitet wurde. Viertens, immer noch zum allgemeinen Teil, die Frage, welche Folgeprobleme ergeben sich aus der, wie Herr Jarass es formulierte, Entdifferenzierung: Geht es wirklich um die Reduzierung der Leistungsfähigkeit und die besondere Fehleranfälligkeit der Rechtsanwendung? Als fünfter Aspekt im allgemeinen Teil könnten die verfahrensrechtlichen Fragen, die Vorfragenkompetenz, beweisrechtliche Fragen und vor allen Dingen die Aussetzungsproblematik angesprochen werden. Auf die Punkte II. und III. habe ich bereits eingangs hingewiesen, insoweit möchte ich keine weiteren Untergliederungen vorschlagen. Hier könnten die besonderen Probleme angesprochen werden, bis hin zu den praktischen Fällen des Umweltstrafrechts, des Steuerstrafrechts, und der Aussetzungsprobleme.

Ich wäre Ihnen sehr dankbar, wenn sie wieder die Diskussionskarten verwenden würden und die Gliederungspunkte angeben könnten, zu denen Sie sprechen wollen - möglicherweise verbunden, soweit sie sich zum allgemeinen Teil melden, mit einem der von mir eben genannten Stichworte. Aber das ist nicht in einem exklusiven Sinne gemeint: Sie können auch andere Stichworte hier in die Diskussion einbringen. Schönen Dank.

Badura: Das Thema „Verwaltungsrecht als Vorgabe für Zivil- und Strafrecht" hat mit einer gewissen Zwangsläufigkeit eine große Fülle von Einzelheiten und Einzelfragen zutage gefördert, und die Referenten haben sich mit großer Regsamkeit und großem Scharfsinn auf die Suche nach einem roten Faden begeben. Sie haben allerdings zu Recht eine Generallösung vermieden, in folgenden vier Punkten vor allem. 1. Sie sind nicht der Versuchung erlegen, sich einfach darauf zurückzuziehen, daß das Gesetz eben die wesentliche Entscheidung zu treffen hätte. Der Umstand, daß es derselbe Gesetzgeber ist, der privatrechtliche und verwaltungsrechtliche Sätze erläßt, ändert doch nichts daran, daß es einen in unserer Rechts- und Verfassungsordnung tief verankerten Unterschied zwischen den Gesetzen des Privatrechts und denen des Verwaltungsrechtes gibt, auch wenn zum Teil eine gewisse Austauschbarkeit der Instrumente bestehen mag. Eine gewisse Austauschbarkeit, die allerdings nur dann so gesehen werden kann, wenn man den instrumentalen Charakter des Rechtes sehr in den Vordergrund stellt und damit die innere Verschiedenheit etwas beiseite schiebt. Zweitens ist der Gedanke der Einheit oder Widerspruchsfreiheit der Rechtsordnung zwar zu Recht genannt worden - er hat ja zum Teil eine verfassungsrechtliche Seite - aber er ist keineswegs 
geeignet, wie vor allem Herr Schröder in These 5 sehr einleuchtend dargelegt hat, als eine Art Zauberstab für die Lösung zu dienen. 3. In dem Thema sind die Beziehung zum Privatrecht und die zum Strafrecht sozusagen gleichgeschaltet worden, ich glaube aber, daß gerade die beiden Vorträge deutlich gezeigt haben, daß hier eigentlich doch recht verschiedene Dinge vorliegen. Während in einem Falle es darum geht, daß der Gesetzgeber Privatautonomie und Privatrechtsbeziehungen zu ordnen hat und gegebenenfalls sie durch verwaltungsrechtliche Intervention oder Modifikation beeinflußt, haben wir es in dem anderen Falle mit der staatlichen Strafgewalt zu tun und mit der Frage, inwieweit sie durch verwaltungsrechtliche Regelungen normativ beeinflußt oder, was die Jurisdiktion anbetrifft, auch gebunden werden könnte. 4. Ich glaube, daß ein Grundsatz unserer Rechtsordnung die selbständige Entscheidungskompetenz jedes Richters der einzelnen Gerichtsbarkeiten ist, und daß deswegen die Vorfragenkompetenz als Grundsatz zu unserer Rechts- und Gerichtsorganisation gehört. Es ist also eine Ausnahme, finde ich, wenn man sagt, daß es eine Bindung im Bereiche der Vorfragen gibt, und es mag durchaus so sein, daß die „Verwaltungsakzessorietät", wie man das nennt, aufgrund selbständiger Beurteilungs- und Entscheidungskompetenz der Exekutive sich insbesondere im Bereich dieses Sanktionsrechtes findet, also etwa im Umweltstrafrecht, wo in der Tat man dann sagen kann, daß durch diese besonderen Entscheidungsregeln der, wie ich meine, Grundsatz der Vorfragenkompetenz des Richters verdrängt wird, in diesem Bereich.

Schließlich ist das, was von den Referenten ja erwartet wurde, der rote Faden also, letzten Endes eine dogmatische Aufgabe. Aber die beiden Vorträge haben, wie ich finde, sehr deutlich gezeigt, daß unsere Verwaltungsrechtsdogmatik letzten Endes auf den materiellen Grundsätzen und Garantien des Verfassungsrechtes aufbaut und daß auch für dieses Thema, wie kaum anders zu erwarten war, die wesentlichen Präjudizien für die dogmatische Behandlung der Fragen sich aus dem Rechtsstaatsgedanken, den Grundrechten und anderen materiellen Prinzipien ergeben.

Jarass hat, wenn ich noch einige Bemerkungen zu den beiden Einzelbereichen sagen darf, mit vollem Recht darauf hingewiesen, daß das Verwaltungsrecht eine gewisse Sozialisierung des Rechtsstoffes bewirkt. Er hat das Wort von der „Publifizierung“ des Zivilrechtes zitiert. In der Tat ist das Ansteigen des Verwaltungsrechtes seit der Zeit des ersten Krieges sicherlich der Ausdruck eben der sozialstaatlichen Expansion der Staatsaufgaben. Diesen Vorgang kann man, wie ich glaube, nur dann richtig verstehen, wenn man die Konfrontation 
dieses Zugriffs oder dieser Gestaltungsaufgabe des Staates mit den Privatrechtsbeziehungen vor Augen hat, für die Privatautonomie, Vertragsfreiheit und Eigentum grundsätzlich bestimmend sind. Dies belegen die Beispiele von Herrn Jarass zur Entwicklung vom privatrechtlichen zum öffentlich-rechtlichen Nachbarrecht, zum Baurecht, zur Präklusion privatrechtlicher negatorischer Ansprüche und anderes. Alles das zeigt diese, nicht überall, aber jedenfalls in erheblichem Maße bestehende Konfrontation, wobei auch die Beobachtung interessant ist, daß bei $\$ 906$ BGB möglicherweise die Opferschwelle des Privatrechts - der privatrechtlichen Zumutbarkeit - mit Hilfe von immissionsschutzrechtlichen Klauseln oder sogar Verwaltungsvorschriften beeinflußt sein könnte.

Der allgemeine Hintergrund für das Thema „Verwaltungsrecht und Privatrecht" sind die Grundrechte. Wie ich finde, haben sich mittlerweile im Planungsrecht und im technischen Sicherheitsrecht gewisse Teildogmatiken entwickelt. Sehr stark durch die Rechtsprechung des Bundesverwaltungsgerichts beeinflußt, haben sich hier - vielleicht stärker als in anderen Bereichen - Teildogmatiken entwickelt, abgeleitet insbes. aus der gesetzlichen Planungsaufgabe und dem rechtsstaatlichen Abwägungsgebot. Dies mündet im übrigen in die Frage, in welcher Weise diese Teile unserer Rechtsordnung in einer rechtsstaatlich einwandfreien Weise, zugleich aber in einer Weise, die der Verwaltung die Erfüllung ihrer Aufgabe ermöglicht, zu normieren seien.

Was das Strafrecht nun anbetrifft, kann es nicht anders sein - wie es Herr Schröder sagte -, daß wir hier eine autonome Ausformung des Rechtsgüterschutzes haben, wenn auch z.T. in Anknüpfung an verwaltungsrechtliche Pflichten. Gerade wenn man den Vortrag von Herrn Schröder gehört hat, glaube ich, muß man um so deutlicher fordern, daß die Strafbarkeit an eine eindeutige, sachlich und zeitlich bestimmte und berechenbare Pflichtverletzung anknüpfen muß. Es ist in der Tat eine grundlegende Aufgabe des Strafrechtes, d.h. in der ersten Reihe eine rechtsstaatliche Aufgabe des Gesetzgebers, dafür zu sorgen, daß die Pflichten, an die Strafrechtssanktionen anknüpfen, klar, eindeutig, bestimmt und unzweifelhaft niedergelegt werden, mit Einbeziehung auch des Falles, daß das Strafrecht bei „Sanktionsrecht", wie es genannt worden ist, an verwaltungsrechtliche Pflichten anknüpft und dort möglicherweise ein Teil der Strafnorm durch verwaltungsrechtliche Entscheidungen fixiert sein kann, unbeschadet natürlich dessen, was Herr Schröder auch sagte, daß die Strafe die ultima ratio sein muß. Die Rechtsprechungsaufgabe der Strafjustiz also wird zu unterscheiden sein von der rechtsstaatlichen Aufgabe des 
Gesetzgebers. Diese beiden Ebenen sind ja auch in den Thesen von Herrn Schröder unterschieden worden, wenn auch vielleicht etwas mehr immanent als explizit. Die Rechtsprechungsaufgabe der Strafjustiz also, die anknüpfen muß an den Gedanken der Gewaltenteilung und an die Aufteilung der Verantwortung zwischen der Exekutive und dem Richter. Diese Aufteilung der Verantwortung liegt, wie ich finde, den Thesen $7 \mathrm{~b}, 12,14,17 \mathrm{~b}$ von Herrn Schröder zugrunde, wo er für verschiedene Bereiche, etwa für die normkonkretisierenden Verwaltungsvorschriften oder für die Frage der Tatbestandswirkung des Verwaltungsaktes oder für die abschließende Bindungswirkung einer Erlaubnis, je nach ihrer begrenzten Regelungswirkung natürlich, auf diese unterschiedliche Verantwortung der einen oder anderen Seite hingewiesen hat. Das ist in meinen Augen auch der rechtsstaatliche Hintergrund, der dann eine hinreichende Klarheit für die Rechtsprechungsaufgabe des Strafrichters liefern müßte. Ich möchte schließen mit der Betonung, daß ich auch finde, daß die grundrechtliche Schutzwirkung sich hier auch in Verfahrensnormen äußern kann, also etwa in der Frage der Aussetzung, wenn für den Strafrichter sich abzeichnet, daß er andernfalls in eine Kollisionssituation geraten würde. Auch an dieser Stelle zeigt sich also, daß die Lösung in einer öffentlichrechtlichen Dogmatik auf der Grundlage der rechtsstaatlichen Grundsätze und Garantien gefunden werden muß.

Rupp: Herr Vorsitzender, meine sehr verehrten Damen und Herren, ich möchte an das anknüpfen, was Herr Badura gesagt hat. Wir haben in den neueren Wirtschaftsgesetzen häufig gleich drei Sanktionssysteme bei Rechtsverletzungen: einmal des Verwaltungsrechts, sodann des Zivilrechts und schließlich - bei groben Verstößen - des Strafrechts. Musterbeispiel dafür ist nicht so sehr das UWG, das hier genannt worden ist, sondern das GWB. Es enthält verwaltungsaufsichtsrechtliche Bestimmungen in Gestalt der Kontrolle durch das Bundeskartellamt, sodann umfaßt es zivilrechtliche Vorschriften über den Schutz des einzelnen gegen wettbewerbsbeschränkende Kartelle und zum dritten entsprechende Strafvorschriften. Wir haben es also - systemtheoretisch gesprochen - mit drei Sanktionssystemen zu tun, die die Einhaltung der Rechtsordnung erzwingen sollen. Jhering hatte es bekanntlich geradezu als moralische Pflicht angesehen, das individuelle Recht durchzusetzen, weil damit sich ein Stück objektiver Rechtsordnung verwirkliche. Der „Kampf ums Recht“ wird dadurch legitimiert. Heute sehen wir, daß dieses zivilrechtliche und zivilprozessuale - Durchsetzungssystem aus vielerlei Gründen nur noch bedingt greift - die Verbandsklage, wie sie 
das GWB kennt, zeugt davon. Deshalb gibt es daneben das verwaltungs- und das strafrechtliche Sanktionssystem. So ist es beispielsweise auch beim Immissionsschutz. Der Unterschied liegt nur darin, daß das Bundesimmissionsschutzgesetz nur das verwaltungsrechtliche Instrumentarium des Umweltschutzes enthält und das zivilrechtliche im BGB, das strafrechtliche nunmehr im Strafgesetzbuch enthalten ist. Dies mag der Grund sein, daß das verwaltungsrechtliche Instrumentarium mit demjenigen des Zivilrechts nicht harmoniert: $\$ 906 \mathrm{BGB}$ schließt den zivilrechtlichen Abwehranspruch - der überdies als eigentumsrechtlicher, nicht als personenbezogener konzipiert ist u. a. dann aus, wenn die Beeinträchtigung „ortsüblich“ ist. Es kommt also für den zivilrechtlichen Schutzanspruch darauf entscheidend an, ob das in Betracht stehende Gebiet ohnehin immissionsbelastet ist und - so scheint das Gesetz anzunehmen - eine weitere Belastung nicht zu Buch schlägt. So gesehen handelt es sich bei der „Ortsüblichkeit“ des $\$ 906$ II BGB um einen deskriptiven Begriff. Das Interessante liegt nun darin, daß die Zivilgerichte angesichts des Umstandes, daß auf diese Weise ein wirksamer Umweltschutz nicht möglich ist, über eine Neuinterpretation des $\$ 906$ II BGB den zivilrechtlichen Umweltschutz dem Standard des verwaltungsrechtlichen Umweltschutzes anzunähern versucht haben, und zwar dadurch, daß sie die „Ortsüblichkeit" nicht mehr als faktische, sondern als gesollte Größe, also präskriptiv, interpretieren, nämlich im Sinne der vom Immissionsschutzgesetz postulierten Werte. Dieser Vorgang der Uminterpretation eines Ist-Befundes in einen am Immissionsschutzgesetz orientierten Sollenbefund und die dadurch bewirkte Harmonisierung zweier Sanktionssysteme scheint mir - so problematisch dieser Weg interpretationstheoretisch auch sein mag - für unser Thema außerordentlich interessant zu sein.

Noch etwas Zweites möchte ich sagen, nämlich zum Thema der Einheit der Rechtsordnung, das heute wiederholt angeklungen ist. Ich glaube, es gibt keinen Rechtsgrundsatz der Einheit der Rechtsordnung, und zwar deshalb nicht, weil die personalen Beziehungsstrukturen des Rechts immer relational und deshalb auch die Kategorien der Rechtmäßigkeit und Rechtswidrigkeit relativ sind.

Ein Wort noch zu den Verwaltungsvorschriften als Kontrollmaßstäben, nachdem beide Referenten sich mit diesem Problem und mit der Unterscheidung von norminterpretierenden, normkonkretisierenden und normergänzenden Verwaltungsvorschriften zum Zwecke der Gewinnung von "Außenrecht" auseinandergesetzt haben. Ich meine, man sollte diese Ladenhüter endgültig beiseite legen. Denn der Umstand, daß - wie sich inzwischen herumgesprochen haben dürfte 
- auch Verwaltungsvorschriften Rechtsnormen sind und kein „impermeables“ Nichtrecht, allerdings "Innenrecht" in dem schon von Adolf Merkl gebrauchten Sinn, begründet absolut nicht einen Umschlag von Innen- in Außenrecht. Auch das Hantieren mit norminterpretierenden, normkonkretisierenden und normergänzenden Verwaltungsvorschriften mit dem Ziel, die "Außenwirkung“ bestimmter Verwaltungsvorschriften zu erreichen, sollte - so meine ich - so schnell wie möglich wieder der Rechtsgeschichte überlassen werden. Denn dieses Hantieren ist verfassungsrechtlich unhaltbar, weil es das verfassungsrechtliche Erfordernis der gesetzlichen Ermächtigung mißachtet und es der Verwaltung überläßt, ob sie ihren Verwaltungsvorschriften Außen- oder nur Innenwirkung geben will, und es ist methodisch verfehlt, weil es zur Bestimmung der Normqualität eine Unterscheidung von bloß "norminterpretierenden" einerseits und "normkonkretisierenden“ oder "normergänzenden“ Normen andererseits nicht gibt. Wir sollten - wie ich meine - die vergeblichen Distinktionen der Vergangenheit nicht wieder aufnehmen.

Bettermann: Das Thema, das heute behandelt wird, ist nicht neu. In den ersten Jahren nach dem Kriege waren die Eingriffe der öffentlichen Verwaltung in das wirtschaftliche und gesellschaftliche Gefüge und damit in das Privatrecht an der Tagesordnung. Da haben uns die heute erörterten Probleme insbesondere der Vorfragenkompetenz und der Bindung an Verwaltungsakte, bei denen damals bei bestimmten Behörden, etwa Wohnungsämter und Straßenverkehrsämter, die Vermutung für die Rechtswidrigkeit sprach, stark beschäftigt.

Dies ist ein Feld, auf dem mit allgemeinen Grundsätzen wenig auszurichten ist, wo die Gefahr der Verallgemeinerung nur partiell richtiger Aussagen groß ist. Wenn irgendwo der Satz „bene cernit, qui bene distinguit" gilt, dann ist es hier.

Zum Beispiel hat Herr Schröder unter Ziffer 18 gesagt, der Strafrichter könne eine fehlende, aber gesetzlich vorgeschriebene Genehmigung nicht ersetzen. Das halte ich für richtig, wenn es sich um eine Ermessensgenehmigung handelt. Aber bei gebundenen Genehmigungen erscheint mir das fraglich. Wenn die Genehmigungsvoraussetzungen vorliegen, also das Handeln, dessen Rechtmäßigkeit und Strafbarkeit zur Diskussion stehen, materiell rechtmäßig ist, soll dann trotzdem die Strafsanktion eintreten? Hat doch Herr Schröder die Strafe als die ultima ratio des Rechtsstaats bezeichnet - freilich eine Behauptung, die ohne Diskussion mit den Strafrechtlern und Kriminologen m. E. nicht unbesehen akzeptiert werden kann. Ich kenne jedenfalls 
andere Sanktionen, die im Einzelfall sehr viel einschneidender und belastender sind als Strafen.

Aber selbst innerhalb der gebundenen Erlaubnisse würde ich noch Bedenken haben, daß der Strafrichter von der materiellen RechtmäBigkeit oder Rechtswidrigkeit auszugehen habe. Wenn jemand ohne Fahrerlaubnis fährt (zu unterscheiden vom Fahren ohne Führerschein), so kann kaum ein Zweifel sein, daß der Strafrichter diese Erlaubnis, obwohl sie eine gebundene ist, nicht substituieren darf. Bei fehlender Bauerlaubnis, wo also unerlaubtes Bauen strafbar oder bußgeldbewehrt sein sollte, ist das schon zweifelhafter. Da würde es vielleicht naheliegen zu sagen: wenn bloß Ordnungswidrigkeit, handelt es sich um ein Formaldelikt, so daß die Ordnungswidrigkeitssanktion eingreifen muß, wenn ohne Erlaubnis gebaut worden ist, also verfahrensrechtliches Unrecht begangen wurde. Aber auch das wäre voreilig, wieder eine unzulässige Verallgemeinerung. Denn vom Ordnungswidrigkeitengesetz (OWiG) werden nicht nur bloße Verstöße gegen die öffentliche Ordnung und Sicherheit, reines Verwaltungsunrecht, erfaßt. Vielmehr sind bei der Entkriminalisierung zahlreiche Delikte gravierenden Unrechtgehalts, echte Straftatbestände, ins OWiG hinübergeschoben worden.

Gravierend in der neueren Entwicklung sind die Steuerstrafprozesse. In Hamburg hatten wir den Spendenprozeß gegen den Reemtsmavorstand. Da war offenkundig, daß der Strafkammervorsitzende die Sache unter allen Umständen durchziehen und zu einer Verurteilung kommen wollte, obwohl der Fall noch beim Finanzamt hing. Jeden Tag berichtete das Hamburger Abendblatt über den Prozeß und verschaffte so dem Vorsitzenden Publizität. Es wundert mich, daß Herr Scbröder nicht energischer eine Reform des $\$ 262$ StPO in Vorschlag gebracht hat. Die Aussetzung wegen sachfremder oder kompetenzfremder Vorfragen muß ja nicht im Ermessen des Richters stehen. Wir haben im geltenden Recht genügend Fälle obligatorischer Aussetzung. Sie brauchen in der Zivilprozeßordnung nur bei $\$ 148$ weiterzulesen, da finden Sie Fälle von Aussetzungszwang. Näher liegt uns Art. 100 GG, der die Aussetzung zur Pflicht macht. Es wird hier immer nur an die Vorlage gedacht, aber Art.100 GG spricht von Aussetzung und Vorlage. Es ist ein Fall der Vorlage wegen kompetenzfremder, nämlich verfassungsrechtlicher Vorfragen. Es muß darüber nachgedacht werden, in welchen Fällen die Aussetzung wegen streitbefangener Vorfragen obligatorisch gemacht werden soll. Auch hier muß man wieder differenzieren. Wir können nicht generell die Aussetzung von Zivil- und Strafverfahren wegen vorgreiflicher Verwaltungsverfahren zur Pflicht machen, weil dann die Gefahr besteht, 
daß durch die Anfechtung des Verwaltungsakts die Durchführung des Justizprozesses um Jahre verzögert wird, wenn der Verwaltungsprozeß durch die Instanzen getrieben wird. Nach fünf oder sieben Jahren aber ist die Bestrafung uninteressant, auch wenn keine Verjährung eingetreten ist. Aber hier haben wir Instrumente, die weiterhelfen z.B. den Suspensiveffekt. Wo die Anfechtung des vorgreiflichen Verwaltungsaktes aufschiebende Wirkung hat und diese nicht im Einzelfall ausgeschlossen worden ist, da muß, meine ich, der Strafrichter den Ausgang des Verwaltungsstreits abwarten - wobei vielleicht der Streit wieder hochkommt, ob der Suspensiveffekt Vollzugshemmung oder Wirksamkeitshemmung auslöst. Im Steuerrecht hat die Anfechtung von Steuerbescheiden generell keine aufschiebende Wirkung; aber sie kann im Einzelfall wiederhergestellt werden, notfalls durch das Gericht, wenn die Behörde es abgelehnt hat. Wenn die Aussetzung der Vollziehung angeordnet ist, dann ist damit von kompetenter Stelle entschieden, daß ernsthafte Bedenken gegen die Rechtmäßigkeit des Steuerbescheids bestehen. Also kann nicht nur, sondern $\mathrm{mu}\} \mathrm{m}$. E. der Strafrichter warten, bis der Steuerstreit ausgetragen ist.

Bullinger: Herr Vorsitzender, meine sehr verehrten Damen und Herren, ich möchte wieder anknüpfen an das, was Herr Badura sagte. Ich glaube, daß die beiden Referate eigentlich vor dem falschen Publikum gehalten wurden. Herr Schröder hätte vor der Vereinigung der deutschen Strafrechtslehrer und Herr Jarass vor der Vereinigung der deutschen Zivilrechtslehrer sprechen müssen. Beide wären dabei auf ein unterschiedlich abwehrendes Vorverständnis gestoßen. Bei den Vertretern des Strafrechts läßt sich durchaus Verständnis dafür wekken, daß eine Verwaltungsentscheidung, die ja auch die Durchsetzung des Rechts bezweckt, und eine strafgerichtliche Entscheidung aufeinander bezogen und wechselseitig abhängig sein können. Freilich findet sich die Vorstellung, daß letztlich der unabhängige Strafrichter frei entscheiden müsse. Aber das läßt sich beheben. Dagegen wären Sie, Herr Jarass, mit ihrem Vortrag vor der Vereinigung der deutschen Zivilrechtslehrer nach meiner nun mittlerweile über 25jährigen Erfahrung in Freiburg auf ein fast unüberwindlich ablehnendes Vorverständnis gestoßen. Denn das Zivilrecht wird, anders als das Strafrecht, immer noch weitgehend als eine dem Öffentlichen Recht gegenüber nicht nur autonome, sondern antinomische Ordnung verstanden. Das Zivilrecht lebt modellhaft von der Vorstellung, die eigentlich mehr vom Schuldrecht herkommt, es handele sich um eine nicht national gebundene, weltrechtsfähige Ordnung einer als autonom gedachten Erwerbs- und Verkehrsgesellschaft. Für sie sind Interventionen eines 
Staates in Form seines nationalen Verwaltungsrechts nicht eine Vorgabe, sondern eine Störgabe, etwas Fremdes, das man möglichst restriktiv handhabt und als Zivilrichter oder Zivilrechtslehrer, wenn es irgend geht, gar nicht erwähnt. Nicht Unkenntnis, sondern innere Ablehnung bestimmt also hier das Verständnis. Das große Problem ist, wie man dieses negative Vorverständnis überwinden kann.

In ähnlicher Weise wird im angelsächsischen Recht traditionell das common law als vorgegebene Ordnung betrachtet, in die der Gesetzgeber störend eingreift. Das House of Lords fragte eines Tages, es war 1959, die Parteien eines Prozesses, ob sie nicht ein Gesetz angewendet sehen wollten, das immerhin schon 10 Jahre in Kraft sei. Alle Beteiligten zogen es aber vor, es beim common law zu belassen. Das zeigt Ihnen, wie stark ein negatives Vorverständnis durchschlagen kann.

Meine Hoffnung geht dahin, daß Sie, Herr Jarass, mit Ihrem Referat dazu beigetragen haben, das negative Vorverständnis des Zivilrechts gegenüber dem Verwaltungsrecht abzubauen. Im Wege steht aber immer noch ein Überlegenheitsgefühl auf seiten des Zivilrechts. Nur die Zivilgerichte sind „ordentliche Gerichte“, und die Einführung eines neuen Landgerichtspräsidenten ist ein größeres Ereignis als die Einführung eines neuen Verwaltungsgerichtspräsidenten. Wir müssen also das Verwaltungsrecht aufwerten, damit es dann unbefangen als Vorgabe auch für das Zivilrecht betrachtet werden kann.

Hans-Peter Schneider: Herr Vorsitzender, meine Damen und Herren, im Unterschied zu Herrn Bullinger glaube ich doch, daß beide Referenten ihre Vorträge heute vor dem richtigen Publikum gehalten haben. Denn es geht hier nicht um irgendeinen Prioritätenoder, was das Zivilrecht angeht, auch Anciennitätenstreit. Jedenfalls sollten wir nicht der Versuchung erliegen, diesen Streit fortzusetzen, sondern wie Herr Jarass in seinen einleitenden Bemerkungen sehr deutlich gemacht hat, aufzeigen, daß es gar nicht darum geht, wer hier letzten Endes wem etwas vorgibt, sondern um die Frage einer sachund funktionsgerechten Arbeitsteilung innerhalb einer nach Problemund Lebensbereichen, auch nach Sanktionsformen gegliederten Rechtsordnung. Wenn man die Dinge so sieht, dann muß man allerdings, und da würde ich Herrn Bettermann voll zustimmen, sehr vorsichtig sein mit jeder Art von Generalisierung und sehr genau differenzieren, d.h. sich fragen, ob und wie jeweils ein Rechtsgebiet von seinen Strukturen her in der Lage ist, Anforderungen des anderen aufzunehmen oder nicht.

Wenn ich noch einmal das Beispiel des Steuerstrafrechts aufgreifen darf. Hier war es ja so, daß in den meisten mir bekannten Fällen 
lediglich vorläufige Steuerbescheide vorlagen, also sog. Steuerbescheide unter Vorbehalt der Nachprüfung, so daß das eigentliche Besteuerungsverfahren nicht einmal abgeschlossen war, weil immer noch die Außenprüfung bevorstand. Hier ist es natürlich in der Tat so, daß wir zunächst einen bestandskräftigen Steuerbescheid brauchen. Dem würde ich zustimmen. Ich würde aber davor warnen, für die Strafverfahren eine Aussetzungsregelung vorzusehen, weil dies die Vorfragekompetenz, an der Herr Badura mit Recht festhalten möchte, letzten Endes doch in Frage stellen würde. Wenn wir eine Aussetzung ermöglichen, heißt das ja, daß insoweit jedenfalls die Vorfragekompetenz nicht akzeptiert wird. Dabei besteht im übrigen das Problem der Verjährung. Die meisten Strafgerichte standen doch unter ungeheurem Verjährungsdruck. Das muß man, glaube ich, der Vollständigkeit halber hinzufügen.

Eine letzte Bemerkung noch zum Punkt „Systemgerechtigkeit“. Ich glaube nicht, daß dieses Prinzip, ähnlich übrigens wie die Einheit der Rechtsordnung, einen brauchbaren Maßstab dafür abgibt, wer sich nach wem zu richten hat. Denn welches System soll denn im konkreten Fall eigentlich maßgeblich sein? Ich wähle ein Beispiel aus dem Sozialrecht und will das, was Herr Badura für den Richter gesagt hat, auch auf den Gesetzgeber beziehen. Wir haben im Sozialrecht eine sehr komplizierte Regelung der Hinterbliebenenversorgung: das sog. Anrechnungsmodell. Jeder weiß, daß sich dieses Modell nur schwer einfügt in die zivilrechtlichen Vorgaben des Versorgungsausgleichs. Bei der Teilhaberente wäre das relativ einfach gewesen. Soll nun der Gesetzgeber, einem Prinzip der Systemgerechtigkeit folgend, sagen: $\mathrm{Da}$ die zivilrechtliche Versorgungsausgleichsregelung bestimmte Strukturen vorgibt, muß sich das öffentliche Recht, hier das Sozialrecht, dem anbequemen? Ich bin nicht dieser Meinung. Ich bin der Meinung, daß hier der Gesetzgeber im Bereich des öffentlichen Rechts durchaus eigene Wege gehen kann, die nicht von irgendeinem „System" her vorgegeben sind, und daß es im Konfliktfall um das Problem einer sach- und funktionsgerechten Harmonisierung geht, die im wesentlichen der Richter zu leisten hat.

v. Arnim: Herr Vorsitzender, meine Damen und Herren, ich möchte auf die Frage eines eventuellen Imperialismus des Öffentlichen Rechts auf Kosten des Strafrechts und des Zivilrechts, die Herr Bullinger und Herr Schneider eben angesprochen haben, nicht insgesamt eingehen. Ich möchte nur einen Teilausschnitt ansprechen und eine Bemerkung machen zu dem Fall: günstiger Steuerbescheid und dennoch strafrechtliche Verfolgung, also zur steuerlichen Parteispen- 
denaffäre, die eben von Herrn Schneider, aber auch von Herrn Bettermann behandelt worden ist. Herr Scbröder geht ja davon aus, hier sei die finanzbehördliche Entscheidung maßgeblich, und in der Tat spricht vieles dafür, aus der Sicht des Steuerzahlers sein Vertrauen auf den günstigen Verwaltungsakt zu schützen und ihn davor zu bewahren, daß er strafrechtlich wegen desselben Sachverhaltes noch einmal belangt wird. Ich meine aber, daß man dem Verhältnis Finanzamt - Strafgericht doch nicht voll gerecht wird, wenn man nicht auch auf die Frage der Unabhängigkeit des Entscheidenden eingeht, - wir haben eine ähnliche Frage in anderem Zusammenhang auf einer früheren Tagung einmal unter dem Stichwort Distanz oder distance diskutiert. Ein Grund für das An-sich-reißen der Entscheidungen durch die Strafgerichte war ja doch wohl die Befürchtung, daß die Verwaltung hier nicht ganz unabhängig, nicht ganz unbefangen war, weil eine Art Zusammenspiel zwischen Verwaltung, Parteien und Steuerpflichtigen hier stattgefunden hatte, wenn Sie so wollen, etwas überspitzt gesagt, ein Kollusionsdreieck. Ich spreche also das Milieu des Verwaltungsvollzugs an, das Herr Jarass am Schluß seines Referats kurz erwähnt hat. Bedenkt man, daß die Parteispendenaffäre tiefgehende Auswirkungen hatte - Stichworte: Erschütterungen des Rechtsstaats, Beeinträchtigung der Legitimation des Parteienstaates -, dann muß man das Eingreifen der Staatsanwaltschaften und die Einschaltung der unabhängigen Strafgerichte zumindest auch unter dem Aspekt der Aktivierung einer Legitimationsreserve zur Bewältigung der Parteispendenaffäre und zur Wiederherstellung des öffentlichen Vertrauens in die Rechtsstaatlichkeit verstehen. Wie immer man in der Sache dazu Stellung nimmt, meine ich doch, daß dieser Aspekt gerade von der Staatsrechtslehre nicht ausgeblendet werden sollte, wenn sie sich nicht ihrerseits dem Vorwurf aussetzen will, sie würde ebenfalls zu wenig Distanz zu den politischen Parteien haben.

Vogel: Eine Bemerkung im Anschluß an Herrn von Arnim. Der Gedanke der Legalitätsreserve leuchtet mir einerseits ein. Denn es ist ja in der Tat so: wenn die Verwaltung das Recht zu Lasten des Bürgers verletzt, kann sich der Bürger verteidigen; wenn sie aber das Recht zugunsten bestimmter Bürger, jedoch zu Lasten der Allgemeinheit verletzt, gibt es niemanden, der klagen kann. Es gilt dann der alte Satz, wo kein Kläger ist, ist auch kein Richter. Also: Zustimmung zum Gedanken der Legalitätsreserve. Aber die systematisch richtige Lösung wäre dann doch wohl nicht die, daß der Staatsanwalt Anklage wegen strafbarer Handlungen erhebt - die Strafgerichte können nun 
einmal, wie sich etwa in der Parteispendenaffäre gezeigt hat, schwierige öffentlich-rechtliche Fragen nicht immer richtig beurteilen -, sondern die systematisch richtige Lösung müßte darin bestehen, daß der Staatsanwalt (oder sonst ein Vertreter des öffentlichen Interesses) Klagebefugnis vor den fachlich zuständigen Gerichten erhält.

Ossenbühl: Herr Vorsitzender, meine sehr verehrten Herren Kollegen! Die Referenten hatten es mit dem Thema schwer, denn sie konnten nicht einen bunten Ballon der Visionen steigen lassen, um diesem Ballon dann sinnend nachzuschauen, sondern sie mußten auf dem Boden der Tatsachen und im Rahmen des juristischen Alltagsgeschäfts bleiben und hier enge Parzellen vermessen. Denn der Teufel steckt bei dem gestellten Thema im Detail. Das Problem der Zuordnung zwischen Zivilrecht und Strafrecht einerseits und Verwaltungsrecht andererseits läßt sich nicht durch ein globales Prinzip lösen. Einheit der Rechtsordnung und Widerspruchslosigkeit der Rechtsordnung sind Ziele, die wir anstreben müssen. Aber auf welchem Wege wir dahinkommen, ob mit der Präponderanz des einen oder anderen Systems, das ist die große Frage. Nun, ich will keine Bemerkung machen zu speziellen Einzelheiten, dazu habe ich mich an anderer Stelle geäußert. Ich will auch nicht den von Herrn Rupp leichthändig hingeworfenen Fehdehandschuh zum Streit über die Verwaltungsvorschriften aufnehmen. Der Zahn der Zeit, Herr Rupp, hat gewissermaßen die Argumentationslast inzwischen so umgekehrt, daß ich mich zunächst in Schweigen hüllen kann.

Ich will nur einige Bemerkungen machen zum Ambiente der Problemstellung und drei kurze Lösungshinweise geben. Dabei möchte ich mich auf das Verhältnis zwischen Strafrecht und Verwaltungsrecht beschränken, also das Zivilrecht ausklammern. Für die Genese der ganzen Problematik nicht unwichtig zu wissen ist, seit wann das Problem auf dem Tisch liegt. Ursache des Problems war das vor etwa 10 Jahren erlassene 18. Strafrechtsänderungsgesetz, welches das Umweltstrafrecht vom Nebenstrafrecht in das Kernstrafrecht transplantiert hat. Wie wir gesehen haben, hat die Schweiz das nicht getan. Deshalb stellen sich dort die Probleme nicht. Die Transplantation des Umweltstrafrechts ins Kernstrafrecht hat eine bestimmte Motivation und einen bestimmten praktischen Effekt gehabt. Die Motivation war die, daß man sagte, Umweltschutz allein mit den Mitteln des Verwaltungsrechts funktioniert nicht. Wir müssen die große Keule des Strafrechts holen. Dadurch wurde das Strafrecht gewissermaßen gleichrangig mit dem Verwaltungsrecht im Umweltrecht als Sanktionsmechanismus etabliert. Diese Gleichordnung hat von der vorma- 
ligen im Nebenstrafrecht existierenden Nachordnung des Strafrechts zu einer Konkurrenz zwischen Verwaltungsrecht und Strafrecht geführt. Da hinter dem Verwaltungs- und Strafrecht riesige Institutionen stehen, auch zur Konkurrenz zwischen diesen Institutionen. Dahinter steckt, wie es übertreibend ausgedrückt worden ist, ein bürgerkriegsähnlicher Zustand in der Praxis. Das Problem besteht darin, Strafrecht und Verwaltungsrecht so aneinanderzukoppeln, daß beide in Harmonie zueinander stehen. Um insoweit weiter zu kommen, ist es zunächst einmal notwendig, daß man sich in aller Kürze klarmacht, wo das Trennende liegt. Das Trennende liegt einmal darin, daß wir eine völlig unterschiedliche Dogmatik zwischen Strafrecht und Öffentlichem Recht haben. Zweitens darin, daß wir vom positiven Recht her bedingt auch eine institutionelle Trennung zwischen Strafrecht und Öffentlichem Recht vorfinden. Wir haben im Strafrecht die Gerichte und die Staatsanwaltschaft und im Verwaltungsrecht die Verwaltungsbehörden, die beide nebeneinander und unabhängig voneinander arbeiten. Wir haben drittens, jetzt komme ich zu den wichtigeren Punkten, erhebliche Unterschiede in den Zielen, die sich das Strafrecht setzt und die das Verwaltungsrecht anstrebt. Wir haben erhebliche Unterschiede in den Wertsetzungen, in den Handlungsformen usw. Dazu nur ein Beispiel. Wir halten im Umweltschutz das Kooperationsprinzip hoch. Ohne Kooperation sind die komplexen Probleme des Umweltschutzes gar nicht zu lösen. Immer wenn die Verwaltungsrechtler „Kooperation“ sagen, hören die Staatsanwaltschaften „Kollusion“. Dritter Punkt: Die größte Schwierigkeit der Verknüpfung besteht in der Kontaktlosigkeit, in der Entfremdung, in dem gegenseitigen Mißtrauen zwischen Verwaltungsbehörden einerseits und Staatsanwaltschaft, aber auch Strafrichtern andererseits bei der Erfüllung ein- und derselben Aufgabe, nämlich der Realisierung des Umweltschutzes. Die Strafrechtler sagen, das Verwaltungsrecht hat versagt, jetzt machen wir's mal. Dabei gehen sie soweit, sogar die Beamten in den Umweltbehörden als Mittäter anzusehen, indem sie ihnen vorwerfen, bei der Erteilung von Wasserbescheiden beispielsweise zumindest fahrlässig, wenn nicht schon grob fahrlässig oder mit dolus eventualis Wertsetzungen angegeben zu haben, die völlig unvertretbar seien. Auf der Basis solcher Vorwürfe verfolgen sie ihre Kollegen in den Umweltschutzbehörden und setzen sie hinter Schloß und Riegel. In Nordrhein-Westfalen hat es vor zwei Jahren über 100 Ermittlungsverfahren gegen Hauptverwaltungsbeamte gegeben, die in den Kommunen verantwortlich sind für den Betrieb von Kanalisationsanlagen, und denen vorgeworfen wurde, daß sie unter Schädigung der Umwelt falsche Werte angegeben hätten. Das 
alles hat seine Ursache, wie sich dann herausgestellt hat, darin, daß Unklarheiten bestehen über die Frage des Standards, der Werte usw. Nun, meine Herren, das ist der eigentliche Punkt. Hinter der Diskussion, die hier emotionsfrei geführt wird, steckt eine brodelnde Wirklichkeit mit erheblichen Komplikationen.

Drei Bemerkungen zu der Frage, wie läßt sich eine Harmonisierung wenigstens annähernd erreichen? Erstens müssen wir fächerübergreifende Diskussionen führen. Was Herr Bullinger sagt, hat natürlich wie immer, wenn er was sagt, nicht nur ein Körnchen Wahrheit für sich, sondern es ist vollkommen richtig zu sagen, wir müßten jetzt mit den Strafrechtlern diskutieren. Im Grunde genommen hätten wir die Strafrechtler und Zivilrechtler heute einladen müssen. Wir haben insoweit die Generalprobe schon hinter uns beim Juristentag in Mainz 1988. Aus dieser Erfahrung heraus darf ich sagen, daß eine solche Diskussion sehr fruchtbar sein kann. Und es ist $\mathrm{ja}$, in Parenthese gesprochen, heute so, daß kein Mensch mehr Beamter bei einer Umweltschutzbehörde werden will, weil er dann mit einem Bein im Knast sitzt. Das war also eine sehr positive Erfahrung. Es hat sich nämlich gezeigt, daß die Strafrechtler viele verwaltungsrechtliche Dinge nicht verstehen, und daß die Verwaltungsrechtler in vielen Dingen die Realität auch nicht richtig einschätzen. Man muß also zu einer Kooperation kommen. Zweiter Punkt: Wir brauchen klare gesetzgeberische Aussagen. Vor allem Aussagen, die dazu führen, daß der Bürger nicht unter diesem Behördenkrieg leidet. Die Rechtsordnung ist für den Bürger da. Deshalb muß der Dispositionsschutz des Bürgers auch ersten Rang haben. Wir dürfen nicht immer nur auf den Rechtsgüterschutz schauen. Der Kern des ganzen Problems liegt darin, daß es technisch unmöglich ist, die Standard- und Immissionswerte, deren Überschreitung zu Strafsanktionen führt, exakt festzulegen. Letzter Punkt: Ich sehe das Heil mit Herrn Schröder in einer verfahrensrechtlichen Lösung. Herr Bettermann hat schon m. E. zu Recht gesagt, insoweit hätte man gegenüber den geltenden Aussetzungsregeln offensiver vorgehen können und fragen müssen, ob sie noch zeitgemäß sind. Aber es bestehen Bedenken, ob der Gesetzgeber einen Ausweg bieten kann oder ob nicht vielleicht das Bundesverfassungsgericht doch irgendwann einmal die gestellte Frage aufgreifen muß. Denn es geht nicht nur um eine Frage der rechtstechnischen Zuordnung zweier Disziplinen. Letztlich steckt dahinter eine existentielle verfassungsrechtliche Frage, nämlich die, ob der Staat gegenüber dem Bürger mit mehreren Zungen sprechen darf oder nicht. 
Häberle: Herr Vorsitzender, verehrte Kolleginnen und Kollegen. Ich konzentriere mich auf drei Fragen: Erstens auf das Problem „Einheit der Rechtsordnung“ in Herrn Schröders Leitsatz 5 a und b sowie Herrn Jarass' Leitsatz 14. Zweitens folgt ein Wort zu der Frage, ob unser heutiges Problem nicht auch im größeren Zusammenhang des europäischen und internationalen Rechts steht, ich meine vor allem das europäische Verwaltungsrecht, das europäische Privat- und Arbeitsrecht. Drittens ein Wort zum hohen Rang des Privatrechts im Ganzen freiheitlicher Verfassungen. Doch zunächst eine nicht nur scherzhafte Vorbemerkung zu Herrn Bullinger. Ganz offenkundig unterschätzt er die Wirkung seiner Freiburger Antrittsvorlesung aus den 60er Jahren über das „Öffentliche Recht und Privatrecht“. Herr Brobm und ich, damals junge Assistenten, saßen in den letzten Reihen und sogen alles gehörig in uns auf, einschließlich der Fußnoten. Herr Bullinger schlug den Weg des "Gemeinrechts" vor, als Relativierung des Dualismus von Öffentlichem und Privatem Recht. Herr Bullinger, Sie hätten die Kollegen vom Zivilrecht und Strafrecht vor allem in diese Antrittsvorlesung schicken sollen, dann wären wir alle heute insgesamt weiter. - Jetzt zum ersten Punkt. Ich bin sehr dankbar, daß beide Referenten und eben auch Herr Badura und Herr Rupp das geleistet haben, was auf der Tagesordnung steht: eine "Entzauberung“ der meist unreflektiert als vorgegeben fingierten Formel der „Einheit der Rechtsordnung". Oft genug hat diese Schablone den Zugang zu den differenzierten Strukturen und Funktionen der Teilrechtsordnungen, die ja historisch wandelbar sind, die Einsicht in ihre propria, ihre unterschiedlichen Gerechtigkeitskriterien verdeckt. -

Die zweite Frage: Ist das Thema von heute nicht etwas zu nationalrechtlich-introvertiert aufgefaßt worden? Die Vorgabefunktion des Privat- und Strafrechts für das Verwaltungsrecht steht jetzt doch in einem europäischen Gesamtrahmen. Ich verweise auf Gestriges zum Thema „Europäisierung, Internationalisierung“ des Rechts. Ich erinnere an die hervorragende Trierer Arbeit von Müller-Graff zum Privatrecht im Europarecht; 1991 wird sich die Strafrechtslehrertagung in Bochum mit dem Problem des Strafrechts auf der europäischen Ebene befassen. In dem Maße, wie alle Teilrechtsgebiete in die europa- und internationalrechtlichen Dimensionen hineinwachsen, können wir unser heutiges Vorgabe-Problem nicht mehr von der "Einheit" der (nationalen) Rechtsordnung her angehen. Hier rückt die Ganzheit des Europäischen vor Augen. - Zum dritten Punkt, zum hohen Stellenwert des Privatrechts im Rahmen der anderen Teilrechtsordnungen bzw. der Verfassung. Hier habe ich gewisse Vorbehalte gegenüber dem letzten Leitsatz (19) von Herr Jarass, wo Privat- 
recht und öffentliches Recht im Sinne eines Vorrangdenkens bzw. im Namen der Leistungsfähigkeit gegeneinander ausgespielt werden. Wenn man wie ich derzeit in halboffizieller Mission vom Wissenschaftsrat aus die ostdeutschen Länder der Ex-DDR besucht und die osteuropäischen Länder hinzunimmt, dann wird einem schlagartig klar, was eine Privatrechtsordnung, „Treu und Glauben“", "gute Sitten“, „ehrbarer Kaufmann“ und ähnliche rechtsethische Prinzipien, wie wir sie im gemeineuropäischen Privatrecht und seiner Privatrechtsgesellschaft aus dem BGB und ZGB kennen, für die Gerechtigkeit, für die private und öffentliche Freiheit eines politischen Gemeinwesens bedeuten. Im übrigen sind Eigenwert und Eigenständigkeit des Privatrechts und seine die Verfassung mitkonstituierende Bedeutung jüngst von Konrad Hesse in seinem Karlsruher Vortrag „Verfassungsrecht und Privatrecht" von 1988 herausgearbeitet worden. Vielen Dank.

Thieme: Man kann unser Thema auf verschiedenen Ebenen diskutieren. Man kann es auf der Ebene der Institutionen diskutieren. Dann stellt man alsbald fest, daß die Differenziertheit der Institutionen, die unser Recht zu wahren haben, so etwas wie inkongruente Teilordnungen des Rechtes entstehen lassen. Es ist sicherlich notwendig, darüber etwas zu sagen. Diese Differenzierheit ist ein empirischer Befund, der nicht weiter belegt werden muß.

Es geht aber, so glaube ich, hier doch mehr darum, das Recht als solches anzusprechen und nicht seine Institutionen. Jedenfalls möchte ich mich darauf beschränken. Dabei stößt man natürlich auf den Topos der „Einheit der Rechtsordnung“. Das ist eine Leerformel, die - wir haben es gehört - nichts nützt. Im Gegensatz zu dieser Formel halte ich allerdings die "Widerspruchslosigkeit der Rechtsordnung“ für einen ganz erheblichen Wert, der gepflegt werden sollte und das halte ich auch für unsere Aufgabe.

Dann stellt sich die Frage, ob das, was wir akademisch pflegen, was wir mit dem Begriff des Verwaltungsrechts bezeichnen, in seiner Abgrenzung sinnvoll ist. Da habe ich unter dem Gesichtspunkt der Widerspruchslosigkeit der Rechtsordnung ganz erhebliche Bedenken. Das beginnt damit, daß es gewisse Materien gibt, die weder dem Zivilrecht noch dem Öffentlichen Recht zuzuordnen sind; ich denke etwa an das Personenrecht. Und wenn ich etwa an unsere Hamburger Deiche denke, die öffentlich-rechtlich sind, und nebenan beginnen die niedersächsischen Deiche, und die gehören dann dem Zivilrecht an, dann wird einem klar, daß die Abgrenzung des Verwaltungsrechts ganz vordergründig ist und keinen allzu großen Erkenntniswert hat. 
Das können wir im Strafrecht fortsetzen, bei den verschiedenen Sanktionsordnungen. Ich will nicht werten, ob die eine schärfer ist als die andere. Aber da ist der Verwaltungszwang, mit dem man zunächst einmal vorgeht, im Immissionsrecht auch. Weiter wird die ganze Palette der verwaltungsrechtlichen Normen ja im Grunde durch das Ordnungswidrigkeitenrecht erledigt, das Bußgeld. Die Zahl der strafrechtlichen Verfahren ist demgegenüber dann ja nur noch eine Winzigkeit, die das Wesentliche gar nicht mehr erledigt. Wir würden auch gar nicht auskommen, wenn nicht die Masse der Verfahren über das Bußgeldrecht, nämlich durch die Verwaltung selbst erledigt werden würde.

Nun stelle ich die Frage: Was bedeutet denn eigentlich Verwaltungsrecht, die Arbeit mit dem Verwaltungsrecht? Da rekurrieren wir, das haben die Referenten auch getan, auf die Verfassung, die den Vorrang des Privatrechts, der marktwirtschaftlichen Ordnung kennt. Aber genauso gut wissen wir, daß der Markt nicht überall funktioniert. Dann kommt die Verwaltung mit ihrer spezifischen Ordnung und legt sich über den Markt. Jetzt haben wir den Konflikt. „Markt versus staatlichen Eingriff." Auf diesem Konfliktfeld befinden wir uns, und dieses Konfliktfeld muß dann natürlich, und das haben die Referenten ja auch getan, ganz sorgfältig Stück für Stück abgeschritten werden, wie wir die Konflikte im einzelnen erledigen. Wenn wir als Beispiel dafür das Baurecht nehmen, das mit dem Immissionsrecht kollidiert, so sind das zum Teil keine Konflikte in dem Sinne, wie sie hier gesehen worden sind. Wenn ich einen bauplanungsrechtlich zulässigen Bau habe, der gleichwohl nicht zulässig ist, weil er mit dem Immissionsrecht konfligiert, bedeutet das doch, daß jeweils eine gewisse Intention hinter jeder Teilrechtsordnung des Verwaltungsrechts steht. Wir müssen die einzelnen Teilrechtsordnungen des Verwaltungsrechts nehmen und sie gesondert sehen und dann auch fragen, etwa im Eigentumsrecht, was beschränkt wird. Ist es wirklich so, wenn mir das Verwaltungsrecht sagt, du darfst das Eigentum nicht so nutzen, wie du möchtest, daß damit die Frage entschieden ist? Es stellt sich doch - genauso wie im Zivilrecht oder einer anderen Teilrechtsordnung - die zweite Frage: Wenn man das nicht nutzen darf, wenn man sein Recht verliert, bekommt man dann eine Entschädigung? Die Differenziertheit der Rechtsfiguren, die wir entwickelt haben, muß hier wirksam werden. Ich danke den Referenten dafür, daß sie diese Differenzierheit zum Tragen gebracht haben.

Kloepfer: Die Thematik, die wir hier behandeln, führt zu Fragen der Gerechtigkeitssicherung, der Rechtssicherung und der Zuständigkeitssicherung. Es ist hier gegen die Vorstellung der Einheit der Rechtsordnung sehr scharf formuliert worden. 
Soweit sich dies auf die Einheit der Rechtsordnung als Rechtsvorstellung bezieht, ist diese Kritik auch richtig. Ich glaube aber, daß es auch Vorstellungen außerhalb rechtlicher Faßbarkeit als Gesetzgebungsmaximen gibt, gewissermaßen als rechtspolitische Maximen. Es ist vernünftig, Rechtsordnungen nach gewissen einheitlichen Vorstellungen zu formulieren und eine Harmonie innerhalb der Rechtsordnung anzustreben. Daß das nicht perfekt zu erreichen ist, ist wieder eine andere Frage, aber als politische Gesetzgebungsmaxime halte ich die Einheit der Rechtsordnung für eine wichtige Sache. Insoweit hat die Vorstellung der Einheit der Rechtsordnung auch die Aufgabe der Gerechtigkeitssicherung.

Im übrigen wird dies ja auch rechtlich in ganz vorsichtiger Sicht durch die durchgängige Bindung der Gesetzgebung an unsere Verfassung gewährleistet. Interessant ist dabei für die Juristen sicherlich die Frage, welche Instrumente und Gedankenfiguren zur Sicherung der Rechtseinheit führen können. Die Systemgerechtigkeit - dies ist m. E. von Herr Schröder ganz zutreffend behandelt worden - wird (aus der Ableitung aus Art. 3 GG heraus verständlich) nicht allzu viel bringen. Für meine Begriffe führen die Erwägungen, die hier anzustellen sind, zu einem grundsätzlichen Defizit unserer verfassungsrechtlichen und einfachrechtlichen Konzeption überhaupt. Wir haben es bis heute aus meiner Sicht nicht geschafft, uns grundsätzlich von den punktuellen Betrachtungsweisen zu lösen. Wir können sehr schön sagen, der Verwaltungsakt gegenüber dieser Person wird die und jene Rechtsfrage berühren. Was wir nicht können oder kaum können, sind Fragen der Belastungskumulation rechtlich in den Griff zu bekommen, oder eben die Fragen, die hier eine Rolle spielen, nämlich einerseits bespielsweise die verwaltungsaktmäßige Behandlung einer Sache und dann deren strafrechtliche Bewertung. Gerade in dieser gesamthaften Betrachtung fehlen uns weitgehend einheitliche Rechtsmaßstäbe.

Es ist von den Referenten zutreffend darauf hingewiesen worden, daß wesentliche Problemgehalte, die wir hier zu behandeln haben, solche der Zuständigkeitssicherung sind, wobei sich freilich - und ich glaube, auch das haben die Referenten im Grundsatz richtig gesehen - das Problem der Verwaltungsrechtsaktakzessorietät und das der Verwaltungsaktsakzessorietät sich doch sehr unterschiedlich stellen. In der Tat - bei der Verwaltungsaktsakzessorietät geht es maßgeblich um die Fragen der Gewaltenteilung. Anders ist dies aber, aus meiner Sicht jedenfalls, bei der Verwaltungsrechts- oder Verwaltungsnormakzessorietät; dort bleibt dies primär eine Frage von Gesetzgeber zu Gesetzgeber. Und für diesen Problembereich möchte ich wenigstens als Idee noch einbringen, Teillösungen aus der verfassungsrechtlichen 
Kompetenzordnung - z. B. aus Art.74 GG - zu entwickeln. Insoweit kann man fragen, ob hier nicht eine Vorstellung der Verfassung zugrunde liegt, wonach ein bestimmter Ordnungsbereich der Strafrechtspflege, ein bestimmter Ordnungsbereich der Zivilrechtspflege und des jeweiligen Verwaltungszweigs vorhanden ist. Ich hätte jedenfalls verfassungsrechtliche Bedenken, gestützt nur auf Art. 74 Nr.1 GG, gewissermaßen über den Umweg zivilrechtlicher Regelungen oder über den Umweg gar von Strafrechtsnormen, die ganzen Kompetenzen an sich zu ziehen, die etwa dem Bund im Bereich der Verwaltungsrechtsregelungen vorenthalten sind. Es ist doch ganz unmöglich, die Begrenzung des Art. 75 GG auf den Wasserhaushalt dadurch zu umgehen, daß ich sage, das mache ich jetzt im Strafrecht und damit habe ich die ganze Regelungskompetenz.

Ich gebe zu, daß in den meisten Fällen dieser Kompetenzansatz verwischt werden kann durch die Möglichkeit der Kompetenzkombination, wie wir sie kennen. Das schließt aber die grundsätzliche Rückgriffsmöglichkeit auf die Kompetenzordnung zur Lösung der Verwaltungsnormakzessorietät nicht aus.

Wichtig ist, daß die Kollisionsregelung bei Normkollisionen an sich Aufgabe des Gesetzgebers ist. Er tut dies auch häufig, wie etwa im Baurecht oder in der Altlastenregelung im Einigungsvertrag; da steht ja ausdrücklich drin: Privatrechtliche Ansprüche bleiben unberührt.

Eine Bemerkung noch zur sog. Gleichrangigkeit der Rechtsnormen, gerade im Hinblick auf das Verhältnis von Zivil- und Verwaltungsrecht. Herr Jarass vertritt wohl die Ansicht, daß im Prinzip beides gleichrangig ist. Ich kenne auch andere Überlegungen, die durchaus auch ohne Fachchauvinismus davon ausgehen, daß es ein gewisses Indiz dafür geben könnte, Verwaltungsrecht im Zweifel vorgehen zu lassen. Warum? Weil das Verwaltungsrecht eben typischerweise das Gemeinwohlinteresse zum Ausdruck bringt. Allerdings ist dies nicht zwingend, weil heute das Zivilrecht auch als Mittel der staatlichen Politik dient. Frage, Herr Jarass: Könnte es nicht so sein, daß die Bindung des Privatrechts an das Verwaltungsrecht nicht auch Ausdruck der Verfassungsbindung des Privatrechts sein kann und daß sich jedenfalls dann automatisch eine Höherrangigkeit des Verwaltungsrechts insoweit ergibt, als das Verwaltungsrecht dann sozusagen den verfassungsrechtlichen Ordnungsauftrag durchsetzt?

Eine letzte Bemerkung und eine Anregung bei der weiteren Behandlung des Themas. Die Referenten haben ja recht daran getan, sich auf das Thema, wie es der Vorstand vorgegeben hat, zu beschränken. Aber interessant könnte es doch sein, die Erfahrungen zu verarbeiten, die wir gemacht haben mit der Thematik: Verwaltungsrecht als 
Vorgabe von Verwaltungsrecht bzw. mit der Frage: Verwaltungshandeln als Vorgabe von Verwaltungshandeln.

$\mathrm{Zu}$ berücksichtigen sind etwa die Legalitätswirkungserwägungen, die in der Altlastenproblematik angestellt worden sind. Hier haben wir eine ganze Menge Erfahrungsmaterial, daß Verwaltungsrechtsnormen oder Verwaltungsentscheidungen unter bestimmten Voraussetzungen andere Verwaltungsentscheidungen binden. Ich glaube, diese Einbeziehung der verwaltungsinternen Bindungsproblematik wäre eine schöne Abrundung, jedenfalls bei der weiteren Erkundung unseres Themas.

Pitschas: Herr Vorsitzender, meine Damen und Herren! Die Frage, wie die Ressource Recht in ihrer Steuerungskraft durch Kongruentsetzung verschiedener Teilrechtsordnungen am besten eingesetzt werden kann, hat $\mathrm{m}$. E. Herr Jarass in ganz vorzüglicher Weise - wenn ich das sagen darf - angegangen. Er hat zu These 10 seine Erörterungen nicht nur auf die Normebene beschränkt, sondern er hat sich auch der Vollzugsebene zugewendet. Dies aber bedeutet, daß er die Frage ausdrücklich stellt: Wer entscheidet über die Anwendung des Verwaltungsrechts? Und ich möchte hinzufügend ergänzen: Wie wird entschieden? Denn die Antwort auf diese Teilfrage - wie wird entschieden? - ist zugleich eine Antwort darauf, wer entscheidet. Herr Jarass hat das Thema dann in den weiteren Thesen Nr. 12 und 13 in einer verwaltungswissenschaftlichen Art ausgeführt, die ich ganz überzeugend fand, soweit sie nämlich daran ansetzte, das privatrechtliche Instrumentarium in den Dienst der Kongruentsetzung und der verwaltungsrechtlichen Bindung zu stellen. Allerdings meine ich Herr Jarass, Sie entschuldigen das bitteschön -, daß Sie diese verwaltungswissenschaftlichen Ansätze nicht hinreichend weiter- oder durchgeführt haben. Die Indienstnahme des Privatrechts erinnert bei Ihnen etwas an den Steuerungstyp - Sie entschuldigen die verwaltungswissenschaftliche Wortwahl -, der Hierarchie. Es wird in einer Art Stufensetzung das Privatrecht in den Dienst des verwaltungsrechtlichen Bindungswillens genommen. Anders würde ich aus einer verwaltungswissenschaftlichen Sicht argumentieren: Das Privatrecht hat Selbststand und es wirkt in diesem Sinne selbststeuernd, also weder antinomisch zum Verwaltungsrecht noch gar autonom, sondern in einem durchaus von dem jeweiligen Teil-Gesetzgeber so und nicht anders gewollten eigenständigen Regelungsmuster. Nun muß man dann allerdings verwaltungswissenschaftlich einen weiteren Schritt gehen. Wir können nicht dabei stehenbleiben, die Instrumente zu betrachten, sondern wir müssen die Akteure ins Auge fassen. 
Akteure sind hier auf der einen Seite die Privatleute - Privatrecht - , auf der anderen Seite die Richter - Strafrecht. Zunächst zu den Privatleuten. Wir finden, und dies ist durchaus in einem verfahrensrechtlichen Sinne gedacht, die Privatleute auf der Basis des Privatrechts als ihre eigenen Steuerungsinstanzen vom Gesetzgeber selbst eingesetzt. Das heißt mit anderen Worten: Für mich stellt sich nicht mehr in ihrer Schärfe die Frage der Bindungswirkung, sondern für mich erhebt sich dann eher die Frage, wieweit belasse ich als Verwaltungsrechtler dem Privatmann und damit der Privatautonomie die Geltungskraft, ihre Steuerungskraft. Ich sehe die Dinge also nicht antinomisch, sondern durchaus zugunsten des Zivilrechts miteinander verbunden. Was dann bedeutet, daß ich eine Art Kompetenzverteilungsregel jetzt verwaltungsrechtlich entwickle, wodurch ich zu einem Gegensatz, Herr Jarass, zu Ihren Thesen 17 und 18 komme. Mit der indiziellen Wirkung des Verwaltungsrechts kann ich dann nicht mehr schrecklich viel anfangen, sondern ich sage, eher hat das Privatrecht eine indizielle Wirkung. Und auch die These 18 mag ich nicht unterschreiben. Es gibt dann wohl kaum ein derivatives Privatrecht.

Etwas mehr noch erschreckt hat mich bei Herrn Schröder aus dieser verwaltungswissenschaftlichen Sicht, aus der Akteursperspektive, seine sehr die Geltung des Strafrechts abwehrende Sicht der Dinge. Akteurspezifisch gesehen, muß man sich doch auch in die Lage des Strafrichters versetzen. Das klang bei Herrn Ossenbübl vorhin nicht so sehr an. Ich denke nicht, daß der Mitarbeiter einer Vollzugsbehörde im Umweltschutz immer mit einem Bein im „Knast“ steht, sondern - wenn man die Dinge aus der Sicht des Strafrichters sieht dann muß man sagen, warum macht ihr denn das bei Euch im Verwaltungsrecht so? Konkret: Bei der These Nr.14 b von Herrn Schröder ist die Rede von der Tatbestandswirkung des Verwaltungsakts, bei der prinzipiell die Verantwortung der Erlaßbehörde geschützt werden soll. Nein, denke ich, wir müssen auch sehen, daß prinzipiell die Zuständigkeit des Akteurs "Strafrichter" geschützt werden muß. Kompetenzverteilungsregeln sind folglich zu entwickeln mit der Konsequenz, die Herr Bettermann angedeutet hat. Wir müssen in das Prozessuale hinein und in diesem Bereich der Eigenart des strafgerichtlichen Verfahrens als eines gerichtlichen Prozesses seinen Wert belassen. Konsequenz: Ich kann mich mit der These $14 \mathrm{~b}$ nicht anfreunden und dann auch nicht mit der These 12 a von Herrn Schröder. Die spezifische Verantwortung für die Verwaltungsrechtslage ist, so meine ich, zugleich eine spezifische Verantwortung des Strafrichters für die Strafrechtslage vor Gericht. Wir müssen - und damit kehre ich zurück abschließend zur Verwaltungswissenschaft - 
eben wirklich sehen, wer handelt und in diesem Sinne dem je handelnden Akteur seinen vom Gesetzgeber zugedachten Steuerungsspielraum belassen. Auftretende Konflikte müssen wir prozessual lösen. Hier schließe ich mich Herrn Bettermann an. Vielen Dank.

Bullinger: Bevor sich ein Mißverständnis einschleicht: Herr Pitschas meinte eben, die Vorstellung von der autonomen Struktur des Privatrechts sei meine eigene Meinung. Ich habe ja nur versucht, das Selbstverständnis des Privatrechts darzustellen, um zu sagen, daß es überwunden werden muß, bevor Herr Jarass mit seiner nüchternen Funktionsanalyse zum Zuge kommen kann.

Meyer: Ich habe eine Frage an Herrn Pitschas. Ich will Ihnen einen von den hypothetischen Fällen schildern, wie sie in Frankfurt nicht selten Realität werden. Die Stadt will einen Hochhausbau zulassen, da eine potente Investorgruppe Interesse zeigt. Doch das Baurecht läßt es nicht zu. Aus der Sicht der Stadt sind das einzige Problem die Nachbarn, die vielleicht klagen könnten. Was wird also gemacht? Dem Bauherrn wird gesagt: Wenn Du die Widerspruchsrechte abkaufst, dann bekommst Du die Baugenehmigung. So geschieht es. Der Preis für ein solches Abkaufen ist in einem Falle dem Vernehmen nach 50 Millionen DM gewesen, 50 Millionen DM! Angesichts eines solchen Falles frage ich Sie, ob das für Sie ein Beispiel dafür ist, daß wir in solchen Fällen dem Markt sein Recht geben sollen. Denn die Verträge, die mit den Nachbarn gemacht worden sind, sind privatrechtliche Verträge, als solche außerordentlich koscher, wenn auch teuer.

Jörn Ipsen: Herr Vorsitzender, meine Damen und Herren. Es trifft sich gut, daß ich mich der Fragestellung von der Verfassungsdogmatik her nähern möchte, anders als Herr Pitschas, der sich der Frage mehr verwaltungswissenschaftlich genähert hat. Ich möchte den von Herrn Jarass zum Schluß angeführten Gesichtspunkt des Vollzugsdefizits in der Verwaltung aufgreifen und in Frage stellen, daß ein solches durch straf- und zivilgerichtliche Rechtsprechung ausgeglichen werden kann. Die in der Literatur spürbaren Versuche einer stärkeren Verselbständigung namentlich des Umweltstrafrechts scheinen mir auf enge, auch verfassungsrechtliche, Grenzen zu stoßen. Wird eine behördliche Genehmigung erteilt, ein Verhalten also erlaubt, so kann der Strafrichter es nicht mit der Begründung als verboten und damit strafbar ansehen, die Genehmigung sei rechtswidrig. Ich würde im übrigen hier Unterschiede machen wollen zwischen Erlaubnissen und Steuerbescheiden. Meines Erachtens verlangen die Steuerbescheide 
gerade in den Parteispendenaffären eine andere Beurteilung. Denn das sollte in der Diskussion um die Parteispenden doch nach wie vor nicht übersehen werden: Gegenstand der Steuerbescheide waren eben nicht Zuwendungen an Parteien, sondern solche an verkappte SpendenSammelstellen, möge auch die Finanzverwaltung von deren Aufgaben gewußt haben. Diese Kollusionsfälle aber scheinen mir für unser Thema eher atypisch zu sein. Bei der Frage der Verselbständigung des Strafrechts gegenüber dem Verwaltungsrecht sind die Gesichtspunkte, die dagegen sprechen, so zahlreich, daß ich sie hier nicht alle nennen kann. Ich möchte aber erwähnen, daß sich mit einer solchen Verselbständigung eine für das Verwaltungsrecht typische ex-post-Betrachtung an die Stelle der im Strafrecht gebotenen ex-ante-Beurteilung setzen würde, mit anderen Worten könnte ein Erlaubnisinhaber nie sicher sei, sich nicht strafbar zu machen, wenn er von der Erlaubnis Gebrauch macht: Ein im Hinblick auf Art. 103 GG unhaltbares Ergebnis, das auch durch vorgebliche Vollzugsdefizite, etwa im Umweltschutzrecht, nicht gerechtfertigt werden könnte. Vollzugsdefizite haben zeitweise auch die Zivilrechtsprechung zu stärkerem Ausgreifen in das Verwaltungsrecht veranlaßt. Als Beispiel sei nur an die vom $B G H$ in seiner früheren Rechtsprechung vorgenommene Verknüpfung von kommunalrechtlicher und wettbewerbsrechtlicher Zulässigkeit bzw. Unzulässigkeit wirtschaftlicher Betätigung der Gemeinden erinnert. Für beide Fälle würde ich meinen, daß - ohne $\mathrm{daß}$ ich mich einer „fachchauvinistischen Befürwortung einer Dominanz des Verwaltungsrechts" verdächtig machen möchte - das Vollzugsdefizit nur durch eine Vervollkommnung des verwaltungsrechtlichen und des verwaltungsgerichtlichen Rechtsschutzes auszugleichen ist, nicht dagegen durch eine verfassungsrechtlich zweifelhafte, in jedem Fall dysfunktionale Aktivität der Straf- und Ziviljustiz. Herzlichen Dank.

Bayer: Herr Vorsitzender, wenn Sie erlauben, ein paar nicht ganz unkritische Bemerkungen zu den systematischen Grundlagen der vier Referate dieses Vormittags. Ich habe, und ich glaube, Herrn Bullinger ist es genauso gegangen, den Eindruck gewonnen, es gibt, wenn wir den Referaten folgen, drei Rechtsgebiete: das Verwaltungsrecht, das Strafrecht und das Zivilrecht. Alle drei stehen fein säuberlich - Herr Bullinger spricht von "autonom" - nebeneinander, haben im Grundsatz nichts miteinander gemein. Sind sie gleichwohl miteinander „verknüpft“, vielleicht sagt man neudeutsch besser „vernetzt“, so nur aufgrund des Gedankens von der Einheit der Rechtsordnung, rein rechtstechnisch durch die Verweisungstechniken, über die hier heute 
morgen gesprochen worden ist. Ich halte diesen Ansatz, wie ich ausführen möchte, für bedenklich, ich halte ihn für gefährlich, nach meiner Meinung ist es eher so, daß sich die drei großen eben genannten Rechtsgebiete schon von Hause aus nicht wirklich trennen lassen. Ich möchte das, Herr Schröder, an dem von Ihnen gewählten Beispiel der Steuerhinterziehung, $\$ 370$ der Abgabenordnung, demonstrieren. Sie haben den $\$ 370$ AO mit Hilfe der bekannten Begriffe „Nebenstrafrecht" oder "Strafrecht als Folgerecht zum Steuerrecht" charakterisiert. Darin steckt sicherlich ein erhebliches Maß an Wahrheit, aber es ist nicht die ganze Wahrheit, man wird wohl etwas präziser fragen müssen: Ist $\$ 370 \mathrm{AO}$ denn nun „Strafrecht“ oder „Verwaltungsrecht", sprich „Steuerrecht"? Die Antwort auf diese Frage wird von keiner Seite eindeutig gegeben. Früher galt wie selbstverständlich, zu finden bei dem großen Straf- und Völkerrechtler Franz von Liszt, der Satz: Steuerdefraudation oder, wie wir heute sagen, Steuerhinterziehung ist Strafrecht. Das Thema bildet einen selbstverständlichen Bestandteil seines Lehrbuchs, anders als heute, in den modernen Lehrbüchern des Strafrechts ist dazu nichts mehr zu finden. Umgekehrt haben sich nunmehr die Steuerrechtler des $\$ 370$ angenommen, bei ihnen gehen die Meinungen durcheinander, wenn ich es richtig sehe, behandelt man den $\$ 370$ hier überwiegend unter der headline "Steuerrecht", ist also offenbar der Meinung, das Steuerstrafrecht sei Steuerrecht. Wie dem indessen auch sei, ganz sicher ist: Der $₫ 370 \mathrm{AO}$ knüpft eine spezifisch strafrechtliche Sanktion an das, was Sie, Herr Schröder, mit dem Begriff der Verletzung verwaltungsrechtlicher, steuerrechtlicher Aufklärungspflichten umschrieben haben. Ich würde mich Ihnen insoweit auch anschließen wollen, freilich mit der Folge, daß wir von $\$ 370 \mathrm{AO}$ auf Vorschriften wie die $\$ \$ 140 \mathrm{ff}$. AO verwiesen werden, also auf die Regeln über die steuerlichen Buchführungsund Bilanzierungspflichten. Damit wären wir dann in der Tat im Verwaltungsrecht, im steuerlichen Verwaltungsrecht. Nur, wenn wir den $\$ 140 \mathrm{AO}$ noch einmal seinerseits nehmen, werden wir von dort sofort in ein nächstes Rechtsgebiet verwiesen, nämlich in das der $\$ \$ 238 \mathrm{ff}$. HGB, früher, vor dem Bilanzrichtliniengesetz, der $\$ \$ 38 \mathrm{ff}$. HGB. Das sieht so aus, als wenn wir uns nunmehr im Privatrecht befinden würden, denn es geht ja um einen klassischen Privatrechtstext, das HGB. Nur, sind wir wirklich im Privatrecht? Nein, wir sind eben nicht im Privatrecht, wir sind im Öffentlichen Recht. Die Frage ist bisher wenig diskutiert worden, aber immerhin: Das Reichsgericht in Strafsachen hat bereits im Jahre 1886 in einer berühmten Entscheidung aus dem 13. Band gesagt, daß das Recht der "Bilanzziehung“ dem „öffentlichen Interesse“ dient. Die Literatur hat daraus zu Beginn 
dieses Jahrhunderts in den ersten großen Kommentaren zum Aktienrecht dann die Konsequenz gezogen: Das Bilanzrecht ist Öffentliches Recht und noch konkreter, das Bilanzrecht ist Verwaltungsrecht. Es gibt ein Bilanzverwaltungsrecht und es gibt ein Bilanzstrafrecht. Wenn Sie sich heute in den Kommentaren zu $\$ \$ 238 \mathrm{ff}$. HGB umschauen, alle Kommentatoren, etwa Baumbach/Duden/Hopt in ihrer Einleitung, sind sich darin einig: Das Bilanzrecht ist ein Teil des Öffentlichen Rechts. Die Begründung fällt schwer, ich will ihr hier auch nicht mehr nachgehen, ich will jetzt nur noch zwei Konsequenzen ziehen.

Meine erste These: Aus Ihrem Referat, Herr Schröder, könnte man, bezogen auf $\$ \$ 370 \mathrm{ff}$. AO, den Schluß ableiten, wir haben es hier mit einem Verweisungszusammenhang zwischen Strafrecht, Verwaltungsrecht und Privatrecht zu tun. Man könnte dem entgegenhalten: Ausgehend von $\$ 370 \mathrm{AO}$ begegnen uns dreimal Normen derselben Art, das Verwaltungsrecht, sprich: Steuerrecht, in der Gestalt des $\$ 370 \mathrm{AO}$, das Verwaltungsrecht, sprich: Steuerrecht, in der Gestalt des $\$ 140 \mathrm{AO}$ und das Verwaltungsrecht, sprich: Bilanzrecht, in der Gestalt der $\$ \$ 238 \mathrm{ff}$. HGB. Die zweite These, die ich riskieren würde, ist die: Ich bin mit Ihnen der Meinung, daß man die Technik der Verweisungsnormen wohl am ehesten aus dem Gedanken erklären kann: Es bedarf der Fachkompetenz, derjenige, der das Fachwissen hat, soll entscheiden. Es gibt nun, das ist mein letzter Hinweis, ein hochbedeutsames aktuelles „Verwaltungs"-Gesetz, nämlich das D-Mark-Bilanz-Eröffnungsgesetz für die Betriebe in der ehemaligen DDR. Aus dem, was ich hier entwickelt habe, könnte man folgern: Dieses Gesetz bedarf nunmehr der Anwendung, und eben dazu müßten eigentlich die Öffentlichrechtler, die Verwaltungsrechtler berufen sein, sie müßten also in großer Zahl in den deutschen Osten strömen, um dort das Gesetz zur Anwendung zu bringen. Jeder weiß, das genaue Gegenteil ist der Fall. Es strömt kein Verwaltungsrechtler, es strömt freilich auch kein Zivilrechtler. Wer dorthin geht, ist im Zweifel nicht Jurist, er ist Wirtschaftsprüfer oder Steuerberater. Und dieses würde dann zusammengefaßt zu der These führen: Uns begegnet zumindest an einzelnen Stellen der Rechtsordnung weder eine Publifizierung des Privatrechts noch eine Privatisierung des Öffentlichen Rechts, es vollzieht sich vielmehr ein Prozeß einer gewissen „Entrechtlichung“. Vielleicht könnte man dem Vorstand für eine spätere Tagung einmal das Thema vorschlagen: Die Betriebswirtschaftslehre als Vorgabe des Verwaltungsrechts. Dankeschön. 
Vorsitzender: Wie bereits angekündigt, erhalten die Referenten jetzt die Gelegenheit, sich zu äußern, zunächst Herr Jarass, dann Herr Schröder.

Jarass: Zunächst darf ich mich für die Anregungen der Diskussionsbeiträge bedanken. Ich werde nur zu den Beiträgen etwas sagen, in denen an mich Fragen gestellt wurden oder die sich mit meinen Überlegungen nicht vollständig decken.

Der erste Beitrag, auf den ich eingehen möchte, ist von Herrn Bullinger gekommen und betrifft die Frage, ob die Kultur bzw. Unkultur der „Zivilrechtler" nicht so verfestigt ist, daß man gegen die Ausblendung des öffentlichen Rechts mit rationalen und sachlichen Überlegungen nicht ankommen kann, daß man - ich überspitze etwas - mit einer Haubitze ansetzen muß, um die Wand zu durchbrechen. Diese Bedenken sind nicht ohne Grundlage. Trotzdem würde ich optimistischer sein. Wenn man sich die heutigen Großkommentare zum Bürgerlichen Gesetzbuch ansieht, dann finden sich durchaus Öffnungen, sehr viel mehr als vor 10 oder 20 Jahren. Des weiteren erinnere ich mich an ein Gespräch, das ich im Vorfeld dieser Veranstaltung mit einem zivilrechtlichen Kollegen geführt habe, einem Kollegen, der sich gerade mit dem Verhältnis von öffentlichem Recht und Privatrecht intensiv beschäftigt hat. Als er von dem Thema unserer Tagung erfuhr, hat er spontan angemerkt, daß die „Öffentlich-Rechtler" hier den "Zivilrechtlern" wieder einmal voraus sind. Auch die zivilrechtlichen Kollegen müßten sich mit dem Thema beschäftigen. Das nehme ich als ein gutes Zeichen; zudem ist das ein Kompliment für den Vorstand. Wenn Sie des weiteren darauf hinweisen, daß ein Landgerichtspräsident sehr viel mehr Ansehen als der Präsident eines Verwaltungsgerichts hat, dann kann man demgegenüber anführen, daß die jungen Juristen mit den besseren Noten zunächst zu den Verwaltungsgerichten und erst dann zu den Zivilgerichten streben. Ich meine daher, daß auf Dauer durchaus Hoffnung besteht, hier voranzukommen. Nichtsdestoweniger muß man sich der Widerstände bewußt sein. Nur stetes Bohren kann hier Fortschritte bringen.

Herr Häberle hat zwei Punkte aufgegriffen: Zunächst die EGrechtliche Dimension. Dahinter verbergen sich schwierige Probleme. Von Ihren Beiträgen wissen wir aber, daß Sie vor solchen Fragen nicht zurückschrecken. Da ich mich mit dem EG-Recht in den letzten Jahren intensiv beschäftigt habe, finde ich die Frage zwangsläufig besonders interessant. Auf der Ebene des EG-Rechts stellen sich die Dinge allerdings zum Teil etwas anders dar, und zwar deshalb, weil es dort die institutionelle Trennung von Privatrecht und öffentlichem 
Recht nicht gibt. Für das EG-Recht spielt es meist keine Rolle, ob die betreffende Vorschrift des EG-Rechts privatrechtlicher oder öffentlich-rechtlicher Natur ist. Das liegt sicherlich auch daran, daß es nur einen Gerichtshof gibt. Die Frage der Abgrenzung und Zuordnung von privatem und öffentlichem Recht ist daher im EG-Recht sehr viel weniger gravierend als innerstaatlich. Die Frage von Herrn Häberle hat allerdings noch eine zweite Dimension: In welchem Verhältnis steht etwa das EG-Privatrecht und das innerstaatliche offentliche Recht? Besteht da nicht die Gefahr, daß das öffentliche Recht zu kurz kommt, weil das EG-Recht Vorrang hat, wie wir gestern gehört haben? Die Antwort auf diese Frage erfaßt auch bereits das von Herrn Kloepfer angesprochene Problem. Sieht man sich die Konflikte zwischen Privatrecht und öffentlichem Recht näher an, und überlegt man, wie sie sich auflösen lassen, dann ist in den meisten Fällen mit den gängigen Kollisionsregeln „höherrangiges/niederrangiges Recht" oder "lex specialis/lex generalis" nicht viel zu bewegen. Engisch und Larenz, auf die ich mich bei meinen Überlegungen stark gestützt habe, haben dazu herausgearbeitet, daß man häufig mit einer teleologischen Reduktion arbeiten muß, weil die anderen Kriterien bei näherem Zusehen nicht weiterhelfen. Wenn dem aber so ist, dann stellt sich die Spannung zwischen EG-Privatrecht und nationalem Verwaltungsrecht nicht so kritisch dar. Bewältigt ist das Problem damit aber natürlich nicht; man wird darüber weiter nachdenken müssen. Schließlich waren Sie mit meiner letzten These nicht ganz zufrieden, in der ich die Leistungsfähigkeit des öffentlichen Rechts nach Ihrem Geschmack zu sehr herausgestellt habe. An sich war meine These durchaus vorsichtig gemeint. Zwar will ich dem offentlichen Recht seine Leistungsfähigkeit nicht absprechen; die Verdrängung und Publifizierung des privaten Rechts ist ein Indiz für diese Leistungsfähigkeit. Aber - und gerade das wollte ich betonen - die Verdrängung und Publifizierung ist nur dann berechtigt und legitim, wenn das öffentliche Recht tatsächlich leistungsfähiger ist. Dabei kommt es nicht nur auf das öffentliche Recht selbst, sondern auch auf den Vollzug an. In diesem Sinne handelt es sich nicht nur um ein Problem, das uns betrifft, sondern alle, die an der Umsetzung des Verwaltungsrechts beteiligt sind.

Aus den Überlegungen von Herrn Kloepfer möchte ich zunächst einen Punkt aufgreifen, der mir wichtig ist, weil eine Reihe von Beiträgen sich doch etwas kritisch mit dem Prinzip der Einheit der Rechtsordnung befaßt haben. Dafür lassen sich durchaus Gesichtspunkte anführen, zumal sich hinter der Einheit der Rechtsordnung alles Mögliche verbergen kann. In meinen Ausführungen habe ich das 
Prinzip sogleich auf die Widerspruchsfreiheit der Rechtsordnung beschränkt. Unter der Einheit der Rechtsordnung kann man aber auch ganz andere Dinge verstehen. Ähnliches gilt etwa für die Einheit der Verfassung, die manche Bedenken auslösen kann; die Widerspruchsfreiheit der Verfassung kann man sehr viel eher akzeptieren. Wenn man aber die Einheit der Rechtsordnung als Widerspruchsfreiheit versteht, dann meine ich, daß darin ein wichtiges Postulat liegt, nicht nur auf der Normebene, auf der Widersprüche vom Gesetzgeber beseitigt werden müssen. Vielmehr stellt sich hier eine Aufgabe auch für uns als Rechtswissenschaftler. Ich sehe es geradezu als ein ethisches Postulat der Rechtswissenschaft, zur Widerspruchsfreiheit der Rechtsordnung beizutragen, auch auf der Wertungsebene. Das bedeutet sicherlich nicht, daß wir alle Teilrechtssysteme über einen Kamm scheren können und sollen. Sie haben spezifische Rationalitäten, die voneinander abweichen können, weil sie verschiedene Ziele zu erreichen haben. Auf eine andere Frage von Herrn Kloepfer kann ich keine abschließende Antwort geben. Es ging dabei darum, wie die Kollisionsfälle aufgelöst werden müssen. Sie haben dazu interessante Überlegungen gebracht und gefragt, ob man die Kollisionsfälle nicht über die Kompetenzordnung und die Kompetenznormen der Verfassung bewältigen kann. Das Problem stellt sich übrigens nicht nur im Verhältnis von Privatrecht und Verwaltungsrecht, sondern auch in anderen Zusammenhängen. In einem Fall, mit dem ich kürzlich beschäftigt war, ging es darum, daß ein Landesrundfunkgesetz die Beteiligung einer öffentlich-rechtlichen Rundfunkanstalt an einem privatrechtlichen Rundfunkunternehmen vorsieht. Gegen die Beteiligung schritt dann das Kartellamt ein, unter Berufung auf das Kartellrecht, weil die Rundfunkanstalten eine marktbeherrschende Stellung haben. Hier haben Sie einen Konflikt zwischen dem Rundfunkrecht einerseits und dem Wettbewerbsrecht andererseits. Diesen Konflikt könnte man versuchen, mit Hilfe des Grundsatzes der Spezialität aufzulösen; man könnte anführen, das Rundfunkrecht sei spezieller. Bei genauerem Zusehen zeigt sich jedoch, daß der Grundsatz der Spezialität, der übrigens noch bemerkenswert wenig untersucht wurde, hier nicht weiterhilft. Auch die Kollisionsnorm „Bundesrecht bricht Landesrecht" kann nicht zum Tragen kommen. Man wird die Lösung des Konflikts vielmehr von einer anderen Seite her versuchen müssen, die ich in einer Monographie demnächst vorstellen werde. Es gilt zwischen zwei Ebenen zu unterscheiden: Der Ebene der Normkollision, auf der man den Konflikt meist zu lösen sucht, und der Ebene der Normanwendungskollision, auf der nach meiner Meinung das genannte Problem eigentlich bewältigt werden müßte. Das führt 
dazu, daß man nicht pauschal dem Rundfunkrecht oder dem Wettbewerbsrecht den Vorrang geben muß, sondern daß man, je nach Sachverhalt, zu einer unterschiedlichen Lösung kommen kann. Dieser Ansatz dürfte ganz generell bei Konflikten zwischen Privatrecht und Verwaltungsrecht weiterhelfen.

Schließlich war Herr Pitschas mit der Figur des „derivativen" Privatrechts nicht zufrieden. Wenn ich Ihren Beitrag richtig verstanden habe, dann wollten Sie sagen, daß es ein derivatives Privatrecht gar nicht gebe, daß das Privatrecht immer autonom und eigenständig neben dem Verwaltungsrecht stehe. Lassen Sie mich zunächst an einem Beispiel illustrieren, daß Privatrecht und Verwaltungsrecht durchaus dem gleichen Ziel dienen können, daß sie also nicht unverbunden nebeneinanderstehen müssen: Als man über den Erlaß des Gesetzes zur Regelung der Allgemeinen Geschäftsbedingungen nachdachte, hatte man auch überlegt, eine Behörde zu schaffen, der jeder Entwurf Allgemeiner Geschäftsbedingungen vorzulegen ist und die dann geprüft hätte, ob sie genehmigt werden können oder nicht. Man hat dann auf diesen verwaltungsrechtlichen Weg verzichtet und einen privatrechtlichen Weg gewählt. Bestimmte Standards können also verwaltungsrechtlich oder zivilrechtlich durchgesetzt werden. Besonders deutlich wird dies auch an der Vorschrift des $₫ 823$ Abs. 2 BGB, die für die Durchsetzung von verwaltungsrechtlichen Standards ein zusätzliches Instrument darstellt. Und in diesem Bereich wird die privatrechtliche Durchsetzung durch verwaltungsrechtliche Standards bestimmt. Diesen Zusammenhang hat, wenn ich recht sehe, erstmals Herr Breuer treffend mit dem Begriff des derivativen Nachbarrechts belegt, der sich durchaus verallgemeinern läßt.

Schröder: Da die Überlegungen zur Einheit der Rechtsordnung, soweit ich sehe, weitgehend Zustimmung gefunden haben, möchte ich darauf nicht weiter eingehen. Die Widerspruchsfreiheit, hat Herr Thieme nochmals besonders betont, müsse gepflegt werden. Das ist auch meine Auffassung. Nur war ich der Meinung, daß man daraus nicht allzuviel für die Frage der konkreten Anknüpfung an das Verwaltungsrecht entnehmen könne. Verschiedene Diskussionsteilnehmer haben mit Recht betont, daß allgemeine Grundsätze hier überhaupt wenig ergiebig seien und man eine Detailbetachtung vornehmen müsse. Eine wichtige, in der Zukunft zu leistende Aufgabe besteht vermutlich darin, einzelne Teilrechtsbereiche des Verwaltungsrechts konkreter auf ihre Vorgabewirkung in bezug auf das Strafrecht und Zivilrecht zu untersuchen und sich nicht immer auf das Verwaltungsrecht schlechthin zu beschränken. Hier könnten sich 
durchaus verschiedene Lösungen anbieten. - Sehr wichtig fand ich den Hinweis von Herrn Rupp, daß sich neuerdings in einem Gesetz verschiedene Sanktionsinstrumente verwaltungsrechtlicher, zivilrechtlicher und strafrechtlicher Art finden. Darin kann ein Hinweis des Gesetzgebers auf die notwendige Gesamtwürdigung der Instrumente liegen. - Kritisch ist unter dem Gesichtspunkt der allgemeinen Grundsätze, insbesondere von Herrn Bettermann, die Frage der Genehmigungsfähigkeit bei gebundenen Erlaubnissen angesprochen worden. Ausgangspunkt meiner Überlegungen zu These 18 war die meist diskutierte und z.T. bejahte Behauptung, daß bei einer Ermessensreduzierung auf Null der Strafrichter die Genehmigung ersetzen könne. Insoweit bleibe ich dabei, daß es eine Entscheidung der Verwaltung bleiben muß, ob eine Ermessensreduzierung auf Null erfolgt ist, oder nicht. Die andere Frage ist, wenn es nicht um eine Ermessenserlaubnis, sondern um eine gebundene Erlaubnis geht, etwa eine Bauerlaubnis, ob dann der Strafrichter davon ausgehen darf, daß keine strafbare Handlung vorliegt. Sicherlich ist der Eingriff in die Verwaltungsrechtsordnung hier geringer, wenngleich ich meine, daß auch insoweit die Beurteilungs- oder Entscheidungskompetenz der Verwaltung berührt ist. Man muß sich auch einmal über die Konsequenzen klarwerden: Wenn man über das Strafrecht die Erlaubnis sozusagen erschleichen könnte, wird es verwaltungsrechtlich uninteressant, sie einzuholen, weil jedenfalls strafrechtlich keine Konsequenzen drohen. Herr Bettermann hat weiter kritisch angemerkt, daß die Vorstellung von der Strafe als ultima ratio eigentlich nicht zutreffe. Darüber kann man natürlich nachdenken. Es handelt sich hierbei allerdings, wenn ich es recht sehe, um eine gängige Auffassung sowohl in der Rechtsprechung des Bundesverfassungsgerichts wie auch in der Strafrechtslehre und Praxis, die in erster Linie am Freiheitsentzug orientiert ist. Aber in der Tat kann man fragen, ob die heutige Strafpraxis, soweit sie auf Geldstrafen hinausläuft, wirklich so scharf ist, daß man die Strafe als ultima ratio ansehen muß. Auf der anderen Seite bleibt immer die gesellschaftliche Diskriminierung, die mit der Strafe in besonderer Weise verbunden ist. $\mathrm{Zu}$ den Verwaltungsvorschriften, Herr Rupp, die Sie besonders angesprochen haben, möchte ich nur ganz kurz anmerken: Ich habe mich bemüht, obwohl ich der neueren verwaltungsrechtlichen Einordnung zuneige, für die strafrechtliche Betrachtung nicht einfach auf das Verwaltungsrecht zu verweisen und zu sagen, was sich neuerdings hier abzeichnet, muß so auch im Strafrecht gelten. Denn die Hürde des Art. 103 Abs. 2 muß trotzdem überwunden werden, was nicht ganz einfach ist. - Eine ganze Reihe von Bemerkungen galten der Frage der Aussetzung des 
Strafverfahrens. Ich bin dankbar, daß diese Überlegungen so vielfältig aufgegriffen worden sind. Ich bin - ganz im Sinne von Herrn Badura - der Meinung, daß die Vorfragenkompetenz im Prinzip eine fest verankerte Institution in unserer Rechtsordnung ist. Empfehlungen oder Überlegungen, die Vorfragenkompetenz einzuschränken, gar gesetzgeberisch zu einer generellen Aussetzungspflicht auch nur bei kompetenzfremden Vorfragen zu machen, werden wahrscheinlich rechtspolitisch wenig Erfolg haben. Schon im Steuerrecht ist ja die Entwicklung genau umgekehrt verlaufen. Hier gab es ursprünglich eine Aussetzungspflicht mit der Maßgabe, daß die Entscheidung des Reichsfinanzhofs und später des Bundesfinanzhofs abzuwarten war, was zu erheblichen Schwierigkeiten in der Praxis geführt hat und dann zu der Neufassung der Abgabenordnung. In Betracht kommt daher auf der Grundlage eines prinzipiellen Aussetzungsermessens nur die Einschränkung im Einzelfall. Damit stellt sich das Problem der Kriterien für die Einschränkung. Zudem ist, das darf ich noch einmal betonen, die außerordentlich geringe, um nicht zu sagen gegen Null tendierende Bereitschaft der Strafgerichte zur Aussetzung festzuhalten. Die Gerichte wollen eben einfach die Entscheidung an sich ziehen, ganz sicherlich aus Gründen, die in der Kontrolle der Verwaltung liegen. Das gibt mir Anlaß, auf die Bemerkung von Herrn von Arnim einzugehen. Meine Überlegungen zum Steuerbescheid hatten einen ganz konkreten Hintergrund: Die Analyse der einschlägigen Entscheidungen der Strafgerichte in der Parteispendenaffäre ergibt nämlich, daß die Strafgerichte sich einfach über diese Bescheide hinweggesetzt und gesagt haben, wir wissen aus dem Gesetz heraus, was für eine Steuerschuld bestand, und auf die kommt es im Rahmen der Steuerverkürzung an, auf nichts anderes. Dem wollte ich widersprechen. Daß das Milieu oder die besonderen Konstellationen der Parteispendenaffäre noch zu ganz anderen Überlegungen Anlaß geben, wollte ich keinesfalls ausschließen. Ich würde aber im Gegensatz zu Herrn von Arnim doch mehr der Auffassung von Herrn Vogel zuneigen, daß die Strafjustiz nicht die richtige Instanz ist, um hier Korrekturen vorzunehmen, sondern daß man eher daran denken könnte, daß der Staatsanwalt die zuständigen Gerichte anrufen kann. - Zu der Bemerkung von Herrn Bayer betr. $\$ 370$ Abgabenordnung: Darüber kann man natürlich lange reden, nur eine Lösung für die Parteispendenaffäre ergibt sich daraus nicht. Das muß mit aller Klarheit gesagt werden. Denn wie immer Sie $\$ 370$ AO zuordnen, ob dem Steuerrecht oder dem Strafrecht, es bleibt die Frage, was ist mit den "armen Sündern“ zu machen, die sich in bestimmter Weise verhalten haben. - Herr Häberle, Ihrer Bemerkung zur Europäisierung kann 
man, so interessant der Ansatz ist, entgegenhalten, was wir heute über die Schweiz gehört haben: Die Vorgabeproblematik hängt auch stark von der Gesetzgebung in den einzelnen Staaten ab. In dem Augenblick, in dem Sie eine Gesetzgebung haben, die verwaltungsrechtsferner ist, sind die Kollisionen, auf den ersten Blick jedenfalls, weniger stark, werden sie weniger diskutiert; im umgekehrten Fall ist es wieder anders. In einem größeren Zusammenhang kann das sicher einmal anders werden.

Vorsitzender: Schönen Dank! Wir beginnen jetzt die zweite Diskussionsrunde. Meine Damen, meine Herren, es ist das eingetreten, was ich ursprünglich eigentlich gar nicht erwartet hatte, wir sind unter Zeitdruck geraten, oder wir geraten unter Zeitdruck. Ich darf Sie also bitten, Ihre Diskussionsbeiträge in dem vorbezeichneten Rahmen zu halten. Herr Brener, Ihre Begriffsbildungen sind bereits zitiert worden, jetzt sollen Sie auch persönlich das Wort erhalten.

Breuer: Herr Badura hat ganz zu Anfang dieser Debatte die Frage nach dem roten Faden gestellt, und ich will versuchen, diese Frage noch einmal aufzugreifen, weil ich der Meinung bin, daß wir eine einheitliche Rechtsordnung haben und daß nicht die drei Teile des Privatrechts, des Verwaltungsrechts und des Strafrechts auseinanderfallen dürfen. Herr Ossenbübl hat meines Erachtens zu Recht in prononcierten Ausführungen darauf hingewiesen, daß diese Probleme von sehr praktischer Bedeutung sind. Wenn widersprüchliche Entscheidungen von Verwaltungsbehörden einerseits und Staatsanwaltschaften und Strafgerichten andererseits den Bürger betreffen, dann ist es die Aufgabe des Rechtsstaates, für Klarheit zu sorgen und die Gewichte der Staatsgewalten einander wieder richtig zuzuordnen. Nicht von ungefähr haben die Referenten sich die Beispiele im Umweltrecht, im Bau- und Planungsrecht und auch im Wirtschaftsverwaltungsrecht gesucht. Das Symptomatische dieser Gebiete besteht darin, daß das Verwaltungsrecht in einem sozialstaatlichen Impetus die Verwaltungsbehörden mit neuen Aufgaben betraut. Dies sind nicht mehr allein liberal-rechtsstaatliche Zuständigkeiten und Befugnisse der Verwaltung, sondern Planungsbefugnisse und Verteilungsbefugnisse. Es sind Befugnisse zur Regulierung der ökologischen und ressourcenökonomischen Möglichkeiten, und deshalb steht der Verwaltung hier die Aufgabe zu, in unsicherer Grenzsituation zu entscheiden. Herr Rupp hat darauf hingewiesen, daß zunehmend administrative Entscheidungsspielräume angenommen werden auch dort, wo man es früher noch abgelehnt hat. Die Gründe sind naheliegend, und ich will hier nicht den Unterscheidungen nachgehen, 
wo ein Ermessensspielraum vorliegt, wo ein administrativer Beurteilungsspielraum vorliegt und inwieweit normkonkretisierende Verwaltungsvorschriften im Verhältnis zum Bürger maßgeblich sind. Kennzeichnend ist, daß die Verwaltung hier mit einem sozialstaatlichen Auftrag betraut ist. Es sind ihr neue Aufgaben zugewiesen. Sie muß im unsicheren Grenzbereich entscheiden, und dadurch kommt es der Verwaltung notwendigerweise zu, mit ihren Instrumenten der Gesetzeskonkretisierung das geltende Recht zu Ende zu denken. Herr Schröder hat sehr zu Recht darauf hingewiesen, daß die Gesetzeskonkretisierung der maßgebliche Ansatz der sozialstaatlichen Verwaltung ist. In diesen Kontext gehören auch die Überlegungen, daß normkonkretisierende Verwaltungsvorschriften sehr wohl dem Bürger gegenüber eine Rechtswirkung entfalten können und daß auch der Verwaltungsakt als verbindliche, dem Bürger gegenüber ergehende Regelung ernst zu nehmen ist. Das Erschrecken der Zivilrechtler über die wachsenden Verwaltungsbefugnisse kann ich verstehen, das Erschrekken der Strafrechtler auch. Das Zivilrecht und das Strafrecht gehen ursprünglich von der Vorstellung aus, daß die Verwaltung lediglich äußerste Verhaltensgrenzen festzulegen, nicht aber in der skizzierten Weise sozialstaatliche Lenkungs- und Verteilungsentscheidungen vorzunehmen habe. Mit vielen anderen Diskussionsrednern bin ich der Meinung, daß die Einheit der Rechtsordnung zwar nicht als positives Ideal vorgegeben ist, wohl aber - darauf möchte ich doch einen deutlichen Akzent legen - gehört es nach meiner Vorstellung zu den rechtsstaatlichen Prinzipien, daß die Rechtsordnung widerspruchsfrei zu sein hat. Widersprüchliche Gebote und Eingriffe in die Freiheit des Bürgers sind mit den Grundrechten nicht zu vereinbaren, und sie widerstreiten fundamentalen rechtsstaatlichen Postulaten. Wenn also zum Beispiel das Verhalten eines Bürgers, das von einer Verwaltungsbehörde genehmigt worden ist, in einem Strafverfahren von einer Staatsanwaltschaft oder einem Strafgericht für rechtswidrig erachtet wird und darauf eine strafgerichtliche Verurteilung gestützt ist, dann ist es ein elementarer Widerspruch, der in unserer Rechtsordnung so vor dem Rechtsstaatsprinzip nicht Bestand haben kann.

Nachdem ich in diesem ersten Schritt versucht habe, das allgemeine Problem noch einmal zu umreißen, will ich nun im zweiten Schritt zum Strafrecht kommen. Hier muß der angedeutete Zusammenhang zu der Erkenntnis führen, daß Strafrecht und Verwaltungsrecht notwendig miteinander verkoppelt sind, sie dürfen nicht entkoppelt werden. Hier geht es jeweils um Mittel der Rechtsdurchsetzung und der Rechtserzwingung. Die Verwaltungsbehörden haben hierzu ihre Instrumente, und die Strafgerichtsbarkeit hat ebenfalls solche Instru- 
mente. Da der Staat hier in zwei verschiedenen Institutionen auftritt, gleichwohl aber jeweils als hoheitliche Entscheidungsgewalt dem Bürger gegenübertritt, muß die Stufenfolge ihrer Instrumente eingehalten werden. Die Crux besteht darin - und darauf hat Herr Ossenbiubl zu Recht hingewiesen -, daß das Strafrecht vor einigen Jahren vorverlagert worden ist in dem Bestreben, im Umweltbereich auch die strafrechtlichen Instrumente greifen zu lassen. Ich glaube, hier gibt es nur eine zweifache Möglichkeit für den Gesetzgeber, mit dem Strafrecht zu operieren. Entweder wird das strafrechtliche Instrumentarium wirklich bis an die kritische, progressive Front der Rechtsentwicklung vorverlagert. Dann muß es streng verwaltungsakzessorisch sein, und zwar nach meiner Auffassung verwaltungsrechtsakzessorisch und verwaltungsaktsakzessorisch, damit die schärferen strafrechtlichen Sanktionen nicht angewandt werden, wenn der Fall nach verwaltungsrechtlichen Maßstäben und von den Verwaltungsbehörden rechtsverbindlich gedeckt ist. Die andere Möglichkeit bestünde darin, das Strafrecht zurückzuverlagern. Ich könnte mir unter dieser Prämisse auch ein eigenständiges Strafrecht vorstellen, das einem Rechtsgüterschutz für Leib, Leben, Gesundheit und andere fundamentale Rechtsgüter Platz gibt, das - anders gesprochen - qualifiziertes Unrecht unter das besondere Instrumentarium des Strafrechts stellt. Wenn also das Strafrecht eigenständig verstanden werden soll, dann muß es sich zurückziehen auf die Bereiche evidenter Rechtsverletzungen, die den Einsatz der schärfsten Instrumente rechtfertigen.

Ich stimme ausdrücklich der These 19 von Herrn Schröder zu, der sich zur Amtsträgerverantwortlichkeit im Strafrecht geäußert hat. Es stellt einen Wertungswiderspruch dar, wenn auf der einen Seite die Verwaltungsbehörden mit einem sozialstaatlichen Vollzugsauftrag betraut werden im Hinblick auf planerische und ressourcenökonomische Entscheidungen und wenn auf der anderen Seite eben diesen Verwaltungsbehörden das Damoklesschwert der strafrechtlichen Sanktionen entgegengehalten wird. Ein Wertungswiderspruch liegt meines Erachtens auch darin, daß schon seit Jahrzehnten im Amtshaftungsrecht eine andere Lösung gewählt worden ist. Durch die staatliche Haftungsübernahme ist nämlich seit den Amtshaftungsgesetzen zu Anfang dieses Jahrhunderts, dann durch Artikel 131 der Weimarer Reichsverfassung und schließlich durch Artikel 34 des Grundgesetzes der Beamte entlastet worden, um seine Entscheidungsbereitschaft zu steigern, und der Rückgriff des Staates gegenüber dem Beamten ist nur bei Vorsatz und grober Fahrlässigkeit möglich. Der Gesetzgeber hat hier also offenbar schon in einem früheren Stadium erkannt, daß das Verwaltungsrecht mit seinen Vollzugsaufträgen nicht durch Regelun- 
gen anderer Normbereiche konterkariert werden darf. Wenn das schon für die Amtshaftung gilt, muß es meines Erachtens um so mehr für die strafrechtliche Frage der Amtsträgerstrafbarkeit gelten.

Dritter Schritt: Herr Jarass, mir scheint, daß das Zivilrecht und das Verwaltungsrecht entkoppelt werden dürfen. Ganz anders als im Strafrecht ist es meines Erachtens nicht zwingend geboten, daß das Zivilrecht prinzipiell oder durchgängig an den verwaltungsrechtlichen Vorgaben orientiert ist. Sie haben darauf hingewiesen, wie unterschiedlich die Frage geregelt ist, ob nach einer verwaltungsrechtlichen Entscheidung, etwa einer behördlichen Genehmigung im Umweltrecht, im Planungsrecht, im Baurecht, noch privatrechtliche Ansprüche geltend gemacht werden können. Dies ist eine Frage der materiellen Risikoverteilung. Es kann so sein, daß in einem Verwaltungsverfahren unter Abwägung aller öffentlichen und privaten Belange eine Entscheidung getroffen wird, die abschließend gilt und dann auch entgegenstehende privatrechtliche Ansprüche ausschließt. Dann nimmt der Staat dem Begünstigten das Risiko ab, eventuell auf Gegenansprüche Dritter zu stoßen. Es kann aber auch das Verhältnis zwischen Privatrecht und Verwaltungsrecht ganz anders gestaltet sein, indem nämlich privatrechtliche Ansprüche erhalten bleiben und der Staat dem Begünstigten nicht das Risiko privatrechtlicher Ansprüche Dritter abnimmt. Interessanterweise ist mit der Gefährdungshaftung, die jetzt im Umwelthaftungsgesetz geregelt wird, der zugrundeliegende Gedanke des gefährlichen Tuns betont worden. Selbst wenn eine Anlagengenehmigung erteilt und eingehalten wird, kann sehr wohl eine Gefährdungshaftung der Betreiber aus den neuen Tatbeständen erwachsen. Das zeigt, daß die Entkoppelung zwischen Zivilrecht und Verwaltungsrecht sehr wohl möglich ist und auch eine sinnvolle Regelung sein kann angesichts der Frage der Risikoverteilung. Herr Jarass, dies schien mir nicht deutlich genug in Ihren Thesen hervorgetreten zu sein. Ich glaube, insoweit war es gut, daß die strafrechtlichen und die zivilrechtlichen Komplexe hier gesondert behandelt worden sind. Während im Strafrecht eine Verkoppelung mit dem Verwaltungsrecht geboten ist, ist im Zivilrecht meines Erachtens eine Entkoppelung gegenüber verwaltungsrechtlichen Entscheidungen aus guten Gründen möglich. Hier hilft nur eine differenzierte Betrachtung weiter.

Trzaskalik: Sehr geehrter Herr Vorsitzender, meine Damen und Herren. Die Referenten sind zu keinen einheitlichen Lösungen gekommen. Ich frage mich eigentlich, woran das liegt. Und das liegt meines Erachtens schlicht daran, daß man nicht über Vorgaben des 
Verwaltungsrechts, des Strafrechts oder des Zivilrechts reden kann, ohne sich Gedanken darüber zu machen, welche Aufgaben sollen eigentlich Zivilrecht, Öffentliches Recht und so weiter haben. Und deshalb hätte ich erwartet, daß man etwas mehr über die alten Unterschiede Öffentliches Recht, Privatrecht und dergleichen nachdenkt. Denn ohne die Aufgaben zu bestimmen, kann man die „Vorgaben" kaum bewerten. Dazu ein Beispiel, das werden Sie erwarten, aus dem Bereich des Steuerrechts. Und da möchte ich anknüpfen an Herrn Badura. Das Dilemma des Steuerstrafrechts, das liegt nicht auf der verfahrensrechtlichen Ebene, wie das gesehen wurde. Wenn ein Strafrechtler beurteilen kann, ob ich „noch alle Tassen im Schrank habe" und dergleichen oder ob Kunstfehler bei Operationen vorkommen, dann wird er wohl auch in der Lage sein, unsere harmlosen Steuerrechtsfragen zu beurteilen. Die Probleme liegen im materiellen Steuerrecht, in den Blankett-Tatbeständen. Wenn jeder Steuerzahler im Grunde Steuerstraftäter ist, so sehen die Dinge aus, dann wird das Ganze natürlich problematisch. Und deshalb wäre eben diese Anknüpfung an das Steuerrecht zurückzunehmen. Das Steuerstrafrecht müßte selbständige Schutzgüter ausbilden. Sie haben auch die umgekehrten Fälle, in denen die „Vorgaben“ nicht weit genug reichen. Genau dazu zwei Beispiele: Nehmen Sie etwa den Arbeitgeber, der Steuern einzieht. Da operieren wir im Steuerrecht nahezu mit einer verschuldensunabhängigen $\mathrm{Haftung}$, dies auch gerechtfertigt vor dem Hintergrund, daß der Arbeitgeber beim Arbeitnehmer, dem Steuerschuldner Regreß nehmen kann. Was wird daraus? Der Regreß wird dem Zivilrecht zugeordnet und dann sagt das BAG mit lockerer Hand, für den Regreßanspruch zivilrechtlicher Natur gelten tarifvertragliche Ausschlußklauseln, also ist der Anspruch nach drei Monaten kaputt. Das kann so nicht richtig sein. Wenn man den Arbeitgeber für Steuererhebungszwecke einschaltet, muß auch der Regreß - und das im Öffentlichen Recht - zu Ende gedacht werden. Oder, um den letzten Fall zu nehmen: Falls es Ihnen passieren sollte und der Computer einen Fehler macht und man Ihnen 2 Millionen vor Weihnachten auf Ihr Konto überweist und falls Sie den Betrag im Folgejahr zurückzahlen, werden Sie Ihr bitteres Erstaunen erleben. Sie werden im ersten Jahr möglicherweise ein paar hunderttausend Mark Steuern gezahlt haben und im nächsten Jahr weniger zurückbekommen. Da hat selbst das Bundesverfassungsgericht die Idee gehabt, die Differenzbeträge dem Arbeitgeber in Rechnung zu stellen, unter Berufung auf Wegfall der Bereicherung. Das kann sicherlich nicht richtig sein. Auch da liegt es daran, daß man in Kästchen denkt und eigentlich nicht überlegt, wo liegt der Fehler, welche Aufgabe hat die jeweilige 
Rechtsordnung? Und wenn Fehler der Steuererhebung da sind, müssen sie dort zu Ende gedacht werden; die kann man dann nicht ins Zivilrecht verlagern.

Schachtschneider: Herr Vorsitzender, erlauben Sie, vier Aspekte anzusprechen, die auch schon angeklungen sind: Die Einhaltung des Privatrechts ist Gemeinwohlverwirklichung und damit eine Art bürgerlichen Gesetzesvollzuges. Das zeigt, daß das Privatrecht, jedenfalls soweit es vom staatlichen Gemeinwesen gesetzt ist, öffentliches Recht ist, sei es zwingend oder sei es nicht zwingend gestaltet. Das klingt paradox, ist aber keineswegs neu und in der Sache hier schon angesprochen worden. Von diesem öffentlichen Privatrecht ist das Staatsrecht zu unterscheiden. Das ist das Recht des Staatlichen. Es können durchaus dieselben Vorschriften herangezogen werden, die aber in den jeweiligen Rechtsverhältnissen ihre Besonderheiten entfalten. Daneben gibt es den nichtstaatlichen Bereich des Rechts, also die von Privaten selbst geschaffenen Regelungen, die ich private Gesetze nennen würde. Auch das ist ein Aspekt der Einheit der Rechtsordnung. Das Prinzip der Widerspruchsfreiheit ist unsere Ethik, wie Herr Jarass schon sagte; denn Logik ist Ethik, weil wir kommunizieren müssen. Wenn die Kommunikationsmöglichkeit mangels Logik aufgehoben ist, ist Recht nicht mehr möglich. In diesem Zusammenhang ist heute immer wieder die Wertungsjurisprudenz zum Tragen gekommen. Es stellt sich die Frage, ob die Wertungsjurisprudenz diesem Prinzip der Widerspruchsfreiheit noch gerecht wird. Wenn nämlich das Prinzip der Rechtseinheit nichts anderes ist, als daß der Richter in jedem Einzelfall das Recht spricht, so ist die Rechtseinheit niemals verletzt, weil sie in der Einzelfallgerechtigkeit aufgehoben ist. Die Widerspruchsfreiheit der Gesetze teilt dann das Schicksal der Gesetze, die Maßgeblichkeit für den Richter einzubüßen. Das führt zu bestimmten Rechtsfindungsmethoden, vor allem zur Abwägungsregel. Zweitens: Die Verwaltungsvorschriften setzen Recht. Diese und auch die Verwaltungsakte sind Sollenssätze, als Rechtssätze. Die Rechtsfolgen dieser Rechtssätze sind unterschiedlich gestaltet; dem folgt der differenzierte Rechtsschutz. Soweit die Rechtssätze wirksam sind, sind sie m.E. bindend für die Strafrichter und die Zivilrichter. Sie sind wirksam, wenn sie den Gesetzen entsprechen, also nicht rechtswidrig sind, und - das und möchte ich betonen - nicht aufgehoben sind. Insofern ist die Vollzugsebene jedenfalls auch eine Normebene. Eine dritte Bemerkung, die anschließt an das, was Herr Vogel sagte: Der Umweltreferent einer nicht ganz kleinen Stadt hat mir neulich gesagt, daß die Gesetze ihn überhaupt nicht interessieren 
würden. Er kooperiere. Wenn die Aufsichtsbehörden in solcher Weise in den Fällen versagen, in denen ein Bürger nicht mehr klagen darf, dann müssen wir überlegen, ob das Prinzip der GesetzmäBigkeit der Verwaltung nicht durch die Bürger durchgesetzt werden kann, dann sollten wir das Tabu der Popularklage noch einmal überdenken. Es geht schließlich um die Umwelt der Bürger selbst. Viertens, schon etwas vorgreifend zum Satz nulla poena sine lege: Art. 103 Abs. 2 GG muß sehr zurückhaltend interpretiert werden, wenn man das Umweltproblem bewältigen will. Die Sanktionen müssen entpönalisiert werden. Die rechtsstaatliche Bestimmtheit kann auch durch Verwaltungsregelungen im Rahmen hinreichend bestimmter Gesetze erreicht werden. Übermäßig enge Bestimmtheitsanforderungen dürften in diesem Bereich nicht mehr hilfreich sein. Schönen Dank.

Wieland: Herr Vorsitzender, meine Herren. Um an Ihren Beitrag, Herr Schachtschneider, anzuknüpfen, so hege ich doch gewisse Zweifel, ob beim gegenwärtigen Stand der Dogmatik des Verwaltungsrechts gegenüber Zivilrechtlern oder Strafrechtlern überzeugend dargelegt werden kann, warum auch Verwaltungsvorschriften Pflichten des Bürgers begründen sollen. Mir scheint in einer klaren Dogmatik eine Grundbedingung der Wirksamkeit von Vorgaben des Verwaltungsrechts für Strafrecht und Zivilrecht zu liegen. Es reicht nicht aus, Vorgaben $\mathrm{zu}$ machen, sondern diese Vorgaben müssen auch angenommen werden. Und angenommen werden sie nur, wenn sich das Verwaltungsrecht in den Augen der Vertreter anderer juristischer Disziplinen als leistungsfähig erweist; Herr Jarass hat das zum Schluß seines Referates zu Recht betont.

Wie sieht es nun mit der Leistungsfähigkeit des öffentlichen Rechts aus, soweit die Verbindlichkeit von Verwaltungsvorschriften für Bürger und Gerichte begründet werden soll? Nach Ihrem Beitrag, Herr Ossenbühl, konnte man den Eindruck gewinnen, diese Frage sei inzwischen abschließend geklärt. Weisen Strafrechtler aber nicht zu Recht auf das Gebot der gesetzlichen Bestimmtheit einer Straftat in Art. 103 Abs. 2 GG hin? Zeigen nicht die Bedenken gegen den Versuch, ungeachtet dieser verfassungsrechtlichen Vorgabe normkonkretisierenden Verwaltungsvorschriften strafbarkeitsbegründende Wirkung zuzumessen, auch für das öffentliche Recht noch einmal die Probleme auf, die angesichts des allgemeinen Vorbehalts des Gesetzes mit der Annahme von für Bürger und Gerichte verbindlichen Verwaltungsvorschriften verbunden sind? Strafrechtler und Zivilrechtler werden die Vorgaben des Verwaltungsrechts 
sicher eher akzeptieren, wenn das Verwaltungsrecht selbst die Vorgaben des Verfassungsrechts strikt beachtet. Danke.

Gröschner: Herr Vorsitzender, meine Herren. Meine Frage an beide Berichterstatter wäre, ob man den sicher richtigen und wichtigen dogmatischen Differenzierungen auf verfahrens- und prozeßrechtlicher Ebene nicht eine materiellrechtliche Grundlage geben könnte. Aus meiner Sicht müßte diese Grundlage die verschiedenen Rechtspositionen enthalten, über die behördlicherseits entschieden wird, und zwar auf der Basis eines nur selten zweiseitigen, meist aber mehrseitigen Verwaltungsrechtsverhältnisses. Am Beispiel der Nachbarrechte ließe sich dann zeigen, daß die Bindungswirkung etwa einer immissionsschutzrechtlichen Genehmigung nicht zunächst eine Frage des allgemeinen Verfahrensrechts, sondern des materiellen Immissionsschutzrechts ist. Erst die Nichtberücksichtigung oder die nicht hinreichende Berücksichtigung einer nachbarrechtlich geschützten Position schafft eine korrelative Beziehung zwischen der Genehmigungsbehörde und dem durch die defizitäre Behördenentscheidung in seinen Rechten verletzten Nachbarn. Nach meiner Auffassung hat der Nachbar also primär ein absolutes öffentliches Recht, das erst durch Verletzung relativiert, d.h. in ein relatives Abwehrrecht gegenüber der Behörde transformiert wird. Und auf dieser materiellrechtlich orientierten dogmatischen Grundlage müßte dann weiter gefragt werden, was dies für die doch ganz anders strukturierten Straf- und Zivilrechtsverhältnisse bedeutet. Die Kernfrage im Rahmen der sogenannten Tatbestandswirkung der Genehmigung wäre, ob sich die behördliche Entscheidung über das absolute Nachbarrecht im Tenor und in den Gründen des Genehmigungsbescheids überhaupt niedergeschlagen hat, und ob von daher eine zivilrechtliche Ausschlußwirkung gegenüber dem Nachbarn oder eine strafrechtliche Rechtfertigung des Anlagenbetreibers im Hinblick auf die Individualrechtsgüter des Nachbarn überhaupt denkbar ist. Denn wo ihm gegenüber materiellrechtlich nicht entschieden wurde, entfaltet sich ihm gegenüber ja auch keine formellrechtliche Bindungs- und Ausschlußwirkung. Für mich käme es zusammengefaßt also auf die Ergänzung - nicht etwa die Ersetzung - der traditionellen verwaltungsrechtlichen Dogmatik durch eine Dogmatik der verschiedenen Rechtsverhältnisse des materiellen Rechts an und auf eine Betrachtung der in diesen Rechtsverhältnissen bestehenden Rechtspositionen. Vielen Dank.

Schenke: Herr Vorsitzender, meine Herren! Ich möchte nur eine kurze Bemerkung zur These $16 \mathrm{~b}$ von Herrn Schröder machen. In ihr hat Herr Scbröder m. E. zu Recht die Ansicht des BGH kritisiert, 
derzufolge die verwaltungsgerichtliche Aufhebung eines rechtswidrigen Verkehrszeichen nichts an der Strafbarkeit desjenigen ändern soll, der dieses Verkehrszeichen vorher nicht beachtet hat. Ich möchte seine These dahingehend verallgemeinern, daß generell die verwaltungsgerichtliche Aufhebung eines mit Strafe bewehrten rechtswidrigen Verwaltungsakts nicht nur zur Beseitigung der verwaltungsrechtlichen, sondern auch der strafrechtlichen Folgen des Verwaltungsakts führen muß. In diesem Zusammenhang ist ein Blick auf die Begründung interessant, mit welcher das Bayerische Oberste Landesgericht in einer Entscheidung, auf welche die von Herrn Schröder zitierte BGH-Entscheidung uneingeschränkt Bezug nimmt, die gegenteilige Auffassung zu rechtfertigen versuchte. Das Gericht hat hier darauf verwiesen, es sei angeblich allgemein anerkannt, daß die verwaltungsgerichtliche Aufhebung eines Verwaltungsakts gem. $\$ 113$ Abs. 1 S. 1 VwGO keine ex-tunc-Wirkung habe. Diese Auffassung ist aber offensichtlich unhaltbar. Damit entbehrt auch die auf dieser Prämisse aufbauende Folgerung, die spätere Aufhebung des rechtswidrigen strafbewehrten Verwaltungsakts stünde einer aus seiner Nichtbeachtung resultierenden Strafbarkeit nicht im Wege, der Grundlage. M.E. ist vielmehr im Hinblick darauf, daß ein Verwaltungsakt gem. $\$ 113$ Abs. 1 S. 1 VwGO rückwirkend aufgehoben wird und damit auch mit Wirkung für die Vergangenheit seine Tatbestandswirkung entfällt, zu folgern, daß nicht nur seine verwaltungsrechtlichen, sondern auch seine strafrechtlichen Folgen beseitigt werden müssen. Man kann hier durchaus eine Parallele zum verwaltungsrechtlichen Vollzugsfolgenbeseitigungsanspruch ziehen. Ist es nicht inkonsequent, wenn man mit der h.M. davon ausgeht, daß die Aufhebung eines rechtswidrigen Verwaltungsakts einen verfassungsrechtlich garantierten verwaltungsrechtlichen Vollzugsfolgenbeseitigungsanspruch auslöst, gleichzeitig aber die These vertritt, daß die strafrechtlichen Folgen dieses aufgehobenen Verwaltungsakts, die in der Regel für den Betroffenen ja weit gravierender sind als die verwaltungsrechtlichen, durch die Aufhebung des Verwaltungsakts unberührt bleiben? In einer solchen Annahme scheint mir jedenfalls ein schwerwiegender Wertungswiderspruch zu liegen. Das zeigt auch ein Blick auf $\$ 79$ BVerfGG, der vorsieht, daß die verfassungsgerichtliche Nichtigkeitserklärung einer Norm gem. $\$ 79$ Abs. 2 BVerfGG eine nicht mehr anfechtbare Entscheidung, die auf dieser Norm beruht, grundsätzlich nicht berührt und nur die Vollstreckung aus ihr unzulässig ist, während bei einem rechtskräftigen Strafurteil, das auf einer derartigen Norm basiert, gem. $\$ 79$ Abs. 1 BVerfGG ein Wiederaufnahmeverfahren nach den Vorschriften der StPO zulässig ist. Wenn hier durch den Gesetzgeber zum 
Ausdruck gebracht wird, daß die Rechtsordnung an der Beseitigung der strafrechtlichen Folgeakte einer nichtigen Norm ein höheres Interesse hat als an der Beseitigung sonstiger auf der Norm beruhender Entscheidungen, spricht dies gleichfalls dafür, bei Aufhebung eines strafbewehrten rechtswidrigen Verwaltungsakts einen der Sache nach „strafrechtlichen Vollzugsfolgenbeseitigungsanspruch" zu befürworten.

Mußgnug: Herrn Trzaskaliks Bemerkung über den Strafrichter, der den schwierigen Fragen der Zurechnungsfähigkeit oder des ärztlichen Kunstfehlers vollauf gewachsen sei, ist so nicht richtig. Diese Fragen kann der Strafrichter nur mit Sachverständigenhilfe beantworten. Ob er mit den nicht ganz so schwierigen verwaltungsrechtlichen Problemen, vor die ihn nicht nur das neue Umweltstrafrecht, sondern seit eh und je auch die Tatbestände des Fahrens ohne Fahrerlaubnis, des unerlaubten Waffenbesitzes u. a. m. stellen, aus eigener Kraft fertig werden kann, weiß ich nicht. Jedenfalls muß er mit ihnen fertig werden. Auch dabei stehen ihm freilich Hilfen zu Gebote, die ihm seine Arbeit leicht machen, wenn er sie richtig zu nutzen versteht.

Seine Kompetenz zur Entscheidung über verwaltungsrechtliche Vorfragen überforderte den Strafrichter nur, wenn ihn das Verwaltungsrecht bei ihrer Ausübung im Stiche ließe. Aber dem ist nicht so. Das Verwaltungsrecht schlägt die Vorfragenkompetenz des Strafrichters in enge, für ihn einfach zu überschauende Grenzen. Hat er es mit einem Angeklagten zu tun, der sich um die für die Teilnahme am Straßenverkehr, den Waffenbesitz, den Umgang mit radioaktivem Material, etc. nötige behördliche Erlaubnis bemüht und sie erhalten hat, obgleich er sie nach Auffassung des Staatsanwalts nicht hätte erhalten dürfen, weil er die für ihre Erteilung erforderlichen rechtlichen oder tatsächlichen Voraussetzungen nicht erfüllt, so beginnt und endet auch die strafrichterliche Prüfung dieser Erlaubnis bei $\$ 43$ VwVfG. Denn $\$ 43 V_{w} V f G$ verbietet kategorisch jede Verurteilung eines Angeklagten, der die für sein Verhalten gesetzlich vorgeschriebene Erlaubnis korrekt eingeholt hat. Diese Erlaubnis ist ungeachtet ihrer eventuellen Fehlerhaftigkeit wirksam. Daher darf von ihr Gebrauch gemacht werden. Wer das tut, der handelt nicht „unerlaubt". Er hat schließlich genau das getan, was das Gesetz von ihm verlangt. Ihm vorzuwerfen, daß er die von ihm erwirkte Erlaubnis nicht kritischer geprüft hat als die zu ihrer Erteilung zuständige Behörde seinen Antrag, wäre abwegig. Damit scheidet die Strafbarkeit a limine aus.

Hält man sich daran, so gehen das Straf- und das Verwaltungsrecht nahtlos miteinander Hand in Hand. Die Vorfragenprüfung bleibt 
jedenfalls bei den verwaltungsakt-abhängigen Straftaten ganz unproblematisch. Sie stellt den Strafrichter nur vor die Frage, ob der Angeklagte eine wirksame Erlaubnis vorweisen kann. Ob diese Erlaubnis fehlerbaft ist, geht ihn nichts an, es sei denn, sie erweist sich ausnahmsweise als nichtig. Die Nichtigkeit bleibt das einzige Instrument, mit dem die Strafjustiz den von ihr als dubios erachteten Erlaubnissen beikommen kann. Mit der Nichtigkeit tun sich die Strafrechtler allerdings unnötig schwer. Denn sie nehmen die Evidenz- oder Stirnbandtheorie allzu penibel beim Wort. Diese Theorie verlangt keineswegs, daß die Fehlerhaftigkeit des Verwaltungsakts auch für jeden, der die näheren Umstände nicht kennt, unübersehbar zutage tritt. So ist z. B. der durch Bestechung erworbenen Fahrerlaubnis zwar nicht anzusehen, daß sie eindeutig und grob rechtswidrig ist. Daß der Polizist, dem sie vorgelegt wird, das nicht durchschauen kann, spielt jedoch keine Rolle. Den Ausschlag gibt, daß ibr Adressat Bescheid weiß. Es kommt allein auf seine Kenntnis und darauf an, daß ihm klar sein muß, daß ihn eine auf Schleichwegen erworbene Fahrerlaubnis nicht zum Führen von Kraftfahrzeugen berechtigen kann. Das gleiche gilt für jede Erlaubnis, die einem Adressaten erteilt wird, der genau weiß, daß er sie nie und nimmer hätte erhalten dürfen. Denn es geht um den Empfängerhorizont, nicht darum, was außenstehende Dritte zu erkennen vermögen. Der an eine Frau gerichtete Einberufungsbescheid ist wohlgemerkt auch dann nichtig, wenn diese Frau Hosen trägt und daher leicht für einen Mann gehalten werden kann. Ihre Einberufung ist nichtig, weil sie selbst weiß, daß sie nicht wehrpflichtig und damit vor der Bestrafung wegen Fahnenflucht sicher ist.

Die Verwaltungsrechtsdogmatik liefert dem Strafrichter somit hinreichend stichhaltige Argumente an die Hand, die es ihm ermöglichen, gar zu grob fehlerhafte Verwaltungsakte als unbeachtlich abzutun, ohne sich von den bewährten und wohl begründeten Lehren des allgemeinen Verwaltungsrechts mit abenteuerlichen Konstruktionen wie der des nur verwaltungsrechtlich, aber nicht strafrechtlich wirksamen Verwaltungsakts abheben zu müssen. Die Probleme der verwaltungsaktabhängigen Straftatbestände bekommen die Strafrechtler jedenfalls mit einer exakteren Rückbesinnung auf das, was den Verwaltungsakt nichtig macht, leicht und vor allem auch mit nicht nur für sie nachvollziehbaren Überlegungen in den Griff. Wir brauchen uns also nicht um die Vereinheitlichung einer vermeintlich uneinheitlichen Rechtsordnung zu streiten. Die Einheit der Rechtsordnung mag an anderen Stellen gestört sein. An der Schnittstelle zwischen dem Verwaltungs- und dem Strafrecht hält sie das VwVfG mit mustergültiger 
Konsequenz aufrecht. Die Regeln, mit denen das VwVfG das bewerkstelligt, sollten die Strafrechtler nicht hinterfragen, sondern schlicht und einfach anwenden.

Im übrigen habe ich mich darüber gefreut, daß Herr Schröder der Unterscheidung zwischen dem feststellenden und dem konstitutiven Verwaltungsakt jede strafrechtliche Bedeutung abgesprochen hat. Daß er damit richtig liegt, beweist das Staatsangehörigkeitsrecht. Es kennt neben der konstitutiven Einbürgerung die deklaratorische Feststellung der Staatsangehörigkeit. Beides kann für die Frage, ob ein Straftäter ins Ausland ausgeliefert werden darf, von entscheidender Bedeutung sein. Ist ein Ausländer nach einer in seiner Heimat begangenen Straftat von der Bundesrepublik eingebürgert worden, so steht das gemäß Art. 16 Abs. 2 Satz 1 GG seiner Auslieferung als unüberwindliches Hindernis entgegen. Ist die von ihm beantragte Einbürgerung statt dessen abgelehnt worden, weil die Behörde meinte, er sei ohnehin Deutscher, und läßt sie es deshalb bei der bloßen Feststellung seiner Staatsangehörigkeit bewenden, so geht dem zwar die konstitutive Wirkung der Einbürgerung $a b$, schließt die Auslieferung aber ebenfalls aus. Alles andere zielte weit an Art. 16 Abs. 2 Satz 1 GG vorbei. Es ist gut, daß Herr Schröder das klargestellt hat.

Trzaskalik: Herr $M u \beta g n u g$, wir machen es ja, wenn ausländisches Recht angewandt wird, gängig so, daß wir die Auskünfte der MaxPlanck-Institute einholen. Da würde ich bei Ihnen natürlich vorschlagen, falls der Strafrichter mit Steuerrecht zu tun hat, daß er sich an Sie wendet und ein entsprechendes Gutachten einholt. Dann wäre das Thema schon gelöst.

Ronellenfitsch: Herr Bullinger, ich muß Ihnen insofern widersprechen, als das genau die richtige Vereinigung ist, um die Thematik zu besprechen; denn am Dissens zwischen Straf- und Öffentlich-Rechtlern über die Verwaltungsakzessorietät des Strafrechts sind wir zum großen Teil mitschuldig. Im Betäubungsmittel- und im Umweltstrafrecht hat die Generalprävention Konjunktur. Es wird nicht gebessert; es wird gestraft, um abzuschrecken. Wir haben so lange, wie Herr Jarass heute auch wieder, über die Vollzugsdefizite des Umweltrechts geklagt und lamentiert, bis andere sich dieses Problems angenommen haben, bis - Herr Ossenbuibl hat das in seiner bekannt introvertierten Art zum Ausdruck gebracht - Staatsanwaltschaften die Aufgabe übernommen und sich zu Umweltschützern aufgeschwungen haben. Es fehlt nur noch, daß die Umweltstrafkammern in grüner Robe auftreten, aber vermutlich will man Verwechslungen mit den Chirurgen vermeiden. Nach dem Selbst- und Rollenverständnis spezieller 
Umweltkammern ist es ganz klar, daß es deren Anliegen ist, den Umweltschutz nach vorne zu bringen, und das ohne Rücksicht auf Verluste. In der Strafjustiz herrscht die Meinung, die Verwaltungsbehörden erfüllten die Aufgaben des Umweltschutzes nicht zulänglich und nicht ausreichend. Die Folge ist, daß Staatsanwaltschaften und Strafgerichte das Verwaltungsrecht dilettantisch und formalistisch selbst anwenden. Beispiel für den Dilettantismus: Eine Genehmigung ist nur dann eine Genehmigung, wenn sie förmlich als Genehmigung bezeichnet wird. Uns allen ist natülich klar, daß auch im Umweltverwaltungsrecht Verwaltungsakte die Freiheit, die Umwelt zu gestalten, feststellen oder gelegentlich erst herstellen. Entscheidend ist allein, ob die Freiheit nach der behördlichen Entscheidung besteht oder nicht. Der Verzicht auf eine Planfeststellung oder auf eine qualifizierte (formalisierte) Genehmigung, eine Vorabzustimmung oder ein Freigabebescheid sind auch dann Genehmigungen, wenn sie nicht als solche firmieren. Gestattet eine Behörde ein Vorhaben formalrechtlich anders, als es die Strafverfolgungsbehörde für erforderlich hält, so liegt allenfalls ein rechtswidriger Verwaltungsakt vor, aber gleichwohl eine Genehmigung. Der Betrieb des Vorhabens ist materiell nicht illegal. Die Behörden, welche die Genehmigung im materiellen Sinne ausgesprochen haben, leisten nicht Beihilfe zum ungenehmigten Betrieb. Dennoch gehen die Strafverfolgungsbehörden gegen sie vor. Der „Bürgerkrieg“ im Umweltstrafrecht erfolgt noch viel subtiler und unangemessener, als das Herr Ossenbübl angedeutet hat. Die Haupttäter werden freigesprochen, weil ihnen kein Schuldvorwurf gemacht werden kann. Die Genehmigung, wenn auch die falsche, lag ja vor; der Verbotsirrtum war unvermeidbar. Die Übeltäter sind die Genehmigungsbehörden. Ihre Beamten können nur deswegen nicht bestraft werden, weil die Haupttäter freigesprochen wurden. Also wird das Verfahren eingestellt. Die diskriminierende Behauptung kollusiven Zusammenwirkens der Umweltbehörden mit den Antragstellern bleibt bestehen.

Die materiellrechtlichen Probleme lassen sich bereinigen, Herr Mußgnug hat völlig recht, indem man das klassische Verwaltungsrecht beim Wort nimmt. Nichts ist anachronistischer, als den Verwaltungsakt für anachronistisch zu halten. Über die Nichtigkeit und Rechtswidrigkeit des Verwaltungsakts findet sich mit Sicherheit eine angemessene Lösung. Schwieriger sind die prozeßrechtlichen Folgeprobleme. Das Aussetzen, das mehrfach angesprochen wurde, führt meistens nicht weiter. Denn was geschieht dann? Wie geht es weiter, wenn das Strafverfahren ausgesetzt wurde? Der Angeklagte hat doch eine Genehmigung erhalten - wozu soll dann das Strafverfahren 
ausgesetzt werden? Doch wohl nur, um verwaltungsprozessual zu Lösungen zu finden. Damit sind wir auch bei den Verwaltungsgerichten, denen immerhin größeres Vertrauen entgegengebracht wird als den Verwaltungsbehörden. Ich meine, daß wir hier nur über die Feststellungsklage zu einer Lösung gelangen; die Klage auf Feststellung, daß eine Genehmigung vorliegt und daß die Genehmigung rechtmäßig ist. Man muß also $\$ 43$ VwGO großzügiger auslegen. Das ist nun wieder ein Defizit von unserer Seite. Im Verwaltungsprozeßrecht soll nämlich nach nahezu einhelliger Meinung eine derartige Feststellungsklage unzulässig sein, da es sich um eine vorbeugende Klage handele, für die das qualifizierte Feststellungsinteresse fehle. Nichts ist falscher. Natürlich ist das keine vorbeugende Feststellungsklage. Es soll zwar einem Strafverfahren vorgebeugt werden. Aber der Gegenstand der Feststellungsklage ist die aktuelle Rechtmäßigkeit eines Verhaltens. Deswegen muß gerade an dieser Stelle noch weitergedacht werden. Vielen Dank, daß ich die Zeit ausnutzen durfte.

Hufen: Herr Vorsitzender, meine Herren. Auch mein Thema ist das Problem der Bestimmtheit der Normen, vor allem der Strafrechtsnormen und die Konkretisierungsleistung, die das Verwaltungsrecht in dieser Beziehung zu erbringen hat. Ich meine, schon in den bisherigen Diskussionsbeiträgen ist sehr deutlich geworden, daß wir es hier mit einer Art "Konkretisierungskonkurrenz" in der Ausfüllung z. B. umweltstrafrechtlicher Tatbestände zwischen dem Öffentlichen Recht, teilweise auch dem Zivilrecht und dem Strafrecht zu tun haben, und ich meine auch, der weit verbreitete Eindruck ist widerlegt worden, daß sich das Öffentliche Recht auf breiter Front in die Gefilde des Strafrechts einmischt. Im Gegenteil: Mir scheint es eher umgekehrt zu sein, und wir sind in weiten Bereichen heute zu einer Art Strafrechtsakzessorietät des Verwaltungsrechts und nicht - wie es sein sollte - umgekehrt zur Verwaltungsrechtsakzessorietät des Strafrechts gelangt. In den meisten der hier angesprochenen Problemfelder geht es um sehr komplizierte Ursachenzusammenhänge und Risikozuordnungen. Hier werden öffentlich-rechtliche Pflichten formuliert oder vorausgesetzt, die sich nicht nur als Nebenprodukte des strafrechtlichen Fahrlässigkeitsbegriffs begreifen lassen. In der Sache geht es nämlich um öffentlich-rechtliche Verpflichtungen, Verkehrspflichten, Sorgfaltspflichten des Betreibers usw. Dabei meine ich, der notwendige Vorsprung des Öffentlichen Rechts in der Definition und Konkretisierung solcher Pflichten muß gegenüber dem Strafrecht gewahrt bleiben, denn nur solche Handlungen und Unterlassungen können strafbar sein, die mit hinreichender Bestimmtheit aus dem 
Gesetz selbst abgeleitet werden können oder - wenn die Tatbestände zu unbestimmt sind - durch die Verwaltung konkretisiert werden müssen. Hier hat das Urteil des BVerfG zur Fernmeldeanlagenverordnung neue Maßstäbe gesetzt. Ein Instrument, das in dieser Diskussion überhaupt noch nicht erwähnt worden ist, ist das Bußgeldverfahren. Dieses spielt in der Praxis eine sehr viel größere Rolle, als es hier bisher deutlich geworden ist. Wir haben ja in weiten Bereichen das Phänomen, daß die Behörden gar kein Strafverfahren einleiten; sie leiten aber auch kein Verwaltungsverfahren zur Klärung öffentlichrechtlicher Pflichten ein, ja, sie geben vielfach nicht einmal verbindliche Auskünfte über solche Pflichten, aber sie erlassen einen Bußgeldbescheid. Genuin öffentlich-rechtliche Handlungs- und Verkehrspflichten werden dann praktisch in zweiter Instanz von den Oberlandesgerichten abschließend geklärt. Wenn wir z. B. wissen wollen, welche Sorgfaltspflicht den Lebensmittelhändler oder Lebensmittelimporteur trifft, dann müssen wir beim OLG Koblenz nachlesen, nicht etwa in irgendeiner Quelle, die dem Verwaltungsrecht zuzuordnen wäre.

Fazit: Das Öffentliche Recht muß bei den genannten Verpflichtungen die entscheidende Priorität bei der Konkretisierung wiedergewinnen. Das ist ein Problem rechtsstaatlicher Bestimmtheit; es ist aber auch ein Problem des Vertrauens der Bürger und der Bindung der Gerichte, auch der Strafgerichte und Bußgeldbehörden, an Art. 103 II GG.

Drei konkrete Vorschläge in diesem Zusammenhang, teilweise als Fragen formuliert. Zunächst eine Frage an Herrn Schröder: Wären auch Sie der Auffassung, daß das Bußgeldverfahren gegenüber dem Verwaltungsverfahren nachrangig ist - eine in der Praxis äußerst wichtige Frage? Hier wird teilweise völlig unspezifisch von einer Ermessensfreiheit der Behörden zwischen Verwaltungsverfahren und Bußgeldverfahren gesprochen. Die zweite Frage: Ließe sich daran denken, einen allgemeinen Feststellungsanspruch oder zumindest einen Auskunftsanspruch des Bürgers über seine Sorgfaltspflichten zu institutionalisieren? Und der dritte Punkt - sehr im Einklang mit Herrn Ronellenfitsch: Müssen wir nicht die Zulassungshindernisse der verwaltungsprozessualen Feststellungsklage zur präventiven Klärung von Sorgfaltspflichten, nicht nur zur Vermeidung von Straf- und Bußgeldsanktionen, beiseite räumen? Zu dieser Frage ist derzeit im Bereich des Lebensmittelrechts noch ein Revisionsverfahren vor dem Bundesverwaltungsgericht anhängig, von dem ich weitere Klärung erhoffe. Vielen Dank! 
Meyer: Ich habe drei Punkte. Der erste Punkt betrifft das, was Herr Mußgnug und Herr Ronellenfitsch gesagt haben: ich schlage in die gleiche Kerbe. Ich bin erfreut, daß zum erstenmal seit zwei Stunden in dieser Versammlung $\$ 43 \mathrm{VwVfG}$ überhaupt genannt worden ist, die einzige Gesetzesnorm, die sagt, daß Verwaltungsakte Wirksamkeit haben und also von jedem in ihrer Wirksamkeit zu beachten sind. Aber ich möchte doch etwas Wasser in diesen Wein gießen: Beide haben auf $\$ 44 \mathrm{VwVfG}$ verwiesen, und ich glaube, daß der $₫ 44 \mathrm{VwVfG}$, jedenfalls in der bisherigen Auslegung, die Fälle nicht löst, die tatsächlich Ärgernis bereiten. Das sind die Fälle der Kollusion. Herr Ossenbiibl hat gesagt, Kooperation sei gefragt. Bedauerlicherweise geht die Kollusion nicht ohne Kooperation, die Kooperation ist nämlich regelmäßig ein Modus der Kollusion. Ich habe Ihnen eben einen baurechtlichen Fall der Kollusion vorgetragen. Wir haben den ganzen Parteifinanzierungsstreit - natürlich einen globalen Kollusionsfall, wobei die Kollusion nicht durch Absprache, sondern durch augenzwinkernde Nichtabsprache in parallelem Verhalten vonstatten gegangen ist. Und Herr Mußgnug hat einen dritten Fall erwähnt, den er für falsch entschieden hält, nämlich den Hanauer Strafprozeß, den auch ich für falsch entschieden halte; freilich, Herr Mußgnug, nur deswegen für falsch entschieden halte, weil der $\$ 44$ VwVfG die Kollusion nicht zum Nichtigkeitsgrund erklärt hat. Das ist der entscheidende Punkt. Ich habe mittlerweile das Vertrauen darin verloren, daß wir grundsätzlich sagen könnten, die Verwaltung fühlt sich, wenn sie einseitig hoheitlich handelt, prinzipiell an das Recht gebunden. Die Verwaltung fühlt sich daran gebunden, ihre politischen Ziele, ihre Verwaltungsziele durchzusetzen, und wenn das Recht stört, dann ist die Verwaltung intelligent genug, Umwege zu suchen. Im Falle der Hanauer Nuklearbetriebe ging das so: zum einen war der Geschäftsführer Bundestagsabgeordneter einer der regierenden groBen Parteien, zum zweiten wurde in einem Bundesministerium ein Rechtsgutachten gemacht, das entgegen dem eindeutigen Atomrecht, das gerade geändert worden war, es für erlaubt erklärte, vielleicht doch so eine Art Zwischengenehmigung zu erteilen, obwohl die Frist des Atomgesetzes abgelaufen war. Das schaffte den atomrechtlichen Behörden in Hessen für das, was sie sowieso vorhatten, das gute Gewissen, denn "die wissen es ja besser in Bonn“, und folglich konnten sie die Genehmigung erteilen. Also ein typischer, wenn auch etwas komplizierter Fall von Kollusion. Ich meine, wir müßten dazu kommen, daß solche Kollusionsfälle zur Nichtigkeit des Verwaltungsaktes führen. Wir haben ja die Parallele beim öffentlich-rechtlichen Vertrag. 
Zum zweiten Punkt. Was das allgemeine Verhältnis vom öffentlichen Recht zum Zivilrecht angeht, Herr Bullinger, so bin ich der festen Überzeugung, daß Ihr Problem nur eine Frage der Modernität der jeweiligen Fakultät ist. Wir haben in Frankfurt überhaupt keine Schwierigkeiten. Wir haben drei Zivilrechtler, die auf den Gebieten des Medienrechts, des Umweltrechts und des Datenschutzrechts außerordentlich erfolgreich sind und daher keine Verständnisschwierigkiten haben. Ich glaube auch nicht, daß es ein Problem der Verständnisschwierigkeiten ist zwischen dem öffentlichen Recht und dem Zivilrecht, sondern es ist ein Kompetenzproblem, d. h. ein übliches Machtproblem, und die werden so oder so entschieden. Dabei kommt es eher auf die Konstitution der einzelnen an, ob sie nämlich großzügig oder weniger großzügig sind.

Zum dritten möchte ich, obwohl wir schon am Ende sind, auf den Anfang zurückkommen. Mir kamen die ganzen Erwägungen zur Einheit der Rechtsordnung, ja selbst zur Widerspruchslosigkeit der Rechtsordnung so vor, als würden wir im dunklen Wald pfeifen. Jeder von uns weiß doch, daß die Rechtsordnung eines modernen demokratischen Staats alles andere als eine Einheit darstellt. Sie ist ein außerordentlich widersprüchliches System. Und jeder von uns, der nur einmal ein Gesetz kommentiert hat, weiß, wie schwierig es ist, allein für ein Gesetz die Widerspruchslosigkeit herzustellen. Das einzige, was wir verlangen müssen und erreichen können, ist, daß für einen bestimmten Fall nur ein Recht gilt, und das festzustellen, ist schon schwierig genug. Die Widerspruchslosigkeit der Rechtsordnung ist nicht zu erreichen. Wir können uns bemühen - und es ist sicherlich vernünftig, Herr Jarass, wenn wir uns bemühen -, aber wir können nicht davon ausgehen, daß das auch nur annähernd der reale Zustand einer modernen Rechtsordnung ist. Wir müssen durchaus mit diesen Widersprüchen leben.

Sachs: Ich habe zunächst einige mehr technische Fragen zu stellen, die sich mit der Bindungswirkung von Verwaltungsakten für die Zivilgerichte beschäftigen. Zunächst eine eher verständnisbezogene Frage an Herrn Jarass: Die Thesen 16 und 18 scheinen mir - so wie ich sie jetzt verstehe und auch im Referat gehört habe - doch Widersprüche zu bergen. In These 16 wird davon ausgegangen, daß die Zivilgerichte nur bei besonderen Vorschriften gebunden sein sollen. Die These 18 operiert dann mit Bindungen, wohl allgemeinerer Art, die die Gestaltungswirkungen umfassen sollen, aber auch Feststellungen sollen verbindlich sein. Sind das dann dieselben Fälle, die in These 16 angesprochen sind, oder sind das doch weitergehende Bindungen? Da schien mir vielleicht nicht klar, was gemeint ist. 
Eine Frage an beide Referenten, die ich aber besonders an These $17 \mathrm{~b}$ von Herrn Schröder festmachen kann. In der These $17 \mathrm{~b}$ ist von der Wirksamkeit und Bestandskraft von Verwaltungsakten die Rede. Und Herr Mußgnug hat eben auf $₫ 43$ VwVfG hingewiesen - das sei alles eine Frage der Wirksamkeit von Verwaltungsakten. Wie stehen die Referenten zu dieser Frage? Muß ein Verwaltungsakt, der diese Bindungswirkungen äußern soll, nur wirksam sein, oder muß er bereits bestandskräftig geworden sein? Weitere Frage: Gegenüber wem bestandskräftig geworden sein? Muß er auch gegenüber einem Drittbetroffenen bereits bestandskräftig sein? Denn es sind ja in der Regel etwas komplexere Verfahren, die auch von Drittanfechtungen betroffen sind, die evtl. diese Bindungswirkungen noch in Frage stellen können. Dann muß ich erneut zu den leidigen Normwidersprüchen eine kurze Anmerkung machen. Ich meine, daß es nicht angeht, auch in der modernsten und demokratischsten Gesellschaft nicht, daß wir dasselbe Verhalten gebieten, das wir verbieten; das ist einfach ein logisches Unding. Wenn solches in Gesetzen drinsteht, stimmt irgendetwas nicht. Das müssen wir wieder passend machen.

Bei Herrn Breuers Aussage bin ich ein bißchen skeptisch. Es ist vielleicht schon denkbar, daß wir ein Verhalten genehmigen, das zugleich von einem Verbot betroffen ist. Wir müssen bei der Genehmigung ja immer sehen, von welchem Verbot diese Genehmigung freistellt. Das muß nicht immer auch schon das zivilrechtliche oder strafrechtliche Verbot sein; das kann ja ein ganz davon getrenntes verwaltungsrechtliches Verbot sein.

Und ein letzter Punkt. Mir fiel auf, daß die grundlegende Frage, die zumindest bei der Legalisierungswirkung ja im Raume stand, die Frage - wie halten wir es mit dem Erfolgsunrecht oder dem Handlungsunrecht? - hier nicht besonders angesprochen worden ist; wahrscheinlich findet sich dazu irgendwie ein Verweis in den Fußnoten. Vielen Dank.

Vogel: Ein Zwischenruf, der mir nötig erscheint: Wenn wir von Widerspruchsfreiheit sprechen, sollten wir endlich klar unterscheiden zwischen Gebotswidersprüchen und Wertungswidersprüchen. Das war's.

Rupp: Ich möchte noch kurz etwas sagen zur Einheit der Rechtsordnung als Rechtsprinzip: Eine Einheit der Rechtsordnung im hier gebrauchten Sinn gibt es nicht und kann es nicht geben. Die Rechtsordnung eines hochdifferenzierten Sozialgebildes verlangt nach differenzierten Strukturen, und insofern hat Herr Meyer völlig recht.

Es kann also allenfalls um die Einheit und Widerspruchslosigkeit der einzelnen Rechtsverhältnisse gehen: A kann gegenüber B nicht zu 
etwas verpflichtet sein, was ihm andererseits verboten ist. Gleichwohl gibt es problematische Fälle: Ich denke beispielsweise an die Regelung von Allgemeinen Versicherungsbedingungen, die sowohl unter die Genehmigungspflicht des Versicherungsaufsichtsgesetzes als auch unter das AGB-Gesetz fallen. Es kann also sein, daß Allgemeine Versicherungsbedingungen vom Bundesaufsichtsamt genehmigt werden, und anschließend im AGB-Verfahren dieselben Versicherungsbedingungen von den ordentlichen Gerichten für unwirksam erklärt werden. Hier muß meines Erachtens eine materiell-rechtliche Harmonisierung im Wege der Auslegung erfolgen, und sie ist auch möglich. Vielen Dank.

Berg: Als ich mich vor längerer Zeit unvorsichtigerweise zu Punkt $3 \mathrm{zu}$ Wort gemeldet habe, da hatte ich die Absicht, einen gewissermaßen letzten Blick auf das zivilrechtliche Urgestein zu werfen, bevor es ganz verschüttet ist. In der Zwischenzeit haben, Gott sei Dank, einige Kollegen das Zivilrecht doch wieder erwähnt und vielleicht ein bißchen am Urgestein poliert. Ich nenne Herrn Badura, Herrn Häberle, Herrn Thieme und Herrn Pitschas, so daß ich mich auf ganz wenige Bemerkungen beschränken kann. Ich möchte auf einen Aspekt hinweisen, der im Referat von Herr Jarass m. E. zu kurz gekommen ist. Für uns sollte das Privatrecht doch wenigstens insofern von Interesse sein, als es typischer Ausdruck der Grundrechtsverwirklichung ist. Das gestern so häufig zitierte Subsidiaritätsprinzip im Verhältnis der Staaten zueinander klang heute nicht einmal dem Gedanken nach mehr an, und zwar in dem Sinne, daß der Bürger Ziel aller unserer Überlegungen sein sollte. Dabei ist die primäre, die normale Handlungsform zwischen den Bürgern als Grundrechtsträgern und Ausdruck ihrer Privatautonomie der Vertrag. Die These Nr. 11 von Herrn Jarass, daß Grundrechte einen höheren Rang als das Privatrecht besitzen, ist natürlich formal richtig. Aber sie wird der Bedeutung des Privatrechts für die Grundrechtsverwirklichung nicht gerecht. Wenn etwa beispielsweise durch Flurbereinigungsverfahren über viele Jahre bis zu anderthalb Jahrzehnten hinweg der gesamte private Grundstücksverkehr zum Erliegen kommt, dann verfehlt m. E. das Verwaltungsrecht seine Service-Funktion zur Grundrechtsverwirklichung.

Dementsprechend verkürzt ist auch die These Nr. 13 formuliert, jedenfalls dann, wenn man sie so allgemein versteht, wie sie geschrieben ist und nicht so differenziert anwendet, wie sie wahrscheinlich gemeint ist. Für Auslegung und Anwendung des Verwaltungsrechts sollen nach dieser These immerhin Verwaltung und Verwaltungsgerichte zuständig sein; für das Privatrecht hingegen nur noch die 
Zivilgerichte. Soll die Rechtsverwirklichung durch Private durch Vertrag in Ausübung ihrer Privatautonomie keine Rolle mehr spielen? Es müssen ja nicht gleich Verträge über 50 Millionen sein, die Hans Meyer angesprochen hat. Ich meine, man sollte das bürgerliche Recht nicht auf die pathologischen Fälle der hoheitlichen Streitentscheidungen verkürzen. Vielen Dank.

Vorsitzender: Vielen Dank! Meine Herren, dem Umstand, daß Sie so diszipliniert, straff und konzentriert diskutiert haben, danken wir, daß wir die Diskussion rechtzeitig schließen können. Ich darf nun das Schlußwort vergeben, zuerst an Herrn Schröder und dann an Herrn Jarass.

Schröder: Herr Vorsitzender, meine Herren. Ich beginne mein Schlußwort mit dem Dank für die kritischen und zustimmenden Diskussionsbeiträge zu meinen Überlegungen. Zugleich bitte ich um Nachsicht, daß ich wegen der fortgeschrittenen Zeit nicht mehr auf alle Beiträge eingehen kann. Vorab möchte ich aber in Erinnerung rufen, daß aus der Sicht des Strafrechts unser Thema auch ein Preis der Rechtsstaatlichkeit ist. Wenn man nämlich den Blick rückwärts wendet und sich mit der Entwicklung des sog. Verwaltungsstrafrechts befaßt, dann sieht man, daß, solange das Strafrecht und die Bestrafung in der Hand der Verwaltung selbst liegt, was wir natürlich heute nicht mehr akzeptieren können, manche von den Problemen, die wir heute diskutiert haben, keine Rolle mehr spielen. Nun aber im einzelnen zu den Diskussionsbemerkungen: Ich glaube, daß die Problematik zwischen Strafrecht und Strafrechtspflege einerseits und öffentlichem bzw. Verwaltungsrecht andererseits nach wie vor besteht, auch wenn Herr Bullinger gemeint hat, es gehe heute eigentlich eher um das Privatrecht. Die "Störvorgabe“ des Verwaltungsrechts, um diesen Begriff noch einmal aufzugreifen, wird noch immer von den Strafrechtlern sehr empfunden. Insofern bleibt der Versuch eines Schutzes der Verwaltungsrechtsordnung, sei es auf dem Wege des Schutzes der Kompetenz der Verwaltung, sei es auch unter dem anderen Aspekt des Schutzes des Bürgers, für die Zukunft von Bedeutung. Er muß sich weiter bewähren, und dabei kommt es auch auf die Leistungsfähigkeit des Verwaltungsrechts an. So ist etwa auf die Überlegungen zur Überprüfung, insbes. der Auslegung des $\$ 44 \mathrm{VwVfG}$. hinzuweisen. Oder es ist zu überlegen, ob die restriktive Handhabung der negativen Feststellungsklage in der VwGO nicht im Zuge engerer Beziehungen zwischen Strafrecht und Verwaltungsrecht anders gesehen werden muß. - Die Frage, ob nicht der Vorrang dem Verwaltungsverfahren auch gegenüber dem Ordnungswidrigkeitsverfahren 
gebührt, würde ich vorsichtig bejahen wollen. Hier wie zu anderen Beiträgen gilt: Letztlich ist das Vorgabe-Problem auch eine gesetzgeberische Aufgabe und insoweit, meine ich, kann man sehr wohl von der Einheit der Rechtsordnung als Aufgabe der Gesetzgebung - als Gesetzgebungsmaxime sprechen.

Vorsitzender: Vielen Dank, Herr Schröder. Die Reihenfolge des Schlußwortes war mit den Referenten abgesprochen und beruht auf dem Umstand, daß das Zwischenwort zunächst bei Herrn Jarass lag. Also, ich bitte um Verständnis, wenn wir so verfahren. Es ist jedenfalls im vollen Einverständnis mit den Referenten geschehen. Bitte, Herr Jarass.

Jarass: Zunächst darf ich mein Einverständnis mit dieser Vorgehensweise bekräftigen. In der Sache werde ich auch in meinen Schlußbemerkungen nicht auf die vielen Beiträge eingehen, die ganz auf der Linie meiner Überlegungen liegen.

Ich beginne mit dem Beitrag von Herrn Berg. Wenn ich Sie richtig verstehe, dann war ich Ihnen zu wenig strafrechtsfreundlich. Was zunächst den Vorrang der Grundrechte vor dem Privatrecht angeht, so läßt er sich nicht ernsthaft bestreiten. Ihre Bedenken zielen aber wohl etwas tiefer und gehen in die Richtung der Überlegungen des privatrechtlichen Kollegen, den ich in meinem Referat, ohne ihn zu nennen, erwähnt habe. Er ist der Auffassung, daß das Privatrecht die Freiheit des Bürgers fördere und das öffentliche Recht sie beschränke. Auf den ersten Blick klingt das ganz plausibel: Die Privatautonomie beläßt dem Bürger die Freiheit, in der er sich bewegen kann. Dann kommt der Verwaltungsakt und setzt Schranken; der Polizist kommt und stoppt den Bürger. Gleichwohl erscheint mir dieser Ansatz nicht hilfreich. Er mag in manchen Zusammenhängen zutreffen, in anderen aber eben nicht. Nehmen Sie den Fall eines Nachbarn, der durch einen Betrieb beeinträchtigt wird, etwa durch den Betriebslärm, mit der Folge, daß seine Nachtruhe dahin ist. In diesem Falle fördert das Privatrecht nicht die Freiheitsentfaltung und das öffentliche Recht umgekehrt behindert sie nicht, im Gegenteil, es trägt zur Freiheitsentfaltung bei. In einer vorzüglichen, privatrechtlichen Dissertation aus Göttingen zum Verhältnis von privatem und öffentlichem Recht wird denn auch die genannte Vorstellung ausdrücklich als unzutreffend eingestuft. Auch das öffentliche Recht trägt zur Freiheit des Bürgers bei, vorausgesetzt natürlich, daß es sachgerecht ausgestaltet ist. Das gilt aber für das Privatrecht in gleicher Weise.

Herr Sachs, Sie haben zunächst gefragt, ob zwischen den Thesen 16 und 18 nicht ein Widerspruch besteht. Diese Frage ist hilfreich, da mir 
im Laufe der Diskussion deutlich wurde, daß ich zu den damit aufgeworfenen Aspekten noch ein Wort sagen sollte. These 16 betrifft sozusagen den Regelfall, die Genehmigungskonformität außerhalb des Bereichs des derivativen Privatrechts. In diesem Bereich sind die meisten Streitfälle um die Vorgaben des Verwaltungsrechts für das Privatrecht angesiedelt, jedenfalls im Bereich der Rechtsprechungsentscheidungen. Die Fälle des derivativen Privatrechts spielen eine sehr viel geringere Rolle. Die Unterscheidung zwischen den beiden Bereichen ist für mich deshalb so wichtig, weil nach meiner Auffassung dem Verwaltungsrecht im „Regelbereich“ nur eine indizielle Wirkung zukommt, während im Bereich des derivativen Privatrechts dem Verwaltungsrecht eine volle Bindung zukommt. Es geht also in den Thesen 16 und 18 um zwei verschiedene Bereiche, weshalb insoweit kein Widerspruch auftritt. Dieser Befund ist andererseits deshalb von Interesse, weil ich den Eindruck habe, daß im Strafrecht die Fälle des derivativen Strafrechts, man spricht dort von akzessorischem Strafrecht, wohl die größere Rolle spielen. Wenn dem aber so ist, dann erklärt dies auch die unterschiedliche Behandlung der Konflikte zwischen Verwaltungsrecht und Privatrecht einerseits und Verwaltungsrecht und Strafrecht andererseits. Eine volle Bindung des Strafrechts ist dann sehr viel häufiger angebracht als eine volle Bindung des Privatrechts. Darüber müßte man noch einmal näher nachdenken. Schließlich komme ich zu Ihrer Frage, ob ein Verwaltungsakt bestandskräftig sein muß, damit man daran Bindungen für das Privatrecht knüpfen kann. Zunächst ist das eine Frage, die vom Gesetzgeber zu entscheiden ist. Meist ist aber der betreffenden Norm nicht zu entnehmen, ob die Bindungswirkung die Bestandskraft des Verwaltungsakts voraussetzt. Dann würde ich dazu neigen, die Frage zu bejahen.

Herr Meyer, mit Widersprüchen muß man leben können, sagen Sie. Da stimme ich Ihnen zu; aus Widersprüchen ergeben sich immer wieder Fortschritte. Andererseits würde ich das nicht zu weit treiben. Obwohl oder vielleicht gerade weil ich Ihrem Befund zustimme, daß wir in der Rechtsordnung immer wieder auf Widersprüche stoßen, ist es doch unsere Aufgabe, die Widersprüche abzuarbeiten. Dabei wird man allerdings, worauf Herr Vogel zu Recht nochmals hingewiesen hat, zwischen Normwidersprüchen und Wertungswidersprüchen unterscheiden. Normwidersprüche müssen beseitigt werden; sie können wir nicht akzeptieren. Bei Wertungswidersprüchen kommt es auf die Umstände an.

Herrn Mußgnug und Herrn Ronellenfitsch stimme ich insoweit zu, als manche der uns beschäftigenden Probleme gar nicht auftreten 
würden, wenn wir mit der Nichtigkeit von Verwaltungsakten vernünftiger umgehen würden, wenn man eher bereit wäre, die Folge der Nichtigkeit anzunehmen. Allerdings habe ich insoweit, jedenfalls wenn man auf die Praxis sieht, keine sehr große Hoffnung.

Herr Ronellenfitsch hat sich mit etwas kritischem Unterton zu den Klagen eingelassen, die auf die Vollzugsdefizite im Umweltrecht hinweisen. Die Verwaltungsjuristen würden durch ihre Klagen über diese Defizite Probleme mit den Strafgerichten und den Zivilgerichten geradezu stimulieren. Ich weiß nicht, ob Ihr kritischer Unterton sich darauf bezieht, daß Sie keine Defizite sehen - was man relativ leicht widerlegen könnte - oder ob Sie nur sagen wollen, man dürfe darüber nicht sprechen, weil das die Strafrechtler auf falsche Gedanken bringt. Nun mag es ja sein, daß die Vertreter des Strafrechts Herr Ossenbühl hat darauf hingewiesen - gelegentlich zuwenig Verständnis für die Feinheiten des Verwaltungsrechts aufweisen. Auch bei Vertretern des Zivilrechts mag man derartiges antreffen. Aber gilt das möglicherweise nicht auch umgekehrt? Seien wir da nicht zu selbstgerecht. Gerade wenn wir andere kritisieren, sollten wir über Probleme im Bereich des Verwaltungsrechts ebenfalls offen sprechen, und damit auch über Vollzugsdefizite. An sich sind Vollzugsdefizite alltägliche Erscheinungen einer Rechtsordnung. Kritisch wird es erst, wenn sie ein zu großes Maß annehmen. Dann ist es aber gerade die Aufgabe des Rechtswissenschaftlers, auf solche Mißstände hinzuweisen und $\mathrm{zu}$ verlangen, daß entweder die entsprechende Norm beseitigt oder sie tatsächlich umgesetzt wird.

Eine kurze Bemerkung noch zu den Ausführungen von Herrn Schachtschneider, da er einen Punkt angesprochen hatte, der auch in anderen Beiträgen auftauchte. Sie haben sich für eine stärkere Gleichstellung von Verwaltungsvorschriften und Rechtsnormen ausgesprochen. Dieses uralte Thema kann und will ich nicht in voller Breite angehen. Ich meine aber, daß man die Unterschiede nicht einfach beseitigen kann, auch wenn man einräumt, daß Verwaltungsvorschriften Rechtsnormen sind. Anderenfalls muß man sich fragen, warum es überhaupt noch zwei Instrumente gibt. Es kann nicht sein, daß Verwaltungsvorschriften in jeder Hinsicht praktisch wie Rechtsvorschriften zu behandeln sind. Irgendwo müssen sich in den Folgen Unterschiede ergeben. Ich habe in früheren Arbeiten vorgeschlagen, bestimmte Verwaltungsvorschriften unter bestimmten Voraussetzungen den Rechtsnormen anzunähern und habe solche Vorschriften als qualifizierte Verwaltungsvorschriften bezeichnet. Im übrigen muß man aber daran festhalten, daß die Unterschiede zu den Rechtsnormen doch ganz erheblich sind. 
Herr Breuer, Ihre Ausführungen liegen nach meinem Eindruck ganz auf meiner Linie. Ich kann Ihnen praktisch in allen Punkten zustimmen. Allenfalls sind Sie vielleicht noch eine Nuance privatrechtsfreundlicher als ich das gewesen bin. Sie haben offensichtlich Ihre Position im Vergleich zu Ihren Beiträgen, auf die ich mich in meinem Referat gestützt habe, geändert, jedenfalls was die Genehmigungen angeht. Nun bin ich nicht so selbstgefällig, die Ursache dafür in meinen Ausführungen von heute morgen zu sehen. Sie haben sicher über die Probleme noch einmal nachgedacht, mit der Folge, daß unsere Positionen nunmehr weitgehend übereinstimmen. $\mathrm{Da}$ ich gerade Ihre Arbeiten besonders schätze, bestärkt mich das in meinen Überlegungen. Aber vielleicht habe ich Sie nicht richtig verstanden; dann bitte ich um Nachsicht.

Zum Schluß möchte ich mich gerne bei allen Diskussionsteilnehmern sehr herzlich für die äußerst interessanten Anregungen bedanken. Vor allem aber möchte ich nicht versäumen, dem Vorstand für die Wahl des Themas zu danken. Sie haben sicher festgestellt, daß das Thema mich fasziniert hat. Es bietet viele hochinteressante Querverbindungen zu den Grundlagen unserer Wissenschaft. Der Vorstand verdient daher besonderen Dank.

Vorsitzender: Meine Herren, es bleibt mir nur noch, den Referenten, den beiden Landesberichterstattern und vor allen Dingen auch Ihnen allen, die an der Diskussion teilgenommen haben und ihr mit Interesse gefolgt sind, für diesen Tag zu danken, und die Sitzung hinsichtlich des fachlichen Teils für heute zu schließen.

Vogel: Wir stehen damit am Ende des wissenschaftlichen Teils unserer Tagung, und das ist der letzte Augenblick, der uns Gelegenheit gibt, denen zu danken, die uns die Durchführung dieser Tagung ermöglicht haben. Den Züricher Kollegen, besonders Herrn Georg Müller, der in unermüdlicher Arbeit die Voraussetzungen unseres Zusammenseins hier geschaffen hat, werden wir noch gesondert danken. Schon jetzt danken möchte ich aber den vielfältigen Helfern des Herrn Müller, den Heinzelmännchen, die mitgewirkt haben, daß alles seinen richtigen Ablauf finden konnte. Es war viel Arbeit, es war hilfreich für uns, und es ist alles mit großer Bereitwilligkeit und Freundlichkeit geschehen. Dafür sagen wir: Danke schön! (Applaus). 
